\title{
Promoting Heritage Language in Northwest Russia
}

Siragusa, Laura

Routledge

2017-10-23

Siragusa, L 2017 , Promoting Heritage Language in Northwest Russia . Routledge Studies

in Linguisitc Anthropology, vol. 1 , Routledge , New York and London . https://doi.org/10.4324/9781315112459

http://hdl.handle.net/10138/311899

https://doi.org/10.4324/9781315112459

cc_by_nc_nd

publishedVersion

Downloaded from Helda, University of Helsinki institutional repository.

This is an electronic reprint of the original article.

This reprint may differ from the original in pagination and typographic detail.

Please cite the original version. 


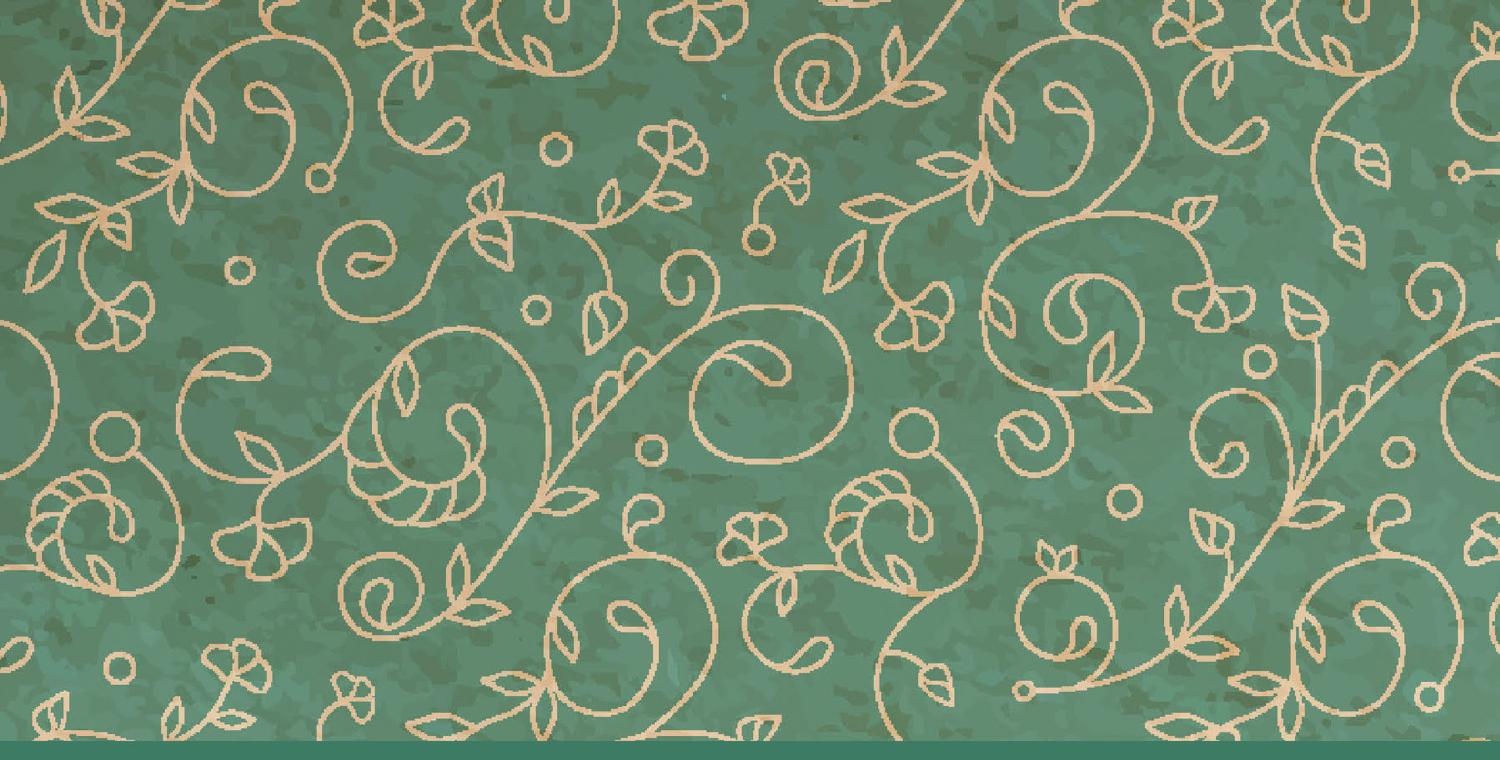

Routledge Studies in Linguistic Anthropology

\section{PROMOTING HERITAGE LANGUAGE IN NORTHWEST RUSSIA}

Laura Siragusa

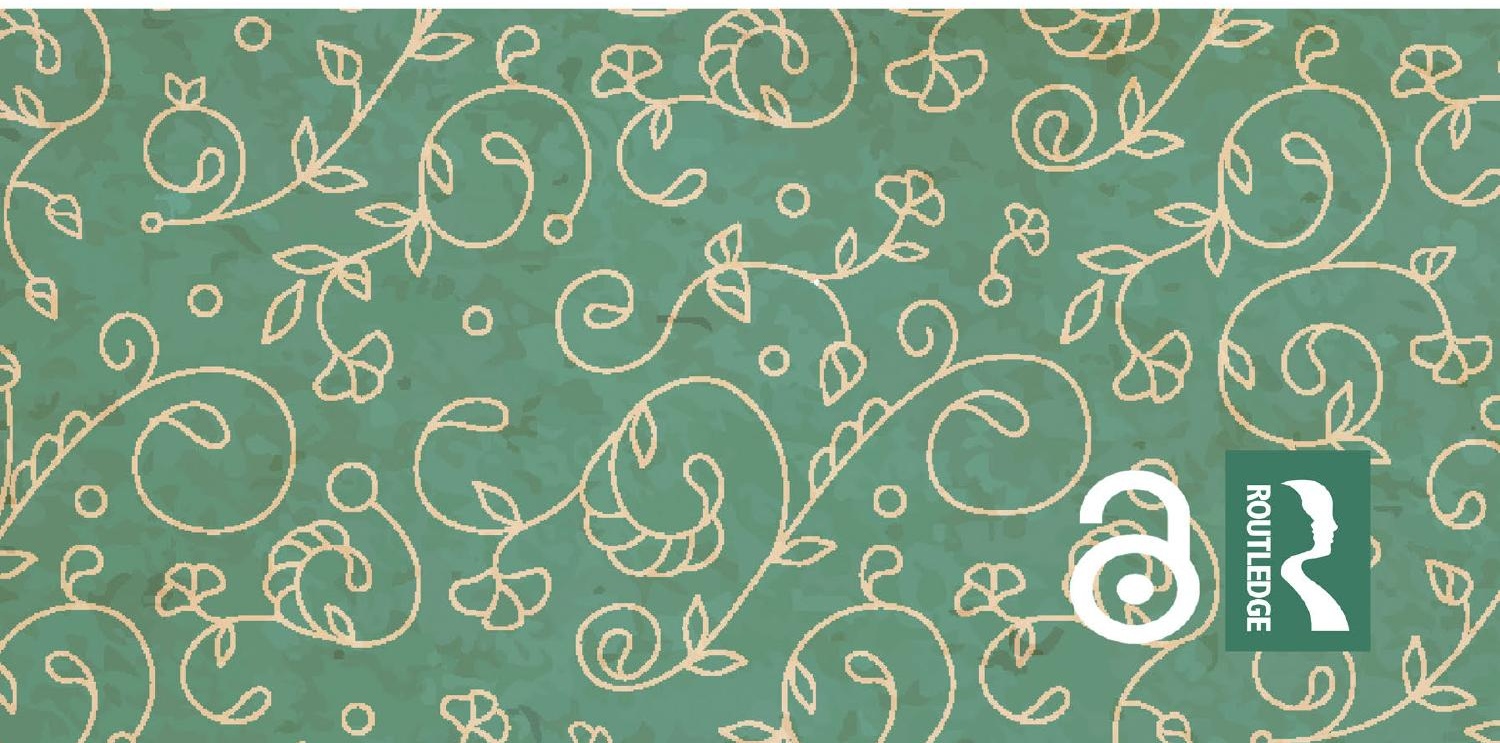




\section{Promoting Heritage Language in Northwest Russia}

This volume illustrates how language revival movements in Russia and elsewhere have often followed a specific pattern of literacy bias in the promotion of a minority's heritage language, partly neglecting the social and relational aspects of orality. Using the Vepsian Renaissance as an example, this volume brings to the surface a literacy-orality dualism new to the discussion around revival movements. In addition to the more-theoretically oriented scopes, this book addresses all the actors involved in revival movements including activists, scholars, and policy makers, and opens a discussion on literacy and orality, and power and agency in the multiple relational aspects of written and oral practices. This study addresses issues common to language revival movements worldwide and will appeal to researchers of linguistic anthropology, sociolinguistics, education and language policy, and culture studies.

Laura Siragusa is a linguistic anthropologist working within a program on Indigenous Studies at the University of Helsinki. She has co-edited a special issue on language sustainability for the journal Anthropologica and published miscellaneous articles on Vepsian matters in Sibirica, JEFUL, and Folklore. 
Routledge Studies in Linguistic Anthropology

1 Promoting Heritage Language in Northwest Russia Laura Siragusa 


\section{Promoting Heritage Language in Northwest Russia}

Laura Siragusa

(2) $\begin{aligned} & \text { Routledge } \\ & \text { Raylor \& Francis Group } \\ & \text { NEW YORK AND LONDON }\end{aligned}$ 
First published 2018

by Routledge

711 Third Avenue, New York, NY 10017

and by Routledge

2 Park Square, Milton Park, Abingdon, Oxon OX14 4RN

Routledge is an imprint of the Taylor \& Francis Group, an informa business

(C) 2018 Taylor \& Francis

The right of Laura Siragusa to be identified as author of this work has been asserted by her in accordance with sections 77 and 78 of the Copyright, Designs and Patents Act 1988.

The Open Access version of this book, available at www.taylorfrancis.com, has been made available under a Creative Commons Attribution-Non Commercial-No Derivatives 4.0 license.

Trademark notice: Product or corporate names may be trademarks or registered trademarks, and are used only for identification and explanation without intent to infringe.

Library of Congress Cataloging-in-Publication Data

A catalog record for this book has been requested

ISBN: 978-1-138-08256-4 (hbk)

ISBN: 978-1-315-11245-9 (ebk)

Typeset in Sabon

by Apex CoVantage, LLC 
To my own "sebr" 
$\because$ Taylor \& Francis

Taylor \& Francis Group

http://taylorandfrancis.com 


\section{Contents}

List of Figures $\quad$ ix

Gloss xi

Vepsian Toponymy $\quad \mathrm{xv}$

Maps xvii

A Note on Transliteration xix

Acknowledgments xxi

A Note on Anonymity $\quad x x v$

1 Introduction: Revival of a Heritage Language.

A Question of Literacy and Orality 1

1.1 The Research: Vepsian Revival Movement 6

1.2 Language Revival Programs: Literacy Versus Orality or Literacy and Orality? 15

1.3 Language Revitalization: Pros and Cons of Literacy Chauvinism 18

1.4 Vepsian Language: Power and Agency in the Spoken Word 20

2 Vepsian Representations and Language in History

2.1 Representing a Natsional'nost' 26

2.2 Villages: Sebr and Khozyaystvo 28

2.3 Vepsän ma: A Borderland Between Sweden and Russia 33

2.4 Veps and the Soviet Regime 35

2.5 Perestroika and Glasnost: Efforts in Unifying the Land 44

2.6 Contemporary Karelia: Veps in a Multiethnic Territory 46 Maps 57

3 Multilingual Russia: Superdiversity Meets Language Revival

3.1 Superdiversity Meets Language Revival in Russia 61

3.2 International Cooperation and New Directions in Language Revival 65

3.3 Why "Saving?" And Saving What? 68 Map 71 
viii Contents

4 Revaluation of Language: Fieldwork as a Give-and-Take Phenomenon

4.1 Fieldwork in Social Research and Language Studies 75

4.2 Fieldwork as a Give-and-Take Phenomenon:

Re-becoming an Italian Svoya 79

4.3 Social Research: A Matter of Preparation, Flexibility, and Improvisation 90

5 Metaphors of Language: Independent Entity Versus Experience of Life

5.1 Life Cycle of a Language in Academic and Political Discourse 100

5.2 Vepsian Language and "Optimism” 104

5.3 Speaking in Villages: An Experience of Life 106

6 A Way to Make Sense of the World Using Dialects in Villages

6.1 Speaking Differently: Dialects 124

6.2 Dialectal Variations in Phonology 125

6.3 Dialectal Variations in Morphology 126

6.4 Dialectal Variations in Lexicon and on the Discourse Level 127

7 Vepsän kel' and the City

7.1 Literacy in Russia 132

7.2 Literacy and Feeling "Not Inferior to Anyone on any Level” 134

7.3 Language Policy to Support Heritage Language Revival 142

7.4 Multiple Experiences of Writing 148

8 Education and the Babushka

8.1 Education and Revitalization in History.

Current Issues in Language Planning 164

8.2 Contemporary Vepsian Education in Cities and Villages 165

8.3 The Babushka and Her Social and Language Role 185

Conclusion: Revitalizing a Heritage Language. Toward Multimodality and "Multispatiality" 


\section{Figures}

I took most of the pictures displayed in the present volume during my fieldwork between 2009 and 2015. In case I use a picture from another source, I will state it in the text.

1.1 Pondal, a Vepsian village in the Vologda Oblast

1.2 Two journalists (center and right) from Petrozavodsk on their way to work in Pondal

1.3 Veps taking part in the festival Drevo Zhizni in Vidl in $2010 \quad 7$

1.4 Paginklub (V. Speaking club) at the Centre for National Cultures in Petrozavodsk

1.5 Street sign indicating the Vepsian village Kalag' in Russian and in Vepsian

2.1 Mäggärv', Leningrad Oblast

2.2Päč (V. Stove) in a house in Pondal

2.3 Jumalčoga at the Vepsian ethnographic museum in Pondal

2.4 The cannon industry around which Petrozavodsk was built

2.5 On the left side one of the buildings of the kolkhoz in Pondal, Vologda Oblast, as the few left cows graze the grass

2.6 Suburban district Kukkovka in Petrozavodsk

2.7 Vepsian ethnographic museum in Šoutjärv', Republic of Karelia

3.1 Participants of the VII International Congress of the Finno-Ugric Peoples in Lahti (Finland) in 2016

4.1 Gathering cranberries in a swamp near Pondal in 2013

4.2 Slobod, a sub district ( $a g^{\prime}$ in Vepsian) of Pondal in the Vologda Oblast

4.3 During an expedition to Vepsian villages in 1974, the researcher Lepp Lembit took this picture of a woman with her magpie friend (ERM FK 1729: 47)

4.4 Main road in Kalag', Republic of Karelia

4.5 Dom Kul'tury (R. House of Culture) in Vil'häl, Leningrad Oblast 
4.6 Master class at the school in Kuja, Vologda Oblast 95

5.1 Vepsian ethnographic museum in Kurb, Leningrad Oblast 106

5.2 Soviet gramophone in the administration office of the Vepsian ethnographic museum in Kurb 108

7.1 School in Šoutjärv', Republic of Karelia 144

7.2 A Russian/Finnish sign outside the actors' area at the State National Theatre, Petrozavodsk

7.3 A plate in Russian and Finnish, which is situated outside the building of the Government of the Republic of Karelia

7.4 Shop in Petrozavodsk. The board sign is written in Finnish, ruokatavaraa, which literally means food stuff

7.5 Vepsian primer, which won the best book of the year 2009 in the Vepsian, Karelian, and Finnish languages

8.1 The Finno-Ugric school E. Lönnrot in Petrozavodsk

8.2 The school plate of the Finno-Ugric school E. Lönnrot is written in Russian, Finnish, Karelian, and Vepsian

8.3 Vepsian classroom at the Finno-Ugric school E. Lönnrot. The sign on the door is in Russian and Finnish

8.4 Baltic-Finnish and Finno-Ugric Faculty of Petrozavodsk State University

8.5 Vepsian classroom at the Baltic-Finnish and Finno-Ugric Faculty of Petrozavodsk State University

8.6 Details of the Vepsian classroom at the nursery in Šoutjärv' 180

8.7 Vepsian class in the secondary school in Šoutjärv' 181

8.8 Competition Vepsian families in Šoutjärv' in May 2010

8.9 Children playing along the river in Vil'häl, Leningrad Oblast 187 


\section{Gloss}

As I began my research in 2009 , I spoke mostly Russian, and only on occasion I also spoke Vepsian until my language skills failed me. As I progressed with my work, I pushed myself to engage in Vepsian ways of speaking more often, trying not to be discouraged by my recurrent inaccuracies. When possible, I embrace dialectal variations not only to better integrate in the villages where I work but also because this is how the villagers teach me to speak. In this volume, I regularly employ those Vepsian and Russian words and phrases, which Veps repeatedly use and which I identified as crucial when discussing Vepsian revival movement. I indicate Vepsian words and phrases with "V." ("R." for Russian) and provide a translation in brackets. I denote Karelian and Finnish words by "K." and "F.," respectively. The following list of words and phrases together with a brief description also serve the purpose to avoid repetition throughout this volume. Besides, just like King (2011) who omits the article "the" when discussing Koryaks, I decided to drop the definite article when discussing Veps as not to bind them in a restricted category that does not allow change.

\section{Vepsian Words and Phrases}

Word, phrase Brief description or translation

Kül'bet'

Sauna. It is a Finnic word. In Finnish the word külpeä means bathing. The architectural structure of the kül'bet', its social symbolism and use do not differ from the Russian banya.

Paginklub Speaking club. It is a club led by Larisa Smolina at the Centre for National Cultures in Petrozavodsk. She organizes and suggests miscellaneous activists to discuss and speak Vepsian. The club convenes pensioners, young workers, and students from the city (and sometimes from the villages, too). The participants meet once a week, with the exception of the summer months and unexpected circumstances. 
Enchantments, spells, charms. The word puheged is etymologically linked to the verb pubuda, which means to blows. In other words, blowing powerful words has the capacity to influence the course life has taken. They are used to cure someone who has fallen ill and to appeal to the territorial masters when searching for lost cattle, when deciding where to build the house, when asking permission to make use of water and the land (see phono-archives at KarNTs RAN).

Sebr Community, team, people who work together, jointly, and more recently also society. In Vepsian, words such as sebranik (Friend) and sebrnik (Member of the society) have a common root with sebr. It epitomizes the sense of community which had characterized the Vepsian lifestyle for centuries. Sebr also epitomizes how the Vepsian villagers have, nonetheless, maintained close bonds not only among one another but also with the land and its non-human inhabitants, comprising territorial masters and non-human animals. Saarinen (2001) extends such a sense of community to other Finno-Ugric groups, too.

Ühtes The adverb ühtes (V. Together) is used to address cooperation and joint operations. Other Vepsian words share the same root with ühtes, such as the verb ühteta which means "to unite, to join, to participate," the noun übtenik which means "unity," and the adjective ühthine which means "single, common."

Tedai If translated literally it means "the one who knows the way." This is a person instructed in certain practices, such as performing enchantments for healing purposes, to find a compromise with the territorial masters, and so on.

Toižin Differently. This word has developed from the demonstrative pronoun too which indicates objects which are physically distant from the speaker. In the present work, the adverb toižin often follows the verb pagišta (V. To speak). The Central Veps tend to describe other languages mostly as different ways of speaking and not to enclose them in a categorical name. Instead, the Northern Veps more likely refer to languages by name. Pagišta toižin (V. To speak differently) is also used to make reference to other Vepsian dialects.

Vepsän ma Vepsian land, territory. The phrase Vepsän ma refers to the whole territory inhabited by those of Vepsian nationality. Specifically, it refers to the southeastern part of the Republic of Karelia where Veps have received the political status of Vepsian district in 1994 and to the confining 
villages of the Leningrad and Vologda Oblasts, inhabited mostly by Vepsian national residents (Maps 1 and 2).

\section{Russian Words and Phrases}

\section{Word, phrase Brief description or translation \\ Babushka \\ Grandmother. \\ Banya \\ Russian sauna.}

Khozyaystvo

Housekeeping, farming. Khozyaystvo typifies Vepsian traditional village lifestyle together with the Vepsian word sebr (V. Joint work, community, society).

Sokbranit' To maintain, to preserve.

Razvivat' To develop. The Vepsian activists do not adopt the verb spasti (R. To save), as per international terminology in regard to endangered languages and the goals of revival movements. Instead, they most likely say to maintain (sokbranit') and to develop a language, thus, they emphasize a link to the tradition and to the future generations.

Svoy, chuzhoy Own, foreign. The dualism svoy-chuzoy characterizes both Vepsian and Russian worldviews, at times overlapping, at other times clashing with each other. In fact, such polarity sometimes reflects attitudes and life metaphors which villagers and urbanites have developed in relation to the environment in which they live, independently of the nationality people claim to have. Strict dualist social paradigms hardly occur since social systems are fluid and often overlap. However, while living in this Northwestern Russian territory, I was confronted with a recurrent discourse on binary paradigms on what was felt as close and what was felt as foreign. And this also dominated utterances around national identity, written and oral practices as much as urban and rural ways of living. Therefore, I maintain the svoy-chuzhoy polarity, yet admitting space for fluidity and referring to it throughout my presentation of Vepsian revival movement. 
$\because$ Taylor \& Francis

Taylor \& Francis Group

http://taylorandfrancis.com 


\section{Vepsian Toponymy}

The following list provides the names of those Vepsian villages which I mention in this volume. I list them in alphabetical order, using the Vepsian name on the left and the Russian name in brackets. I should also indicate that the Vepsian names are those chosen by the activists as the standard form since they often comprise localized, dialectal variations.

Himd'ogi (R. Gymreka), Leningrad Oblast

Kalag' (R. Rybreka), Republic of Karelia

Kurb (R. Kurba), Leningrad Oblast

Ladv (R. Ladva), Leningrad Oblast

Mäggärv' (R. Myagozero), Leningrad Oblast

Nemž (R. Nemzha), Leningrad Oblast

Ošt (R. Oshta), Vologda Oblast

Pondal (R. Pondala), Vologda Oblast

Šoutjärv' (R. Sheltozero), Republic of Karelia

Šimjärv' (R. Shimozero), Vologda Oblast

Šokš (R. Shoksha), Republic of Karelia

Toižeg (R. Drugaya Reka), Republic of Karelia

Vidl (R. Vinnitsy), Leningrad Oblast

Vil'häl (R. Yaroslavichi), Leningrad Oblast 
$\because$ Taylor \& Francis

Taylor \& Francis Group

http://taylorandfrancis.com 


\section{Maps}

Maps 1 and 2 show the territory where at present most of the Vepsian population lives. For a matter of convenience, I placed the other maps at the end of those chapters in which they are first mentioned.

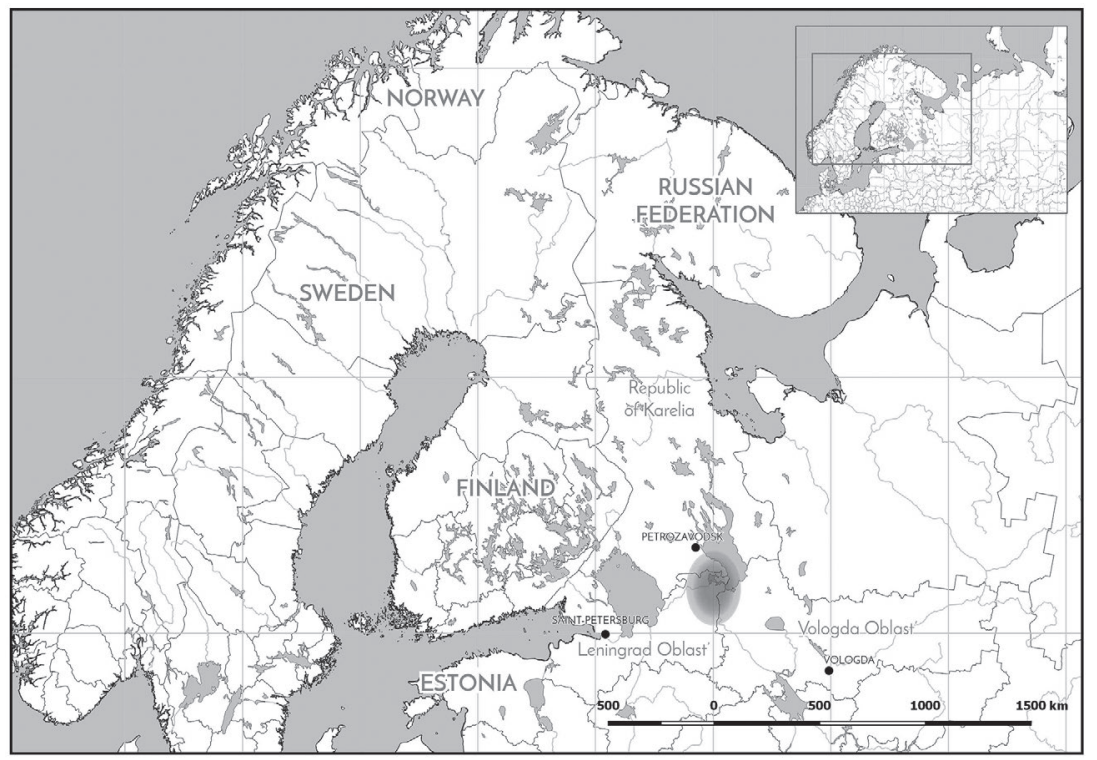

Map 1 Northwestern Russia. The elliptical shape below Petrozavodsk indicates the approximate territory in which Vepsian villages are currently situated. As illustrated on the map the villages are located in three different administrative regions-i.e., the Republic of Karelia in the north, the Leningrad Oblast in the west, and the Vologda Oblast in the east. Map by Arch. Pasquini 




Map 2 Vepsän ma (V. Vepsian land, territory). The two sections at the center of the map represent the territory covered by contemporary Vepsian villages. I also indicated the main dialects of Vepsian. Map by Arch. Pasquini 


\section{A Note on Transliteration}

Throughout this volume I use the BGN/PCGN system, also called the British Standard, to Romanize the Russian Cyrillic characters into the Latin alphabet. Nevertheless, I decided to keep words such as "perestroika" and "glasnost" intact since they have entered the English usage in a different form.

Russian letter Romanization of Russian letter

A (a)

A (a)

Б (б)

B (b)

B (в)

$\mathrm{V}(\mathrm{v})$

$\Gamma(г)$

G $(\mathrm{g})$

Д (д)

$\mathrm{D}(\mathrm{d})$

$\mathrm{E}(\mathrm{e})$

Ye (ye) at the beginning of a word, after a vowel, semivowel, soft and hard signs. E (e) in all other cases.

$\ddot{\mathrm{E}}(\ddot{\mathrm{e}})$

Ж (ж)

$3(3)$

Yë (yë) at the beginning of a word, after a vowel, semivowel, soft and hard signs. Ë (ë) in all other cases. Ë (ë) represents the sound $/ \mathrm{jo} /$.

$\begin{array}{ll}\text { И (и) } & \text { I (i) } \\ \text { Й (й) } & \text { Y (y) } \\ \text { К (к) } & \text { K (k) } \\ \text { Л (Л) } & \text { L (l) } \\ \text { M (м) } & \text { M (m) } \\ \text { H (н) } & \text { N (n) } \\ \text { O (о) } & \text { O (o) } \\ \text { П (п) } & \text { P (p) } \\ \text { P (р) } & \text { R (r) } \\ \text { C (с) } & \text { S (s) } \\ \text { Т (т) } & \text { T (t) } \\ \text { У (у) } & \text { U (u) } \\ \text { Ф (ф) } & \text { F (f) } \\ \text { Х (х) } & \text { Kh (kh) } \\ \text { Ц (ц) } & \text { Ts (ts) }\end{array}$


$\mathrm{xx}$ A Note on Transliteration

$\begin{array}{ll}\text { Ч (ч) } & \text { Ch (ch) } \\ \text { Ш (ш) } & \text { Sh (sh) } \\ \text { Щ (щ) } & \text { Shch (shch) } \\ \text { Һ (ъ) } & \text { ( (hard sign) } \\ \text { Ы (ы) } & \text { Y (y) } \\ \text { Һ (ь) } & \text { (soft sign) } \\ \text { Э (э) } & \text { E (e) } \\ \text { Ю (ю) } & \text { Yu (yu) } \\ \text { Я (я) } & \text { Ya (ya) }\end{array}$




\section{Acknowledgments}

\section{Midä Zavod'ie? (V. Where to Start?)}

This work has been possible only thanks to the generous and honest help and support I have received since I decided to embark on such a research project. It is said that when one is ready to learn, the master will appear. When I was ready to learn, all my masters came to me in floods, sometimes in the form of a person, others in the form of a place, a word, a sound, an event, and a lot more.

So, mid̈̈ zavod'ie? Who to thank first and express my infinite gratitude for being there for me and with me in this journey? I believe it would be fair to start from the moment this project took off, the moment when knowledge on the topic was limited and enthusiasm was the main force which led me. I would like to express my heartfelt gratitude to both my $\mathrm{PhD}$ supervisors, Dr. Alex King and Prof. Barbara Fennell who wisely guided, advised and supported me throughout my postgraduate studies, from its initial to final stages. I could have not gone in so much depth in my analysis without their words of encouragement and interest in my work. Support came also from staff and friends who were at the time at the Department of Anthropology at Aberdeen University. Especially, I want to express my gratitude to Dr. Cristián Simonetti for his continuous words of encouragement and interesting discussions, to Dr. Jenanne Ferguson whose comments and observations are always inspirational, and to Dr. Serena DiGenova with whom, besides academic discussion, I always have a good laugh.

My gratitude extends to my colleagues at the University of Tartu where I continued my research on Vepsian language matters between 2013 and 2015. Particular thanks go to Prof. Kristin Kuutma for her advice and suggestions on my work and to Dr. Madis Arukask for the constructive and enlightening discussions on Vepsian and more broadly Finno-Ugric related issues.

This work has been completed in a spirit of cooperation and trust. It is my pleasure to thank Profs. Eva Toulouze and Jean L. Léonard in Paris for their valuable feedback, Prof. Riho Grünthal, Prof. Janne Saarikivi, and Dr. Karina Lukin in Helsinki for their infinite support and advice, and Dr. Heini Karjalainen in Oulu for our talks over Vepsian matters. Heartfelt gratitude 
goes to Dr. Nina Zaitseva, Prof. Irma Mullonen, Dr. Valentina Kuznetsova, Dr. Irina Vinokurova, and Dr. Zinaida Strogal'shchikova at the Academy of Sciences in Petrozavodsk for their comments and endless help during my fieldwork and contact from afar. Special thanks also go to Natal'ya Antonova for being a model of strength and determination. I want to thank Carol Witney from RMIT Saigon who has followed me since I first contemplated taking on this research project. Her feedback and encouragement has helped me maintain strong and focused.

Besides colleagues, other scholars, and activists, I am grateful to those who helped me focus and live peacefully throughout my work. Natasha Krauze and Neil Shaw were able to create a relaxing atmosphere at home and provide me with an environment where I could work peacefully and develop ideas during my doctoral studies. Special thanks also to Joakim and Noora Pyyry for hosting me in Helsinki during my travels to Russia and showing genuine interest in my investigation. I also enjoyed discussing and comparing work with Vello and Eva-Clarita Pettai in Tartu.

This work would have not been possible without the kindness, support, trust, help, and love from those Veps whom I encountered and with whom I spent my journey in the Russian territory. I would like to thank all the 5,936 Veps who reported Vepsian nationality at the 2010 census and particularly those who have been closer to me. I am mostly indebted to (in random order): Ol'ga Zhukova, Galina Baburova, Alëna Egorova, Larisa Smolina, Faina Kozlova, Irina Baranova, Natal'ya Silakova, Aleksey Maksimov, Vladimir Solov'yëv, Mariya Filatova, Irina Sotnikova, Nadezhda Kukkoeva, and many more in Petrozavodsk. I also want to thank Natal'ya Ankhimova, Ol'ga Kokorina, and Yuliya Naumova in Šoutjärv', and Yuliya Aprodu, Mariya Mironova, Ol'ga Mironova, Elena Mironova, Aleksander Makeev, and Valentina Mironova in Kalag'. My warm felt thanks go to Lyudmila Ivanovna in Toižeg; Galina Lokkina in Nemž, and Svetlana Ershova in Kurb. Enormous thanks also go to the 36 permanent residents of Pondal, starting with Nadezhda Mednikova who hosted me in the autumn 2013 and summer 2015. They have all disclosed their world to me and have made me feel part of it.

Needless to say that I could have not undertaken multiple trips to Russia and conducted archival research in Russia and Estonia without the financial support of several institutional bodies. I am extremely grateful for the assistance provided by the College of Arts and Social Sciences and the School of Social Sciences at the University of Aberdeen during my doctoral studies. I could complete my fieldwork in 2010 also thanks to a bursary received from the Carnegie Trust in Scotland. I want to further extend my gratitude to the Estonian Research Mobility Scheme Grant (ERMOS120 project) which supported my first post-doctoral post in Tartu and the ERC Advanced Grant (Arctic Domus project, 295458) which has been supporting me since 2015. The discussions within the Arctic Domus project, led by Prof. David Anderson, have been extraordinarily stimulating and thought-provoking. 
And David Anderson with his pursue to excellence has been an extraordinary role model.

ESUKA-JEFUL granted me the permission to revise an article previously published with them (Issue 6(1)) in 2015 called, Metaphors of language: the Vepsian ecology challenges an international paradigm. I expanded this article into Chapter 5, providing further examples and giving depth to my previous conclusions. ERM, Estonian National Museum, also allowed me to publish photograph 1729: 47. This picture always make me smile as it portrays a Vepsian lady playing and laughing with her magpie; thus, it indicates playfulness and the deep relationality with the rural environment in which many Veps live.

Infinite gratitude and beyond goes to my parents, Giuseppe and Miretta, who have shared every step, every thought, and effort of my work together with me. Their attitude toward life has always been an inspiration and I often wonder how they can be such extraordinary role models. Thanks also to my twin sister, Elena, and her family, Alessandro and Agata. Agata, whose life journey has corresponded to the life journey of this project, has kept grounded while also making me dream. Special thanks to Alessandro who has been the author of the maps used in this volume and whose assistancesometimes as a matter of urgency-has always been impeccable.

I do not know who to thank for meeting Dima, who later became my husband, at a conference in Petrozavodsk in the summer 2011-he came to Karelia accidentally after drawing lots at the Kunstkamera in SaintPetersburg where was working at the time. Our meeting could not have happened otherwise, but in Petrozavodsk where the wonders of this journey began! I have learned loads from his enthusiasm toward the discipline of anthropology and overall interest in and openness toward life.

There are many more friends and colleagues I could add here-to all of you, a massive thank you! This cooperative work matches the Vepsian concept of sebr (Joint work, community, society). This concept has transcended time, developed, changed its shades, and emerged here in this volume to splendor! It is this sebr, our joint work, commitments, goals, and sense of community that I ultimately want to thank. We have done this togethersur' spasib, thank you, spasibo, aitäh, kiitos, grazie! 
$\because$ Taylor \& Francis

Taylor \& Francis Group

http://taylorandfrancis.com 


\section{A Note on Anonymity}

Throughout the present volume I introduce those people with whom I interacted and worked during my fieldwork and whom I often mention. In fact, many often claimed to feel privileged and happy to contribute to my work. I will not make my sources anonymous, since many so agreed by signing a release form. However, many of those who mostly live in remote areas of the Vepsän ma could not provide me a signed release form. In such a case, I keep their identity covered.

Moreover, I have decided not to opt for the anonymity of my friends and colleagues since most of them are activists and continuously appear on the news, both on radio and TV, and on the newspapers-I would do them wrong if I hid their identity, as in their eyes my work supports their cause and what they work toward. Our relationship is built on trust and on a sense of community based on joint work, sebr in Vepsian-a concept which I thoroughly explain in the book.

Furthermore, I argue that in the case of minority groups hiding someone's identity might in fact concur with invisibility, namelessness, and being put at the margins of society as irrelevant and not noticeable. By avoiding anonymity, I want to make a clear statement against this.

Nonetheless, when a situation is controversial and/or puts the source of information at risk or in case they preferred to maintain their identity covered, I adopt a pseudonym which I designate with brackets the first time I mention them (see AAAs Statement of Ethics and Research Ethics Framework at the University of Aberdeen).

I am aware that the practice of disclosing people's identity can be criticized and has been source of debate. In the Russian context, there has been different stages and attitudes toward the identification of those with whom the scholars work in the field. Scholars used to reveal the names of field partners until WWII. This practice later on branched out into two directions: either the scholars employed passive forms of the verb to avoid revealing the names of their field partners or they employed folkloristic sources which allowed them to disclose the source of information given the temporal gap. At present two main practices are in place among Russian scholars. Some follow the practices in place during the Soviet period; others only 
identify people by making reference to social categories, such as their gender, age, and the place where they are from. The Russian anthropological community has not yet agreed on a common ethical code of practice. The only discussions which targeted such a topic were conducted in 2006 in the issue number 5 of the Journal, Antropologicheskiy Forum-and yet reference on anonymity was only done in passing-, and also in 2016 in the issue number 30 of the same journal.

What's more, at present it is common practice among Russian academics to employ the word "informant" when addressing someone from the field. I do not agree with this use, as it reduces people to almost an encyclopedic source of knowledge which, in fact, I understand is often co-created together with the researcher, and in relation to the ecology in which certain practices occur. Opting for the use of the word "informant" also hints at the fact that knowledge is only shared during interviews and not other research methods, such as participant observation. 


\section{Introduction}

\section{Revival of a Heritage Language. A Question of Literacy and Orality}

On a September afternoon in 2013, acknowledging my limits in speaking Vepsian with the local villagers in Pondal I asked my friend and host, Nadezhda Mednikova, if I could borrow one of her books on Vepsian poetry so I could learn some new vocabulary. Pondal is a Vepsian village in the Vologda Oblast, Northwestern Russia, mostly surrounded by forests, lakes, rivers, and swamps, and, thus, quite isolated from the other villagesthe closest one, Kuja, is at about $25 \mathrm{~km}$ (Figure 1.1 and 4.2). Pondal itself encompasses rivers, forests and smaller inhabited districts, $a g$ ' in Vepsian (namely, Sür'g, Rand, Slobod, Aksintanaz, Turžin, and Kün'dišt') and this comprehensive territory is called külä. This partial isolation from urban influence is believed to be one of the main causes for the maintenance of Vepsian, a minority and "endangered" language of the Russian Federation, in this area. Indeed, like her co-villagers Nadezhda Mednikova is bilingual in her heritage language, Vepsian, and in Russian, and she can freely switch between the two depending on the circumstances. To my request, not only she gave me a volume by the poet Nikolay Abramov (1961-2016) as a present, but she also invited me to take all the other books written in Vepsian which she had carefully arranged on her shelf. She told me to go ahead and help myself with all the books I wanted. She invited me to also take those that the devushki (R. Girls) had given her since nobody read them. The "girls" she was referring to were, in fact, Mariya Filatova and Larisa Smolina, two Vepsian journalists and activists in their early 30s with whom I had reached Pondal from Petrozavodsk by car (Figure 1.2). Indeed, Mariya Filatova is a former Vepsian student, currently working as a Vepsian journalist for the State Television of the Republic of Karelia (GTRK: http://tvkarelia.ru/). Larisa Smolina is also a former Vepsian student at Petrozavodsk State University and is now working as a Vepsian journalist for Radio Russia-Radio Karelia (http://tv-karelia.ru/radio/radio-rossii/). She also runs a Vepsian Paginklub (V. Speaking club) at the Centre for National Cultures in Petrozavodsk, the capital of the Republic of Karelia.

During their tertiary studies at Petrozavodsk State University, Mariya Filatova and Larisa Smolina learned the Vepsian standard form whose lexicon and morpho-syntactic structures are based on several Vepsian dialects; 


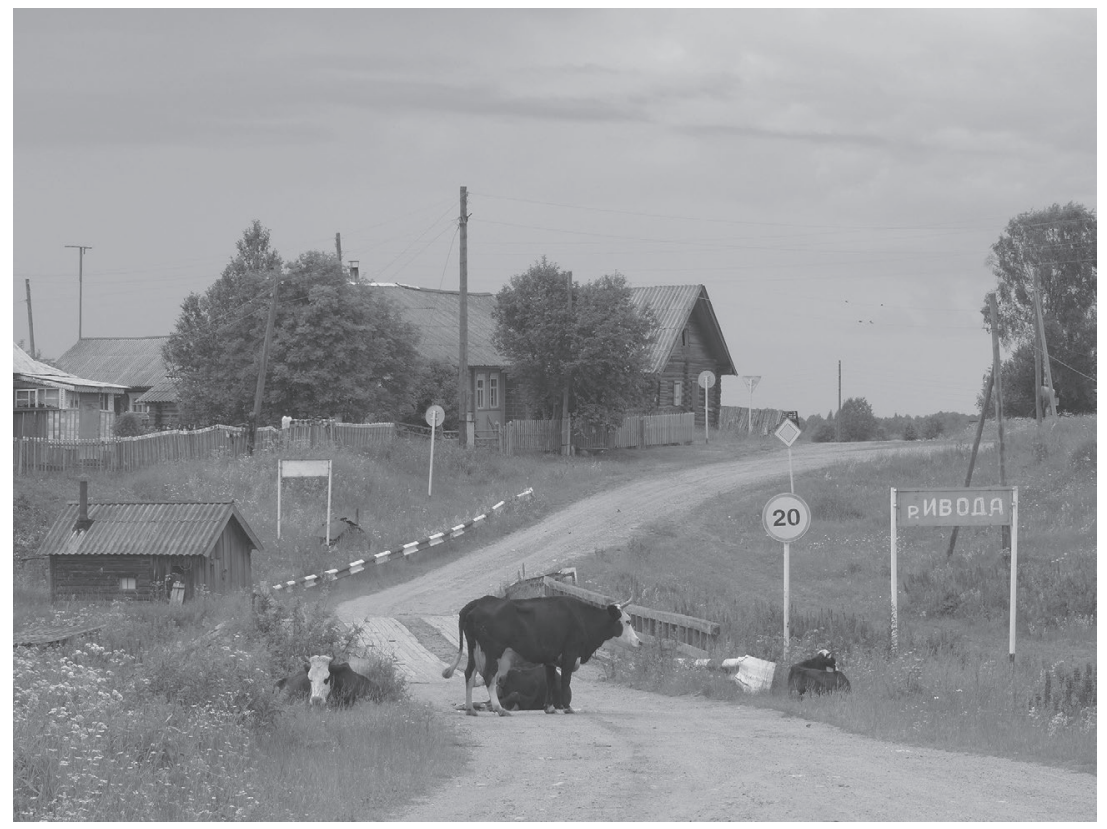

Figure 1.1 Pondal, a Vepsian village in the Vologda Oblast

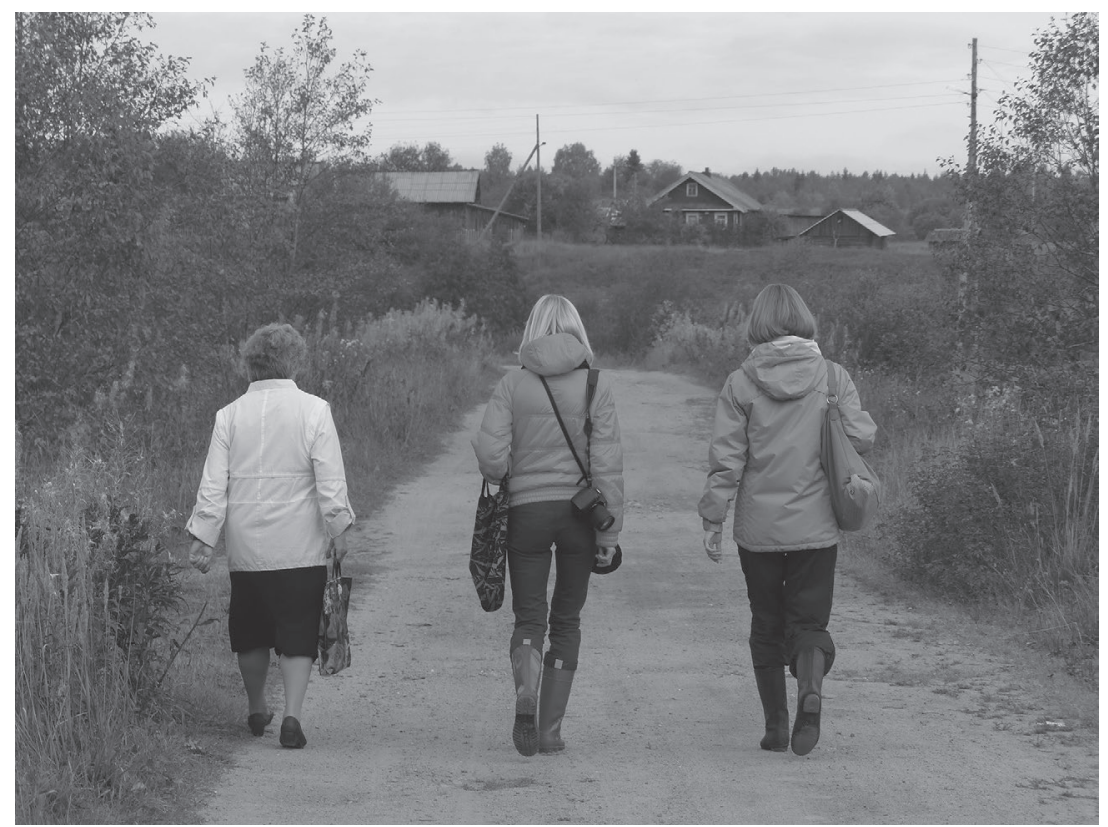

Figure 1.2 Two journalists (center and right) from Petrozavodsk on their way to work in Pondal. I took this picture in September 2013 
thus, it may sound simultaneously different and familiar to the native Vepsian dialect speakers. Galina Prokhorova and Taysiya Smerdova who have been living in Pondal all their lives admitted being confused when verbally interacting with the young journalists, despite supposedly speaking the same language. During an interview at the post office where she used to work, Galina Prokhorova justified herself for not promptly responding to the questions the young journalists asked her, admitting that she kind of understood what they were saying, but still could not make sense of it. And that seemed to be one of the reasons why she continuously found herself shifting into Russian. As soon as Mariya Filatova and Larisa Smolina completed their studies, they took on permanent positions as journalists in Petrozavodsk, promoting Vepsian language and traditional lifestyle. They often travel to the villages for work and report those expeditions in the form of documentaries, TV, and radio programs. During their trip to the Vologda Oblast, they managed to visit several Vepsian villages and collected a substantial amount of data which, as Larisa Smolina happily stated, "will last for the years to come." Besides their journalistic duties, they also distributed books, textbooks, journals, newspapers, and films in Vepsian to the local Houses of Culture, libraries, and schools which the activists in the Republic of Karelia had compiled; hence, they also fulfilled their duties as Vepsian activists and promoters of their heritage language. As such, they embody the desired outcome of the late-1980s Vepsian revival movement which invested in the generational transmission of the Vepsian standard form and literacy. In their eyes, indeed, this was a successful trip! And in many ways, it was. Yet, some questions remain unanswered when digging deeper into the promotion of a heritage language that focuses primarily on literacy, standardization, and generational transmission as signs of success, and risks neglecting some aspects of language use which result from a continuous interaction with the broader language ecology.

Indeed, the two journalists/activists from Petrozavodsk and the villagers in Pondal (as well as in other villages) apply different metaphors to their heritage language and overall engage rather differently in Vepsian ways of speaking (and writing). I put "writing" in brackets on purpose, since most villagers cannot read or write in Vepsian, especially those in their 60s and above, and more generally those who had not been exposed to the more recently created Vepsian standard form. Overall, the ways the activists and the village dwellers perceive and use their heritage language diverge quite substantially, due to the continuous and multifaceted relations with the dynamic language ecology in which they find themselves, comprising rural and urban locales. Although admitting that a radical split between rural and urban environments cannot occur in life, since people move in between these spaces and, thus, appropriate and exchange practices and systems of value, I became more and more inclined to embrace it as the inhabitants of this Northwestern Russian territory often describe and perceive it as something tangent and real. Such bipolar ontology is shown in their daily practices, including verbal 


\section{Introduction}

and nonverbal communicative practices, and the use of the written and oral mode of Vepsian. That is the reason why throughout the volume I often present binary paradigms, such as that of svoy-chuzhoy (R. One's own-foreign), urban-rural ways of living, and literacy-orality polarity, despite being aware that elsewhere such separations might be felt as artificial and a scholarly construction (cf. Ahearn 2011, 143; Ferguson 2013).

With the present volume, I aim to problematize ideas of language revival and promotion in relation to the overarching language ecology, maintaining at the core of my discussion a focus on literacy and orality. More specifically, I intend to demonstrate how different usages and metaphors of a language are complexly intertwined in social life. Hence, on the one hand, local ontologies can match the revival goals set by the activists; on the other hand, they can either enter in conflict with or simultaneously match and clash with the revival efforts. This volume aims to tackle often taken-forgranted and widely shared questions about language use and promotion and to challenge the assumption that signs of success in the revival efforts of an endangered language, such as Vepsian, can only be provided by a strong focus on literacy and standardization. My presentation of Vepsian revival movement grounds on two main concepts, language ecology and heritage language, and it further extends to power and agency in speech acts and the spoken word more widely.

Ecology as a metaphor of language has long existed, beginning with the biological model by Haugen (1972) and language shift by Mackey (1980). Their approach represented languages as systems in competition and described language shift as the result of such competition, hence, accepting evolutionary assumptions. The phrase language ecology began to uphold a biological and evolutionary conceptualization of language, correlating languages to natural organisms. This phrase has matched tree-of-life metaphors, which dominated during the Romantic Movement. Thanks to such a controversial and yet influential figure as Nikolay Marr genealogical paradigms were also popular in Soviet Russia. However, in this volume the phrase language ecology does not reiterate languages neither as competing entities nor as organisms conducting their own independent life. Rather it concurs with contemporary ideas of interaction and socialization with the world and can be understood not only as synonymous with context but also as an engagement and interaction with the environment where people use language (Bateson 1972; Garner 2004; Haugen 1972; Mühlhäusler 1996, 2000; Ochs 2012). I analyze language as a dynamic phenomenon, based on interaction and context, appreciating the term context per its Latin etymology, cum (with) and texere (to weave)-that is, to weave together (cf. Blommaert 2014; Ebongue and Hurst 2017). However, I should point out that the notion of context has its own ideological constraints, given that it came to be widely used in linguistic anthropology in the 1960s-1970s and its use was likely to ignore a diachronic approach to language and a focus on language ideologies which developed in later years (Duranti 2003). The 
notion of language ecology allows me to encompass such constraints. In other words, people engage in speech and written events, kinetic and paralinguistic practices in relation to and together with the forces in place at a specific time, and this practices do not emerge in a historical vacuum but are part of dialogic and diachronic developments which have repercussions and manifest in the present. If stretching this understanding of language ecology even further, it could be argued that languages are themselves an expression of relations (on the analogic language see Bateson 1972), and "modes of experiencing [and simultaneously constructing] the world" (Ochs 2012, 142). Therefore, I present how Veps use Vepsian, where they employ its written and/or oral mode in relation to the forces that come into play, and what the different usages indicate socially. The term Vepsian indicates the language and Veps the people. Vepsian does not have a gender, so the word $V e p s$ indicates both men and women. Such forces comprise an interaction with the environment, past legacies in language use and language attitudes, and contemporary language ideologies which incorporate belief systems shared by members of a group and extend to language (Schieffelin et al. 1998; Woolard and Schieffelin 1994). To present Vepsian language ecology comprehensively allows me to show how the revival of Vepsian heritage language responds to such complex grid of co-existing forces and where some social and political aspects of language prevail and others do not.

Heritage language can be translated as ičemoi kel' in Vepsian, which literally means own language. I have deliberately chosen not to translate this Vepsian phrase as "mother tongue" or "native language" and, instead, to adopt the phrase heritage language in English. My linguistic choice hints at a political discourse on heritage that cannot be dismissed when dealing with a minority language, such as Vepsian. In fact, I concede that this choice is partly the result of a set of relations with contemporary regional, federal, and international debates on minority languages. Undeniably, academic theories and linguistic choices also often result from an engagement with existing academic and political discussions (see Burawoy 2003). So, my choice hints at both the regional and federal positioning of Vepsian against the other languages spoken in this Northwestern Russian territory and at ongoing international debates on tangible and intangible heritage. In 2000, Vepsian obtained the status of national language (alongside Karelian), while Russian remained the official state language, according to the Languages in the Republic of Karelia Act (Strogal'shchikova 2004). In the same year, Veps gained the status of minority indigenous peoples of the Russian Federation which granted them also the status of minority indigenous peoples of the north, Siberia, and the Far East in 2006 (Strogal'shchikova 2016).

Beside this reason, ongoing international debates on the meaning of heritage have pushed me toward choosing the phrase heritage language when translating ičemoi kel'. In this volume, Vepsian heritage language refers to communicative and experiential practices that find their origin in the past and to those practices that are constructed today in the engagement with the 


\section{Introduction}

present language ecology. My linguistic choice focuses on its dynamicity and corresponds to the study made by Kirshenblatt-Gimblett (1998) and Smith and Akagawa (2009) who appreciate heritage not as something "lost and found, stolen and reclaimed," but rather as "something new in the present which has recourse to the past" (Kirshenblatt-Gimblett 1998, 149). This way the phrase heritage language encompasses both the oral communicative practices prevalent among Vepsian elderly villagers, and the new domains of Vepsian mostly used among the urban Vepsian youth.

Last, such linguistic choice closely links to the Russian phrase rodnoy yazyk (literally own, native language) also used among bilingual Veps in reference to Vepsian, where rodnoy has its root in the word rod (R. Family, kin, clan). Rod is also found in such words as rodstvennik (R. Relative, kinsman), narod (R. People, nation, folk), priroda (R. Nature) (Paxson 2005, 59). And in this sense the use of the phrase heritage language adequately summarizes the perception that many Veps (especially elderly villagers) displayed toward their mother tongue-i.e., as a way to relate and reach out to the surrounding rural environment, its human and non-human beings.

\subsection{The Research: Vepsian Revival Movement}

The Vepsian language is classified as seriously endangered by UNESCO, and it is spoken by Veps, a Finno-Ugric minority of the Russian Federation. ${ }^{1}$ The Vepsian language belongs to the Finnic subgroup of the Finno-Ugric languages together with Finnish, Estonian, Karelian, Votic, Livonian, etc. It is the most eastern language of this subgroup and Livonian is the most western. Traditionally, Veps dwell in the northwestern territory of Russia and live in three different administrative regions-namely, the Republic of Karelia (or Karelia in this volume) and the Leningrad and Vologda Oblasts (Maps 1 and 2). The Vepsian language has a long-standing oral tradition and only in the 1920s-1930s during korenizatsiya (R. Indigenization), a group of scholars from the Leningrad Oblast created a standard form and introduced it in the education system (Kettunen and Siro 1935; Salminen 2009; Setälä et al. 1951; Strogal'shchikova 2008a, b). In 1937, however, Vepsian was abruptly forbidden in the public domain. In the late 1980s, a group of activists from the Republic of Karelia sparked an interest in the indigenous peoples of Karelia which spawned the revival of the Vepsian language and culture. Veps and Karelians have received the political status of indigenous peoples of Karelia unlike the Ingrians-i.e., Russian citizens with Finnic ancestors who moved to the territory around St. Petersburg in the seventeenth century. The Vepsian revival movement officially began with a festival called Elon pu / Drevo Zhizni (V./R. Tree of Life) in Vidl, Leningrad Oblast, in 1987 (Figure 1.3). The following year the activists attracted the attention of the authorities from Moscow and organized a conference on the linguistic and socio-economic situation of Veps at the Academy of Sciences in Petrozavodsk (Klement'yev et al. 2007; Zaitseva 1989). In this 


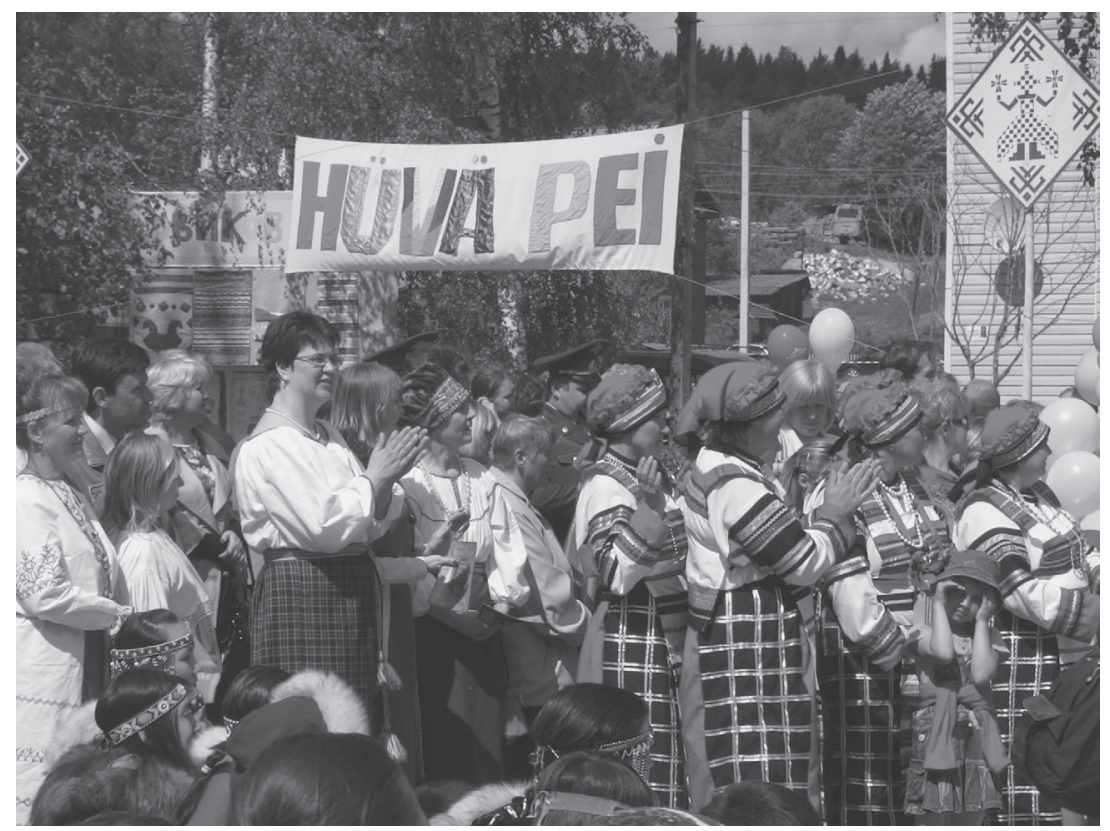

Figure 1.3 Veps taking part in the festival Drevo Zhizni in Vidl in 2010. I took this picture

volume, there is an overlap between those who are Vepsian activists and scholars, since most of those who led the 1980s movement work also at the Academy of Sciences and/or Petrozavodsk State University. Nonetheless, several Veps who are in their 20s/30s now work in institutions that are not necessarily academic. On this occasion, Zinaida Strogal'shchikova also founded the Society of Vepsian Culture. Zinaida Strogal'shchikova is the main political Vepsian activist working at the Institute of Linguistics, History and Literature at the Academy of Sciences in Petrozavodsk. The scholars attempted to obtain economic investment in Vepsian rural areas from the federal and regional authorities (Klement'yev et al. 2007). Once their requests were rejected, they turned to language and culture to achieve their social and political goals. The main founders of this movement were Nina Zaitseva and Maria Mullonen dealing with language matters and Zinaida Strogal'shchikova dealing with ethnographic and political issues. Nina Zaitseva is the main Vepsian linguist at the Institute of Linguistics, History and Literature at the Academy of Sciences in Petrozavodsk. In the late 1980s, Nina Zaitseva created the codified form of the Vepsian language and began promoting Vepsian education. Language revival became political action. 


\section{Introduction}

Since the beginning of the 1980s revival movement, the activists privileged literacy over orality in the promotion of Vepsian. Literacy became an emblem of political intervention as a way to promote the Vepsian language within a multiethnic society such as that of the Republic of Karelia (cf. Nevins 2013, 30-31). The activists and Veps mostly employ the Russian verbs sokhranit' and razvivat' ( $\mathrm{R}$. To promote and to maintain) instead of to save (Spasti in Russian), which is more common in international discourse in regard to the revival of the language of a minority group. I will also adopt such terms systematically, and will oscillate between the terms revitalization and preservation and development of Vepsian in order to link to broader discussions on language revival movements. More recently, the term sustainability has also gained central stage in regard to language revitalization, so I will incorporate it in the language used in the present volume. By privileging literacy in the promotion of Vepsian, the activists primarily followed the language ideologies laid down under the Soviets and already before with missionary activities. In contemporary Russia literacy is usually synonymous with culture and civilization. These two concepts are symbolically loaded there (Paxson 2005, 15-17), but, admittedly, also elsewhere as shown by Finnegan $(2007,91)$ in her studies in Africa. The concept of civilization is particularly complex since it refers back to ideas of development and backwardness under the Soviets. ${ }^{2}$ The choices of the activists, therefore, were also influenced by the existing language ideologies among the multiethnic dwellers of Northwestern Russia. What's more, the regional and central political authorities rejected some of the recommendations put forward by the activists regarding village life at the conference on Veps in 1988. The activists had requested the promotion of village life and prompting a return to rural areas, which they understood as central to the maintenance and preservation of the Vepsian language. Thus, the intellectual elites only partially included the oral usage of the Vepsian language in the movement.

The comprehensive presentation of Vepsian language ecology and Vepsian revival movement aims to investigate how and why certain language modalities and ways of promoting a minority language have gained more divulgation than others. That is to say, the analysis presents sets of language practices and their social symbolism and indexical properties, which have been included in the revival of Vepsian and those that have only partially been included and why this is so. As such, the present volume creates space and puts forth those who are marginalized through a detailed account of the specific practices and structures of marginalization (Blommaert 2005b; Bourdieu 1992). A more rounded description of language practices aims also to contribute to the reduction of inequalities in the revival of Vepsian and to advance those who are only partly included in the movement. Specifically, I refer to the oral practices of the Vepsian speech communities in rural areas of the Vepsän ma (V. Vepsian land) as opposed to the use of Vepsian literacy in the cities, especially Petrozavodsk. Vepsän $m a$ not only comprises all the villages and cities where Veps live, but it also 
includes human and non-human entities that Veps consider svoy (R. One's own). In this study, Vepsian villages refer to those that obtained the official status of Vepsskaya volost' (R. Vepsian district) of Karelia in 1994 as well as those villages in the Leningrad and Vologda Oblasts traditionally inhabited by Veps. At present, many villages include members of other nationalities, too. In line with Vepsian use, the phrase Vepsän ma is also employed to indicate a sense of sebr (V. Community) which had been affected with the promotion of assimilation policies already during the Soviet regime. The word sebr is also charged with several meanings and social symbols. As Ol'ga Zhukova once explained to me, it might have originally meant only work together, jointly; however, it later began also to indicate community, society (cf. Pimenov 1965, 209). This initial meaning hints at the fact that those who cooperate and work together with Veps may become part of the Vepsian sebr: an example of this is the social symbolism I began to be attached to during and after fieldwork as I integrated more and more in the activities of the communities I work with. In this volume, the term sebr also encodes civic action and is tinted of political colors. The activists saw flaws in the political and economic intervention of the authorities in the late 1980s and turned to the creation of a standard language as a symbol of unity among the dispersed villages. It is not surprising that Nina Zaitseva who leads the codification and standardization of the Vepsian language insists that Veps lived compactly and are not dispersed; thus, she emphasizes the need to rely on a feeling of unity and closeness that is augmented by a distinct codified heritage language. The term standardization refers to the process of establishing Vepsian discourse and Vepsian patterns of communication in a standard form that is used for teaching purposes and in written material. The term codification refers to the process of fixing the structural features of Vepsian-i.e., the morphology, phonology, and lexicon of the Vepsian language.

The present study sheds a new light on the scholarly discourse on language and power, which dominated the academic debates in the 1990s. More specifically, it shows how pre-revolutionary and Soviet language ideologies and practices co-exist along with more recently introduced practices and attitudes both in the city and in the Vepsian villages. Indeed, persistence and change is what defined the transition from a Soviet state into what Paxson $(2005,17)$ refers to as something surreal. More than on its surrealistic aspect, the present work focuses on the continuous interactional enterprise that speakers of minority languages have engaged with; thus, allowing for some practices to emerge in certain places and not in others. An example of this is that the Northern Veps who live either in Petrozavodsk or the nearby villages tend to accept political and structural approaches to language with less reservation, given their continuous exposure to the work of the activists. Therefore, it is not uncommon for them to adopt linguistic categories that view languages as bounded systems-e.g., minä pagižen vepsäks (V. I speak Vepsian) or venäks ("Russian" in the standardized Vepsian form). On the 


\section{Introduction}

contrary, the Central Veps who in general are less involved in the promotional activities organized in Karelia, tend to have an ear for different ways of speaking, but not to frame them as enclosed systems. So they would say that people pagižeba toižin (V. Speak differently) or that they speak ičemoi kelel (V. Their own language) rather than vepsäks or venäks (Puura et al. 2013). Such practices are not surreal, but indicate a continuous, dynamic interaction with prevalent forces, including language ideologies. I ask the reader's indulgence for now since these differences in oral language practices will be explained later in the volume.

The use of the word power is also intended to link to a widely spread epistemology among Veps, according to which words carry a weight in shaping reality and, therefore, need to be pondered carefully. The concept of speaking carefully and its social symbolism are also expanded further in the book. For this reason, power can also be understood as agency, as I better explain next.

My intention with the present volume is also to introduce the Vepsian revival movement to a wider audience in accordance with principles of cooperation and divulgation. Indeed, several Veps admitted expecting this from me as a representative of "Western" academia. Besides, I intend to draw the attention of policy makers who deal with language planning, language power inequalities, and human rights at national and international levels to a theoretical as well as practical conundrum. And this lays in the literacy bias within language revival movements. First of all, bringing such a bias to the surface can help us reflect on revival practices that are globally spread and their relevance in our contemporary world. Indeed, the presentation of Vepsian revival aims also to activate a reconsideration of the terminology used internationally to describe language shift phenomena. Re-thinking political and widely spread scholarly terminology on language shift can bring policy makers and grassroots levels of society closer and, ideally, it will facilitate mutual understanding. Furthermore, it is important to maintain the policies and academia updated on the interests of a new generation that is emerging and presenting new sets of language practices and needs. Last, the Vepsian revival movement is yet but one of many movements taking place in the Russian Federation. I can already anticipate and certainly hope for theoretical and conceptual comparative studies with other similar movements in Russia.

\section{Veps, Vepsian Language, and Demographics}

Speaking toižin (V. Differently) pertains to speaking a foreign language and speaking a different Vepsian dialect. The Vepsian language comprises three distinct dialects (northern, central, and southern) which do not correspond to the administrative division as illustrated on Map 2. The northern-speaking Veps, also referred to as Veps of the Lake Onega, live either in Petrozavodsk or along the southwestern shores of Lake Onega in the Republic of Karelia. This region is also known as Vepsskaya volost' (R. Vepsian district). Central Vepsian 
speakers are based in both the Leningrad and Vologda Oblasts. Their dialect can be divided into Central Eastern and Western Vepsian. Veps dwelling in the West along the river Oyat' are also called Veps of the Oyat'. Southern Vepsian is spoken in the Boksitogorsk province of the Leningrad Oblast.

Over the course of the last century, Vepsian language use has declined and this decline has mainly been induced by Soviet language and economic policies (Strogal'shchikova 2006). The movement of the late 1980s acted to reverse this trend. The activists experienced an initial zeal and witnessed an increase in the number of those self-reporting Vepsian ethnicity from 7,550 in 1979 to 12,142 in 1989 . This increase was connected to a greater ethnic consciousness. However, in 2002 the Vepsian population in the whole of Russia decreased to 8,280 and in 2010 down to 5,936 (Table 1.1).

The ways in which the censuses have been carried out in Russia have not always been reliable (Hirsch 2005, 146). The 1926-census had established beforehand what ethnic groups lived in the Russian territory and it could have given a completely different picture of the ethnic composition of the Russian territory, if the census had established the ethnic groups afterwards (Vakhtin 2001). The following census in 1937, instead, was highly politicized and influenced by Stalin's purges. The censuses between 1959 and 1989 did not solve the ambiguity about what heritage, native language (R. Rodnoy yazyk) was defined as. Indeed, the criterion of these censuses was to let the people define rodnoy yazyk for themselves. For some, their heritage language is the first language they learned to speak; for others it is the language which one feels more closely related to or it is an individual's language of heritage.

However, the data provided by the censuses caught the attention of the activists. Most of their concerns have concentrated on the language situation, since it became clear that the Vepsian speakers were getting older and not transmitting their language knowledge to the younger generations (Grünthal 2011). The figures from the census also presented a difference between the preservation and use of the language in the various provinces, where Veps dwell, as well as between the urban and rural settings. With this information, my investigation into the Vepsian revival movement and the Vepsian language use began.

\section{A Recurrent Polarity: Literacy and Orality}

A Vepsian delegation from Petrozavodsk went to take part in the Vepsian festival Elon $p$ (V. Tree of Life) in Vidl in June 2010. It was a warm, sunny day and Alëna Egorova and I were standing on the passenger deck of the steamboat while crossing the Svir' River, which connects Lake Onega to Lake Ladoga. Alëna Egorova is a former student of Vepsian at Petrozavodsk State University. We were speaking Russian as we were admiring the beauty of the scenery. An elderly villager approached us then and started querying who some of us were since he did not know. He asked Alëna Egorova, 


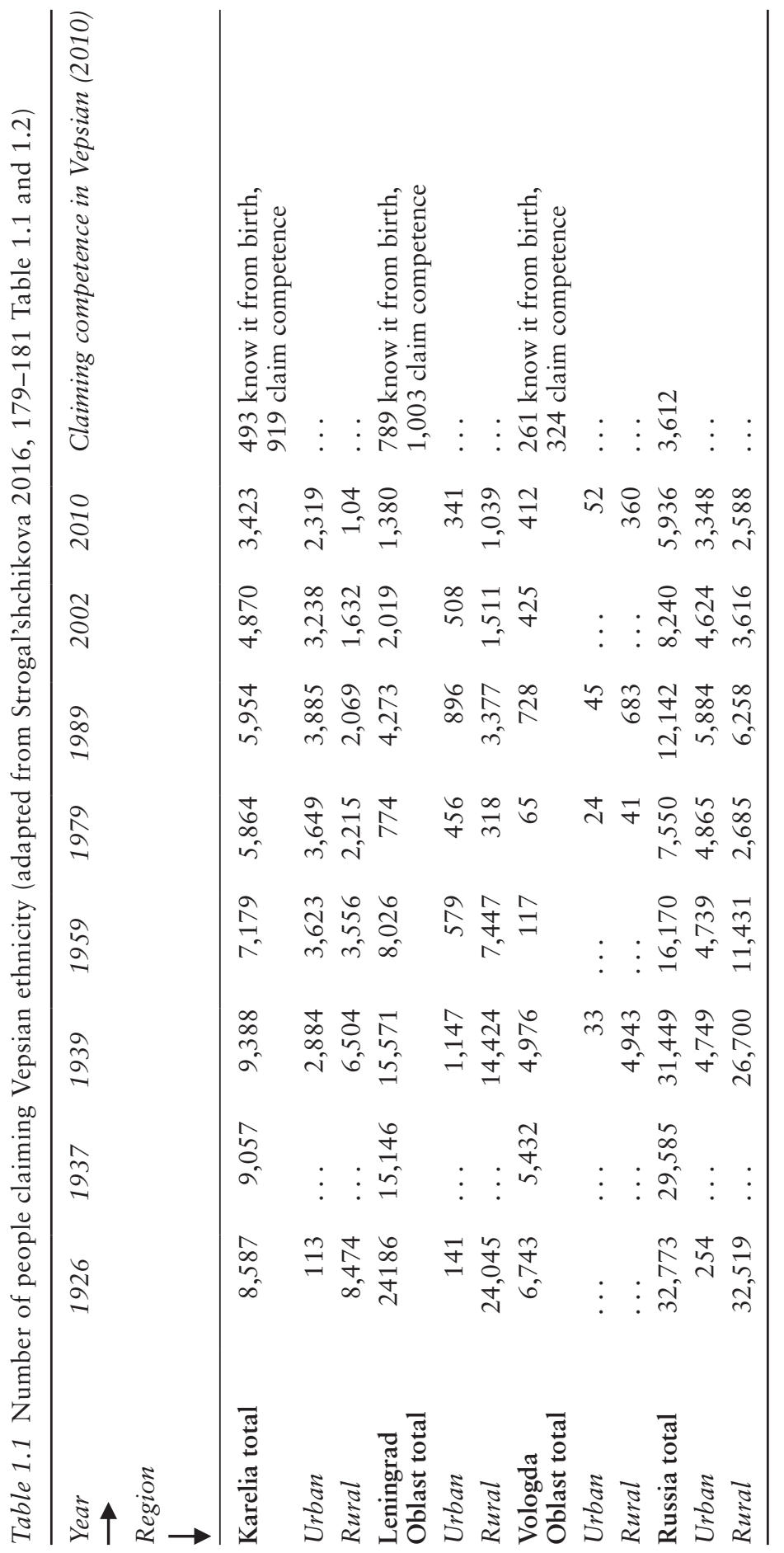


with whom he was acquainted, about some of the passengers. He then commented in Vepsian that he knew about my research interests and began speaking Vepsian to us. When my speaking skills failed, he commented, "You should be speaking more in Vepsian to us." And Alëna Egorova added, "In fact, we should all be speaking more in Vepsian." He agreed. The need to be speaking Vepsian more is a topic that Veps often discuss. On several occasions, I heard Veps demanding more institutional opportunities to support speaking Vepsian. The initiative of establishing a Paginklub (V. Speaking club) in Petrozavodsk in 2011 developed as a result of this request (Figure 1.4). At the Paginklub, its leader Larisa Smolina arranges

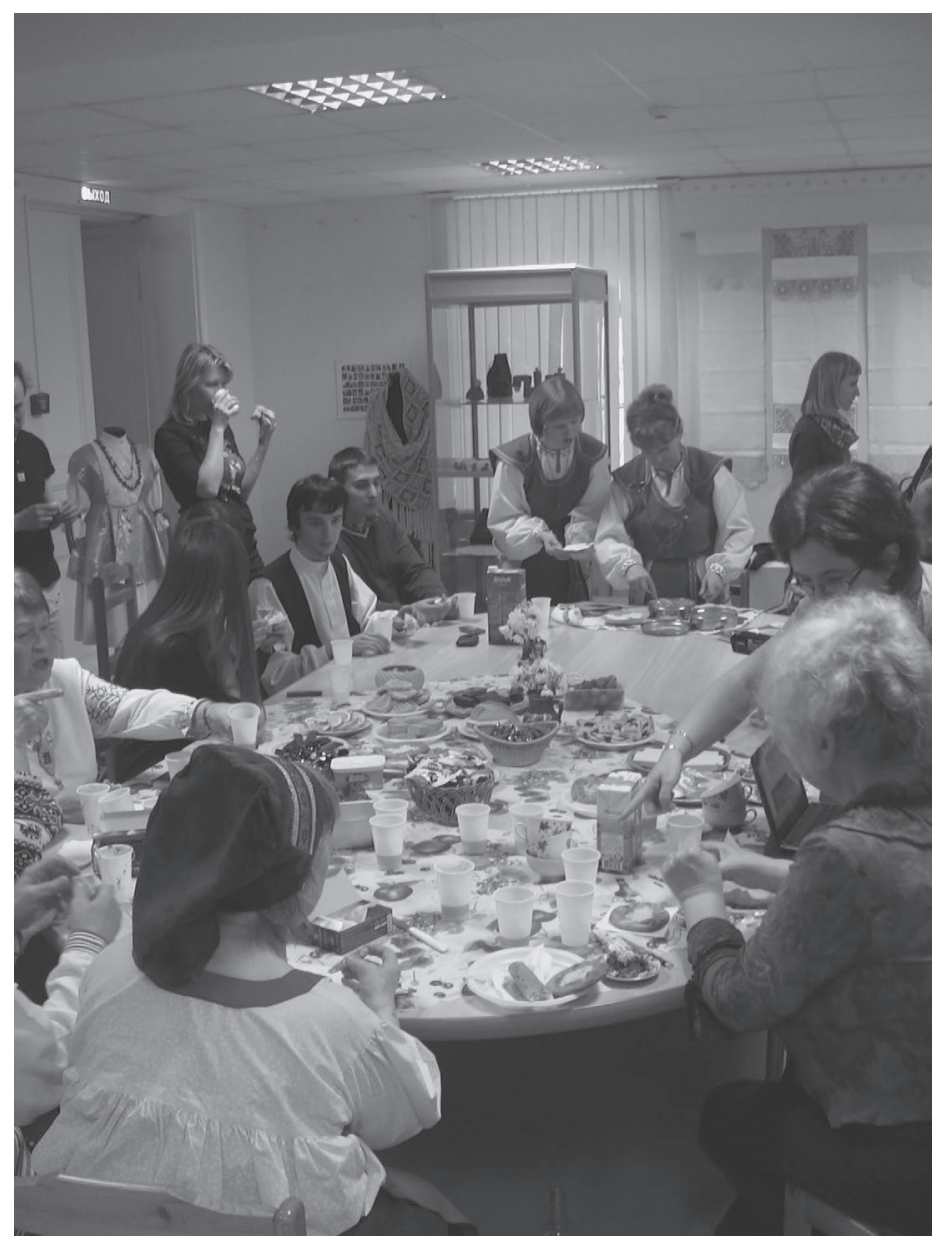

Figure 1.4 Paginklub (V. Speaking club) at the Centre for National Cultures in Petrozavodsk. On this occasion, the club gathered to congratulate me on the completion of my doctoral studies. I took this picture on 29 March 2013 


\section{Introduction}

activities where the attendees can speak Vepsian while engaging in craft making, watching TV reports, and listening to radio interviews. Yet speaking as a social activity as such which needs different methods of promotion has neither formally entered political discourse nor received adequate financial support. In fact, a key area of conflict lies in the promotion of mainly Vepsian writing while institutional opportunities for speaking Vepsian are not always subsidized. Paginklub was initially run on a voluntary basis, for example. To be more precise, while TV and radio programs run in the Vepsian language with the purpose to promote the oral mode of the language, there is still little public space for speaking Vepsian in the city and in the villages. Such limitations are particularly counterproductive in those villages where most elderly master their heritage language and could more actively take part in the revival efforts. Indeed, the promotion of primarily Vepsian literacy risks overshadowing Vepsian orality, which is how Vepsian villagers mostly use the language. Therefore, it is important to bring to the surface those aspects of language use that are partly marginalized from the mainstream movement, mostly because people express such needs. As to marginalization, I refer to dynamic socio-economic, political, and cultural processes in which people are partially shut out. In the case of this volume, I specifically target cultural marginalization, which is not separated from the economic, political, and other aspects of social life. Rather, stressing cultural marginalization aims to draw out the importance of creating and sustaining a dialogue among the different agents involved in a revival movement and to evidence the complexity of the forces that make up social life.

I should point out at once that the literacy bias within the Vepsian (but not only) revival movement finds its origin in specific language ideologies, according to which literacy is the next step in the evolutionary ladder of a language. In fact, the supremacy of literacy cannot be confined only to the Vepsian or other language revival movements, but it extends to how many scholars and nonscholars view language overall. One could argue that this hierarchical approach to language use can find its roots in the Abrahamic religions, especially Christianity, to promote the sacred (written) word in Europe in the Middle Ages and later with the discovery of the Americas. While the indigenous peoples had a closer connection to language orally which they understood carrying more power, the European colonizers saw orality as a lack of literacy and constructed hierarchies, and practiced discrimination and power disparity over it. This view advanced even further adding evolutionary theories and ideas of superiority and civilization which date back to the Enlightenment and the Industrial Revolution (Finnegan 2007; Ong 1982; Vaschenko and Smith 2010). In other words, literacy indexed civilization, and this reinforced the great divide between literate and illiterate societies (Grenoble and Whaley 2006, 105). Such ideologies apply not only to the post-Soviet territory where Veps live, but are dominant also elsewhere (cf. Finnegan 2007). The Soviet regime embraced such discriminatory and evolutionary ideologies that quite possibly spurred from 
precedent missionary activities. Under the Soviets, extending literacy to all the different ethnic groups dwelling in the Russian territory was seen as the equivalent of bringing them up to the standard of Soviet civilization and discarding backwardness once and for all.

The literacy over orality bias has accompanied humanity throughout history. It is difficult to deconstruct it, due to its long-standing and effective tradition. Notably, a few contemporary scholars continue to advocate such a hierarchical viewpoint on language (Ong 1982; Olson 1994). Nonetheless, already in the early twentieth century figures such as Boas $(1940,1966)$ and Sapir (1921) emphasized the importance of considering each language for their unique structure, intrinsic worldview, and ways of expressions. And yet Boas himself strove to establish a written literature for oral cultures. Their approach developed even further in the 1960s-1970s, when scholars began distancing themselves from what they considered to be literacy-based chauvinism. Specifically, Hymes $(1962,1974)$ emphasized the social aspect of oral language use and began to distinguish ways of speaking and speech communities, or more recently referred to as communities of practice (Ahearn 2011, 101). He stressed the importance of the context where people manifest language and, therefore, the various ways of expression in relation to it. Ways of speaking indicate multiple ways to communicate, engage, and socialize with the world, using the oral form of language. They are structurally and symbolically shared within speech communities and, thus, enable communication. However, oral traditions in both their structural and symbolic characteristics should not be understood as static systems since they can adjust to new knowledge. The ethnography of speaking or ethnography of communication acquired a scholarly reputation for bringing to the fore a contextual and situational oral mode of the language which allowed scholars to investigate small-scale verbal interactions and performative acts (cf. Bauman and Sherzer 1974; Bauman 1977). The oral mode of the language received renewed attention from the academic world which, in fact, is continuously revived and developed further (e.g., Blommaert 2014; Finnegan 2007).

Despite such abundant and scholarly engagement with oral traditions, literacy continues to be privileged, to indicate advancement in society more broadly, and to be taken as the next step in the promotion of a language of a minority group. More often than not, favoritism of literacy continues to rule language planning and policy in the discourse of language revival.

\subsection{Language Revival Programs: Literacy Versus Orality or Literacy and Orality?}

The imbalance of oral and written modes within the promotion of a language is not distinctive of the Vepsian movement only. In fact, this situation applies to most language revival movements globally (however, not all, as I indicate in Chapter 8). This observation arouses from an analysis of the studies on revival movements globally, which have taken two main 


\section{Introduction}

directions: one defining language shift and suggesting ways to reverse this negative trend: the other framing language shift within structures of power. I expand on the latter further next. The first direction stems from the notion of language endangerment, assuming that language decline can be described using a biological metaphor. In simple words, language is often conceptualized as an anthropomorphic entity with its own life cycle-it has an origin, it develops and reaches its peak, and then it declines and dies. The language ecology frame that characterizes the present work takes distance from such an approach since it does not conceive language as an abstract entity, but as a mode of experiencing life and in relation to it. Yet, part of the academia has embraced such a metaphor and developed best practices and sequential steps on how revival movements should work, building upon the urgency to save those endangered species (i.e., languages). These academic and political practices are referred to as language planning.

Language planning bifurcates in corpus and status planning. While corpus planning refers to the standardization of a language, with the codification of its morphology, phonology, lexicon, and syntax, often to match educational and publishing purposes; status planning refers to the political positioning of the language and assesses its value in an often multilingual context (Fishman 1991). There cannot be such a fixed distinction between the two, since status and corpus planning often overlap (Fishman 2006). An example of this is the adoption of Vepsian street signs (alongside Russian) for the villages of the Vepsian district in the Republic of Karelia since visibility is aimed at gaining social visibility and status, and the Vepsian village name is part of the codification and standardization process initiated by Vepsian linguists and activists (Figure 1.5).

While a universal paradigm for language planning and policy cannot exist, Fishman $(1991,2001)$ presents a model for revival programs which has often mirrored the steps taken by many activists and policy makers. $\mathrm{He}$ introduces eight stages that should culminate with the minority language being mainstreamed into the education system (Fishman 2001, 466). This model founds on the idea that standard language should be created and promoted through the means of media and at schools. It offers sequential steps, beginning with the assessment of the language situation and moving into the expansion of language domains of use (Hinton and Hale 2001). Other scholars conform to the model proposed by Fishman, such as Hornberger (2008), McCarty (2005), and Hornberger and Swinehart (2012), to name but a few.

Conversely, part of the academia questions this sequential revival model and particularly its emphasis on literacy and education. For Grenoble and Whaley $(2006,102-103)$, literacy is necessary only when it results from a grassroots movement and it is the expression of the needs of the community. If not so, the language-planning model fails to provide the desired results in specific contexts (Breton 1991). It is justified how some scholars remain skeptical about the effectiveness of language policy and planning (Spolsky 


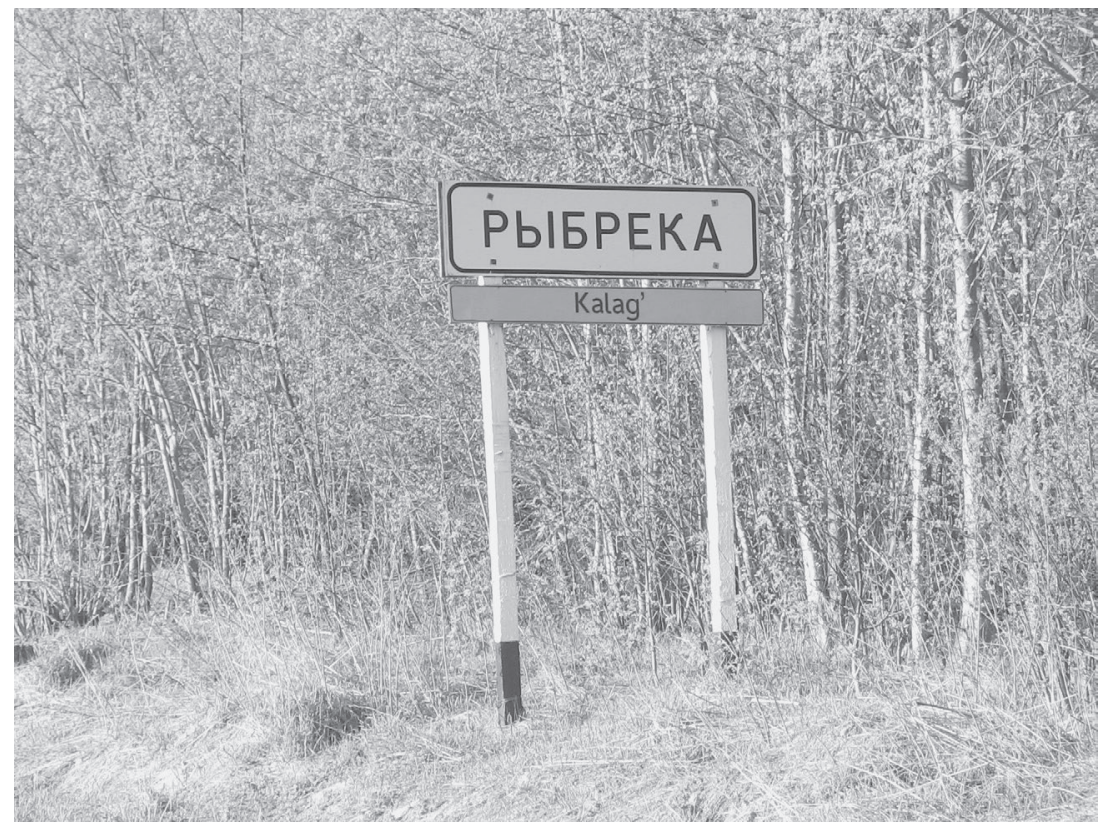

Figure 1.5 Street sign indicating the Vepsian village Kalag' in Russian and in Vepsian. I took this picture

2004). Yet, my analysis of Vepsian ultimately led me to combine the position of both those who view positively and negatively language planning with writing and teaching as ultimate goal.

The promotion of Vepsian literacy and educational approaches followed accepted paradigms of language revival. Supported by the Karelian government, the activists overtly operated in the direction of a standard language in order to preserve and maintain Vepsian and promoted it at school. They created a standard form of the language that could be taught at school. Such intervention was molded on the short-lived 1920s-1930s movement. This way the late-1980s activists matched the model proposed by Fishman (1991), and have unconsciously conformed to western bias and Soviet ideology, privileging literacy over orality in the promotion of a minority language (Krupnik 2005 makes similar observations in Alaska). Vepsian language planning and policy mainly materialized in the creation of a written form, its promotion at school, and publication for recreational, informational, and educational purposes. The question is has this worked within the frames of Vepsian revival? Has Vepsian language ecology comprehensively been included in the revival movement? Considering that the Vepsian language has had a long-standing oral tradition and that Veps (both 


\section{Introduction}

in urban and rural areas) ask for more institutionalized opportunities to speak the language, it is time to put this request forward. It is important to note here that the language model offered by Fishman and the Soviet pattern has provided some positive results in the city where the Vepsian language would have only rarely been used, otherwise. Indeed, Vepsian literacy and Vepsian education has become the main vehicle for transmitting knowledge and communicating between the generations, as there are new users of Vepsian writing and they are creating new domains of use for the language. The present work, therefore, does not entirely discard the model offered by Fishman and the legacy of Soviet ideologies, but aims to complement them with other uses, ideologies, and metaphors of language in a specific context, the rural territory where Veps live.

\subsection{Language Revitalization: Pros and Cons of Literacy Chauvinism}

Literacy is often viewed as a tool that may help the activists supersede inequalities. Indeed, literacy can help the minority group overcome economic differences (Kaplan and Baldauf 1997), and it can help the minority group appreciate the social structure in which it lives and, thus, it can be more active and critical about the existing living conditions (Liddicoat 2004; Street 1984). As a consequence, literacy may open the doors of opportunity to those who are socially marginalized and provide the minority group with more social prestige (Hornberger 1997; McCarty 2005). When the heritage language becomes more prestigious, the minority and/or marginalized group will find motivation to use it more often (Grenoble and Whaley 2006; Phillipson 2003). Or, at least, this is hoped for! Overall, literacy can be socially beneficial, since it propagates values and norms of behavior; it fosters critical thinking and, consequently empowers those who use it (Baker $2003,78)$. It helps the marginalized groups to become more visible, too. In other words, promoting the written language of the minority provides advantages for all. Hence, conforming to this section of the literature on language revitalization, literacy in the minority language seems to serve the purposes of the revival movements. The Vepsian activists and those involved in the language revival generally agree with these claims. They also argue that literacy may boost pride in the population and increase the desire to be speaking more Vepsian.

However, a few scholars contest such claims and their reasons for doing so vary. For example, the creation of a single standard form of the language may reduce language variety (often depicted in the dialects spoken by the members of the minority group) (Mühlhäusler 1992). Such an artificial language can simply be rejected by the majority of speakers of a minority language and, thus, it can simply be a wasted effort (King 2011). Besides, favoring literacy may contribute to the disappearance of oral play-games and reduce variety of expression typical within the marginalized group 
(Grenoble and Whaley 2006, 118). Another claim against literacy chauvinism aims to protect the will of the grassroots levels of society, which may simply not be interested in reading and writing. ${ }^{3}$ On the whole, all levels of society need to be incorporated in the revival of the language for it to succeed. Therefore, it is important to investigate language ideologies and attitudes among the population (Romero-Little et al. 2007, 608-614), or the revival efforts will face an innumerable account of social challenges. If the promotion of literacy causes conflict between social practices and ideologies, it is most likely that revival efforts will fail (Heath 1983). Part of the scholarly world, therefore, calls for a more holistic approach to language revival where the literacy bias needs to be reconsidered in favor of other more context-based modes of language policy and planning. In particular, experts have now begun to consider language ecology in the planning of the corpus and status of a language.

My work with Veps concurs with the latter arguments in favor of a more holistic approach to language revival since it incorporates all levels of society. Building upon observation on language use done in the field, I claim that literacy as a social response has its functions in urban areas more than in rural areas, whereas Vepsian is spoken more in rural areas where Vepsian villagers, especially the elderly, cannot read or write in Vepsian. The power of language for them is to be found in the spoken word and in its socialization with the world. Both literacy and orality are part of Vepsian ecology and respond to the dominant forces in different places.

\section{Literacy and Orality: Vepsian Language and Revival}

In multiethnic Petrozavodsk, Veps interact with one another mostly in Russian, just like members of other ethnic groups. Russian is the language of communication and it dominates public space. Spoken Vepsian is rarely (if ever) heard on the streets of the capital of Karelia. Veps who master the language generally speak Vepsian with one another in places such as the Centre for National Cultures or at the National Theatre. ${ }^{4}$ The Vepsian activists have created space for written Vepsian. At the beginning of their revival movement, their main concern was to gain visibility among a multiethnic environment and re-institute confidence among the Vepsian population. Their practice reflects learned ways of promoting a minority language under the Soviets where literacy was understood as advancement in the evolution of a language. Their intervention indicated the desire to reinstate political power to the Vepsian language by abiding by Soviet language ideologies. Therefore, Vepsian publishing is actively promoted and so is Vepsian writing within educational institutions. Their course of action also responded to the language ideologies of the city dwellers, who tend to view literacy as an indicator of civilization and development. Nonetheless, many Veps have recently begun to demand more institutional space in the city where they can meet and speak Vepsian. A few former students of Vepsian admitted 


\section{Introduction}

having forgotten the language they learned at university, since they "rarely had the opportunity to speak it and cultivate fluency in Vepsian" (Author's field notes, 2011).

The Vepsian villagers face a different situation. Those who master the language in its oral mode often cannot read or write in it. They are primarily the elders in their 60s-70s and, therefore, are being excluded from the mainstream promotion of Vepsian, which mostly focuses on the written mode. Furthermore, public space is often unavailable, such as the Dom Kul'tury (R. 'House of Culture') in those villages with less than 1,000 inhabitants. So the villagers suffer from not having a place to meet and engage in different activities while speaking Vepsian.

In the late 1980s, the written word epitomized a unity, a sebr that the activists feared had been lost under the Soviets. Vepsian literacy became symbol vis-à-vis the power of written Russian and as such the activists mainly responded to Soviet and post-Soviet ideologies in the promotion of the Vepsian language. The present work complements their work by creating space for those who have been more marginal to the movement. In this sense, it is strongly linked to the literature that observes power inequalities also in language use and promotion.

\subsection{Vepsian Language: Power and Agency in the Spoken Word}

The present volume adds a new angle to the conceptualization of power, also by bringing it closer to an understanding of agency in language-something that, according to Ahearn $(2001,116-117)$ is missing in the work on power by Foucault. My work with Veps led me to appreciate the power of language within a system of relations, in which power is not only conceptualized as an external entity (often identified with the political bodies and social impediments) which imposes language choices on people, reinforcing social inequalities. Indeed, people can demonstrate agency in their language practices by manifesting power in language differently, either in their written and oral modality in relation to the context in which they use language. Nonetheless, this concept of agency does not only confine to humans, but it also embraces other beings.

The study on language and power relation has taken three main directions over the course of the last century or so (Philips 2000). The first path revealed the power of language in its structural features, the second in its capacity to influence relations in small-scale situations and the last one in such capacity in large-scale situations. From the beginning, it was understood that language carried a culturally intertwined worldview, and this was expressed in its internal structure. Later in the 1960s-1970s, scholars studied language for its power to create social realities in small-scale situations, such as those of face-to-face interaction and discourse (Philips 2000, 195). Simultaneously, Hymes (1974), Bauman (1977), and Abrahams (1970) 
developed the anthropology of speaking. In their work, they demonstrated how oral forms of language are not inferior, less complex, and socially meaningful than written forms of language. Last, the relation between power and language has been further expanded to larger-scale contexts (Blommaert 2010; Philips 2000). Specifically, this last analysis comprises debates on the linkages between language practices and post-colonial legacies and the formation of nation-States. This position tends to view language shift as an index of hierarchical and hegemonic relations on an unequal playing field, often characterized by multicultural and multilingual conditions. One language dominates over the others and is chosen by the policy makers as the language of public discourse. The claim is that there the State often has the power to control language use and practices of the masses. Language decline is, therefore, perceived as an indicator of social inequalities, while language maintenance enacts the efforts to reverse those inequalities, by giving power to the underprivileged.

In the case of former Soviet nations, language decline has often been perceived as a consequence of Soviet political measures (Comrie 1981, 5; Strogal'shchikova 2008b; Grenoble 2003, 194). It is believed that Soviet language manipulation from the promotion of indigenous languages in the 1920s and 1930s, interrupted by Stalin's terror, dictated almost irreversibly language choice among the population. Power, therefore, was represented by the State through the implementation of certain legislative measures, often dictated by language ideologies. Discussions with scholars, activists and the multiethnic population of Karelia showed how they often see the present language situation in the Russian Federation as a direct consequence of Soviet expedients, where the State acts as the vulture, and the population as the submissive recipient of such forceful measures. During a seminar in Petrozavodsk in May 2010, Zinaida Strogal'shchikova also blamed the 1990s crisis, which hit Russia for having reinforced negative attitudes toward language revivals. Yet again, the State appears as a deus ex machina in its intervention on national language practice. However, despite the influence of the State on language ideologies and choices, it is clear that the State is not the only agent to shape communities and their practices. The multiethnic population of Karelia (both in the city and in the villages) not only applies early Soviet categories to distinguish the various nationalities but also often refers back to pre-revolutionary categories and stereotypes. Those categories and stereotypes also reflect the way in which language use and language loss is understood and perceived among the population. It appears, therefore, that the State, as a post-Soviet entity, has influence on the way language loss and revival are conceived, but not wholly.

More precisely, I aim to restore language practices and power in relation to the overarching ecology in which people engage in language practices more than focusing on language as the result of social inequalities. People are continually in the process of building their practices (including language practices). Relying on the State power only takes agency away from 


\section{Introduction}

them and, more broadly, from the multiple entanglements of life. That is also the reason why I decided not to employ the phrases 'top-down' and 'bottom-up' when referring to language practices since Vepsian ways of speaking and writing result from a multidirectional interaction with the world, and sometimes can be felt as the interaction themselves. Here, the term agency is not synonymous with free will or even resistance and does not only restrict to human beings. I borrow the definition of agency from Ahearn $(2001,112)$, in which "agency refers to the socio-culturally mediated capacity to act" and, I add, is located within a specific ecology where people manifest language. It extends to a broader interaction with the world where engaging in specific practices cannot be isolated from the forces present at that specific time since these influence one another. Agency draws out to the world where the material, ideological, what is spoken and not-, and what is written have the ability to shape the course of events. While Ahearn (2001) in her analyses investigates agency in the structure of the language, I aim to show it in the modality (oral or written) of Vepsian language that people employ in relation to the ecology where speech or written events occur.

Power is exercised in the spoken word also beyond the relations with institutional bodies and any other political activity. The oral mode of the Vepsian language retains a less political hue when used by village dwellers in relation to village life and to the inhabitants of this rural territory, and yet it does things (cf. Austin 1962) and influences the more regular course of life-the spoken word comprises a different kind of power, that has yet got the capacity to create reality (cf. Philips 2000, 194)! In fact, the act of speaking has the faculty to derail the course of life, either when performed with a specific intention in mind or not. Engaging in specific verbal art, such as enchantments and spells, with the purpose to intervene on people's lives and engage with other-than-human beings, is often done purposely by knowledgeable individuals—called tedai (literally, 'The one who knows the way') or noid (V. Sorcerer) in Vepsian-which serves a "collective intentionality" (cf. Kurets 2000; Searle 1990). ${ }^{5}$ The enchantments are often used under request to cure someone who is sick, has been bitten by a snake, has lost their way in the forest, to fix disputes, to interfere in love affairs, and to choose the place where to build a house, and to find lost cattle. Enchantments are called pubeged in Vepsian, which is etymologically connected to the act of blowing (puhuda in Vepsian) and hints at the fact that when words are blown they can do certain things and, thus, retain power.

Veps generally pronounce utterances carefully, given that they share an awareness of their capacity to shape life. Particular attention is given to the spoken word overall-and not only verbal art, such as the spells-which one should aim to use correctly. Once, Svetlana Ershova explained how she thinks about the way her grandmother used to speak when she was in doubt on how to say something in Vepsian. Svetlana Ershova is the director 
of the Vepsian ethnographic museum in Kurb, Leningrad Oblast. She used to teach Vepsian language at the village school, until its closure in 2009. She continued, "I know that if I repeat it the way she used to say it, I will be correct. She was not educated, but she always spoke Vepsian correctly." Her reference to correctness, however, did not imply applying Vepsian grammar rules rather it hinted at the way and context in which language was used. Using Vepsian correctly is found in the socialization and respect for the surroundings, for other human and other-than-human beings. Indeed, using Vepsian incorrectly may upset the balance between the environment and its inhabitants, so one has to be careful.

Through spoken language people have the power (or not) to experience a unity with themselves, the surrounding environment, and its inhabitants, humans or non-humans (Cruikshank 2005). Veps also understand that Vepsian spoken language helps them engage and maintain a unity with the environment where Vepsian developed. Vepsian villagers engage with the environments also through respectful relations with the miscellaneous spirits and territorial masters dwelling in this land, which are believed to be the hosts there. Therefore, removing people, speakers of Vepsian, from the land has consequences on language use as this is so deeply convoluted in this rural locale. What's more, Veps often express to enjoy a deeper connection with their own emotions and embodied experiences when speaking their heritage language (cf. Wilce 2009). Such claims remind me of the perlocutionary effect introduced by Austin (1962) in that utterances can also allow for change in the speakers themselves.

The present study acknowledges the temporal tensions that may pull a language revival movement in different directions, given the repercussions that certain past events and ambitions for the future might have on the current language use. However, it will not assess the present as an almost non-existent time, a hybridity, an in-betweeness, a transition (Geertz 1973; Heathershaw 2010; Spencer 1997), rather, it will address the present-day situation and all the forces in play, including ideologies from the past and future aspirations by bringing together most agents involved in the process of Vepsian preservation and promotion (namely, the policy makers, the activists, and the Vepsian population of urban and rural environments). My approach is not oppositional toward the work of the activists: it is, rather, a synthesis of a number of points of view. Indeed, it shows how the promotion of Vepsian literacy has provided the movement with intergenerational language transmission and confidence and it intends to complete this analysis with an investigation of Vepsian ways of speaking. Specifically, this study matches Vepsian traditional worldviews and the scope of the revival movement in the re-invention of a unity. Such unity also means bringing together the rural and urban contexts where different language practices respond to and engage with different social dynamics and political factors, and academics interested in matters revolving around language loss. 


\section{Introduction}

\section{Notes}

1 UNESCO Red Book on Endangered Languages: Europe. www.helsinki.fi/ tasalmin/europe_index.html.

2 References on backwardness in the Soviet Union can be found in Comrie (1981, 16), Grenoble (2003, vii), Heathershaw (2010, 97), Hirsch (2000, 2005) and Slezkine (1994).

3 On this topic, see also Grenoble and Whaley (1998), Heath (1983), Hinton and Hale (2001), Moriarty and Pietikäinen (2011) and Romero-Little et al. (2007).

4 National in Russian is translated as natsional'nyy. Natsional'nost' means ethnicity and ethnic group which can also be translated as etnicheskaya gruppa. Narodnost' means "people-ness" and derives from the word narod (R. People) (Hirsch 2005, 36; Jääts 2017). Natsional'nost' does not mean grazhdanstvo (R. Citizenship). A Veps, therefore, has Vepsian nationality but is a Russian citizen.

5 Arukask $(2002,54)$ has indicated possible etymological connections between the noun tie (F. Road) and the verb tietää (F. To know) in Finno-Ugric languages. 


\section{Vepsian Representations and Language in History}

We had just attended a festival in Ošt, Leningrad Oblast, and were returning to Petrozavodsk by bus (Map 2). The Vepsian folk ensemble Randaine (V. 'Riverside, lakeside') had performed there. On the bus, the group continued to sing, while eating homemade pirogi (R. 'Pies') and drinking tea and vodka. As we drove through Šoutjärv', Yuliya Larkina (pseudonym) pointed to me that this was her village of origin, then she sat next to me and began telling me her life history. She is now in her 70s and when she was little her family moved to Vladivostok from Šoutjärv', to where they returned in 1964. While her parents spoke Vepsian, she admitted that, "for me it has always been easier to speak Russian, since I spoke Russian in Vladivostok." She later got married to a Vepsian man from Šokš, another Vepsian village in Karelia, and they moved to Petrozavodsk. She continued,

There were more job opportunities in the city. People in the village used to do all sorts of jobs. However, these job opportunities little by little faded away. Plus, they did not pay enough for a living. The people who stayed in the village were left drinking. So we moved. What else could we do?

In the city, they spoke Russian to one another. As she was disclosing her life history, others joined the conversation and began telling me about their childhood and where they spent the first years of their lives. For some, their villages experienced an even more dreadful destiny: they did not exist anymore! Such statements started to resonate familiar, as I got to know Vepsian urbanites who had moved away from their village at a young age: "Many left and the villages remained abandoned" (see Figure 2.1). Indeed, a sense of nostalgia and desolation may arise when wandering around some abandoned villages, noticing traces of a past human presence and trying to figure out what life was like only a few decades back.

In the autumn 2010, Maksim Zhukov, a young Russian city dweller whose wife is Veps and has vast knowledge of Vepsian history and current 


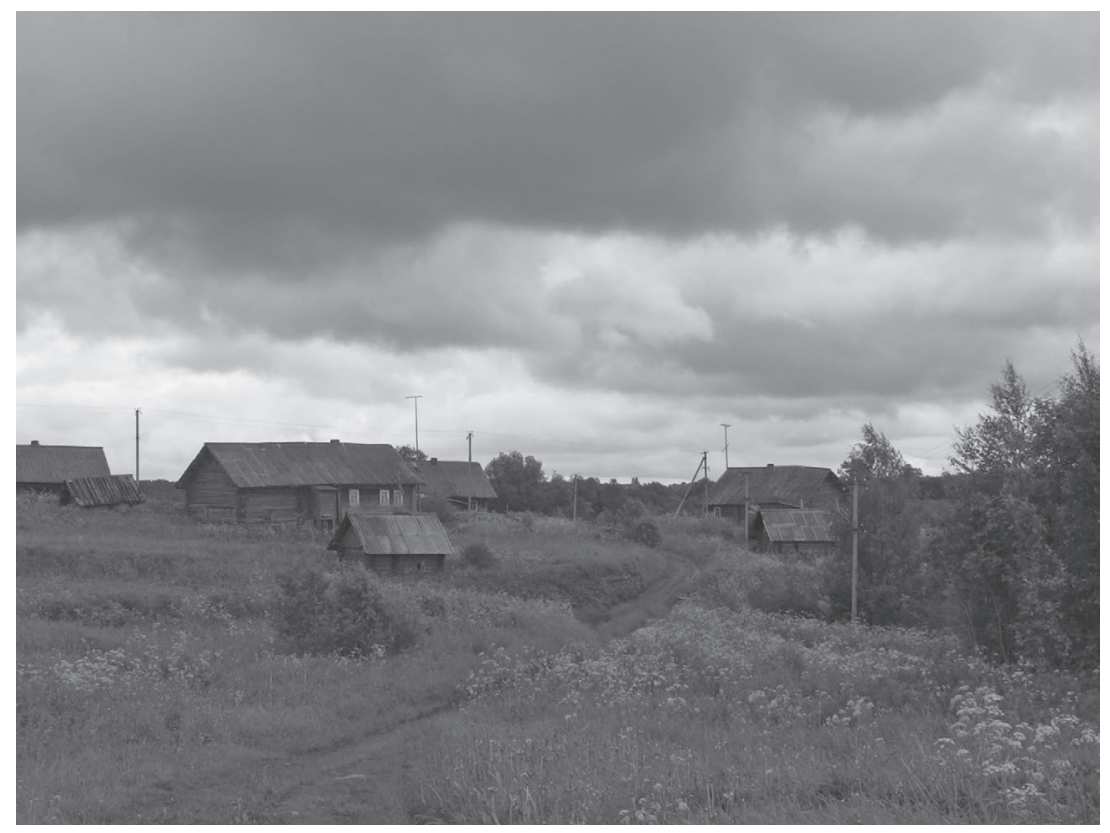

Figure 2.1 Mäggärv', Leningrad Oblast. I took this picture in June 2010

situation, made similar comments, as we were cruising some deserted villages in the Leningrad Oblast:

Can you imagine how this place was once full of children and people? The children used to run about and play together. And the adults were busy working and looking after their khozyaystvo [R. Farming, housekeeping]. Those villages were full of life only 50-100 years ago. ${ }^{1}$ Can you actually picture what it was like then?

Indeed, what has happened in the last 50-100 years that has shaped this landscape so much? ${ }^{2}$ How have specific events also impacted language use?

\subsection{Representing a Natsional'nost'}

Representing groups and nations can be problematic, especially in a postSoviet territory. Indeed, Western and Soviet ideologies typically assume that nations are bounded and that certain elements characterize them through history (Handler 1988, 6). The Soviets went as far as believing that such boundedness could be observed, studied, and enclosed in categories (King 2011, 45; Slezkine 1994). Specifically, the adoption of the word natsional'nost' 
(R. Ethnicity) under the Soviet regime enabled the government to distribute the population in a complex hierarchical system of categories (Anderson 2000, 99; Hirsch 1997, 252). The practice of categorizing people into a bounded and fixed nation aimed to reach out to the remote areas of the Soviet Union and to maintain control over these territories (Hirsch 1997, 251). Indeed, Soviet ethnographers used to collect demographic data of the multiethnic population of the USSR and to closely cooperate with the organs of power. Unsurprisingly, these categories were recorded in an "internal" passport that the members of the various groups received at the age of 16 (Anderson 2000, 99). During the Brezhnev era (from 1964 to 1982), many census takers refused to record Vepsian nationality in the registration papers in the Leningrad and Vologda Oblasts-a practice which was not spread in Karelia (Jääts 2017). According to Jääts (2017) such a practice in the central and southern territory covered by Vepsian settlements was motivated by the desire to accelerate the assimilation of Veps.

History has also been construed in accordance with inquiries of natsyonal'nost', which indeed in the so-called West is perceived as the heart and foundation of the nation (Handler 1988, 17). This applies also to the ideologies that dominated the Soviet Union since WWII. It was believed that natsional'nost' has evolved in history, forming and shaping the essence of a contemporary nation (Bromley and Shkaratan 1972, 570). In other words, the nation had become a bounded group with defined characteristics through sequential evolutionary steps. This belief allowed the Soviets to organize such groups in a grid of hierarchies, where some peoples were regarded as backward and as less evolved than others.

The present analysis builds upon the work of Anderson (2000), and advocates a different, more rounded representation of the indigenous groups of Russia with the aim to avoid boundedness and pre-defined categories. It aims to replace the fixity and belief of an essence of a nation by interpreting signs and their social use. For this reason, just like King (2011) who omits the article "the" when discussing Koryaks I decided to drop the definite article when discussing Veps. Nonetheless, I cannot entirely dismiss the Soviet categorization since I recognize that it still has an impact on present-day social interaction. I specifically refer to a circulation of identities, discussed by Anderson $(2000,101)$, which are distributed both generationally and spatially and appear central in the study of Veps. During perestroika, the Vepsian activists living in the city adopted the Soviet categories to promote their cultural and linguistic cause. Therefore, they concurred with bounded and fixed ideas of a nation and focused on the analysis of certain characteristics representing the essence of Vepsian natsional'nost'. Those Veps who have received an education during or after perestroika and glasnost inherited such approach. And as shown by Saarikivi and Toivanen (2015) the idea of a bounded group has become for some a way to also express their identity. And as Anderson and Arzyutov (2016) articulated, the State-induced writing of such books as "Narody Sibiri" (R. The Peoples of Siberia) and, I can 
add, "Narody Evropeyskoy Chasti SSSR" (R. The Peoples of the European Part of the USSR) where Veps were dedicated an entire chapter, allowed for those bounded descriptions of groups and practices to form (Pimenov 1964). How these texts were organized and shaped, and the concepts that they promoted later circulated among activists and representatives of the indigenous peoples themselves who appropriated such categories in their own descriptions. Vladimir Pimenov developed his chapter on Veps further and a year later he published a book on Veps (Pimenov 1965) which is still considered "the best book written on Veps" among scholars at the Academy of Sciences in Petrozavodsk.

However, Veps have also showed to understand that these boundaries can be fuzzy as a consequence of the practice of mixed marriages and overall long-term contact during which exchange of systems of values and practices occur. The fixed understanding of a nation is also shared by some of the elderly Vepsian villagers who suffered the humiliation to deny their roots and history during their youth. For some of them pronouncing Vepsian ethnicity out loud appears as a process of empowerment against years of repression and it goes beyond language identification. Some villagers have also demonstrated to have a different perception of the geographical boundaries of their nation. And this conforms to certain traditional and pre-revolutionary worldviews, according to which the svoy (R. One's own) extends to distant lands. They believe that there are many more Veps and speakers of Vepsian and that they occupy a much larger territory than they actually do. Furthermore, the urbanites (both Veps and non-) often demonstrate to adopt social categories, such as a natsional'nost', as a way to maintain social order. As much as circulation of identities may be grounded in an illusion, for many living in this Northwestern Russian territory, they are perceived as real and socially necessary.

Given this, I endeavor to provide rounded descriptions of history where certain representations emerge, re-emerge, and merge into a complex grid of social practices and knowledge. I also demonstrate how the Soviet political control worked only to a certain extent, since some traditional representations have endured the hardship and still permeates present-day Vepsian practices, knowledge and views (Anderson 1991; Balzer 1999; Rogers 2009). Despite presenting events in chronological order, this chapter does not aim to reinforce a linear conceptualization of history, rather it aims to show how certain practices, including language practices, have resulted from the relations with the ecology in which people live(d), comprising language ideologies.

\subsection{Villages: Sebr and Khozyaystvo}

\section{Settling and Dwelling in the Vepsän Ma}

Together with Karelians and Russians, Veps are among the first peoples to have settled in present-day Northwestern Russia. Veps, specifically, settled 
in the territory between Lake Ladoga, White Lake, and Lake Onega-a territory also referred to as Mezhozer'ye (R. Among lakes) (see Map 2). Due to the lack of written documentation, it has been difficult to track down the exact date of their arrival and settlement. In $500 \mathrm{AD}$, the historian Jordan mentioned a tribe called Vas, Vasina in his On the origin and feats of the Goths (Pimenov 1965; Pivoev 2003; Tsvetkova 1993). The ancient group Ves', a variant of Vas, Vasina, is later mentioned in the Povest' Vremennykh Let (Tale of the Bygone years) and they are believed to be the ancestors of contemporary Veps (Pimenov 1965). ${ }^{3}$ Similarly, the connections between the tribe of the Chud', Thiudos, and Veps have been largely debated. The scholars generally approve the hypothesis advanced by Bubrikh who suggested that the tribe of Veps formed around the ninth century and that it found its origin in the Chud' (Bubrikh 2005; Kochkurkina 1989; Strogal'shchikova 2016; Vikhoreva 2010).

Bubrikh's theory also implies that around the ninth century the possible ancestors of Veps inhabited a much larger territory than the one they occupy today-that is, from the shore of Lake Ladoga up to the White Sea in the Northeast of Karelia (Kurs 2001; Mullonen 2012) (Maps 1 and 2). At that time, two other ethnic groups occupied the Karelian territory. The ancestors of Saami and Karelians inhabited the northern and central parts of Karelia and the northwestern coast of Lake Ladoga, respectively (Kolesov et al. 2007). It is believed that between the ninth and sixteenth centuries Karelians moved up toward the North and forced Saami either to retreat or to assimilate. They also moved southeastwards and advanced in the territory already inhabited by Veps. The language of two contemporary Karelian groups, the Ludes and the Olonets-Karelians, maintains elements from the Vepsian language. Language and political activists, members of the various nationalities and scholars informally discuss the origin of Saami, Karelians, and Veps. However, at present, these claims do not have political consequences, since both Karelians and Veps have already gained the status of indigenous peoples of the Republic of Karelia. The Vepsian village dwellers also do not show much concern about Saami or Karelians claiming a common origin or even to be their ancestors. They often simply dismiss such allegations.

It is documented that at the same time Slavonic tribes made their move northwards and settled "nearby Ves', along the Svir', in the Zaonezh'ye (R. On the other side of the Lake Onega) and the shores of the White Sea" (Kolesov et al. 2007, 71) (Map 2). Whereas the Northern Veps assimilated with the Slavs, Veps of Prionezh'ye (R. Lakeside) and Mezhozer'ye maintained their cultural and linguistic traits (Map 2). In a nutshell, due to the expansions of Karelians in the West and of the Slavs from the south toward the West and the East, the territory covered by Vepsian settlements receded and its boundaries contracted to the Prionezh'ye and the Mezhozer'ye.

Archaeological studies have shown that between the ninth and the thirteenth centuries, the main activities of Veps involved agriculture, hunting, fishing, and commerce. The Svir' River links Lake Ladoga to Lake Onega 


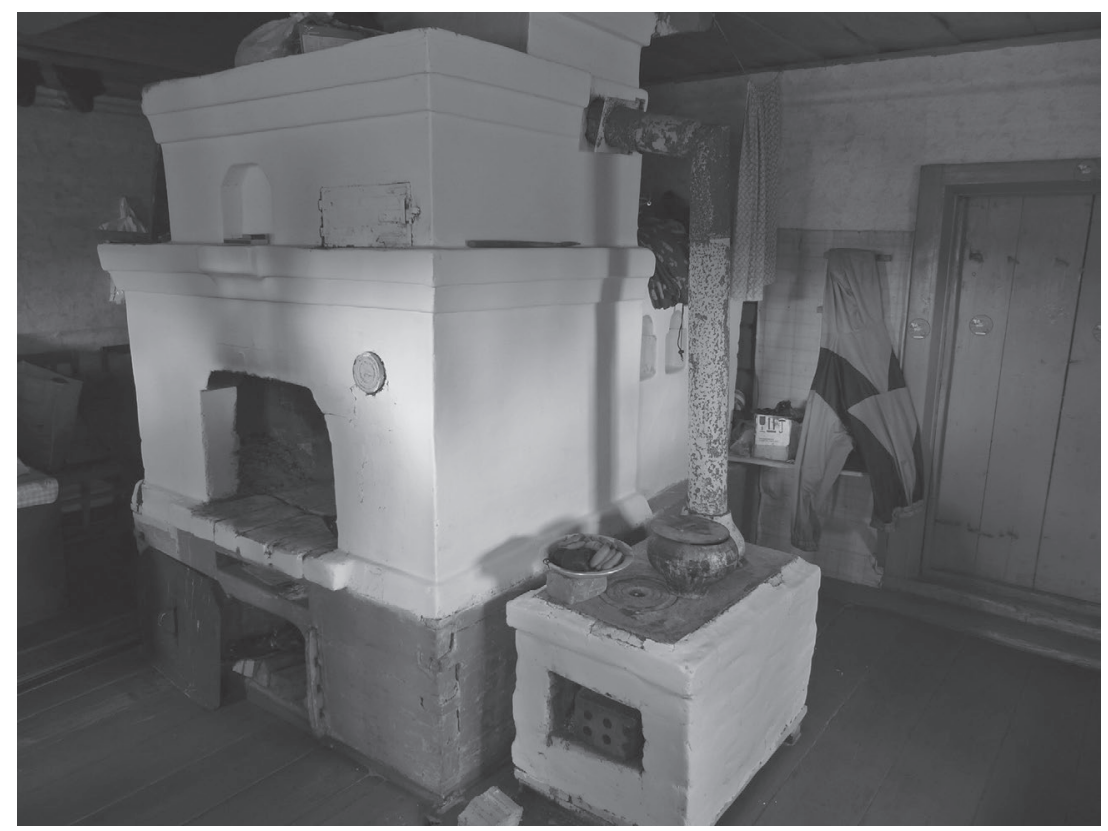

Figure 2.2 Päč (V. Stove) in a house in Pondal. I took this picture in autumn 2013

and Vepsian, Karelian, and Slavonic tribes have used it for trading purposes. The archaeological material found in the kurgany (R. Burial mounds of the ancestors of Veps) exhibited intense trading activities. For example, Veps exchanged fabrics and textiles for locally produced arts and crafts, such as items made from iron and birch (Kochkurkina 1989). The long-term trade with the Slavs is also attested in some features of Vepsian housing. For example, Veps introduced the russkaya pech' (R. Russian stove), päč in Vepsian, in their houses and lifestyle (Figure 2.2). Indeed, it is not surprising that up to now people in Russian and Vepsian villages share common practices, given the long-term contact and exchange. The burial mounds also disclosed how Veps used to live, their worldview, and cosmology. In the burial mounds, they used to deposit ornaments, instruments for hunting, such as weapons, and other everyday tools, such as the hoe for digging (Pimenov 1965). The ornaments for the women often represented animals, such as birds and horses, which played a central role in the life and worldview of Veps (Vinokurova 2006). Similarly, studies of Vepsian place names revealed that the names of the villages, rivers, and lakes often linked to their khozyaystvo (R. Housekeeping and farming) and daily activities (Mullonen 2005, 2012). ${ }^{4}$

The Vepsian families often lived under one roof and shared the daily chores around the sixteenth century (Strogal'shchikova 2008a, 113-119). 
While the khozyaystvo was the domain of the women, hunting, fishing, commerce, and the production of iron, clay and stone tools were all men's enterprises (Korol'kova 2015, 159; Pimenov 1965). This way, they built a strong sense of sebr (V. Community, team, people working together) and nurtured cooperation and working ühtes (V. Together). And this had pragmatic reasons (Makar'yev 1932) which are agreed upon also today. As Irina Baranova, a Vepsian resident of Petrozavodsk, told me during an informal conversation in 2011, "We know that if we help you today, you may help us one day." And she provided an example of how some years before a woman and her child had got lost in the village where her babushka (R. Grandmother) used to live. There was a storm outside and Irina's babushka invited the lady in and fed her and her child, and warmed them up. "This is how people live in the villages," she concluded. Such cooperation was and still is also meant to protect each other from undesired events, and this kind of care encompasses both human and nonhuman animals. Despite possibly a romantic view on village life on behalf of Vepsian urbanites, this appears supported by Vepsian scholars, too. The Vepsian ethnographer Vinokurova (1988) explains how the whole village used to gather together at the beginning of the pasture season and used to create a circle in order to protect the animals before the herd was set out to the land. On this occasion, the local tedai also used to perform an enchantment, due to the powerful capacity to influence life events convoluted in the spoken word.

\section{Policy and Christianity}

Historical documents show how the Slavs were reinforcing their political power in the South at the time. Staraya Ladoga is often considered the first capital of Rus' and Kiev the second. Later, Kiev and Novgorod became important trade centers and Ladoga went under the administration of Novgorod (Strogal'shchikova 2008a). According to the Povest' Vremennykh Let (R. "Tale of the Bygone years") Veps were under the Novgorod administration between the twelfth and seventeenth centuries and the system was at the time feudal (Pimenov 1965).

Meanwhile, Christianity also made its way through the land of Veps. Christianity had reached Rus' in 988 with the conversion of Prince Vladimir. It was only in 1227, however, that it entered Karelia (Vikhoreva 2010). Elements of pre-Christian faith mixed with it. Between the fourteenth and fifteenth centuries the church established a number of pogosts-pagast in Vepsian (that is, the territorial administration unit of the Rus' built around the cemetery or churchyard) (Pimenov 1965; Vikhoreva 2010).

Before Christianity reached the Vepsän ma, the Vepsian cosmology comprised a number of territorial masters and miscellaneous spirits with which Veps interact up to now during their daily activities. Most territorial mas-

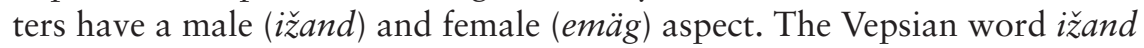


means the head of the house, the host, and it is found in many of the names of the territorial masters with which Veps interact. For example, mec(a)ižand is the host of the forest and it literally means the head of the forest. In Pondal, the master of the forest is also referred to as toine pol' or toine čura (V. The other half) which indicates a relation between equals (Vinokurova 2015, 280-286). Other territorial masters include vedenižand (V. Master of the water), pertinižand (V. Master of the house and land where the house is built), kül'betižand (V. Host of the kül'bet'), pöudižand (V. Master of the field), and so on (Strogal'shchikova 2008a, 155-162; Vinokurova 2014). Up to now Veps pay respect to the masters of the territory by being kind to the environment that they inhabit. In order not to upset them, Veps often claim that they need to keep their land well looked after, refrain from swearing, and keep their houses tidy and clean. Besides, those Veps instructed in performing enchantments (puheged in Vepsian) may appeal to the territorial masters in order to find lost cattle in the forest, to find their way back home when lost in the woods, to ask permission to drink from any water source found in the taiga, to ask where to build the house, and so on (see phono-archives at KarNTs RAN). Their relation is a relation between equals where language plays a key role in maintaining alliance and nurturing mutual respect.

With the introduction of Christianity, the word Ižand began to be used to refer to the Sky God. However, the word god (or Sky God, god of the sky) in Vepsian can be conveyed in different ways. Jumal is another term. ${ }^{5}$ The words Jumalansä (V. Thunderstorm), Jumalanjuru (V. Thunder) and Jumalanheiboine (V. Rainbow) find their roots in the word Jumal. The Vepsian Sky God is associated with the Slavonic pagan god, Perun who is the god of thunder and lightning in the Slavonic pantheon (Paxson 2005). And more widely, the Vepsian (Finno-Ugric and not Indo-European) mythology can be related to that of the Proto-Indo-European tribes (Mallory and Adams 2006). Jumalčoga is the red corner of the house, which is where God is worshiped (Figure 2.3). Besides I žand and Jumal, god can also be translated as Sünd (V. Forefather). Given such a varied terminology to address the Lord, Nina Zaitseva, who translated the Bible into Vepsian, expressed the difficulties that she encountered in choosing the right word for God in Vepsian.

Along with an extension of Vepsian cosmology, the introduction of Christianity and the well-established trade and contact between the Vepsian population and the Slavs are also indicated by the number of words that Veps introduced into their ways of speaking. Along with the words pä̈ and pagast, there are a number of domains where words of Russian origin could be found in Vepsian. Many of those are linked to the political and social spheres, work, life in the house, and the family (Pimenov 1965, 192-194). Such language behavior is not unusual among Veps and I discuss the appropriation of such terms as an indication of the extension of the Vepsian svoy (R. One's own) and sebr in Chapter 5. 


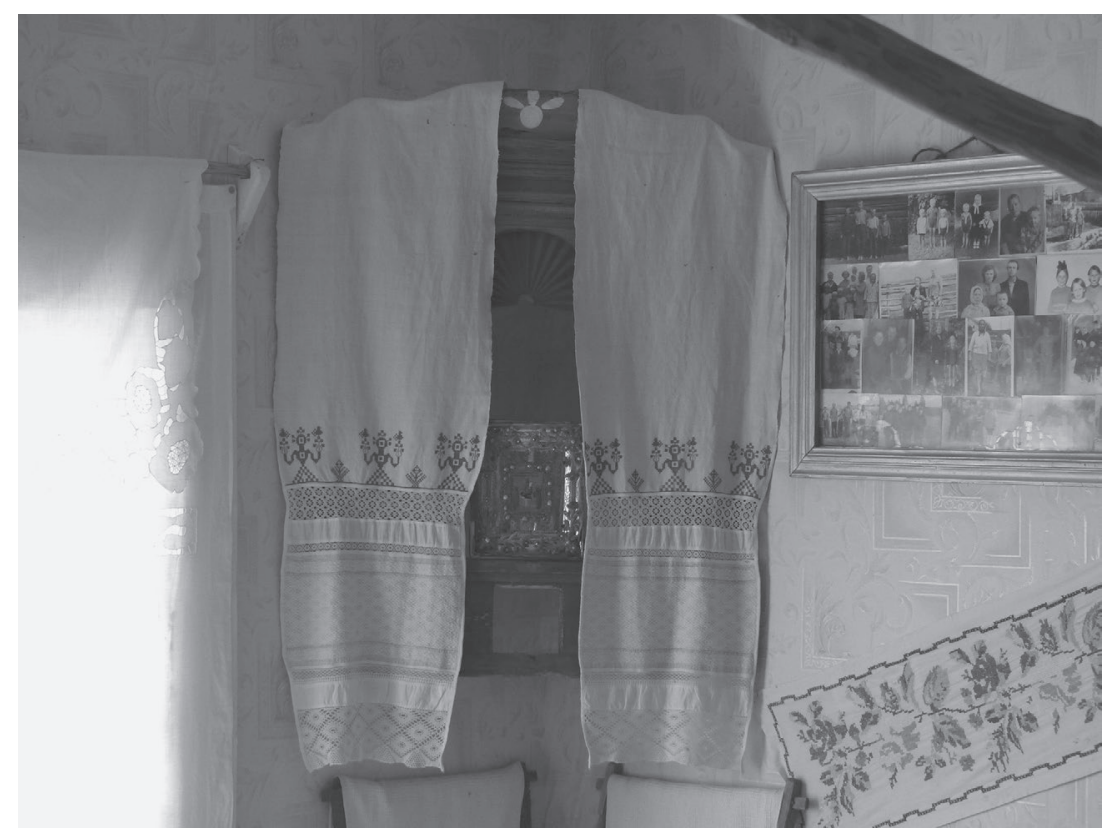

Figure 2.3 Jumalčoga at the Vepsian ethnographic museum in Pondal. I took this picture in summer 2013

\subsection{Vepsän ma: A Borderland Between Sweden and Russia}

The contemporary boundaries of the Republic of Karelia were established at the end of World War II (Map 3). Historical documentation shows how Karelia has shifted its confines many times in the last 500 years. Control over the borderland has caused dispute and frequent armed conflict between the opposing powers. Veps did (and do) not dwell in this contested territory, although they do inhabit its immediate periphery. Nonetheless, they had taken part in the wars and had been subjected to their political, economic, and social aftermaths.

In 1478, Moscow became the capital of Russia. In the sixteenth century, contentions between Sweden and Russia grew. Karelia became a frequent battlefield between the late sixteenth and early seventeenth centuries. In 1617 , the Peace of Stolbovo put a temporary end to the conflict. Sweden obtained the land comprising the Karelian Isthmus and Northern Ladoga, where in 1632, the Swedes founded the city of Sortavala (Kolesov et al. 2007) (Map 3). In response, Russians built a fortress on the eastern shore of Lake Ladoga and founded the city of Olonets. The Vepsian population was then split into two administrations. Part of Veps went under the Novgorod administration, part under Olonets. This administrative division 


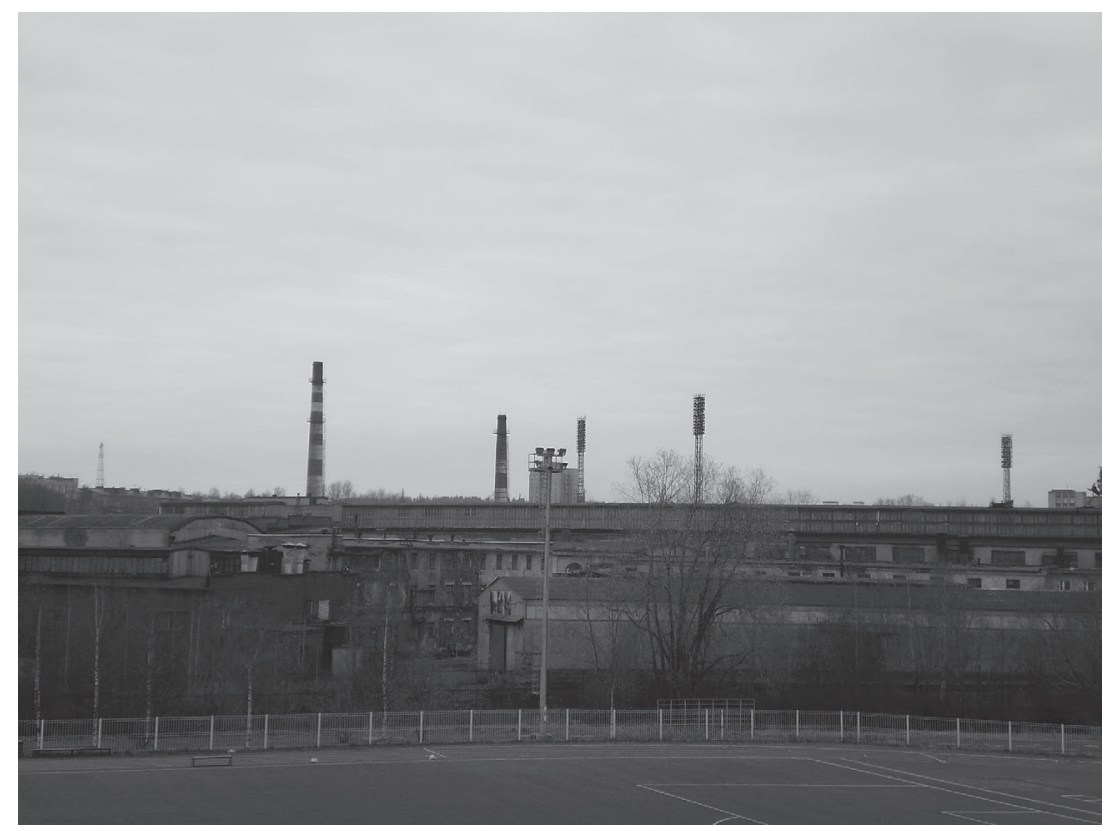

Figure 2.4 The cannon industry around which Petrozavodsk was built. I took this picture in 2010

provided the substratum upon which the Soviets later divided and managed the Vepsän ma.

Despite the Peace of Stolbovo, conflict between Russia and Sweden resumed. The Northern War (1700-1721) ended with the treaty of Uusikaupunki in 1721 and Russia re-established the boundaries as they were before 1617 (Mead 1952) (Map 3). In 1703, Peter the Great founded Petrozavodsk as an arms factory (zavod in Russian) to provide artillery for the war (Vikhoreva 2010) (Figure 2.4). Some of the locals still call Petrozavodsk, the zavod (V./R. Factory) not the capital or the city. It is generally believed that many Vepsian men contributed to the construction of Petrozavodsk.

In the early eighteenth century iron and mining industries developed in the Vepsian region (Davidov 2013; Varfolomeeva 2016). A deposit of quartzite in Šokš was discovered at this time (Kolesov et al. 2007). Meanwhile, wood and other materials were needed to start building St. Petersburg. Hence, Veps provided both the raw materials and workforce to build the factory in Petrozavodsk and the new capital St. Petersburg. As we were walking along the Nevskiy Prospekt in St. Petersburg, Ol'ga Zhukova and Evgeniya Ershova told me that Veps believe to have built St. Petersburg since they provided 
a large number of laborers and raw materials. It is said that Veps built the famous Anichkov Bridge, for example. In this sense, Veps extended Vepsän $m a$ to a distant territory through their work. Indeed, Veps have the tendency to metaphorically embrace new land and extend their sebr, once they cooperate and work together with chuzhie lyudi (R. Foreigners, strangers).

In the eighteenth and nineteenth centuries the timber, iron, and mining industries reached their peak in Karelia. This provided work for Veps, and it also attracted immigrants from other parts of Russia (Yegorov 2006, 244). In 1897, the Russian authorities carried out the first census for the whole of Russia. The results of the census showed that at the time 25,400 people claimed Vepsian nationality, the majority of whom lived in the Olonets (15,700 inhabitants) and Novgorod gubernii (9,300 inhabitants) (Bauer et al. 1991). Specifically, the majority of Veps were under the administration of Lodeynoe Pole (in the guberniya of Olonets) and of Tikhvin and Belozero (in the guberniya of Novgorod) (Strogal'shchikova 2007, 193). The Vepsian population continued to grow and the land became unable to satisfy its needs because freedom to use the forests and land for agriculture had also been reduced (Strogal'shchikova 2008a). As a result, many people left for Siberia, supported by the migration policy that was in place at the time. Two colonies reached the guberniya of Irkutsk in 1911-1913, and a third colony arrived there in 1927-1928 (Strogal'shchikova 2008a, 16).

Throughout this period of time (that is, Tsarist rule), the political authorities chose not to take an active role in fulfilling the Vepsian needs. This is particularly so because the territory where Veps lived had been split among different political administrations. Nonetheless, many activists and villagers argued that Veps were generally wealthy at that time and that it was considered prestigious to live in the villages. Immediately after the Revolution the Soviet authorities took a provisional change of direction in the policies for indigenous peoples. On the surface, this intervention aimed to provide more assistance to the minorities, which had been neglected before the Soviets came to power. However, the actual motivations behind such decisions appeared to be different and to be driven primarily by centralizing ideologies.

\subsection{Veps and the Soviet Regime}

\section{Korenizatsiya and Evolutionary Ideologies}

Right after the Revolution, Lenin's slogan for national self-determination aimed to distance itself from the Tsarist legacy and aimed to defeat the developing capitalism in the country and to gain support among the nonRussians (Hirsch 2005, 29). Self-determination, though, was interpreted differently within the Party. Lenin understood the promotion of national cultures and languages as a way to gain trust from the non-Russians who had been oppressed under the Tsarist rule and had possibly lost faith in the authorities. Stalin's interest was mainly driven by his desire to enhance the 
more undeveloped (backward as he called them) regions and populations for socialist development. At first, the newly formed Soviet regime aimed to improve the economic conditions of all the national minorities and to provide educational facilities in the national languages. They began a program to support education and cultural development of the national minorities and formed autonomous regions throughout the country (Kurs 2001; Smith 1999). The Soviet territory was divided into a hierarchy of regions. This comprised 15 union republics at the top level, the autonomous republic and autonomous areas at the medium level and the autonomous district at the lowest level (Kurs 2001, 69). In 1920 representatives of Southern Karelia established the Karelian Workers Commune which in July 1923 was transformed into the Karelian Autonomous Soviet Socialist Republic (KASSR) (Kostiainen 1996). Despite the re-organization of the Soviet territory depending on nationality, a Vepsian unified land was never established and Veps remained administratively split as they were at the time of the Tsarist rule (Kurs 2001, 72). ${ }^{6}$ Two Vepsian national districts were established in 1927. Veps living around Lake Onega had their main center in Šoutjärv', KASSR. Vidl became the hub of Veps in the Leningrad Oblast (Kurs 2001; Strogal'shchikova 2016). The census carried out in 1926 showed a growth in the number of those who claimed Vepsian nationality $(32,773$ in total compared to 25,400 in 1897), the majority of whom lived in the Leningrad Oblast $(24,186)$ where the national movement had started (Table 1.1). At the time, 8,587 Veps lived in the Karelian territory (Table 1.1).

It soon became clear that the political program to promote the national cultures and languages was not sustainable and did not always match the general objectives of the organs of power of the Soviet Union. First of all, many teachers of the various national languages were not sufficiently qualified. The government initially had to deal with adult illiteracy (Korol'kova 2007). Indeed, scholars such as Bogdanov (1904-1959), one of the scholars who contributed to the standardization, codification, and education of the Vepsian language, expressed their initial concerns as most of their work consisted in preparing the teachers for their didactic endeavors (Strogal'shchikova 2016, 95). Second, Lenin's self-determination policies could not be easily manifested as in practice they worked against the other objectives of the Soviet Unionthat is, to unify and centralize it (Comrie 1981). In addition to this, in 1928 there was a grain shortage. The Soviet authorities reacted with the first FiveYear Plan in May 1929 and the collectivization of the rural areas began in the whole of the USSR (Conquest 1986).

The immediate result of this sudden change in the Soviet policies was seen in the educational measures taken by the regional authorities. While Vepsian was the language of instruction in the Vepsian villages of the Leningrad Oblast until 1937-1938, Finnish was adopted in KASSR. Nonetheless, even Finnish education was not successful everywhere, given that the quality of teaching differed quite substantially among the several schools (Strogal'shchikova 2016, 105). However, Vepsian became the language of 
instruction for Veps in KASSR in 1937, while it was abolished in the Vepsian villages of the Leningrad Oblast. This did not last long either. At the same time, Veps living in the Vologda Oblast were deprived of their national status and were not included in the list of nationalities in the 1939 census (Kurs 2001, 73). Indeed, Veps in the Leningrad and Vologda Oblasts suffered greatly during Stalin's terror. According to Strogal'shchikova $(2016,106)$, 112 Veps were arrested, and 99 of those were shot dead at the time. These continuous political changes had an impact on the population. And the goal to educate all the nationalities of the Soviet Union up to Soviet standard did not provide the expected results in either the KASSR or in the Leningrad Oblast (Smith 1999). Such fast-paced changes in the educational policies are reflected in the miscellaneous accounts of their school days by the residents of Kalag' where Ivan Lokkin (pseudonym), a pensioner in his early 80s, told me, "I can speak Finnish and German. I studied Finnish at school. In those days we used to study Finnish. I also studied Vepsian from the first to the third class." Aleksandra Chirkova (pseudonym) who is from the neighboring village Šokš also confirmed having studied Finnish at school, Suomeks opetihe. [.. .] A minä siloi hivin pagižin da kniigad lugin hivin ("We studied Finnish. Back then I used to speak well and read books well”). Margarita Kozlova (pseudonym) who now lives in Petrozavodsk also claimed to have studied a bit of Vepsian [as a child in Kalag']. Whereas, Marina Kapustina (pseudonym), a pensioner in her early 70s, told me that she studied English as a second language at school but never Finnish nor Vepsian.

The Soviet project aimed to overcome backwardness and elevate the nonRussians to a higher cultural level by providing literacy to all the nationalities. It could be argued that such derogatory attitudes toward the indigenous languages and cultures found their roots in previous missionaries' activities. The plan or Soviet prescriptions for development (Anderson 1991, 13) did not succeed and its legacy is still visible in the attitude that many Russians and non-Russians bear toward the minority languages and cultures. For example, Marina Kapustina and I were having lunch in Kalag' when she said:

People in Sheltozero [Šoutjärv' in Vepsian] are much more active than here [Kalag']. They have a choir and an ethnographic museum. However, the founder of the choir was originally from Rybreka [Kalag' in Vepsian]. You see, we used to be much more active then. We also spoke more kul'turno [R. Culturally, educated]. My mum always pointed out that we spoke more kul'turno. While in Sheltozero [Šoutjärv'] they say hursti [V. Doormat], we say polovikad in Rybreka [Kalag'].

The word polovikad (plural of polovik) finds its origin in Russian. Adopting a Russian word was then viewed as more kul'turno and educated than using a Vepsian word. Just like civilized, the word kul'turno indicates cultural and evolutionary hierarchies, where the Vepsian language is regarded as not quite up to the standard of the Russian language. ${ }^{7}$ 
The introduction of the Five-Year Plan changed the structure of the villages, the lifestyle of the villagers and some of their habits. Little by little, the long-established sebr began to disperse as people moved to the city or other villages and the animals died.

\section{Farm Collectivization and the 1930s}

As we were walking on the edge of the Vepsian village Pondal in the Vologda Oblast in autumn 2013, I noticed a huge, abandoned, stone building in the middle of the field and asked, "What is that building over there?" "A kolkhoz," Nadezhda Mednikova answered almost matter-of-factly (Figure 2.5). The more I worked in rural areas, the more I noticed similar relinquished buildings standing somewhere in the field near the inhabited villages. They became part of the landscape, as an indication of neglect and link to the past. Stalin introduced farm collectivization in 1929. Specifically, Stalin introduced into the village life the kolkhozy, or cooperative farm organizations, and the sovkhozy, or state farms, which all peasants had to join. Those who tried to oppose the collectivization were mostly identified as kulaks, or rich land-owners, and got either deported or killed (Shearer 2006; Thompson 1990; Ward 1993). Some people cannot still make sense of what happened

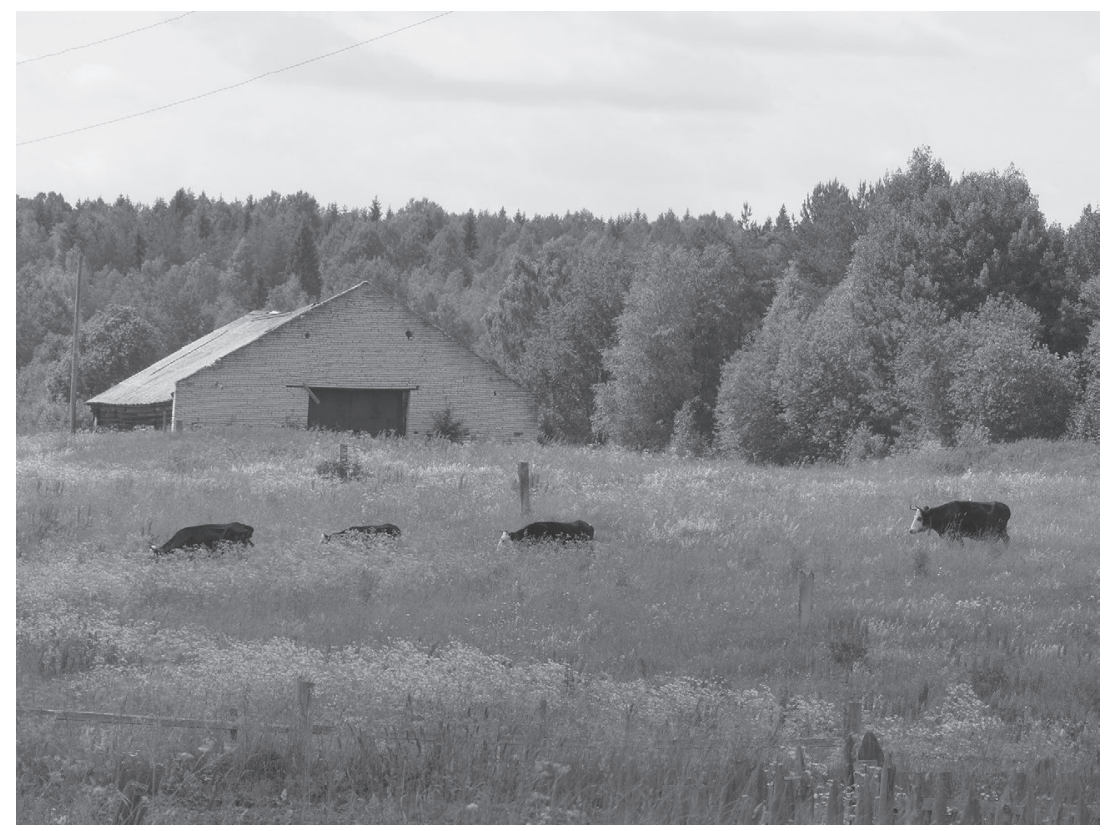

Figure 2.5 On the left side one of the buildings of the kolkhoz in Pondal, Vologda Oblast, as the few left cows graze the grass. I took this picture in July 2015 
and why such measures were taken. In 2013 Larisa Smirnova (pseudonym) in Nemž, a village in the Leningrad Oblast, disclosed how in her youth her father was sent to Yakutia and never made his way back to the village. She told me,

They said he was a rich man and for this reason they took him away. How rich could he possibly be! We were just peasants. Yes, we had our cows ... in fact, they took another man who was living nearby. Well, they took everyone, every man!

I heard similar stories on several occasions. Some of the elderly villagers revealed how they themselves were deported or simply had to relocate to some remote village in the southern or eastern parts of the USSR before coming back (if at all) to this northwestern region and re-settle here.

The villages served as a base to set up the kolkhozy. In this new context, the word sebr extended its meaning of joint work to the activities of the collective farms. This period is often remembered as a time when people came together and enjoyed each other's company, and as a time when everyone struggled keeping their heads above water. In 2013, Galina Lokkina, who is also from Nemž, clarified, "We all lived in the villages and everyone had a job then. But do not get me wrong, we still lived in poverty." Galina Lokkina is a Vepsian pensioner who lives in Petrozavodsk in the winter and in Nemž, Leningrad Oblast, between May and October. Similarly, Natal'ya Silakova who now lives in Petrozavodsk confirmed this when she told me about her childhood in Himd'ogi: 8

We used to have a cow and to make tvorog [R. Curd cheese] and butter from her milk. We used to wait until $10 \mathrm{pm}$ to have dinner. Nobody used to visit us at that time of the day. We could then eat our food and be sure there would be enough for everyone. My grandmother used to make a delicious cheese from the cow's milk right after it had given birth. We used to freeze the milk for the whole winter and melt it in March. So, it could last. It was difficult for everyone. That's how we used to live.

In 2015 in Pondal, Liubov' Smirnova recollected how her mother used to work in the collective farm during the day, looked after the kbozyaystvo in the evenings, and took care of her and her siblings as much as time allowed her to. If this let Liubov' Smirnova be freer from an adult's eye and develop her own circle of friends, she also admitted not spending much time with her mother and learning certain skills from her, such as local ways of relating to the animals and interpreting their behavior.

The animals, which Veps highly regarded as food provision and part of their sebr, also began to fade away. The reasons for this were numerous. First of all, modernization and urbanization remained priorities of 
the Soviet Union. Hence, "the idea that the tractor, replacing the horse, would transform agriculture into a modernized and prosperous sector of the economy was deeply rooted in the Party's mind" (Conquest 1986, 179). Second, the Civil War had severe consequences for livestock in the villages (Shearer 2006, 196). Third, some of the peasants themselves slaughtered their animals in protest against state policies (Shearer 2006, 196). It comes as no surprise, therefore, that "by 1934, the number of cattle, sheep, horses and pigs in the USSR was approximately half of what it had been in 1929" (Shearer 2006, 196). During a tea break, Mariya Chirkova (pseudonym) from Toižeg told me, "There used to be many cows in our village. But there are none now. At first, it was very difficult to see all this happening. Then you kind of got used to it."

Besides the social transformations that took place within the villages, changes began occurring also in the composition of the population in urban as well as rural settings. Movements from the village to the city started taking place more and more regularly after the Revolution (Leasure and Lewis 1967). Between 1926 and 1937, official figures show that the urban population of the Soviet Union doubled, from about 26 to 52 million (Shearer 2006, 200). In Karelia, the urban population rose by 325,000 (Conquest 1986).

The growth in the urban population of Karelia was also due to the construction of the railroad, which was built from St. Petersburg to Murmansk through Karelia (Laine 2001). As a consequence, many loggers moved north for work, especially from Belorussia and Ukraine (Yegorov 2006). Besides the northwards movement within the USSR, immigration also consisted of some 25,000 Finns moving into the Soviet Union from Canada, the United States and Finland between the 1920s and 1930s (Gelb 1993). Karelia had become a multiethnic republic with a population composed of indigenous groups (such as Veps, Karelians and Russians) and immigrants (such as Finns, Ukrainians, Byelorussians and Tatars) (Kostiainen 1996).

In the mid-1930s, Stalin began to mistrust certain ethnic groups as he suspected they could have loyalties outside of the Soviet Union. Among those groups were Germans, Poles, Finns, and the Asian groups of the Far East (Shearer 2006, 211). Consequently, the Finns and other ethnic groups closely associated with them became the primary target of Stalin's repression and of the great mass purges of 1937-1938, including Veps (Strogal'shchikova 2016). By the end of the 1930s, Veps lost their status as an ethnic minority in the Leningrad Oblast. There the repression was stronger than in the neighboring regions (Klement'yev et al. 2007, 13). In Karelia, the district around Šoutjärv' was liquidated in 1956 (Klement'yev et al. 2007, 13). As a consequence, some of the Vepsian activists of the 1920s-1930s movement such as Bogdanov, Makar'yev, and Hämäläinen moved north to Karelia. They had established the Vepsian writing system and had promoted Vepsian education in the early 1930s and continued collecting language and cultural material until the 1950s (Mullonen 2007; Strogal'shchikova 2008a). Bogdanov (1904-1959) as 
well as Petukhov (1934-2016), a Vepsian writer, were born in Šimjärv'. Already in the early 1930s, Šimjärv' had been planned to become the hub of the Vepsian district in the Vologda Oblast-it had now been reduced to a deserted land (Puura et al. 2013). Petukhov (1992) remembers how he moved to Siberia and there received a letter from his mother stating that everyone had abandoned the village. Although he received the letter in 1956, this had been the trend for years.

The census carried out in 1939, right after Stalin's mass purges, presented the following situation: the Vepsian population had dropped from 24,186 in 1926 to 15,571 in the Leningrad Oblast, from 6,743 to 5,432 in the Vologda Oblast, while the number had risen from 8,587 to 9,388 in Karelia (Table 1.1). However, it should be noted that the Vepsian rural population had dropped both in Karelia and the Leningrad Oblast-that is, from 8,474 to 6,504 and from 24,045 to 14,424 , respectively (Strogal'shchikova 2008b).

\section{War Years}

I was walking together with Ivan Lokkin in Kalag' when he said:

Look up there! Do you see that pink house? I met Mannerheim there. ${ }^{9}$ He knew the owner of the house and came for a visit. My grandfather suggested I talked to him since I could speak Finnish. So I talked to Mannerheim. But this is only a secret ... well, I suppose not anymore. Now we can speak about it, but before we could not.

While Ivan Lokkin recollects a more human characterization of Mannerheim, official histories picture the two political leading figures of the Winter War (i.e., Mannerheim and Stalin) as ruthless. On November 30, 1939, the Soviet Union launched an attack against Finland (Kovalev 2006). The war took a particularly bitter course in the Leningrad Oblast. As a consequence, Stalin repressed this region more harshly than KASSR (Strogal'shchikova 2008a). On March 12, 1940, the Winter War was already over. The Soviet army had defeated the Finnish forces, which accepted the peace proposals made by the USSR. With the end of the war, Finland lost the Karelian Isthmus and Northern Ladoga (Laine 2001). Only a couple of months after the end of the Winter War, KASSR was transformed into Karelian and Finnish SSR (Kolesov et al. 2007). The added word Finnish in the title of the SSR "referred to the formerly Finnish areas of the republic" (Laine 2001, 54). However, in 1956 the Karelo-Finnish SSR was again turned into the KASSR (Zamyatin 2013).

Finland turned to Germany to obtain aid in the dispute over the Karelian territory in 1940. Operation Barbarossa against the USSR in 1941 saw the German and Finnish forces advancing once again on the Soviet territory. The Svir' River became front line for the conflict between the Soviet Army 
and the Finnish and German forces (Bogdanov 1951). The scars from the conflict are still visible in the land. While walking in the forest, a resident from Lodeynoe Pole told me:

We are standing on the front line between the Soviet and Finnish and German soldiers during World War II. The trees got hit by the bullets and were badly injured. So from a certain point onward, they grew in a different direction.

Many of the inhabitants of the area along the Svir' River, mostly Veps, had to evacuate and moved to the heart of the Soviet Union. According to Bogdanov (1951), most of them never made their way back. However, some did: as I was waiting for my train to Petrozavodsk at the railway station in Piazhegaya Sel'ga, a cooperative of summer cottages (Dacha in Russian), a 70-year-old woman told me,

I am also Veps. We came from a small village not far from Sheltozero [Šoutjärv' in Vepsian]. My village does not exist anymore. When they started the bombing, we moved first to another village in Karelia, then southwards. It took us a month to reach our destination. It was a very long journey. Those days were horrible and difficult! [. . . ] My parents spoke Vepsian. So I understand the language, but I do not speak it myself.

Such language practices were typical for those who evacuated and moved out of their land of origin. I often heard that Vepsian became a pocket language. Yuliya Larkina with whose story I opened this chapter told me, "when we lived in Siberia, my parents only used Vepsian to discuss financial issues, so nobody could understand." Away from the Vepsän ma, using Vepsian became optional and often restricted to limited domains.

The Soviet Union redeemed the border established at the end of the Winter War in 1944 (Kirby 1979, 143; Laine 2001, 56). Besides the human losses and the damage that the Vepsian territory had witnessed, village life was also revolutionized by the huge migration that took place at the end of the conflict. At least 400,000 people, among whom were Karelians, Veps, and Finns, moved to Finland (Mead 1952, 52). Between 1939 and 1959 the Vepsian population dropped by about a quarter (Strogal'shchikova 2008a, b). According to Strogal'shchikova $(2006,393)$ in June 1944, 314 Vepsian men followed the Finnish Army and abandoned Soviet territory. The land had been damaged and devastated. Many men had either left or died. For many years, women outnumbered men in the Vepsian villages and this also disrupted the traditional village lifestyle. This phenomenon was, in fact, typical across the USSR. Vepsian women still exceeded in number Vepsian men in 2002 (Strogal'shchikova 2008a). The situation became unbearable also for the women left in the villages after WWII. On a summer day in 2010, as she 
was working in her garden in Kalag', Nataliya Naumova (pseudonym) stared at the house where Anna Lisitsyna used to live as she commented:

You need to understand that those were hard times. On the one hand, there was the Vepsian Soviet hero, Anna Lisitsyna, who died fighting against the Finns. On the other, there were women like her sister, who were making love to them. Those days were like that!

The war period had left the Vepsian territory deserted and desolated. Despite such desolation, however, Vepsian villagers acknowledged that it was still considered prestigious to be living in the villages and that at the time Vepsian language was still spoken among those who survived and remained in the Vepsän ma.

\section{Villages Without Prospects}

Nemž is a Vepsian village in the Leningrad Oblast of about 80-100 permanent residents (Map 2). In the winter, it is mainly populated by men and women ranging from 60 to 80 years old. In the summer, it is mostly populated by grandparents and their grandchildren who come to rest from the cities. Galina Lokkina told me in her home in Nemž one evening:

We moved from a village in the Vologda Oblast to Nemž [in the Leningrad Oblast]. When we arrived we spoke with a different accent. And people laughed at us. We also used different words to refer to everyday tools. And people laughed at us for that, too. Not Russians, but Veps themselves laughed at us.

Moving from one village to another or to a city had consequences on language use. The reasons for moving from one area of Russia to another (specifically, from one village to another village or city) were multiple in the 1950s, 1960s, and 1970s. These fall into the categories of "major social and economic change, includes war, disaster, persecution, windfalls, economic collapse, and government policy" (Grandstaff 1980, 8). In the case of Veps a combination of those reasons determined their migration from one area of the Soviet Union to another.

Nevertheless, the policy promoted by Krushchev between the late 1950s and mid-1960s represented one of the main agents that determined Vepsian movement from the villages to (mostly) the cities. At the Twenty-Second Party Congress in 1961, Khrushchev expressed the need to redistribute manpower (Grandstaff 1980, 21). The policy of liquidation of the villages without prospects was then launched (Yegorov 2006). This policy classified the villages into two categories: those with prospects and those without prospects. Those villages regarded without prospects stopped being provided with any investment on public services and infrastructure (Kurs 
2001, 73). Since its promotion, this policy affected the traditional lifestyle of Veps (and other village dwellers in Russia) irreversibly (Strogal'shchikova $2008 \mathrm{a}, \mathrm{b})$. It caused migration mostly to urban areas and made remaining villages larger and further apart from each other. Just like Yuliya Larkina, the urbanite Margarita Kozlova (pseudonym) told me during a tea break:

My mother understood there was not much to do in the village, so we all moved to the city. In Petrozavodsk we stopped speaking Vepsian even at home. Everything was in Russian and we started speaking Russian within the family, too.

The Vepsian language along with Vepsian rural epistemology and relational qualities dominant there was not needed in Petrozavodsk, a multiethnic city. Petrozavodsk and many villages of the Republic of Karelia developed a strong multiethnic component. As we were discussing the ethnic composition of Karelia in 2009, Irina Ivanova (pseudonym), a city Russian dweller, told me,

Many Ukrainians, Byelorussians and Tatars came up to Karelia since they could work here. Most of them settled near the border with Finland where the jobs were available. ${ }^{10}$ We call them verbovanny [R. Recruited]. But they do not like to be called that!

The composition of the population of the city drastically changed due to such migration. While the urban population increased $36 \%$, the rural population decreased by 2.8\% between 1939 and 1959 (Grandstaff 1980, 52). In fact, more than half of the population in the "Northwest derived from the out-migration of neighboring central regions" (Grandstaff 1980, 49).

Alongside the policy of liquidation of the villages without prospects, most of the kolkhozy disappeared, while the number of the centralizing sovkhozy increased (Laine 2001). And this meant leaving the sense of unity and community, sebr, which had long characterized the Vepsian rural lifestyle. Moving to the city, to a new ecology in relation to different practices, people, and ideologies, involved embracing Russian as the main language of communication and it also facilitated mixed marriages (Kaiser 1994; Saarikivi and Toivanen 2015, 9).

\subsection{Perestroika and Glasnost: Efforts in Unifying the Land}

In the late 1980s, the Vepsian and Ingrian activists appreciated the urgency to unify the Vepsian territory in order to manage it under one administration and recreate the original sebr. Once the territorial issue was sorted, then the activists wanted to invest in the promotion of language and culture. This, at least, was the initial plan. Their work drew attention from the Soviet authorities, and in October 1988, the first congress on Vepsian issues was run in Petrozavodsk. Its heading was Veps: problems of the development 
of the economy and culture at the time of perestroika (Strogal'shchikova 2008a). Members of the Central Committee of the Communist Party of the Soviet Union, the Council of the USSR, the Soviet Fund for Culture, the Organs of Power of Karelia, the Leningrad and Vologda Oblasts, and leading cultural figures of the Russian and Vepsian intelligentsiya participated in the congress (Klement'yev et al. 2007, 17). Taking advantage of these politically favorable times, the activists asked the authorities to:

1. Have an autonomous district;

2. Build roads;

3. Support the khozyaystvo in the villages;

4. Motivate Veps to return to the villages and their traditional lifestyle;

5. Create a commission for the three regions for economic and social issues;

6. Ensure economic and social intervention;

7. Build cultural institutions in the villages;

8. Provide a structural infrastructure;

9. Study the architecture of the villages;

10. Guarantee work;

11. Develop housing;

12. Make use of forestry;

13. Provide education;

14. Create radio and TV programs in the heritage language;

15. Have newspapers in the heritage language;

16. Promote culture;

17. Ensure health and build hospitals;

18. Guarantee scientific research;

19. Guarantee free-will elections also in the Leningrad and Vologda Oblasts;

20. Contribute to the development of the villages;

21. Guarantee plans in the spheres of culture, medicine, and science;

22. Change the education system and the status of Veps.

(Klement'yev et al. 2007, 80)

The activists understood that for Veps, being administratively divided was the key issue that needed to be solved immediately. However, their request was turned down and only the Vepsian territory of the Republic of Karelia received a political status. In other words, they did not manage to include the Vepsian villages of the Leningrad and Vologda Oblasts in the political intervention. On January 20, 1994, they obtained the creation of a Vepsian district in the Prionezh'ye in Karelia (Fomin 2004; Klement'yev et al. 2007). On the basis of Article 131 of the Russian Constitution, three different village administrations decided to join the newly established Vepsian national district-namely, Šokš, Šoutjärv', and Kalag' (Fomin 2004; Puura et al. 2013). It should also be noted that among the recommendations put forward at the conference in 1988, the Vepsian activists requested the authorities to 
stand up for Vepsian traditional lifestyle and to encourage returning to the villages. Conversely, the results of the censuses carried out in 1989 and 2002 showed that more than $50 \%$ of Veps moved to bigger centers, such as Vidl and Podporozh'ye in the Leningrad Oblast, Petrozavodsk in Karelia, and Babaevo in the Vologda Oblast, reinforcing the divide between urban and rural areas (Strogal'shchikova 2008b).

The next section focuses mostly on the Republic of Karelia because this is the region where the late 1980s-revival movement has begun. Nonetheless, the anecdotes presented throughout this volume and the presentation of language use in particular in rural locales come from a multi-sited fieldwork in all the administrative regions where Veps currently live.

\subsection{Contemporary Karelia: Veps in a Multiethnic Territory}

Most often the urban-rural dualism has been addressed in economic terms (Boeke 1953; Deng 2009), or in relation to urbanization and rural-urban migration (Lucas 2007; Guang 2005), or as a combination of social and economic differences (Barnum 1976) and/or racist language use and attitudes (Kurtz 2006). Instead, I intend to discuss such dualism in relation to the attitude of the people dwelling in this multiethnic and multilingual society toward the various nationalities and toward their heritage languages.

As shown earlier, the Republic of Karelia has become a multiethnic region. The 2002 census registered 213 nationalities in total. ${ }^{11}$ The 2010 census estimated that $82.2 \%$ of the population is Russian, $7.4 \%$ Karelian, $3.8 \%$ Belorussian, $2.0 \%$ Ukrainian, $1.4 \%$ Finnish and $0.5 \%$ Veps. ${ }^{12}$ Timber, minerals production, and exports as well as the tourist industry represent the main sources of income. ${ }^{13}$ At present, members of the different nationalities share workplaces and jobs. Apart from specific contexts, where the local resources guarantee jobs primarily for the residents, such as the mining industry in Kalag' and Toižeg, employment does not index belonging to a specific nationality. The same can be said about physical appearance, "as we all look the same," many pointed out. When they need to mark their nationality, urbanites often apply social and language categories and stereotypes some of which have existed since pre-revolution times.

In addition, the inhabitants of Karelia understand the territory of their republic as a mosaic of national districts. Patches of land and nationality go hand in hand, that is. During one of our meetings in 2009, Irina Ivanova (pseudonym) explained,

Veps live in the district of the Republic situated along the south western shores of the Lake Onega. Olonets-Karelians occupy the north eastern region of the Lake Ladoga [cf. Rodionova 2017]. Ludes live in the region between the Lake Onega and Lake Ladoga. Byelorussians, Tatars and Ukrainians are based along the Finnish borders, having moved up there after World War II. Russians are based in the north eastern territory of 
Karelia. And the Karelians of the North occupy the northern area of the Republic [Map 4].

Of course, such strict divisions are artificial as Russians are settled in other parts of the Republic, too, where they are mixed with the other indigenous groups. Indeed, many claim that with the practice of mixed marriages under the Soviet Union, "pure nationalities do not exist any longer. We are all mixed!" And yet, during informal discussions with Russians, Veps, Karelians, and so on what emerged was that the city dwellers often employ the use of stereotypes to refer to certain nationalities and their national characteristics. That is, applying national labels to differentiate oneself from the others appears quite a common practice in this northwestern territory of the Russian Federation.

I also argue that the use of cultural stereotypes is not as destructive as in other parts of the world. Rather the use of stereotypes serves to ease potentially charged inter-ethnic relations and maintain peace in a territory that had been disputed by Russia and Sweden, the USSR, and Finland for many centuries. The racist riots in Kondopoga-a small town situated $100 \mathrm{~km}$ north from Petrozavodsk in 2006 came as a shock to many. Due to an argument over the quality of the vodka served in a restaurant, a group of young Russians injured many Chechens and the fight ended with two ethnic Russians being killed. ${ }^{14}$ The event spurred immediate political reaction from Moscow and Chechnya. Locals still mention it today in order to reinforce their calm position and desire to maintain peace. Many commented on the event, "We are renowned for being peaceful people of the North. ${ }^{15}$ Why did that episode take place in Kondopoga? This is still unclear to us." I confronted similar reactions when discussing the revival of the Vepsian language. Natal'ya Silakova explained,

We do not want to enter in conflict with anyone. We are not asking for any special benefits. We just want to be able to say that we are Veps and speak our language. Everyone has the same right and we respect that.

Galina Lokkina once rested at the residence of the Martsyal'nye Vody, a spa resort in the Republic of Karelia. She laughed at a joke that a group of Armenians made during her stay there:

The joke goes like this, a group of Armenians and a group of Veps have a dispute. The Veps warn the Armenians, Hey, watch out or we will declare war on you! The Armenians respond Oh, yeah? Where will you find people to join the army? The Veps reply, Oh dear! Where can we find people to join the army?

By laughing at their own weaknesses (such as, being a minority group), Veps demonstrate their will to maintain peace. And this appears more important 
than advertising self-regard. I suggest that this is where the population gains strength over the State, while not being in direct opposition to the State. While between the 1950s and 1970s, the population developed the practice of mixed marriages, and later understood this as a way to promote and reinforce social unity, in the 2010s, the population of Karelia seems to appreciate that promoting the traditional and linguistic traits of each group equals promoting and reinforcing social harmony. This is not reflected in the policies which on the contrary have more and more assumed a centralizing tone (Zamyatin 2016a).

\section{Petrozavodsk: Representations of Veps in a Network of Nationalities}

My long-term work with Veps began in 2009. To be more precise, I arrived by train in Petrozavodsk from St. Petersburg on the morning of November 2, 2009. As I got off the train, on a very dark morning, I found myself surrounded by a mist, shadows of men and women queuing to get on the train, showing their tickets and passports to the conductors at the beginning of each carriage. I could not help but notice that, in contrast to what seemed to me a mainly fair-haired population that I had just left in Helsinki, I was now standing on the platform among dark-haired, fair-haired, tall, short, and individuals of all different shapes and sizes. My journey into understanding the Vepsian revival movement began here in this multiethnic environment, in this city of 261,987 inhabitants, of which 2,319 are Veps.

As mentioned earlier, Petrozavodsk developed around a cannon plant built in 1703 by Peter the Great. The ruins of the plant lie at the heart of the city between Karl Marx and Aleksandr Nevskiy Prospekts (Figure 2.4). There has been much debate on the destiny of the ruins, but so far, they remain untouched. For some, the ruins stand there almost unnoticed. For others, they symbolize the poor taste, if not the neglect of the government of Karelia. "Our land is so rich and beautiful," Mariya Ershova (pseudonym) stated, pointing at the forest on the other side of Lake Onega. "But, our city looks so ugly. Our architecture is not in harmony with the environment at all. It damages the view. It does not enrich it." Petrozavodsk sprawls along Lake Onega. The city center lies between the lakeside and the station, which is connected to the lakefront by Lenin Prospekt. The shops, the theaters, the cultural centers, the university, the main administrative, and the political buildings are all situated in this area. However, the majority of its inhabitants do not live in the city center but in the mainly Soviet-looking outskirts, such as Drevlyanka in the West, Klyuchevaya and Kukkovka in the South (Figure 2.6). The majority of the population lives in old wooden houses or blocks of flats. The latter harks back to Soviet times. Back in 2010, Nadezhda Kuznetsova (pseudonym), a Russian city dweller, confirmed, "Everyone lives there, both rich and poor. There is no distinction. The only difference lies in the quality of the furniture and how people maintain their 




Figure 2.6 Suburban district Kukkovka in Petrozavodsk. I took this picture in winter 2010

apartments." Different nationalities as well as different social classes are all mixed together under one roof, so to speak. Admittedly, in recent years, new districts have been developed where cottages and Scandinavian-looking flats are being built-yet, the majority of the population does not live here.

The nationality one belongs to is often not declared. However, there are times when this aspect of one's identity comes to light. In places such as the Centre for National Cultures in Lenin Square, or during the breaks at the National Theatre, discourse on nationality often occurs. It certainly occurred when I explained the purpose of my research, a topic I return to in detail in Chapter 4. As I mentioned earlier, nationality is intertwined in a network of stereotypes that developed either before or under the Soviets. In Petrozavodsk members of Vepsian, Karelian, Ingrian, and Russian groups share social stereotypes when referring to the various nationalities of Karelia. And this is what I have often heard in Petrozavodsk from those I lived with, their families, acquaintances, and friends-the Ukrainians sing all the time. They are warm and always smile and they drink more than in the North (although those with Ukrainian roots claim the opposite!). Drinking here means drinking spirits, since people in Karelia used to drink only beer, not vodka. ${ }^{16}$ The Russians speak louder according to members of 
the Finno-Ugric indigenous groups. They are more eccentric and they read a lot. Russians and Veps have often stressed how Finns keep everything inside and do not share their feelings. They have slow reactions. They do not enjoy meeting up. They go home and lock themselves in their houses. They are not healthy because their country has not opened to other nationalities in the past. Everything works in Finland because of the lack of bureaucracy and they only communicate through computers and not face-to-face interaction. Many Russians commented on how Karelians are also cold and do not show their emotions. However, they do so more than Veps do. They are not as optimistic as Veps and they are sly. Veps are regarded by Russians as those, living in the woods, away from civilization, and more optimistic and careful people. They have strong emotions but do not show them like the Russians $d o$. Veps are very few in number, nonetheless, they are very active. If you ask anything, they will immediately come and help, and, finally, they are goodlooking! ${ }^{17}$ Veps embody both a number of identities that they believe to be and a number of identities that are attached to them by others. As stated by Blommaert, "what we are at any time is a blend of inhabited and ascribed identities, of things we seek to articulate ourselves and of things that others believe we articulate" $(2008,83)$. Most Veps share the earlier noted labels and tend to regard themselves as optimistic, hard-working, pragmatic, careful, peaceful, and modest.

I now want to draw particular attention to the connotation living in the woods, as it explicates a complex relation between the way Veps are perceived among the multiethnic population of Karelia and the way they perceive themselves and the Vepsän ma. The phrase living in the woods represents a double-edged sword, since for the urbanites, this means being far from civilization and modernity, but it also means safety and well fed for many villagers. Early Soviet ideas of modernity still permeate some of the ways the city dwellers comprehend life and its evolutionary stages. Instead, the elderly villagers tend not to view the woods as indicating a lack of civilization. They tend to understand the forest as a place rich in produce (such as berries and mushrooms), a protection from external forces, and where the Vepsian language serves to maintain relations with the other, non-human, inhabitants of this territory. The high trees protect those within their boundaries. The forest, therefore, is included in the svoy (R. One's own) and is not part of the chuzhoy (R. Foreign, stranger) and unknown. Despite this idyllic picture, in the forest people need to perform certain practices, including employing a respectful language toward the others, human and other-thanhuman beings, in order to maintain peace and social balance. Engaging in foul language or simply not showing gratitude by verbally thanking the forest, the lakes, the rivers upon departure might mean that next time the catch will not be abundant (see also the Vepsian film, Živatad vepsläižiden elos, Animals in the life of Veps). The villagers rarely make any reference to civilization in the Vepsian villages where I worked given that the dominant language ecology there favors engaging in different discourse practices. They 
often smirked and asked me if I was ready to live po-derevenski (R. Country like/rustically). This implied having a proper wash in the kül'bet'/banya (V./R. Sauna) only once a week and using toilets without sewage connections, which are at times located far from the main building of the house. While this seems to imply a lack of civilization and rustic-ness, the villagers did not use that terminology. They seemed more concerned about the perception I may have had of rural locales, as an Italian urbanite, hence, symbol of culture and high "Western" standards of living.

In the city, I experienced a different attitude that predominantly appraises places as civilized or not civilized and echoes the Soviet discourse on evolution and backwardness. Civilization can comprise a number of domains and metaphors, most often linked to the family khozyaystvo. For example, people who live in brick flats or houses are considered more civilized than those living in wooden flats or houses. Electric cookers and stoves are regarded as more civilized appliances than those functioning with gas. Houses or flats with a bathroom and a toilet connected to the sewage system are also deemed as civilized. All those civilized appliances and technologies are often missing in the villages, in the woods, while they are available in urban areas. Considering that the Republic of Karelia covers $180,500 \mathrm{~km}^{2}$ and that $76.4 \%$ of its population $(684,200$ in total) is based in the city, it becomes clear that rural settlements indeed are scattered around a huge territory dominated by lakes, rivers, and forests. ${ }^{18} \mathrm{I}$ have often heard mainly people from the city joking that the entire Republic of Karelia is a territory away from civilization, despite its proximity to Europe and its lengthy border with Finland. A combination of embarrassment and matter-of-factness often followed this observation. Most often, the sentence Veps live in the woods synthesized their understanding of the different Vepsian practices, epistemology, and ways of interacting with the world and its inhabitants. Living in the woods has become synonymous with away from civilization and negative connotations among the multiethnic population of Karelia. For Russian villagers, the woods often represent a place of both "munificence and malevolence," due to the abundance of fruits and general products, but also as they may disorientate those entering them (Paxson 2005, 128). In any case, both qualities are wild. Therefore, it comes as no surprise that in the city Veps have not been loudly advertising their nationality and have often submitted to the dominant, urban ways of living and speaking. This does not concern the activists who are making themselves more and more visible through mass media and introducing new ways of promoting their culture.

\section{The Woods and Vepsian Language in the Villages}

On January 9, 2010, I decided to venture out for my first visit to a Vepsian village and arranged to go and see the ethnographic museum in Šoutjärv' (Figure 2.7). So at 6.45 a.m., I caught a minibus at the bus station from 


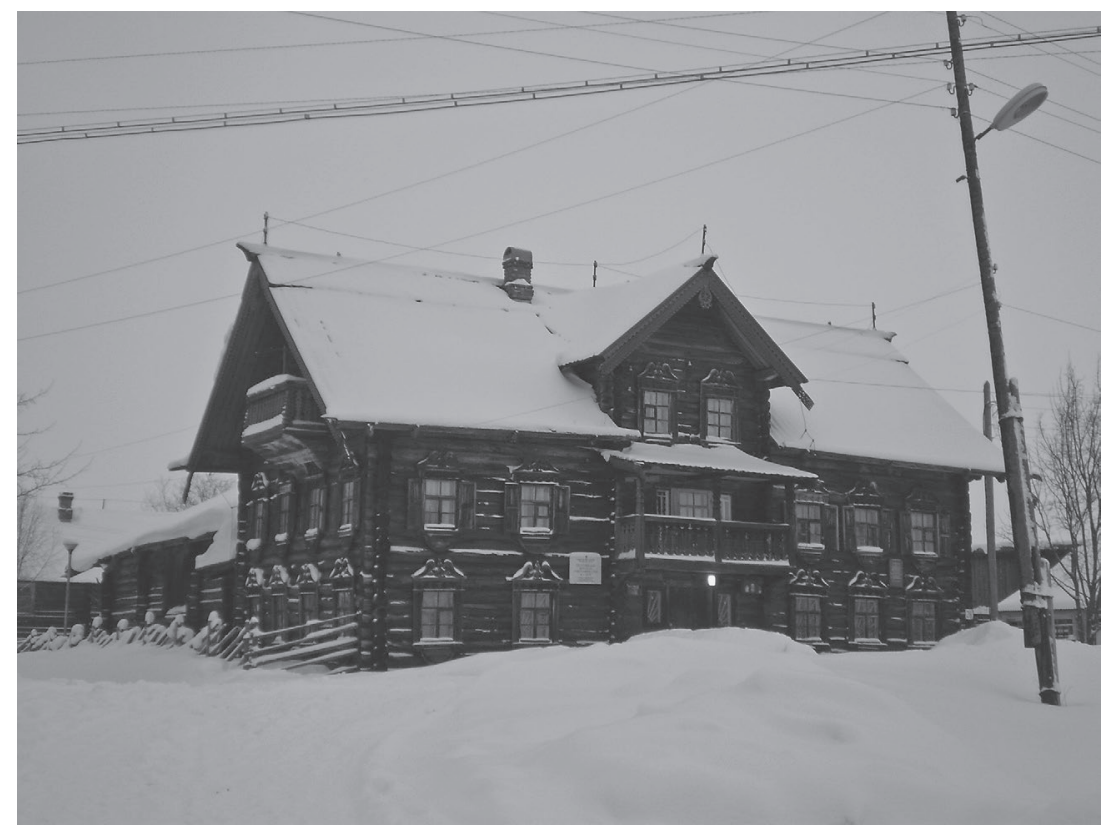

Figure 2.7 Vepsian ethnographic museum in Šoutjärv', Republic of Karelia. I took this picture in January 2010

Petrozavodsk to Šoutjärv'. It was pitch dark, and I could not see anything from the steamy windows. The minibus stopped from time to time (presumably at bus stops) and passengers got on and off. It looked as though souls were appearing from the darkness and others were disappearing into it. Given the rhetoric I had heard in Petrozavodsk, the phrases entering the woods and leaving civilization behind resonated in me.

Šoutjärv' is the administrative center of the Vepsian district of Karelia, and symbolically, it also represents its cultural hub, due to the activities organized by its inhabitants. The neighboring villages Kalag' and Šokš are situated on a hill; while Šoutjärv' is situated in a valley between them. Accidentally, their geographical position reflects their place within the Vepsian Renaissance, too. While Šoutjärv' is at the heart of rural intellectual activities, Kalag' and Šokš remain more peripheral to this movement as their inhabitants tend to participate less in the cultural events promoted by the activists both in Petrozavodsk and Šoutjärv'. Further south in the Leningrad Oblast, Vidl represents the cultural hub of the Veps of the Oyat' (Map 2). The summer festival Elon pu (V. Tree of Life) has taken place there since 1987. In Vidl there is a school to which children from the other villages commute. Some of them spend the school months in the internat (R. Boarding school). The same festival 
is celebrated in the villages of the Vologda Oblast, despite the more limited resources available for such initiatives in this region. As we were driving toward Kalag', Larisa Smolina told me,

You notice that the further south you go, the more people speak the language [i.e., Vepsian]. If you reach Pondal, you will only hear Vepsian in the street [Map 2]. Once my husband [who speaks only Russian] visited those villages together with me. He said he felt as though he had entered a foreign country. None of the villagers spoke Russian to him. When they understood that he did not comprehend what they were saying, they mumbled a few words in Russian. Then they continued in Vepsian.

I had a similar experience when I stayed in Pondal for a month in the autumn 2013 and in summer 2015; however, contrarily to Larisa's husband, I was keen to learn and speak Vepsian to the locals. I have heard similar comments many times. Vepsian painter Aleksey Maksimov confirmed that I would hear people speaking Vepsian in the streets in the villages of the Leningrad Oblast, as opposed to Karelia. Elena Leont'yeva confirmed, “The further you go, the more fluently they speak Vepsian. It is because they are far away from the influence of the city [i.e., Petrozavodsk]. They are out there, surrounded by forests and they preserve the language better." Elena Leont'yeva is a Vepsian activist working for NEVOND at the Centre for National Cultures in Petrozavodsk. NEVOND is the "Youth Information Center of Indigenous People" and is directed in Moscow, with a branch in Petrozavodsk. The overall claim is that being far from the city, surrounded by conifers, has helped the villagers maintain their language. Furthermore, the forest and territory surrounding the villages can also be a source for creativity. This was true for the Vepsian poet Nikolay Abramov, for example, who found inspiration for his poems in his wanders in rural locales. As we were traveling through the forest Ol'ga Zhukova told me, "I once visited Murmansk. I felt almost naked there. There are no trees up there and you feel as though nothing protects you. The forest gives me this sense of protection." 19 The forest, therefore, protects the individual and provides a sense of safety just as it protects the language. The closer to the city the more Veps are influenced in their language use by the language paradigms and ideologies existing there. The further from the city and influence of dominant discourse on progress and civilization, the more people seem to have preserved their heritage language and to use it more spontaneously.

\section{Petrozavodsk: Stereotyping National Languages}

In the city, cultural and social stereotypes also extend to language and language practice. The Russian city dwellers in general seem to view Veps as speaking more slowly, being more accurate and very careful, and needing more time to think. In Karelia, both Russians and members of the indigenous 
Finno-Ugric groups often accentuate how people speak much faster in and outside of Moscow. In these regions of European Russia, they tend to adopt the phonetic practice of vowel reduction (or akan'e), which means that the quality and quantity of the vowels of the unstressed syllables are lowered and that they move toward a schwa. This is true especially for /o/. In other words, the further away from the main stress of the word, the more the vowel is reduced in its quality. This is, in fact, contrary to the way most of the Vepsian villagers speak Russian. They generally say /'horofo/ and not /hər ${ }^{\prime} \mathrm{Jo} / \mathrm{when}$ articulating the word khorosho (R. Nice, good), and often maintain the stress on the first syllable as per Finno-Ugric practice, and do not reduce atonic vowels. In certain regions of the Republic of Karelia, indeed, the Russian speakers tend to put the main stress on the first syllable of each word, as per the Finno-Ugric model. Irina Ivanova (pseudonym) told me:

If you visit north eastern Karelia, you may hear the Russian word sapogi [R. Boots] being pronounced differently, i.e., with the stress on the first syllable. It sounds like this, sapogi. Similarly, the word parochod [R. Steamboat] will be stressed on the first syllable and read parochod. This is a Finno-Ugric influence on Russian pronunciation. Some students and I once went up there on an excursion. One of them cried to a local old lady koza prishla [R. The goat has arrived]. But the poor old lady seemed lost as she did not understand what the student was talking about. As soon as she spotted the goat, she exclaimed, ah, oza prishla! In order to understand, she pronounced the words with the stress on the first syllable.

Among the northwestern population of Russia, such an influence on Russian pronunciation often reinforces stereotypical ideas of peaceful and quiet people of the North who speak more slowly and are accurate in pronouncing every sound of the word. It should also be stressed that pronunciation as opposed to lexicon is generally valued less among the multiethnic population of this Northwestern Russian territory. In this sense, Finno-Ugric influence on Russian pronunciation does not mark a relation of power between Finno-Ugric groups and Russians; rather, it marks a distinction between people living in the northwestern regions of Russia and these living in the central and southern regions of the Federation.

The Vepsian villagers pronounce clearly every single sound within a word also when speaking Vepsian. Every vowel and every consonant is clearly and thoroughly pronounced. Speaking more slowly is often accompanied by slow physical movements, too (Hanks 1996; Ingold 2004, 330). Here, I refer to Hanks's conceptualization of the body as "part of the communicative resources through which other parts of the world are brought into focus" $(1996,249)$. When expressing consensus, indeed, some Veps say ka (V. Yes) while shutting their eyes, smiling, and slowly lowering their head. By doing so, they add more emphasis to their agreement. The movement 
is surprisingly slow and gives time to the interlocutor to fully appreciate the consensus, which normally ends up smiling to one another looking in the eyes. Along with expressive gestures of the face, physical touch is often combined with speaking, too. When leaving the forest, Veps tend to touch the trees and thank out loud the host of the forest. Similarly, they thank the water after a good catch, hoping that this might provide another good catch next time. Many Veps believe to have developed a more intimate bodily relation with the forest and to be immune to ticks, for example.

Among the Vepsian villagers, pronouncing clearly every sound links to markers of identity of the Vepsian group, which is both internally and externally stereotyped as accurate, precise, and patient. Humility is another characteristic that Veps like to describe themselves as possessing. From my observations, I noticed that they are proud of not showing off their qualities and always being thankful to those who helped them achieve their personal and social goals. Humility also extends to the way they use their native language. Several Vepsian friends commented on how the Russians are loud, both in their speaking and way of dressing, and generally in how they present themselves. Veps, on the other hand, do not loudly advertise their presence. I was told that "while the Russian way of speaking is very expressive and loud, Veps keep their feelings to themselves, which does not mean that the feelings are not there, but that they are not on display to everyone." Hence, in the villages and among Veps who moved to the city at a later stage in life, speaking slowly, being accurate and lingering on every sound is both an index of being a good person, of pride, and a response to the environment where they live.

By contrast, Veps and Karelians feel that the urbanites (especially, Russians of this northwestern territory) often develop a different attitude toward speaking slowly and attach a different metaphor to such practice. In the city, speaking slowly at times resembles Soviet references of backwardness. Taking time to think and to respond to questions or simply daily events is frequently understood as a deficiency, rather than a quality, especially when a Vepsian bilingual engages in such practice. This can be extended to Karelian bilingual speakers, too. Indeed, the bilingual Vepsian-Russian and Karelian-Russian speakers are often perceived as lacking wit and insight if they take time to think, as Natal'ya Antonova confirmed: ${ }^{20}$

People laugh at me when I come back from the village. They think that I am slow. It does sometimes take a little longer to get used to speaking Russian again, after having spoken Karelian at my parents' in the village. But, after the first hiccups, I function regularly in Russian!

At times, needing time to think indicates also koldovstvo (R. Witchcraft) and is looked at suspiciously by those who do not have roots in the Vepsian or Karelian villages. I noticed that some city dwellers who master only the Russian language do not like not understanding what other people think and/or say, as they immediately assume that the conversation is about them 
and that some negative energy is being sent in their direction. Words seem to carry a heavy weight among the population of this territory of the Russian Federation since people tend to appreciate their energy and the power within them. Therefore, while in the villages, speaking slowly embraces a positive symbolism, in the city, it can reference back to Soviet ideologies and be perceived as the opposite.

$* * *$

In this chapter, I showed how Veps have experienced and still remember war, deportation, immigration, urbanization and Soviet education policy at the grassroots levels and how these events have also influenced their language use and traditional representations.

For many villagers, moving away from the land of origin has meant dropping the Vepsian language in favor of Russian, abandoning Vepsian rural ontologies and distancing from the original sebr. The Vepsian language, land, and those human and other-than-human beings had been strictly connected for centuries. Once the connection with the land and its inhabitants was broken, Vepsian became a pocket language for some. For those who still dwell in the villages, however, local ways of living, gravitating around the sebr and khozyaystvo still shape their worldview. The main problems reside in the political neglect toward rural life from the very beginning of the Vepsian revival movement.

Pre-revolutionary and Soviet legacies are manifest in the adoption of social and cultural stereotypes, especially, in the city. The urbanites (Vepsian and non-) understand the use of social and language stereotypes as an indication of peace. And language has power in maintaining social order. For this reason, it is generally believed that it is important to give the right to each group to preserve and promote their heritage language. The Vepsian city dwellers tend to put emphasis, therefore, on the reasons why they should invest in the preservation and promotion of their heritage language. The villagers, instead, with their conduct and lifestyle put emphasis on what it is that preserves the language and where the language finds its expression. For them, the power of the language resides in being in the woods, far from the city, in a land surrounded by forests, linked by rivers and lakes. The power of the language comes from living it within the environment where it first emerged and developed. Its power resides in its relationship in unison with the rural world where it first developed. Its existence relies on this relationship. Language finds its expression from this attunement.

From this chapter also emerges how Vepsian verbal engagement with the multi-layered language ecology in which they live depends on the main forces that dominate a place at the time of speech and written acts. If in the villages, especially those situated in the central and southern regions of the Vepsän ma, people tend to socialize in Vepsian and to engage with the territory through a respectful use of their heritage language. In the city, many have dropped it, not only led by pragmatism but also not to reinforce negative stereotypes and, thus, risk being discriminated. 


\section{Maps}
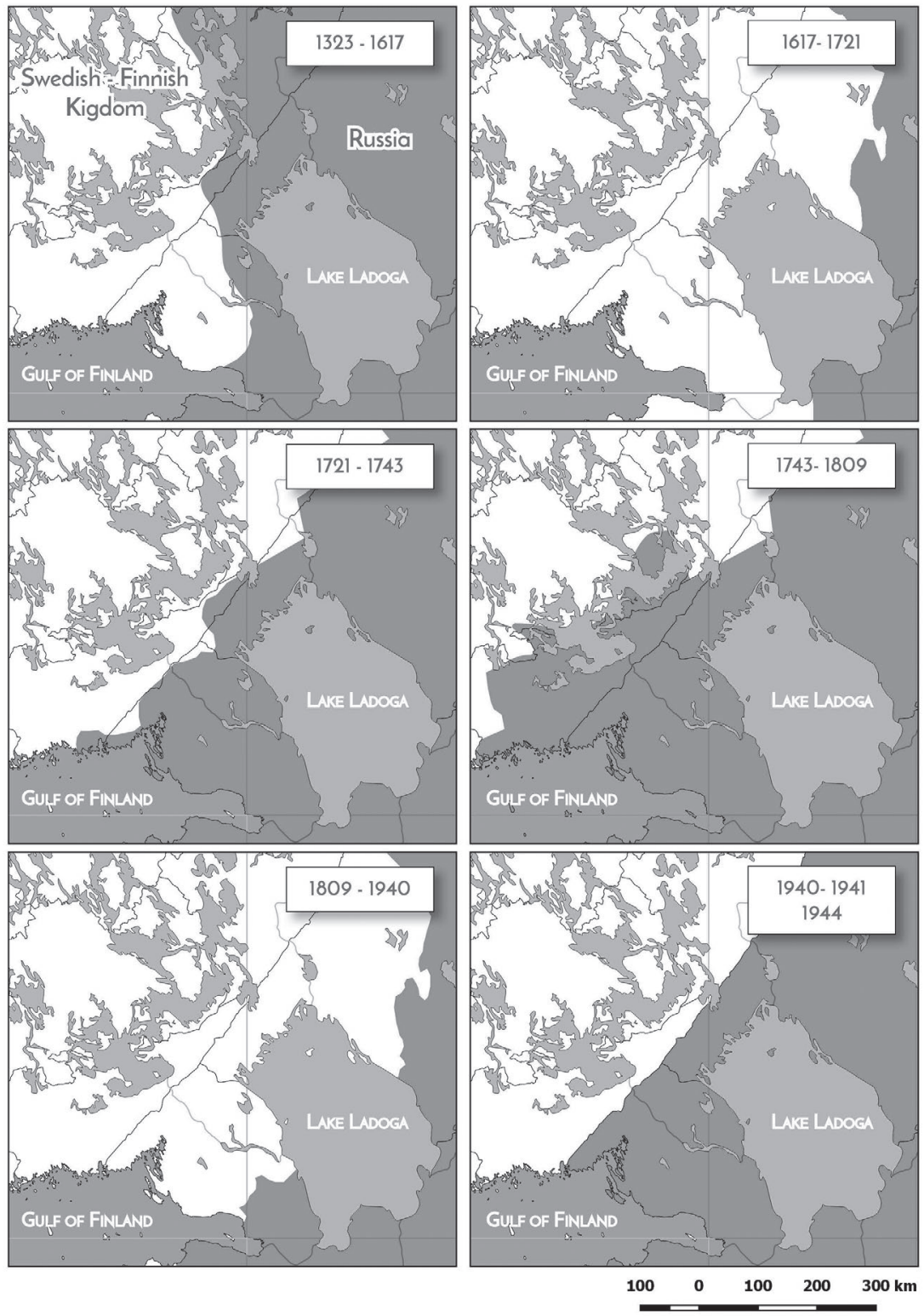

Map 3 Changes in borders between Russian and Finnish territories. Arch. Pasquini has adapted this map from Mead $(1952,45)$ 


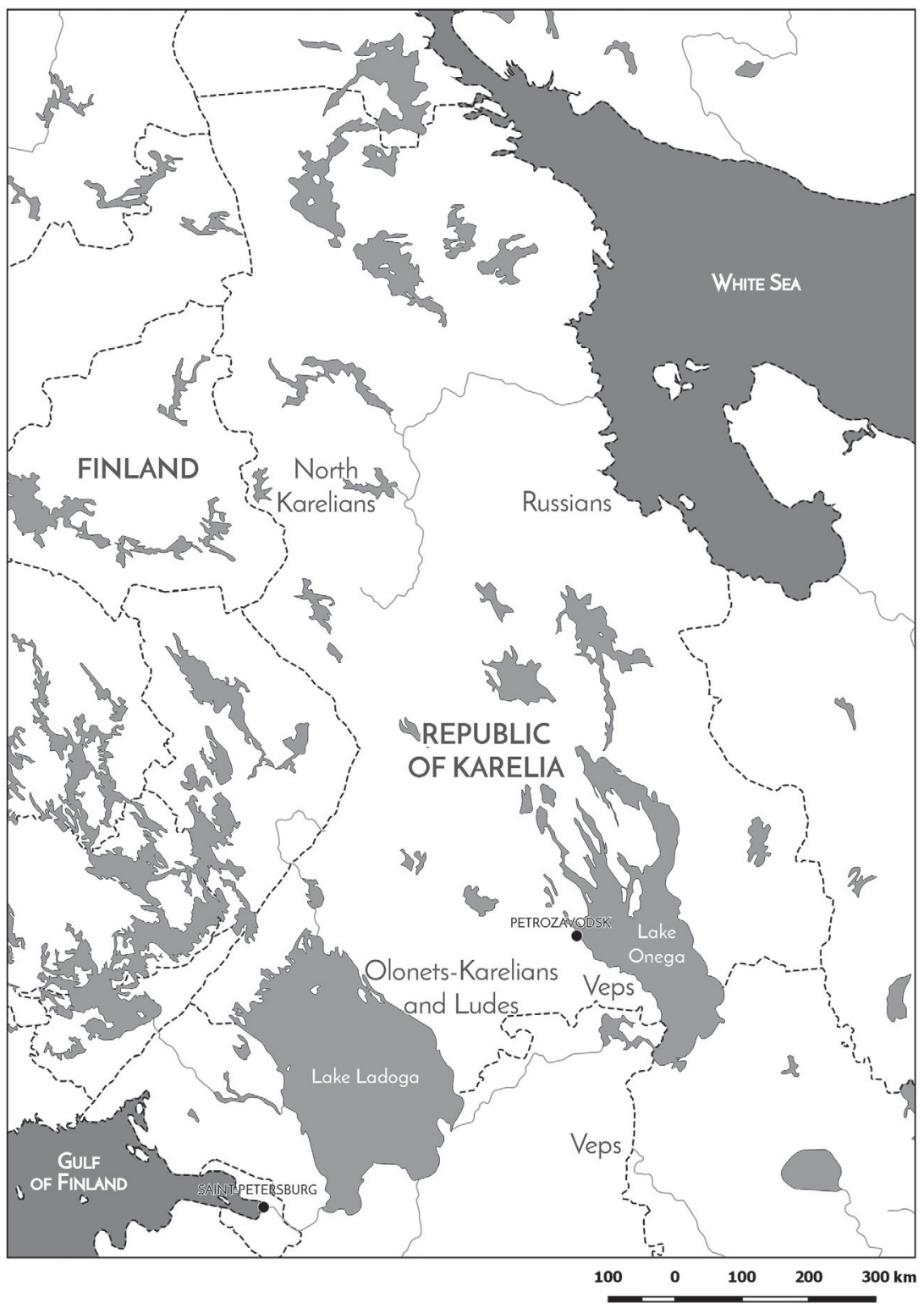

Map 4 Multiethnic Republic of Karelia. Map by Arc. Pasquini 


\section{Notes}

1 Korol'kova (2015) has gathered an exceptional collection of photographs picturing Veps from REM (The Russian Ethnographic Museum) in Saint-Petersburg. Those pictures portray exactly what Maksim was saying: large group of people in the field, children playing around, and large group of villagers gathered together to take pictures. Unfortunately, when I requested to use some pictures, REM asked me to pay $\$ 150$ for each photograph, given that I am a "Western" scholar. I could not accept to pay such a sum also not to spoil future work to future "foreign" researchers.

2 Landscape is to be interpreted as a place where the inhabitants dwell and engage actively with the land, not merely beautiful scenery (Ingold 2000).

3 This chronicle illustrates life in Kievan Rus' from about 850 to 1110 and is considered a central source of interpretation on the history of Northeastern Europe.

4 An interesting parallel can be made with the work by Basso (1996) who demonstrated how Apache used to name places depending on the importance of events that had taken place on the land.

5 This word is also found in other Finnic languages, such as the Finnish Jumala (F. God) and the Estonian Jumal (E. God).

6 The policy to divide and scatter one national group among several krays, oblasts, and okrugs was a typical Stalinist measure. It affected many national groups besides Veps as demonstrated by Anderson (1991, 2000), Long (2010), and Reeves (2007).

7 On the topic of civilization in other parts of the Soviet Union, see also Anderson (1996), and Ventsel (2011).

8 Natal'ya Silakova is a Vepsian writer. Resident of Petrozavodsk and originally from Himd'ogi, Leningrad Oblast.

9 Mannerheim was the Commander-in-Chief of the Finnish defence forces during World War II.

10 Due to the industrialization of forestry and a drop in the local workforce after World War I and II, many jobs became available between the late 1940s and 1960s in Western and Northern Karelia (Klement'yev 1988, 14-17).

11 The Government of Karelia. www.gov.karelia.ru.

12 Perepis. www.gks.ru/free_doc/new_site/perepis2010/croc/perepis_itogi1612.htm.

13 The Government of Karelia. www.gov.karelia.ru.

14 St. Petersburg Times. www.sptimes.ru/index.php?action_id=2\&story_id=18713.

15 While peaceful is a word that is commonly used among the population as a word that summarizes shared common sense; Veps feel that the word tolerance is an imposition from the State. This is also shown in Chapter 7.

16 On drinking patterns among Veps, see also Vinokurova (1996) and Korol'kova $(2015,165)$.

17 Interestingly, in his expedition to Vepsian villages between 1928 and 1930, the scholar Volkov also remarked how stunned he was by the beauty of Veps (AMAE 13-1-94).

18 The Government of Karelia. www.gov.karelia.ru.

19 Ol'ga Zhukova is a Vepsian teacher at the Baltic-Finnish and Finno-Ugric Faculty of Petrozavodsk State University and researcher at the Academy of Sciences. She is originally from Kurb in the Leningrad Oblast and is now resident of Petrozavodsk where she moved to receive tertiary education.

20 Natal'ya Antonova is a Karelian activist and founder of the NGO Nuori Karjala (K. Young Karelia). She lives in Petrozavodsk and spends most of her summer holidays in her village of origin where her parents live. 
$\because$ Taylor \& Francis

Taylor \& Francis Group

http://taylorandfrancis.com 


\section{Multilingual Russia \\ Superdiversity Meets Language \\ Revival}

\subsection{Superdiversity Meets Language Revival in Russia}

Let me start this chapter with a couple of vignettes. The first one took place while attending the Fifth International Conference of Finno-Ugrians, "Finno-Ugric languages and cultures in the socio-cultural landscape of Russia," held in Petrozavodsk in 2014 which I was invited to take part in by my Vepsian friends and colleagues. As I was standing in one of the halls during a break, Elena Leont'yeva approached me and begun telling me how she had been talking to some representatives of a further eastern Finno-Ugric ethnic group of Russia. Indeed, she indicated being surprised by the different challenges they were facing, as opposed to the Vepsian present situation. She remarked, "It seems they have kept their old traditions. We have the language, but we have not maintained our traditions. They do not have the language anymore, but have kept their traditions."

On a different occasion, back in 2011, Ol'ga Zhukova and I were talking about political boundaries and the vastness of the Russian territory as opposed to the Italian crammed landscape. Out of 142,857 inhabitants within the boundaries of the Federation, 105,314 live in urban locales (Perepis 2010). ${ }^{1}$ Given the vastness of the Federation, it is clear that the cities are afar and that most of the territory is covered by land. Ol'ga Zhukova admitted not being able to imagine it otherwise, and remarked, "Veps are a small nationality, but we know that the territory covered by our government is huge. It is difficult to imagine it in another way. If we look at the horizon, we know that the land of our State stretches out there" (and she pointed eastwards). Veps, contrarily to those nationalities which gained independence as soon as the Soviet Union collapsed (e.g., Estonia), do not aspire to separating from Russia; on the contrary, they feel an intrinsic part of it.

While Elena Leont'yeva was trying to make sense of multiethnic Russia (see Map 5), identifying differences and similarities among the different nationalities of the Federation, she also pointed at the preservation of her heritage language, which, ironically, she was not able to master herself. In fact, I suspect that she hinted at language as an identity marker rather than at its current use, whereas, in other parts of Russia, questions of identity 


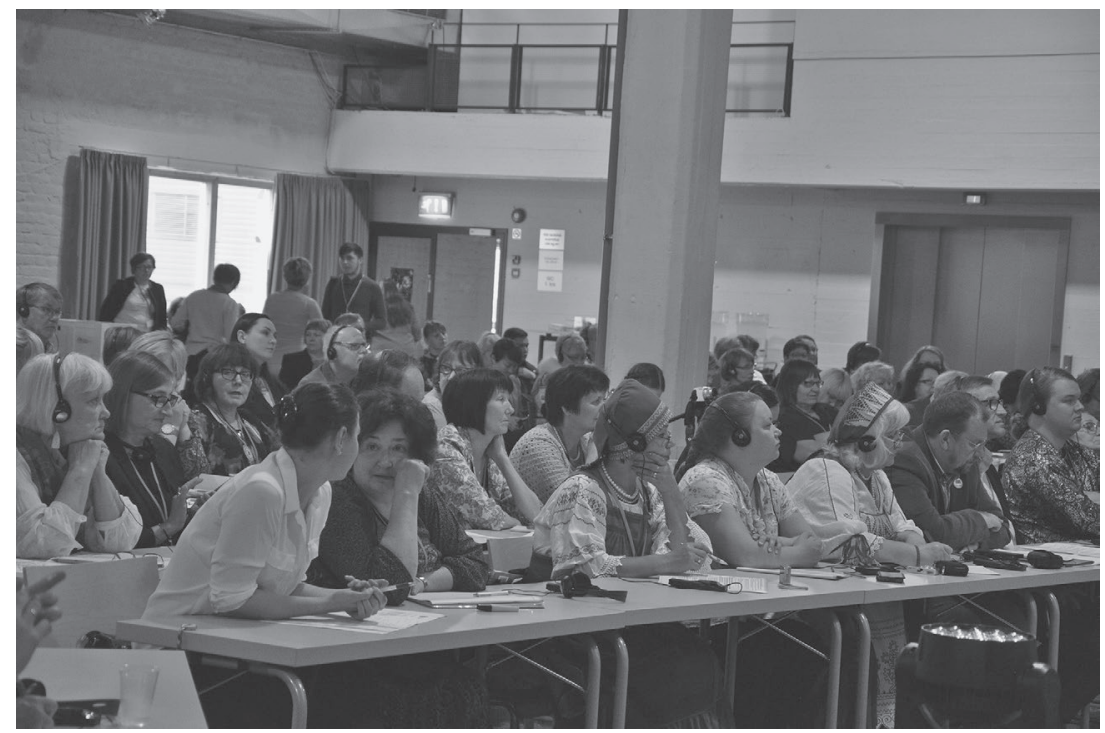

Figure 3.1 Participants of the VII International Congress of the Finno-Ugric Peoples in Lahti (Finland) in 2016. I took this picture

might strike as closely connected to old traditions and cultural practices. Either ways, she revealed an interest toward the other nationalities of the Russian Federation, which often emerges at conferences such as the one we attended in Petrozavodsk, where representatives of different nationalities come together, meet, and compare their experiences (Figure 3.1). Despite the differences, what emerged was also a deep feeling of belonging to the Russian Federation, which Veps demonstrated not to challenge, as displayed by Ol'ga Zhukova. Rather, they exhibited not to feel in isolation but part of a broader multinational State. Indeed, the Russian Federation presents a complex multinational panorama, at times reflected in the administrative organization of the territory that has inherited its structure from the Soviet period. Altogether, there are 83 federal administrative subjects within the Federation and the national subjects represent approximately a fourth of its entirety. There are 160-170 nationalities in the whole of Russia and $19 \%$ of the population belongs to national minorities (Puura et al. 2013, 2; Saarikivi and Toivanen 2015, 14-15). A hundred different languages are reported to be spoken within the boundaries of the Federation. About 20 million people reported knowledge of their heritage language in the last census (Puura et al. 2013; Saarikivi and Toivanen 2015). The languages spoken in Russia belong to 14 language families and Vepsian belongs to the Finnic branch of the Finno-Ugric family (Puura et al. 2013, 42). The other 
Finnic languages are: Meänkieali and Kven spoken in Sweden; Finnish and (Finnish) Karelian spoken in Finland; North, South, and Olonets Karelian, Ludic, Ingrian, and Votic spoken in Russia; Estonian and South Estonian (Võto and Setu) spoken in Estonia; and Livonian in Latvia (Puura et al. 2013, 42-43).

The awareness of being part of a multinational and multilingual State has long existed and must have been reiterated by Soviet ethnographers when the scholars embarked on expeditions to distant lands, reached out to the several groups dwelling in this territory, and classified and categorized practices, language and tales, customs, and so on (cf. Anderson 2000; Arzyutov and Kan 2017). Even though such categorization have been challenged (Blommaert and Rampton 2011), they are real for the citizens of Russia and this pushes me not to embrace an entirely (post)modern and deconstructive approach to my study (see Chapter 2 where I make reference to circulation of identities). These descriptions are still maintained with the difference that at present they are often synonymous with a past that needs to be "resurrected" and a present that allows for political action.

The risk is to exoticize the past (and present as a reflection of the past, for that matter) by creating a fixity through the use of categories which more than anything else indicates fear of change and loss. In this context, the case of Veps is particularly relevant, given its rural-urban polarity, different usage of the written and spoken language that hint at a dynamism within a socially constructed and accepted structure. The activities of the activists, the use of Vepsian spoken and written language in rural and urban locales allow me to make direct links to a discussion on superdiversity and endangerment which was prompted by Vertovec (2007) and later developed by Blommaert (2013), and Toivanen and Saarikivi (2016).

\section{Superdiversity and Language Revival}

The main question that concerns this chapter (and to some extent also some of the following chapters) is the one advanced by Toivanen and Saarikivi (2016): are we facing linguistic genocide or superdiversity when studying new and old language diversities? The current volume presents linguistic change, both in the structure of a language and in its semiotic capacity, and in its oral and written mode, which are manifested in relation to the language ecology in which people experience speaking and writing. Nonetheless, I also show how initial change can stabilize and fix for a certain period of time (cf. Sarhimaa 1999). Is such dynamism an indicator of language loss or is it an indication of supersiversity, Toivanen and Saarikivi (2016) wonder. And, could an ethnographic study help us identify the multiple shades existing between these two extreme positions?

As stated by Blommaert $(2013,4)$, the "wider panorama is a form of social, cultural, economic diversity for which Steven Vertovec coined the term 'superdiversity'-diversity within diversity, a tremendous increase in 
the texture of diversity in societies such as ours." Blommaert (2013) blames the end of the Cold War and the fact that the world went online for such an increase in diversity, which, in his opinion, resulted in new and more complex forms of migration and knowledge circulation. When considering the promotion of Vepsian standard language and its use in the written form and online (Chapter 7), the oral use of Vepsian (Chapters 5 and 6), and the phenomenon of urbanization, the approach presented by Blommaert appears to make sense, at least to a certain degree.

However, when bringing to the fore a detailed ethnographic analysis of grassroots practices and narratives, this configuration begins to shake. First of all, the term "superdiversity" often refers to mostly urban-like locales where miscellaneous groups have come together and have allowed society to become more fluid and diverse. My work with Veps leads me to agree with such a position only to a certain extent since the overarching Vepsian language ecology comprises both rural and urban settings, and change has occurred and is occurring in both locales. Just like Toivanen and Saarikivi (2016, 13), therefore, I am cautious in embracing superdiversity without challenging it and also "take a critical view of the line of research that is willing to deconstruct all traditional linguistic communities and focus on seemingly infinite new variations" (Toivanen and Saarikivi 2016, 13).

When including such configuration in the discussion around language endangerment, the broader language ecology needs to be taken into account if we want to better appreciate what works in favor or against the revival efforts-excluding the rural settings and practices which dominate there would mean getting only half of the picture and not being able to assess the revival movement in its entirety. On top of that, focusing only on "superdiversity" would continue adhering to a narrative of advancement and progress (in the form of literacy and new ways of communication) which once again would discriminate those living in the villages who have limited access to these new forms of communication. Indeed, while the Internet and mobile connection have reached the villages in the Republic of Karelia, those villages in the central and southern part of the Vepsän ma are often disconnected. For example, in Pondal, a village in the Vologda Oblast, where I conducted research in 2013 and 2015, mobile network coverage was not available. What's more, while the public phone boxes worked rather well in 2013, after some maintenance work (sigh!), they stopped working entirely, and I was not able to use them in 2015. A similar situation was experienced by the villagers in Kurb in the Leningrad Oblast. Instead of providing online availability to the local households, the workers only managed to disrupt a few fields where the villagers were raising their crops.

At present change is not constrained to areal and social variation, as it might have in the past (Saarikivi 2006), but it occurs in urban and rural locales, encompasses written and oral practices often in relation to generational ideologies, experiences of repression, discrimination, and violence, as well as cooperation and joint work (Sebr) (see Chapter 5). What's more, this 
overarching approach allows us to surpass the exoticization attached to the oral use of the language in the villages, since such language practices have also gone under change as people respond promptly and continuously to external inputs and adapt their ways of speaking. In order to avoid such exoticization, in the next section, I show how Finno-Ugric studies (with a focus on Veps) have developed from a predominantly folklore and linguistics-based approach and have recently moved to a more practical application with the attempt to reach out both city and village dwellers.

\subsection{International Cooperation and New Directions in Language Revival}

In this section, I provide a brief account of the academic and scholarly work on Finno-Ugric peoples, with a particular focus on Veps. The purpose of such a synopsis is to demonstrate how scholarly cooperation among FinnoUgric peoples has recently undergone a shift. It originated from a more romantic approach based on kinship and the idea of a bucolic country lifestyle and has lately shifted toward a more global orientation in oral tradition and cultural heritage (Harvilahti 2012, 391), and a more pragmatic relationship among Finno-Ugric peoples which evinces a recent rhetoric of language endangerment and loss. The purpose of my presentation, therefore, is not only to surpass the risk of exoticizing language practices in rural settings but also to provide a contemporary account of Finno-Ugric folklore and (socio-)linguistic studies as they help us understand social change and linguistic variation diachronically. Such presentation also allows us to understand how relations among Finno-Ugric peoples have developed over time in connection with the main language ecology in which the scholars and people found themselves.

Let's begin with Daniel Juslenius (1676-1752) who was a Finnish historian under the Swedish rule, and whose main goal was to shed light on a "somewhat imagined Finnish history" (Harvilahti 2012, 392). The need to create a Finnish history can also be found in Christfrid Ganander's (17411790) Finnish Mythology where riddles, proverbs, folk poems, and enchantments can be found. He also compiled a dictionary of Finnish.

The two pioneers in Finno-Ugric studies were followed by the Romantic scholars who grew an interest toward the collection and publication of folktales-as it was in vogue and in line with the work done by German linguists and folklorists at the time-in the hope to recreate a mythical past. The ultimate hope was to help Finland form as a nation-state since it was then an autonomous grand duchy under the Russian tsar (that is, after 1809). In 1831, the Finnish Literature Society was founded in Helsinki (Harvilahti 2012, 395). Elias Lönnrot, the society's first secretary, compiled the Finnish national epic, the Kalevala, whose latest version was published in 1849. Soon afterward in Estonia, Kreutzwald compiled the epos Kalevipoeg. As indicated by Zamyatin $(2013,67)$ the Finno-Ugric myth of unity which emerged at that 
time might have possibly indicated a clear opposition toward the "other" (cf. Saarinen 2001). This appears a clear statement of national identity in opposition. The collections of folklore items expanded at the Finnish Literature Society reaching the number of 200,000 by 1900 (Harvilahti 2012, 396). Folklore studies and interest in Finno-Ugric languages went hand in hand. In 1844, Zacharias Topelius made reference to a possible "pan-Fennicism" and "pan-Finnic community," which soon extended to linguistic kinship and was gradually developed in the nineteenth century (Sommer 2014, 394).

A few Finnish scholars received support from the Imperial Academy of Sciences in order to conduct research among Finno-Ugric peoples of Russia. In the eyes of the tsar, this would have strengthened the bond between Russia and Finland and distanced Finland from Sweden. Among these scholars were Anders Johan Sjögren (1794-1855), Matthias Alexander Castrén (1813-1852), and August Ahlqvist (1826-1889). In the mid-1820s Sjögren conducted research among Veps which he referred to as Chud'. Besides identifying the borders of the territory covered by Vepsian settlements, he also counted approximately 21,000 people living in this land; thus, it is said that he conducted the first census among Veps (Strogal'shchikova 2016, 75; Vinokurova 2015, 13). Ahlqvist referred to Veps, among others, as "Finns living in Russia, outside the borders of Finland" (Sommer 2014, 408). Ideas on a possible Finno-Ugric linguistics was brought to Finland by Gabriel Porthan (1739-1804) and later advanced by Castrén who during a public lecture in 1849 elaborated on cultural and linguistic affinities between the peoples of the Finno-Ugric language family (Saarinen 2001, 41; Sommer 2014, 398). Soon afterwards, a couple of more Finnish scholars, Emil Nestor Setälä (1864-1935) and Lauri Kettunen (1885-1963) also got interested in Vepsian matters. In 1916, Setälä recorded a game accompanied by the Kantele among Southern Veps (Strogal'shchikova 2016, 77-78).

Russian scholars displayed interest in the Finno-Ugric communities of Russia, too. For example, toward the end of the 1880s, Russian ethnographers such as Vladimir N. Maynov (1845-1888), Aleksandr I. Kolmogorov (1870-1922), Nikolay F. Leskov (1871-1915), and others, began conducting research among Veps. While Finnish scholars mostly aimed at finding similarities and connecting the sparse Finno-Ugric populations, the Russian scholars were more interested in observing Vepsian cultural traditions and how these differed from the neighboring ethnic groups (Strogal'shchikova 2016, 79). Overall, the academics from Russia shared a pessimistic view on the Vepsian language, which in their opinion had already been highly assimilated (Strogal'shchikova 2016, 80).

After Finland gained independence in 1917, the focus of the Finnish folklorists shifted toward a combination of diachronic and synchronic methods (Harvilahti 2012, 399). Linguistic studies continued to be financed until World War I and the October Revolution, which, however, indicated the closure of Soviet borders to Finnish and "Western" scholars, with the exception of a few Hungarian academics (Saarinen 2001, 43). 
In the 1930s, a group of scholars from the Leningrad Oblast led by Bogdanov focused on the standardization of the Vepsian language (see Chapter 7). This is when the Vepsian language was codified and standardized for the first time.

Moved by a sense of relatedness and kinship Finland, Estonia, and Hungary strengthened their relations in the period between World War I and World War II. And this culminated in the organization of Finno-Ugrian cultural congresses: the first one was held in Helsinki in 1921, the second in Tallinn in 1924, the third in Budapest in 1928, the fourth in Helsinki in 1931, and the last in Tallinn in 1936 (Saarinen 2001, 45). After the war, Estonia lost its independence and got integrated into the Soviet Union. This interrupted the fluidity of the cooperation with Finland and Hungary. International congresses of Finno-Ugrian studies were only resumed in the 1950s (Saarinen 2001; Zamyatin 2013).

In the 1950s and 1960s, Finnish folklorists experienced a revolution in their methods of analysis and began focusing on the context rather than the single text (Harvilahti 2012, 402). Lauri Honko was the main promoter of this new direction in folklore studies. While Finnish scholars could not have access to the Soviet territory in order to keep on conducting research on the FinnoUgric groups living there, research continued among Estonian and Russian scholars. In regards to the Vepsian language, Paul Ariste, Paul Alvre, Aime Kährik among others studied specific aspects of Vepsian phonetics and grammar among Southern Veps (Zaitseva 2001). Scholars from Russia displayed similar interests and such figures as Matvey Hämäläinen, Mariya Zaitseva, Mariya Mullonen, and later also Nina Zaitseva studied aspects of Vepsian grammar (Zaitseva 2001). They all worked in Petrozavodsk. Nina Zaitseva has continued her work on Vepsian up to now and is currently leading linguistic research at the Academy of Sciences in Petrozavodsk. Here ethnographic work is instead led by Irina Vinokurova and Zinaida Strogal'shchikova. The latter also shades her work of political tones, as she is also the founder of the Society of Vepsian Culture, which has brought together not only young scholars, such as Ol'ga Zhukova, but also Vepsian journalists, artists, and amateurs. The current work done by the scholars in Petrozavodsk has not only scholarly ambitions but it is also colored of political tones and often has pragmatic goals- that is, to reach out to the disperse Vepsian communities, to bestow pride among them, and to draw out language use.

Such a work is also possible in cooperation with the work of Finnish scholars, such as Riho Grünthal, Janne Saarikivi, Heini Karjalainen, and Ulriikka Puura, and Estonian scholars, such as Kristi Salve, Madis Arukask, and Indrek Jääts, among others. Cooperation takes place not only at the academic level but also manifests in the support of the activities promoted in Russia. For example, the Vepsian Paginklub where people of different age and background can meet and speak Vepsian in Petrozavodsk resulted from the cooperation between Nina Zaitseva and Riho Grünthal. The implementation of language nests among the Finno-Ugric peoples of 
Russia has long been promoted by Janne Saarikivi and Annika Pasanen. The Council of the Kindred People's Program in Estonia provides financial support for the work of the Finno-Ugric activists of Russia. What's more, at present in Finland scholars such as Laura Stark and Lotte Tarkka implement methods and analysis which are not only based on the long-tradition of folklore studies but also from other disciplines, such as anthropology (Harvilahti 2012, 405). In France, similar questions are addressed by scholars such as Eva Toulouze and Jean Léo Léonard. Veronika Davidov and Anna Varfolomeeva also investigate a focus on mining and the economy of Veps. Finno-Ugric international conferences and congresses continue to be organized and so does a close cooperation with local NGOs, such as Nuori Karjala and the Society of Vepsian Culture. Scholars from Russia, Finland, and Estonia have never been as unified as they are now, given common goals and desire to have a social impact. Thanks to the long-term scholarly tradition of Finno-Ugric studies, the current academic work has been able to focus on more practical aspects, which surely are also connected to the fear of losing Finno-Ugric endangered languages and cultures.

Of course, by no means has this been an exhaustive presentation of Finno-Ugric studies, rather it is only a brief presentation of past and current trends. However, it has demonstrated how scholars interested in Finno-Ugric matters have always engaged with the ecology and the dominant concerns which characterized the different epochs in which they lived (cf. Siragusa and Arukask 2017). They have recently surpassed an exotization of hunterand-gatherers society, living and dwelling in a bucolic and idyllic space and have more strongly engaged in questions related to survival, maintenance, and preservation of endangered languages and cultures by adding more pragmatic work to their scholarly endeavors. In this sense, the work of the Finno-Ugric scholars and academics interested in Finno-Ugric matters lines up with the concept of "cooperative and joint work" (Sebr), which has long characterized Vepsian worldview.

And to answer to the questions raised by Henne-Ochoa and Bauman (2015), who is responsible for saving the language?, it evinces that throughout time and for different reasons a diverse sebr has been responsible for its maintenance and preservation (cf. Puura and Tánczos 2016). Different epochs characterized by different ideologies, the work of present and past scholars, the miscellaneous communities along with their epistemologies and practices, policy makers, and activists are all equally responsible for its further developments.

\subsection{Why "Saving?" And Saving What?}

When considering the Vepsian revival movement, therefore, a couple of questions come to mind: why should this language be preserved and maintained? And, what is it that contemporary scholars and activists are trying to maintain and preserve? 
More generally, why should speaking a language be secured at all? When addressing this question, the academia splits into two. There are those who neglect the importance of the variety of languages and provide a Darwinist explanation (e.g., Mufwene 2004) - i.e. they apply the evolutionary theory to languages. This is what Grenoble and Whaley (1998) refers to as the "ideology of contempt." Contrarily, the concern toward revitalizing endangered languages has increased massively in the last few decades. This issue has been addressed not only as a topic of interest by the (socio)linguists but also as an international issue. Furthermore and most importantly, more interest has been shown by those speech communities whose language is said to be in the process of shifting completely. Why has such an issue become so burning hot? What would be lost?

The first reason that comes to mind is the emotional constraints that not speaking in the heritage language would bring about to the minor ethnic communities. As elucidated by the Dauenhauers $(1998,63)$, who provided examples from Southeast Alaska, "Native American individuals and communities are plagued and haunted with anxieties, insecurities, and hesitations about the value of their indigenous language and culture." Concerns about the health of the speakers is indeed discussed among scholars who investigate language endangerment issues (to name a few, Bals et al. 2011; Hallett et al. 2007; Hunter and Harvey 2002). Mithun (1998) claims that together with language loss human beings would lose part of their creativity; Hale (1998) stretches this argument by stating that not only creativity would be lost but also human intellectual abilities. Beside language diversity, Saarikivi and Toivanen $(2015,27)$ claim that language loss would entail loss of human, cultural diversity.

There is an overall consensus among academics and activists that ways of speaking (and writing) should be maintained and promoted. In general, Veps from rural and urban areas claim that it is important to speak in their heritage language. Predominantly elderly Veps have claimed to feel closer to their emotions and to better express what they feel when they speak in their heritage language-Russian does not feel quite the same, even when they are entirely fluent in it. Urban dwellers who have learned Vepsian at school and university see in speaking Veps a way to link to their grandparents, village life, and to re-discover their roots. However, ways of promoting the "endangered" languages and what outcomes should be achieved appears to be often fragmented and not always as clear and straight forward as initially thought (see Chapters 7 and 8). The promotion of a standard language, literacy, and more recently the use of new technologies (such as the computer) and online social tools have gained more and more weight within revival movements the recent years. Whether consciously or not, superdiversity has indeed become a key concept within narratives of language revival!

Superdiversity with its focus on literacy, online communication, and multilingual and multinational reality has been at the core of the political action of Vepsian activists and academics. What seems to be at the periphery of 


\section{Multilingual Russia}

their action, in part due to the response of the political bodies with whom they engage, finds its origin in the Romantic studies and bucolic environment where Vepsian villagers (used to) and still live. I suggest bringing this back as both aspects of contemporary language ecology should be taken into consideration for effective revival measures. And I invite scholars (and policy makers) not to exoticize village life not to neglect and discard it as "non-existent," and the dwellers of rural settlements as speakers of a "dead" language. Preserving and maintaining ways of speaking which are dominant in rural locales does not mean idealizing the past, and wanting to return to an idyllic (and idealized) lifestyle and, thus, never wanting to change. Instead, it means valuing active engagement with the territory and its human and non-human inhabitants, and allow for change in this rural space. Veps have demonstrated readiness to move on and change (see also Chapter 5 on appropriating new ways of speaking), adding new practices and expanding their sebr. It is clear that supporting Vepsian ways of speaking in rural locales as well as literacy aims not to reduce the experience of the inhabitants of Russia to a monochrome lifestyle-i.e., the Russian dominant urban life.

$$
* * *
$$

This chapter has brought to the fore an already familiar tension between traditional and modern practices within revival movements. Indeed, such a tension becomes particularly problematic when considering which practices are worth promoting within revival programs. Should one promote practices that are considered obsolete and old in a world that advances and changes often in unpredictable ways? Should one promote new relations and usages of the language discarding the more traditional ones as an index of the idyllic, bucolic past that many feel has long gone?

Some studies have observed how new forms of migration and the introduction of online communication have contributed to the formation of a superdiverse language use (Blommaert 2013). Such superdiversity is often founded on the written mode of a language and dominates urban locales, thanks to the available infrastructure there. Whether consciously or not, many revival movements have primarily invested in this direction by introducing a codified, standardized form of the minority language, and promoting its use online as well. This mode of action has also concurred with the belief that a revival program is successful when generational transmission is guaranteed; therefore, engaging with new technologies, social network, and online activities matches set goals.

I intend to challenge this direction, not only as the possible one but also as the most acceptable one, for a number of reasons: first of all, one cannot forget the long-standing tradition of academic endeavors and relations between Finno-Ugric peoples thanks to which it has been possible to let local epistemologies and ontologies emerge; thus, it has been possible for the scholars to identify the reasons why certain practices (also linguistic 


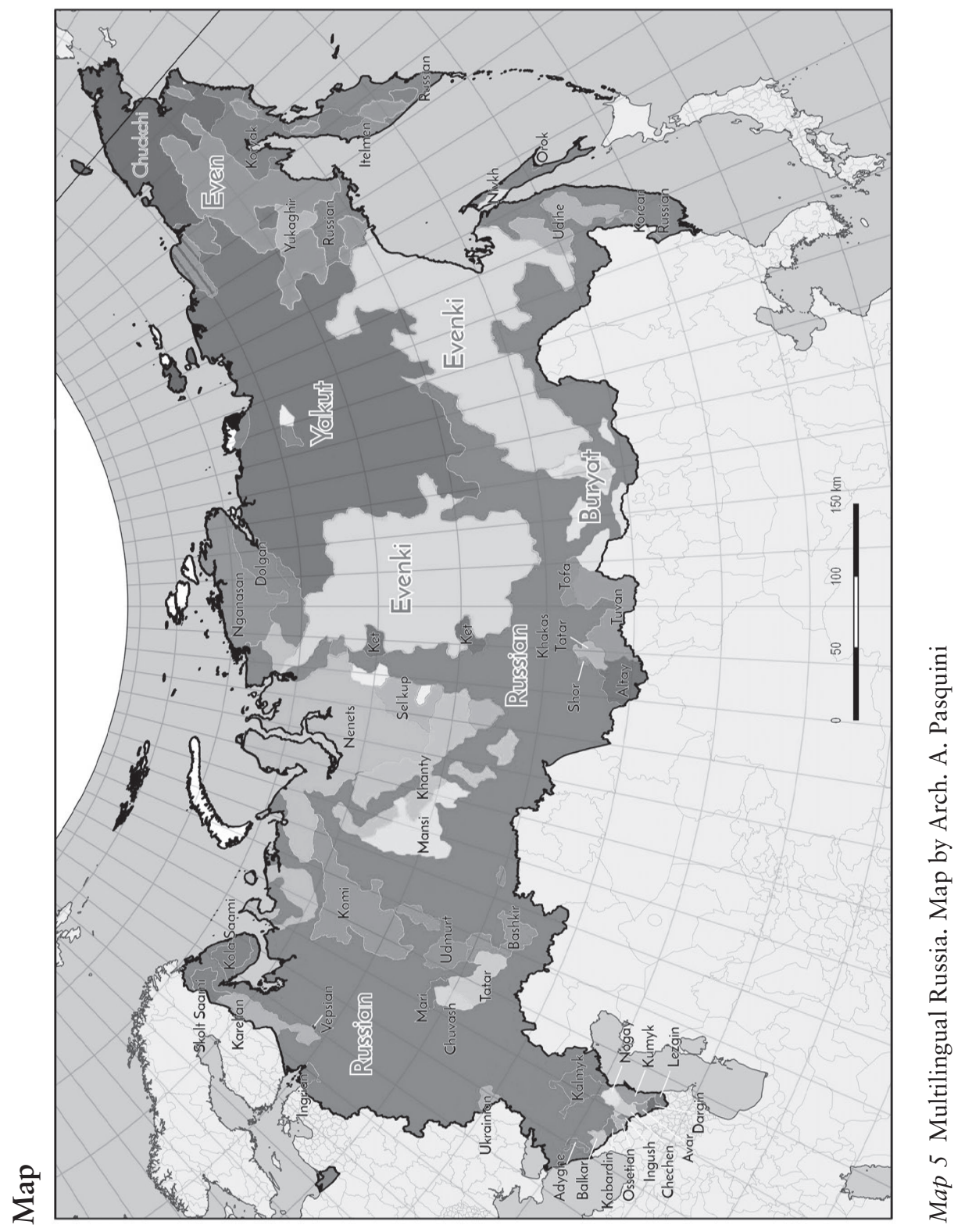




\section{Multilingual Russia}

practices) are maintained and others are not (for more details see Chapter 5). Such diachronic approach allows for comparison and a better understanding of current practices, too.

Second, the work of activists and scholars sits in place and emerges from the relations with the ecology in which they find themselves. If scholars of Finno-Ugric studies during the Romantic period were driven by a patriotic urge, present-day academics and activists appreciate the need to have a more pragmatic impact in order to promote ways of speaking in both rural and urban settings. Such a practical attitude comes from an observation that promoting primarily the written form of the languages provided limited results. There is need for more institutional space where people come together and speak the language in urban locales, and there is the need to attract more people to the villages where the language is still spoken.

Third, nobody likes to be told that he or she is "old," "past," and "asif-dead." People speak the language in rural Vepsian settlements. However, such use appears exotic, since it often discloses relations of respect with the environment and its human and non-human inhabitants, such as the territorial masters, and reveals the power of language in certain practices, such as the pubeged (V. Enchantments) and lamentations which can be regarded as "un-modern" and backward. And the exotic aspect of these practices may create an unconscious link with folklore and linguistic studies that ruled academic debates more than 100 years ago. I argue against such perception since this "exotic" language use is still practiced and, hence, should not be taken as an indication of the "past." What's more, neglecting language practices that dominate in rural locales and are mostly manifested by the elderly would reinforce generational discrimination. Whereas, it is renowned that for a revival program to be successful, the elderly and often bearers of the language, play a key role (see Chapter 8 ).

For this reason, I suggest that success in the revival efforts can be secured only if the written and the oral modes of a language (i.e., multimodality) in urban and rural locales (i.e., "multispatiality") have equal voice within the revival movement. This is so since ways of speaking in the Vepsian heritage language have emerged and initially developed in the villages, according to local epistemologies and ontologies, and the written language has more recently been employed in published material and more modern technologies.

\section{Note}

1 Perepis. www.gks.ru/free_doc/new_site/perepis2010/croc/Documents/Vol1/pub01-01_02.pdf. 


\section{Revaluation of Language \\ Fieldwork as a Give-and-Take Phenomenon}

During a conference promoted by the Academy of Sciences in Petrozavodsk, I met Alessia Fornaci (pseudonym), an Italian researcher from a wellestablished university in Great Britain. At the time, she was investigating human rights in the Russian Federation, and after visiting the Republic of Karelia she was heading down south. Although I had heard about other researchers working in the Karelian territory, I had not met many during my fieldwork. And I had certainly not met any Italian social scientist! Besides speaking Italian, it was pleasant for me to engage with her in different discussions on our observations and on our different methodologies. She largely employed interviews and had a strict schedule on whom to meet, when and where, all of which she had pre-arranged before her trip to Russia. "I need such a defined timetable," she explained. "It gives me a sense of achievement. I cannot do what anthropologists do, just hang out and see what happens." We spoke Italian, so I translated this excerpt into English. Yet, she used the English phrasal verb hang out while explaining what in her opinion anthropologists do. I received similar comments by other scholars on different occasions. Of course, anthropologists do not simply hang out and employ random methods and strategies to collect their data. The word choice of hanging out has negative connotations, as it may appear that the researcher is doing nothing and being lazy, but there are potentially numerous positive outcomes from dwelling in the place of research, surrounded by the people with whom one is collaborating. I aim, therefore, to appraise the methods I employ as a researcher and anthropologist, hoping that it will foster understanding and cooperation among the different disciplines.

Extended fieldwork dominates the research practice of anthropologists where the researcher engages in a number of activities together with the locals and conducts participant observation. However, I should highlight that ethnographic approaches are common in other disciplines such as, for example, sociolinguistics, sociology, and social psychology. In line with current anthropological methodology, my approach is to do fieldwork that is basically ethnographic and responsive to local conditions, rather than predetermined categories. I show through my research findings that I have been 


\section{Revaluation of Language}

able to accomplish the goals set at the beginning of the research (and more) by being flexible and letting events shape the research process and results. This is particularly the case for language investigation, since language use and discussions about language occur very often once the researcher is present. Consequently, valuable data about language use and attitudes can be revealed in any number of situations that could not be planned in advance. Through my work in the Republic of Karelia, and the Leningrad and Vologda Oblasts, I began to appreciate the numerous and unexpected ways in which fieldwork changes and takes shape. Fieldwork continuously determines the path that my research on the Vepsian heritage language has eventually taken, and it does so in a continuous, dialogic reconsideration of pre-established research questions. I strongly believe that being critical toward oneself allows the researcher to maintain a curious eye, to re-invent $\mathrm{him} / \mathrm{herself}$ in relation to the main ecology in which scholars work, and to detect practices, ideologies, and attitudes which might have been discarded otherwise (cf. Siragusa and Arukask 2017).

Indeed, fieldwork was and still is a learning process (Blommaert and Dong 2010, 26-28) in which I and those with whom I work learn from and about one another. I learned routinized behavior with which I was not familiar by taking part and being involved in several events and daily activities. By observing how people interact between themselves in multiethnic Karelia, the Leningrad and Vologda Oblasts, I began to understand their shared system of values, outlooks, and language use. For this purpose, I begin most chapters of the book with an anecdote that is representative of topics, language use, language attitudes, and ideologies which I observe. In fact, such anecdotes are spread throughout the volume as ideologies, practices, and utterances are co-constructed in relation to the ecology in which these are manifested. Indeed, beside avoiding the use of the article "the" not to bound Veps in restricted sets of categories, I often employ anecdotes and vignettes in my written work which provide a description of the context where language and discussions around language use took place with the aim to present ways of speaking and writing in relation to the broader language ecology, as it emerges from the anecdotes. This approach to academic writing lines up with part of the literature which explores how to present people and their practices (Anderson and Smith 2001; Horton and Kraftl 2006; Pyyry 2013; Seigworth 2000), understanding that they arise where the data is created-since it is created together! By employing anecdotes, I contextualize speech events, avoiding bounded and more static representations of people, language practices, and metaphors. As I highlight later in this chapter, my presence also had an effect on social reality (Blommaert and Dong 2010, 27). Expectations were created around my persona, actions, and social symbolism. Fieldwork cannot be bounded to being physically present in the field since such expectations and dialogue continue and continue to develop also after physically leaving the field site. It is also important to be aware that upon the researcher's return to the field site there 
might need a re-adjustment to the new situations and shared views on the researcher's persona as a whole.

Therefore, I maintain that being open to the unexpected and engaging with the field in dialogic ways is the strength of the methods I adopt as a researcher investigating language use and revival. When social research provides these results, it succeeds not only academically, but ethically, philosophically, politically, culturally, psychologically-in other words, anthropologically as the social human remains at the center of the investigation (see also Hannerz 2004). In the case of language and language revitalization inquiries, it succeeds linguistically, too, since metaphors of language extend to the new situations and continue to respond dynamically to life events.

\subsection{Fieldwork in Social Research and Language Studies}

Fieldwork, ethnography, and anthropology have been debated as concepts in academic circles where the scholars appear to have reached the conclusion that they are different entities. As opposed to ethnography and anthropology, which comprise the analysis and writing of the data, fieldwork is when data gathering occurs. Anthropology as a discipline endeavors to unveil ontologies and epistemologies of human beings in the world we live in (Ingold 2008, 69). That is, it tries to explicate different ways of living, socially shared symbolism, knowledge, and practices of people. Ethnography, instead, describes "the lives of people other than ourselves, with an accuracy and sensitivity honed by detailed observation and prolonged first-hand experience" (Ingold 2008, 69). Ethnography literally means to write about different ways of living, cultures, and societies. The idea is to describe it the way it is, while engaging with the groups with whom the ethnographer works. Ethnographers describe multiple ways of living, addressing their social meanings. And these can be a combination of linguistic, gestural, kinesthetic, and visual resources which occur at the time of fieldwork (Heath et al. 2008, 21). Such descriptions gain more depth when a diachronic analysis supported by archival research is also in place (Siragusa and Arukask 2017). Fieldwork is a method that is central to qualitative inquiries (Patton 2003). Traditionally fieldwork involves extended periods of time living with the people, while simultaneously engaging with the imponderables of daily life (Malinowski 1922).

Generally Soviet fieldwork was carried out in the summer, which Dragadze $(1978,67)$ refers to as the "fieldwork season." Instead, I spent one whole year in Russia between 2009 and 2010, and have since returned to the field for shorter trips in different seasons. More recently, however, fieldwork has also taken a different shape and takes place at home. Yet, what unites the different fieldwork experiences are the creative and unpredictable directions they take, and the fact that fieldwork happens "as a real-time process" (Fabian 1979, 19). For this reason, ethnographers often carry out specific case studies, which become exemplar of "some phenomenon" (Dyson and 


\section{Revaluation of Language}

Genishi 2005, 3), without the illusion of providing theoretically universal truths (Patton 2003; Sapsford and Jupp 1996; Street 2001). And due to the dynamic nature of each case study, the ethnographer needs to adapt through a process of trials and errors in continuous dialogue with the surroundings and its inhabitants. When language is at the core of the research project, the researcher who learns it and starts using it will be strongly affected. Language as a mode of experiencing the world has a perlocutionary effect on the researcher who starts noticing different social dynamics and responding to them in new ways (Austin 1962; Ochs 2012). As I began to speak the Vepsian language more often and to understand its structural and symbolic nuances, for example, I began to appreciate a unique way of interpreting odd events and animal behaviors to make future predictions. An example of this is Koir ulaidab mugažo gor'aks, koir ulaidab požaraks (The dog howls with grief. It means there will be a fire) (Author's field notes, 2015). The prediction in this sentence is expressed by the translative case of the word požar (V. Fire): požaraks. I must admit that I began to look at the animals and certain events differently once I returned back home from the villages as I also started to open to possible interpretations and future predictions.

For the very same reason, nowadays fieldwork cannot be limited and bound to the place where the research initially took place. This might have been the case to a certain extent before the adoption of digital communication technologies (such as e-mail, Skype, WhatsApp, Google+, Facebook, and VKontakte). Indeed, this allows me to maintain frequent contact from afar. Yet the requirement that obscures the physical boundaries of fieldwork is that dialogue and engagement continue between the researcher and the people with whom he or she works. As a process, fieldwork continues to take shape even after I have physically left the site of research. Indeed, fieldwork refers not only to the time I spent in the Russian territory, but to the continuous engagement and dialogue with the people I met there, which is enabled by technology. Specifically, I maintain regular contact with Veps through the means of the Internet. I regularly take part in the meetings at Paginklub and meet separate individuals on Skype or Google+. Fieldwork in my research is a process of discovery, a learning process, for me as the researcher and the people with whom I work, where dialogue, confrontation, and cooperation continue to create new realities and symbols, both linguistically and otherwise.

Such unboundedness of the field applies also to the work that the researchers conduct in the archives. Between 2013 and 2017, I had the opportunity to mostly work in the archives at AKNTS (Archive at the Karelian Scientific Centre) in Petrozavodsk, ERM (Estonian National Museum) in Tartu, and SKS (Finnish Literature Museum) in Helsinki. Indeed, the work in the archives allowed me not only to add depth to my work but also to connect temporally and spatially with other researchers, people they engaged with in the field, and an overall different language ecology (cf. Siragusa and Arukask 2017). 


\section{Fieldwork and Social Research}

Thanks to extended fieldwork and frequent consequent short visits, I could become more sensitive to different cultural norms and worldviews due to the experiences shared in the field and an accurate observation of specific practices. I could only come near an understanding of these practices through close observation, work and communication and knowledge in context (Sayer 1984), and my firsthand and bodily experience. This understanding entails unveiling subconscious practices and/or discrepancies and tensions between actual practices and ways of talking about them (Candela 2005, 190; Ladson-Billings 2005, 133; Malinowski 1922). Indeed, observing habitus offered "a perspective on the not necessarily innocent nature of routinized behavior" (Blommaert 2005a, 233). The work in the field brought to the surface attitude, ideologies, and power inequalities. In the case of the Vepsian revival movement, fieldwork enabled me to appreciate some of the mismatches that exist between the promotion of Vepsian written form and Vepsian oral uses in rural areas.

Fieldwork also provides a unique tool to let the voice of the unheard come to light and to subvert power inequalities. The present work endeavors to reduce the distance between the policy makers and the population by presenting grassroots epistemologies and ontologies to the administrative decision makers (Heath and Street 2008). In this sense, fieldwork represents an anti-hegemonic instrument that can contribute to the re-distribution of political and social power (Blommaert 2009, 258; Hymes 1996). In order to achieve such results, though, I had to be very active both when physically in the field and while writing and presenting the results of my research. In the field, I often create situations where valuable data can manifest itself. And this was clearly appreciated by the local activists and scholars who were always pleased to meet me at the miscellaneous events they organized. Such proactive research represents the point of departure from which theoretical questions later emerge (Gilgun et al. 1992; Inghilleri 2003, 262).

\section{Fieldwork and Language Studies}

While all the aforementioned can be applicable to language investigations, fieldwork brings other distinct advantages to this type of research. When studying language use, fieldwork helps me as an ethnographer to avoid simplifying it, and acknowledge the complexity of the context in which people manifest and experience language-i.e., the overarching and multidirectional language ecology in which they find themselves. This way I can combine a structural analysis to language to its capacities to respond to the context (Hanks 1996) and, hopefully, foster cooperation and understanding among various disciplines, methods, and results. Fieldwork has allowed me to appreciate the attitudes, ideologies, and social dynamics, which contribute to language choices (whether conscious or not) (Philips 


\section{Revaluation of Language}

1972; Schieffelin et al. 1998; Wortham and Rymes 2003). The strengths of prolonged fieldwork are, for example, that I could closely observe tensions between language practices, self-perception of language use, and ideologies. During fieldwork I was able to investigate symbols, Vepsian language learning, language generational transmission, language attitude and ideologies, metaphors of language, frictions between the promotion of language and language use, verbal art for healing practices and socialization, and verbal interaction in human-animal relations. These are all constructed in contexts of social interaction. The language ideologies of Veps and other ethnic groups have come to the surface while attending miscellaneous social and cultural events, classes at school and university, visiting and returning to villages in Karelia, the Leningrad and Vologda Oblasts. Metaphors of the Vepsian language have come to the surface through participant observation, while engaging with the activities together with Veps. As I have been committed to those activities, I could discover dynamics involved in codeswitching phenomena, its hows and whens, and how this is intertwined with language revitalization.

In regard to language revival, engaging in fieldwork enables us to comprehend when and where the population resists (consciously or not) the revival efforts and may help activists intervene in more effective ways (Hornberger and Johnson 2007). Indeed, many scholars suggest presenting the results of the research to the language planning bodies, since this may lead them to adjust the trajectories of their revival procedures. ${ }^{1}$ One of the outcomes that this volume aims to reach is to inform policy makers about specific grassroots dynamics and language practices which have partly been neglected in the revival of Vepsian language.

On the one hand, language analysis may help activists, policy makers, and the general population to reach their revival goals; on the other hand, engaging in fieldwork studies also brings about unexpected advantages to the research and researcher (Lassiter 2005). Engaging in discussions about my own language use with Veps and the other groups revealed personal and entrenched positions and attitudes toward language choice and use. And this self-reflection helped me develop trust and honest relations with my interlocutors. Consequently, I could gain valuable data for my research, which I could not have accessed had I not engaged in fieldwork studies. The literature on language studies often mentions the need to be both reflexive and systematic in our work (Foley 2002; Sanjek 1990; Stocking 1984). I agree with Gilgun et al. (1992) in claiming that it is refreshing when the researcher gives voice to him or herself. This is especially necessary when the investigations deal with language issues, choice and use since it exposes the metaphors of language of the researchers and the people with whom they work. And it is also critical since the data is a product of the ethnographer's relationship with people (Bateson 1972, 21; Wagner 1975). However, I should clarify that I stand for a type of research, which is not obsessed with the researcher only but with the coming together of people. 
In this sense, the Vepsian notion of sebr as a community that works together matches my understanding of ethnographic and anthropological research.

\subsection{Fieldwork as a Give-and-Take Phenomenon: Re-becoming an Italian Svoya}

On the first day of my arrival in Petrozavodsk, I met Nina Zaitseva at the Academy of Sciences. As we were becoming acquainted with one another, she warned me that Veps are very proud people and that if they did not like me, they would not cooperate. Specifically, she warned me that if Veps did not like my scientific inquiries, the results of my investigation and the way I relate to them, they might simply discard my research and not be cooperative. From its very genesis the ethos of my research was, therefore, to aim to develop trust and to respect the will and worldviews of Veps, rather than detachedly impose pre-defined scientific targets and outcomes.

On account of this first meeting with Nina Zaitseva, I understood that my research depended on the level of trust that the Vepsian population and I could build together. This awareness put me on the spot, as I made the firm decision not to hide my agenda and research purposes, if I were questioned about them. Rather I decided to be transparent and discuss my reflections throughout the process (McNeill and Chapman 2005, 90). In my case, this conscious decision proved the right approach and it resulted in becoming an in-group member, a svoya (R. Their own) within the Vepsian communities. After my presentation on the dichotomy svoy-chuzhoy (R. Your own/ stranger) within the Vepsian language at the Vepsian ethnographic museum in Šoutjärv' in September 2010, a woman from the audience approached me and said, "Svoya, ty sovsem svoya!" (R. One of us, you are absolutely one of us).

Becoming a svoya did not entail my loss of identity, as the phrase "going native" may suggest (Fabian 1979). On the contrary, this process of becoming created the ground for real bonds and trust which enabled valuable data on language attitudes, ideologies, and use to surface. Indeed, my becoming a member of the in-group meant that Veps and I extended the sense of sebr farther. If the Russian population of the Republic of Karelia generally perceived my Italian-ness as close to their Russian-ness (possibly due to the assumed common level of enculturation), my presence helped Veps transcend the Russian-Italian bond and create an Italian-Vepsian bond, which they found useful for their revival efforts, for example, by involving me in TV reports, concerts, and so on. The semiotic social load attached to my persona allowed Veps to gain even more visibility and prestige among the multiethnic population of Karelia. In a similar fashion, Wertheim (2009) reflected on her presence among the Tatar activists and how her presence was used for revival efforts and the revivalist agenda. While Veps and Russians share the same territory, it often emerged that the Russian population felt that Italians were closer to their worldviews, culture, long-term 
literate tradition, and ways of expressing their emotions. However, I will show later that attitudes toward Italians can also be double-edged: if in general they are perceived as educated and cultured people, they may also be part of a Cold War rhetoric as the Western other and flame rivalry (see Chapter 7, Section 7.1). By embracing the "Vepsian cause," my persona had joined those who were generally felt as other.

What's more, such attitudes and curiosity about what it meant to be Italian had repercussions on my very own self-perception, especially at the beginning of my research in 2009-2010. Such discourse had an effect on me, which could be correlated to the perlocutionary effect described by Austin (1962) in that it did things, and modified the perception I had of myself and what I believed to be my own reality until then. The newly recognized Italian identity forced me to re-establish contact with my roots, which I had distanced myself from during almost ten years of living abroad. However, the Italian-ness I found myself confronted with differed from the contemporary Italian-ness with which I was more familiar. In the Republic of Karelia, Italy was often equated with music (i.e., opera and 1980s popular singers, such as Adriano Celentano), sunny and happy people, beautiful architecture, and a long-established abundant literate tradition. On my very first bus trip to Šoutjärv' the driver kept the radio on and many of the songs that were played were indeed in Italian: I was entering a space that felt both familiar and stranger! I later discovered that Italian music from the 1970s had in fact made its way through to the Soviet Union, possibly due to political connections with the "Partito Comunista Italiano" (I. Italian Communist Party), and many had attached positive memories to it.

Many respected me for using my heritage language as it lined up with their language attitudes and ideologies-i.e., by speaking Italian, I must have clearly felt closer to what I was saying. Ol'ga Zhukova warned her husband during her pregnancy, "Only Laura can say ciao to my belly." That is, people should speak their heritage language to a baby in its mother's womb, since only they can feel the power of the words they are producing.

The Vepsian population often used my presence to promote their revival movement within the regional and federal boundaries. Irina Baranova, director of the folk ensemble, Vepsän Hel'm (R. Vepsian Pearl) stood up on stage at the beginning of our concert in December 2009 and claimed that it was "very important to see how an Italian researcher had come from afar to study our Vepsian language and culture!" It is important to stress that my Scottish academic affiliation was only occasionally discussed. Indeed, during my doctoral studies I was affiliated with the University of Aberdeen. This seemed not to serve their revival purposes since it did not provide the right symbolism. Although this was never clarified to me, I suspect that the bond with Italy might have been due to the popularity of Italian music in the 1970s, its longstanding opera tradition, and because Italy is a southern country and a beautiful holiday destination. Instead, Scotland is yet another northern country; hence, less exotic. It is also small and peripheral while Italy is heir to Roman 
Empire and birthplace of Renaissance. Also, I look stereotypically Italian and not stereotypically Scottish. Irina Baranova later confirmed that my presence on stage indicated that there was international interest for their cause and that I should continue to perform with them, despite my vocal qualities! "If they see that somebody from abroad comes here to study Vepsian, the regional and federal administrations may become more interested in us," she concluded. Similarly, Nina Zaitseva during a seminar for the teachers of the national languages in the Republic of Karelia addressed my presence to inform the teachers about the advantages of being multilingual.

My presence, therefore, matched some of the goals of the activists who have been working on gaining political and social visibility since the late 1980s. As a matter of fact, four articles about me were published in the local newspapers in the first year of my fieldwork. In June 2010, I made an appearance on the front-page of Molodezhnaya Gazeta Karelii (R. Youth Newspaper of Karelia), in August 2010 and 2011 in the Vepsian newspaper Kodima (V. Fatherland), and in November 2010 in the magazine Carelia. Furthermore, the journalist Valentina Kozhevnikova whom I had met through my Italian network in Petrozavodsk produced a report on my work with Veps in November 2010. This report reached the federal TV channels. Ol'ga Zhukova remarked during a conversation with her former students, "it is only thanks to Laura that Veps were able to appear on the federal channels." Thanks to this report, I also received an invitation to participate in a TV program on language use in Šoutjärv' in December 2010. While living in St. Petersburg, my Vepsian friend Yuliya Naumova watched the program and later informed me how she had appreciated my stand on the Vepsian babushki (R. Grandmothers) and their role within the revival of Vepsian. During the program, I defended the position of the elders in the villages. I claimed that many TV reports tend to present a quick (and often inaccurate) account on the status of language use in rural areas. By doing so, they neglect the fact that the elders still speak Vepsian there and they also reinforce suspicion about the results provided by the Vepsian revival movement among the multiethnic population of Karelia. Many more radio, TV, and newspapers appearances took place when I returned to Karelia, the Leningrad and Vologda Oblasts in the following years.

\section{Give-and-Take Phenomenon: Vepsian Language}

On more than one occasion, my presence determined the language choice of my interlocutors. Observing such practices helped me understand differences in generational language use and ideologies in both urban and rural areas. In Šoutjärv' Natal'ya Ankhimova, director of the local Vepsian ethnographic museum, saw the TV report on my research and later admitted that she did not expect me to be able to speak Vepsian (she said this in Vepsian). From that moment onward, she made an effort to use only the Vepsian language with me, despite the presence of Russian-only speakers. However, she 


\section{Revaluation of Language}

adopted the standardized variant of Vepsian instead of the northern dialect that indicated her political awareness of the Vepsian revival discourses. As indicated by Novozhilova (2006), this is not surprising as in her opinion, middle-aged Veps, aware of their partial competence in Vepsian, stick to a more "pure" version of the language trying to avoid loanwords. In Kalag', pensioner Valentina Mironova spoke Vepsian to me all the time based on the perception that I could understand it. However, she spoke only Russian in the presence of Russian speakers. Similarly, Galina Lokkina and Svetlana Ershova in Kurb explicitly asked me, "You do not mind us speaking Vepsian, do you?" (in Russian) and continued to converse in Vepsian among one another. As my research progressed and I became more fluent in Vepsian, the villagers made an effort in speaking their heritage language to me, as was the case in Pondal in summer 2015. Such language behaviors helped me also identify localized and generational differences in language use.

The need to speak Vepsian emerged from conversations in Petrozavodsk during my very first stay in 2009-2010. There, most often I conducted my conversations in Russian and many of the young Vepsian speakers who had learned Vepsian at university expressed the need to "be speaking Vepsian more often" with me. When my Vepsian vocabulary failed in certain topics, we shifted to Russian. Most often our conversations in Vepsian occurred through the social network websites (e.g., VKontakte), as I had the time to look up words in the dictionary and they could write in Vepsian, having studied the codified version of Vepsian.

My presence in the field, therefore, often instigated specific language uses that revealed language attitudes and ideologies. Such observations helped me frame these language practices theoretically and appreciate generational differences attached to different ideologies and experiences of language. Overall, however, fieldwork helped me appreciate that the Vepsian language is experienced differently in urban and rural areas and that such experiences are linked to language attitudes and ideologies as well as past and present experiences of the language and future expectations.

\section{Extension of Svoy, a New Sebr}

The adoption of new technologies and social network sites, such as the Russian page VKontakte and Facebook, and also Skype and Google+ have facilitated maintaining contact with the Vepsian communities and continuing my investigation of written and oral Vepsian practices from afar. This written and oral correspondence has also blurred the physical boundaries of fieldwork and extended the metaphor of belonging to the in-group to distant lands. I began to understand that I belonged to this expanded in-group when I was asked to provide an update on the other Veps, often living in the same city. Have you heard from such and such person? What is (s) he up to? and Who are you in touch with? What have they told you? These questions often occur during our Skype conversations. I am often asked to provide an 
update on various events taking place in the Republic, and to draw together those who are not frequently in touch. Fieldwork never ends; instead, my distant positioning induces further considerations on attitudes and ideologies both on the language and other social semiotic resources.

Being away from the field site acquired also an activist symbolism. ${ }^{2}$ Sotrudnichestvo (R. Cooperation) and sebr (V. Joint work, team, community) became in this sense key concepts. The Vepsian scholars and activists particularly appreciate that I represent them at international events by presenting my work on Vepsian. They are grateful since, through my presentation, I am advancing their case. They also show gratitude for the fact that I try to be as much available as possible when asked to provide some help, often in the form of translation. In summer 2011, Zinaida Strogal'shchikova also invited me to write two articles, one for the Vepsian almanac, Verez Tullei (V. Cool breeze) and one for the edited book, Vepsy i ikh kul'turnoye naslediye: svyaz' vremën (R. Veps and their cultural legacy: link of time). Ol'ga Zhukova translated the first article into Vepsian. In 2015 I also wrote an article for Lonin Chteniya (R. Lonin Seminar) after a conference in Šoutjärv'. Furthermore, Zinaida Strogal'shchikova and I cooperated on the English publication of the readings of the Fifth Finno-Ugric World Congress upon my return to Aberdeen in January 2012. I later translated into English the subtitles of two films made by Larisa Smolina and Vladimir Slavov-i.e., and Paimnen torvut (The Magic Horn) in 2014 and Sel'ktas vedes kala kokib (Fish bite in Clean Water) in 2015. And there has been many more occasions for collaboration, given our common goals to present the Vepsian language to broader audiences. Since 2009 , there have been innumerable accounts of our cooperation and one of them is, of course, the realization of the present volume.

Overall, my activities as an ethnographer (i.e., my writing and engaging with academic universities) are perceived by the Vepsian activists as promotion of the Vepsian language. In 2011, I spent four months at the University of Oulu where I compared my work with that of Heini Karjalainen, a Finnish linguist, whose research focuses also on the Vepsian language. In June 2012, I became acquainted with Professor Eva Toulouze, a specialist in Finno-Ugric language studies at INALCO in Paris, and since then we have been cooperating on various publications. In January 2013, I took on a post-doctoral position at the University of Tartu and this has facilitated further cooperation with the Estonian researchers who work on Vepsian matters, such as Madis Arukask at the University of Tartu.

\section{Vepsian Ways of Speaking: A Svoy Land and Language}

Paxson's (2005) study of Solovyovo, a remote Russian village in the Smolenskiy Oblast, demonstrated how the Russian words svoy (One's own) and svoboda (Freedom) are structurally and symbolically linked and opposed to the concept of chuzhoy (R. Foreign, stranger). She observed how the Russian villagers feel safe and free only when based within their 
own svoy. Svoy alludes to what is familiar and known, both symbolically and physically. The common root svo- in svoboda and svoy enabled her to identify and later establish such connection. In her comparison between different concepts of freedom in Russia, Humphrey (2007) reaches the same conclusion and identifies the links between the words svoboda and svoy as a substratum for the Soviet rhetoric of inclusion and in-group. In the period of stagnation of the Soviet Union, different biosocial models of ethnicity and social relations emerged: one of the key scholars to develop such a model was Lev Gumlyëv, still very popular in academic circles today (Bassin 2016), who actively employed the dichotomy svoy-chuzhoy to explain different ethnicities. The use of such polarity in academic discourse indicates how deeply rooted and used it is in Russia at all levels of society. A person can be free and feel protected by those who share the same habits, traditions, and symbols. By contrast, entering the chuzhoy exposes the individual to a more vulnerable position. In other words, chuzhoy corresponds to the lack of svoy (i.e., safety, protection, and freedom). The forest, where one can get lost, can be in this sense felt as chuzhoy. A journey to an unknown city can be felt as chuzhoy. And what is chuzhoy can be dangerous and affect people negatively; for example, it is often believed that being in contact with foreign eyes can cause illness. A foreigner can also be perceived as chuzhoy.

Not surprisingly, this svoy-chuzhoy dichotomy is shared among the Vepsian population, given the long-term contact between Russians and the indigenous groups of Northwestern Russia. Features of the Vepsian language include the in-out (svoy-chuzhoy) dualism, such as the word coga, which means corner inside the house, and the word saum, which means the corner outside the house, on the street, facing the outside world. The word $u k s$ ' means the door inside the house, whereas the word verai means the door facing the street. Interestingly, the word verai finds its roots in an ancient Slavic word and can be related to the Russian word dver' (Door). Linguistically and metaphorically, it also indicates a link to the outer world where Russians are found.

Despite this common polar view, what strikes me as peculiar is that it generally gains a different symbolism and indexicality between the Russian population, with particular emphasis on those living in urban centers, and the Vepsian villagers. In this Northwestern Russian territory, the Russian svoychuzhoy polarity often indicates that many decisions and actions are, in fact, driven by a sense of fear. Entering a foreign land means putting oneself at risk. The forest, for example, is a place of danger and venturing into it can cause trouble and even lead to death, as one is exposed to foreign forces (Paxson 2005). I often received amazed looks when explaining I would be conducting my research in the villages. During an informal chat with Irina Kormanova (pseudonym), a Russian city dweller, she claimed, "the people in the villages know how to live there, but that would be impossible for us [urbanites]. We would die." During my fieldwork, many Russians living in the city demonstrated to be very resistant to anything foreign, unless they 
deemed it as civilized and sophisticated as Russian (such as my Italian-ness, at least for most). And yet being a "Westerner" could also be felt as a threat and be taken as rivalry (cf. Chapter 7, Section 7.1). Such prejudiced attitudes often referred to practices shared among the indigenous people of this northwestern part of Russia. So, while I was looked with curiosity and interest when I spoke Italian (for example, on the phone), my Vepsian and Karelian friends perceived to be looked at suspiciously when they spoke their heritage language. Ol'ga Stepanova (pseudonym), a Russian city dweller stated, "I do not like it that your Karelian friend wants to speak Karelian even during public events. I would immediately think that she is speaking about me and that would make me very uncomfortable." Some of the more active native speakers of Vepsian (and Karelian as in this example) respond to this type of criticism:

If I do not speak my heritage language when I meet somebody who knows it, when should I speak it? Why do people start immediately thinking I am talking about them? I simply want to be given the opportunity to speak my heritage language!

Others give up, instead, and embrace the Russian language as a sign of reassurance that they are not saying anything bad about anyone else and/or even employing some sort of black magic. The fear of the other and suspicion of what is chuzhoy pushes Veps to speak Russian in the presence of Russian speakers. One of the maintenance ladies of the public banya (R. Sauna) in Petrozavodsk where I used to go quite frequently in 2010 warned me, "Be careful! In our family, we do not like not understanding what they say. That can be dangerous! The way they look at us can also be dangerous.” The evil eye also indicates fear of the other.

On the other hand, the Vepsian villagers often showed themselves not to be fear-driven in their actions, despite also abiding by a dual svoy-chuzhoy ontology. This is evident both in the ways of speaking that they adopt and rapport with the world. When an external element comes along, they tend to ponder whether or not it can be included within their svoy. They usually make carefully such considerations. Both Veps and the other neighboring groups depict Veps as ostorozhnye lyudi (R. Careful people) who take time to think before taking a decision. Once the decision is taken, they take responsibility for the given word and stick to it. The Vepsian word for responsibility, vastusenpidänd appears etymologically connected to the word vastuz which literally means both "answer" and "meeting," and, thus, implies that responsibility can be credited to someone only after some kind of encounter has taken place and implicitly a decision has been made (Zaitseva 2009). ${ }^{3}$ It seemed to me that ultimately Veps do not put a limit to what is svoy as long as this includes common goals and objectives, and joint work (Sebr) (Figure 4.1). So such a notion can encompass people and vast territories. In Vepsian the word külä (Village) refers not only to the actual village which developed around the church but to a larger 


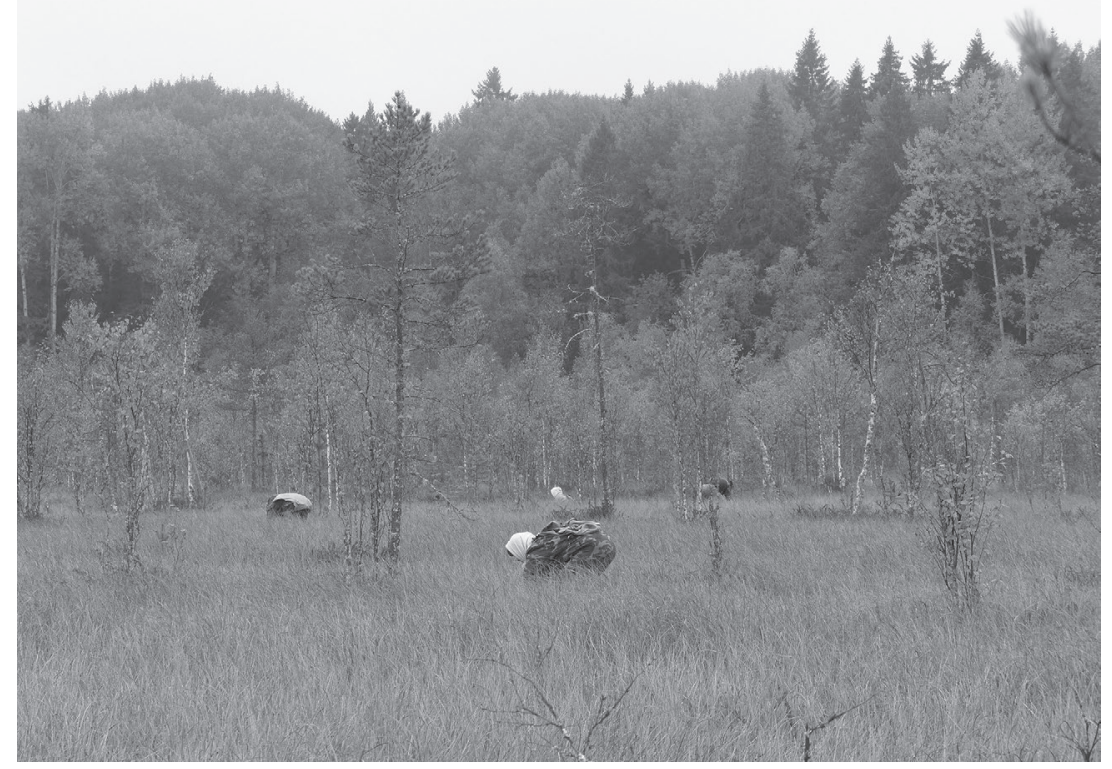

Figure 4.1 Gathering cranberries in a swamp near Pondal in 2013.

territory which comprise forests, rivers, and lakes, which characterize the land where Veps dwell, conduct their gathering activities, go fishing, and hunting (Mullonen 2005, 2007, 51-52) (Figure 4.2). ${ }^{4}$ The words derüun (Central Vepsian dialect, a loanword from the Russian word derevnya) and posad (Northern Vepsian dialect), instead, indicate the village where there is a pagast (Churchyard). Having grown and lived in such territories, Veps do not perceive them as foreign, although they may encompass some level of danger and, therefore, one needs to relate to them carefully. These locales are part of their extended svoy. Admittedly, one has to conduct him/herself with respect not to upset the forces present in this territory, including their masters. This comprises certain verbal practices that show how Veps humbly comply with the territorial masters, spirits, and animals living in such a land. An example of this is the use of puheged (Charms, enchantments) to appeal the territorial master to engage in some activities in its territory. This is how Veps may ask permission to drink water in the forest:

Mecaižandeižed, mecaemägeižed, Ankat minei vedut!

Blaslovigat otta!

Hosts and hostesses of the forest, Let me drink your water!

Take my blessing!

Journal 25, tape 3197, number 381989 (Pondal). Kuznetsova and Lukina interviewed O. P. Gerasimova. $^{5}$ 


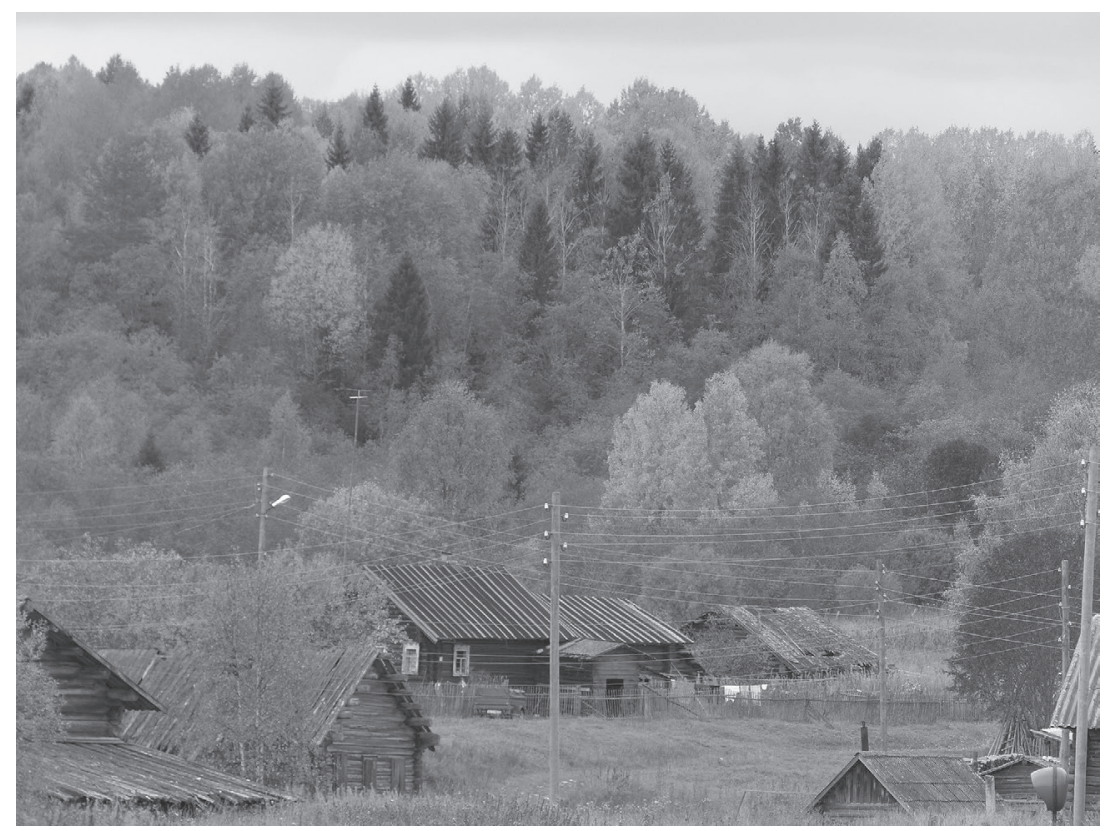

Figure 4.2 Slobod, a sub district (ag' in Vepsian) of Pondal in the Vologda Oblast. I took this picture in September 2013

Such carefulness is seen in the way villagers speak of and to the other inhabitants of the Vepsän ma, whether or not they are human, such as the animals, the spirits, and the territorial masters. I should point out that Veps tend not to distinguish the animals in domestic and wild, but rather to separate them depending on the territory which they usually occupy (Vinokurova 2006). Kodizivatad are the animals which live in the section of the house inhabited by humans, such as cats, dogs, but also the cattle which lives in the cattle-shed-de facto an extension of the house which is built "under the same roof" (Strogal'shchikova 2008a, 113-119). Those animals who permanently live in the forest are called mecživatad (literally, "animals of the forest"). Regardless of the territory in which the animals spend most of their life, they are often believed to speak and understand Vepsian. Therefore, Veps employ the language carefully when talking about the more dangerous ones, such as the bear, which is not referred to directly, but is often called käpš, sur' oc, mecižand or bukač (V. Paw, big forehead, master of the forest or beech) (notes from the Vepsian film, Živatad vepsläižiden elos, Animals in the life of Veps). Similarly, I noticed that snakes are not directly mentioned in an enchantment (V. Puheg) to cure from a snakebite that I was told in Kurb. Rather, in the enchantment, they are referred to as tübkjereine per-pereine, where the first word has no meaning and the second means that 
there is something behind the person who speaks, as Ol'ga Zhukova helped me decipher. Veps also interact in their heritage language with the animals during their visits to the forest and ask them information about the future. The cuckoo is believe to predict the life expectancy of a person so, one may ask how many years (s)he will be left to live and wait for the cuckoo to respond-each creak that the cuckoo makes corresponds to one year. Admittedly, such behavior is also found in other villages that are not traditionally Veps, due to frequent contact, as demonstrated by Loginov (1993). People listen very carefully to the messages given by the animals, either oral-such as the creak-or not. An oddity in the behavior of an animals or even their presence in one's dream may, in fact, bring some useful information that the locals will pay particular attention to. For example, in 2015 in Pondal I was told that, Naku koir, koir unes näguse keks, ičiiž koirrodsvennikaks, ken-se rodn'a. A jesli veraz koir, vs'o ravno znakomida. Koir hüväks näguse. Siga näguse-načal'nikaks (If you dream about your own dog, that means a relative. And if [you see] an unknown dog [in your dreams], this is a good sign in any case, you will get acquainted [with someone]. But to dream a pig refers to your boss.) I have underlined the nominal translative case, which indicates what is expected to happen. The animals hanging out in the inhabited territory of the villages are also told to be speaking Vepsian: kaži miangub (V. The cat mews), lambaz bäläidab (V. The sheep bleats), kana kotkotab (V. The chicken clucks) are some examples of the use of onomatopoeia in Vepsian when reproducing the sounds made by the animals (Figure 4.3).

As such the animals are not chuzhyye (R. pl. Foreign), and should not be feared, but addressed carefully to maintain relations in good terms. During my visit to Marina Kapustina in Kalag' in 2010, she invited me to take a walk to the lake side. Just as I was leaving the house, she advised me to "be careful" as there might be some "snakes, bears, and wolves on the way." Yet, she insisted, "Go, go, and enjoy!" I did not quite appreciate what she meant with be careful and after walking for a few hundred meters outside the village I headed back to the village. Her reference to carefulness became clear on a different occasion as I was gathering berries with Galina Lokkina in the forest near Nemž. It was a hot summer and the mosquitoes were biting us, especially in the swamps close to the lakes. "Do not worry," she said. "You need to speak to the mosquitoes and tell them söundou södaslet them eat us [in Vepsian] - and we will be fine." So, one is safe when speaking Vepsian to the animals and other creatures. As I came out of the forest completely covered in bites, however, she reconsidered her claim and asserted, "Evidently you are still chuzhaya [R. 'Foreign'] to them." 6

Besides the animals, Veps also respect and interact with the territorial masters and miscellaneous spirits found there. The territorial masters carry a name that epitomizes their role and function. Both the Vepsian ways of speaking and actions reflect a very respectful attitude toward those entities, and these often materialize in simultaneous language and physical interaction 


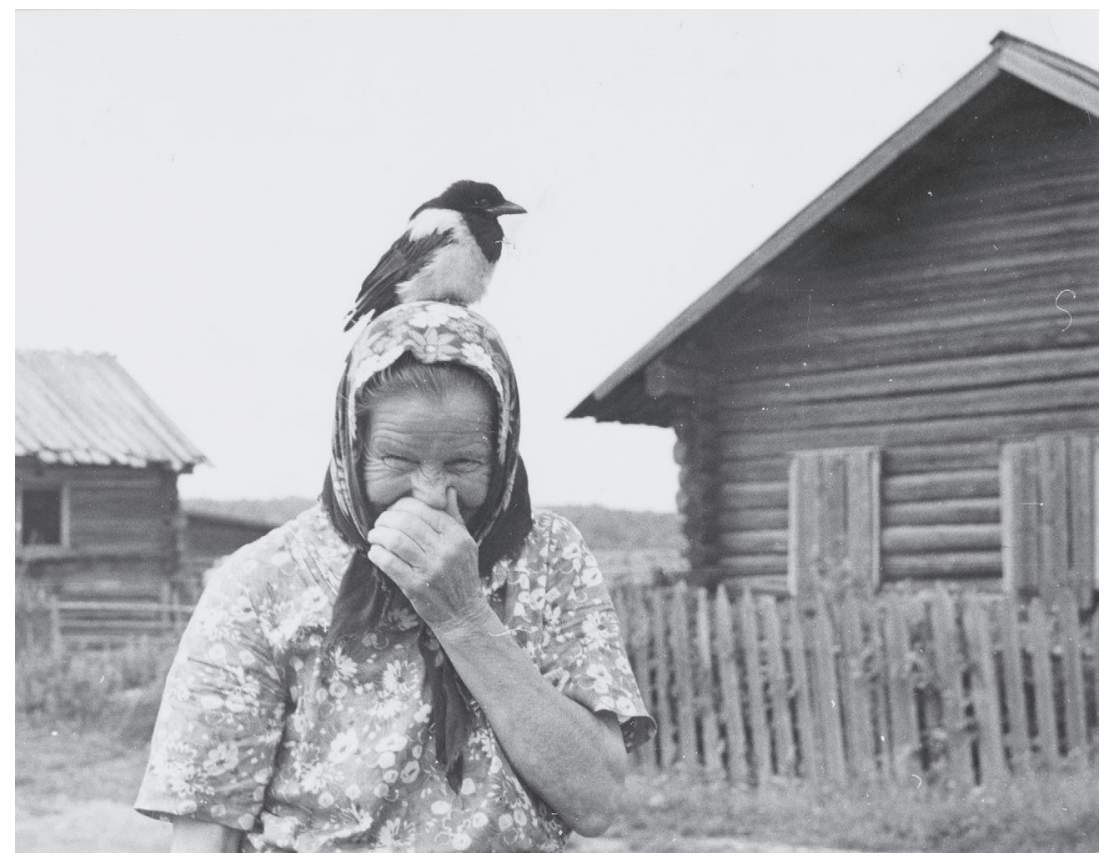

Figure 4.3 During an expedition to Vepsian villages in 1974, the researcher Lepp Lembit took this picture of a woman with her magpie friend (ERM FK 1729: 47).

(Ingold 2004, 330). For example, Galina Lokkina always touches the trees and thanks the master of the forest for letting her/us in and out safely while leaving the forest after gathering mushrooms and berries. When greeting a deceased relative or close friend at the cemetery, the attendees move their hands forward, touch the grave and whisper some words to the deceased. Similarly, upon departing from the lake or river, the fisherman should greet the water while touching it with his fingertips. This way, he guarantees himself a good catch for the next visit. Touch comes simultaneously with language. Specifically, "It is the corporeal field, as the embodiment of values and the setting of practices that provides the necessary interpretive frame for language" (Hanks 1996, 265).

Veps carefully select and employ words that will not upset the balance of the surroundings. The Vepsian saying, hüvä ma andab hüväd plodad (A good land gives good fruits) indicates that the respect for the land also promises future abundance and wealth. In Kalag' in 2010 Ivan Lokkin drew my attention to swearing words and curses. He smirked, "we do not curse in Vepsian. There are no swearing words in our language. If we need to swear, we use Russian words." His wife agreed. Veps claim not to use any 
foul language and/or inappropriate jokes. When asked to disclose some of Vepsian jokes on sexuality, Mariya Chirkova from Toižeg, refused, insisting, "There is none in Vepsian."7 As my research progressed and people got to trust me more, I was told that, however, Veps do swear and that they may simply not do that in front of me-which is highly possible, given my semiotic charge as a woman, an academic, and a Western individual. In Nemž in 2013, Alina Ershova (pseudonym) explained that people might indeed swear and lose their temper from time to time, but the words they use never sound as rough and rude as the correspondent Russian ones. When her mother was upset with her children, she used to say, "Sö sitad" (V. Eat shit!)—she laughed as she brought this back to her memory! "However this does not sound as rude and vulgar as it does in Russian," she explained.

So despite some similarities the social metaphors and indexicality attached to the svoy-chuzhoy dualism is shaded of different tones between the Vepsian village dwellers and the majority of the Russian population (mainly so, if living in the city). The Vepsian heritage language presents an experience of respect toward the land they inhabit and maintenance of peace which is not mainly driven by fear of the unknown and unfamiliar, but mostly carefulness. It shows that svoy can be extended to embrace more land and people. Despite the long contact between the Slavonic and Finno-Ugric groups, the Vepsian language is often felt as chuzhoy among the Russian population. This tension clearly acts against the revival of the Vepsian language, as it forces the Vepsian speakers to employ Russian in the presence of Russian native speakers and drop Vepsian. I would like to stress that such observations were only possible thanks to my fieldwork, as people are not necessarily aware of them and/or do not necessarily want to share such ideology-led behaviors.

\subsection{Social Research: A Matter of Preparation, Flexibility, and Improvisation}

I call into play a great deal of improvisation and openness during my fieldwork. This has enabled me to achieve such data, bonds of trust with several Vepsian communities, to create new realities together, to investigate language practices and ideologies, and to reach out to other communities outside of Russia. My fieldwork with Veps has been ongoing from the beginning of my doctoral program in 2009.

As soon as I began my first fieldwork in autumn 2009, a number of unexpected hiccups and wonderful surprises occurred. I was in forced exile in Italy for two months (i.e., February and March 2010) since my first visa for Russia could not be renewed in loco, despite being instructed so at the Consulate in Edinburgh. At this stage, I interrupted my studies and research, and was uncertain about when I would be allowed to return to the field site. I waited for an invitation from Petrozavodsk State University for two months. As the former director of the Institute of Linguistics, History, and 
Literature at the Academy of Sciences in Petrozavodsk told me, "This event introduced you to our Russian bureaucracy. This is what we face every time we want to obtain something." A second change of plan involved moving continuously back and forth between the villages and the city between 2009 and 2010. I had originally planned to reside permanently in the city for 4-5 months and then spend the remaining months in Kalag' only. This change was mainly due to invitations I received to participate in miscellaneous events both in rural and urban areas. Although in my notebook I kept track of the goals I wanted to achieve on a particular day/week/month, it often happened that some interviews had to be deferred in order to allow other events to take place.

My initial stay in the city in 2009 followed the steps I had pre-arranged from Scotland. Indeed, on the very first day of my stay in Petrozavodsk, I met Irma Mullonen and Nina Zaitseva at the Academy of Sciences and Ol'ga Zhukova at the Baltic-Finnish and Finno-Ugric Faculty of Petrozavodsk State University. With their help, I made contact with other members of the Vepsian community in the city. The Centre for National Cultures also represented a good departure point, and I did not know about its existence until I arrived to Petrozavodsk. Here I began to work with Vepsian activists of different ages and backgrounds, although mostly these were women, given that the educational and cultural spheres are often covered by them.

By contrast, what I did in the villages between 2009 and 2010 was entangled in unplanned procedures. I used the snowball technique via acquaintances in the city. My village gatekeepers helped me reach out to the other villagers. At times, they arranged phone calls and meetings or interviews for me. On other occasions, the villagers themselves showed interest and curiosity once a new face had made an appearance in their neighborhood. In Kalag', for example, some village dwellers expressed curiosity about "that devushka [R. Girl, young lady] with whom you [Marina Kapustina] were walking along the main road this morning" (Figure 4.4). In my research proposal I had proposed hanging a poster with my details in key places (such as local shops and post offices) to reach out to the village inhabitants. This strategy proved useless for mainly two reasons. First of all, a new face in the village could not long pass unnoticed. A pupil in Kalag' told me once, "my mum saw you from the window this morning." However, I had not bumped into anyone in the street at such an early hour. Second, I later realized that many of the villagers struggled to read and/or write in their heritage language, but many also in Russian. My poster would have not helped me reach out to them, in any case. However, this observation, contributed to my exploration on language use and influenced the path my work has taken.

Surprises and personal adjustments kept coming. After completing my doctoral studies, I obtained a position as a Research Fellow at the University of Tartu, Estonia. This research opportunity renewed my interest toward ways of speaking in rural locales and gave me the chance to work in local 


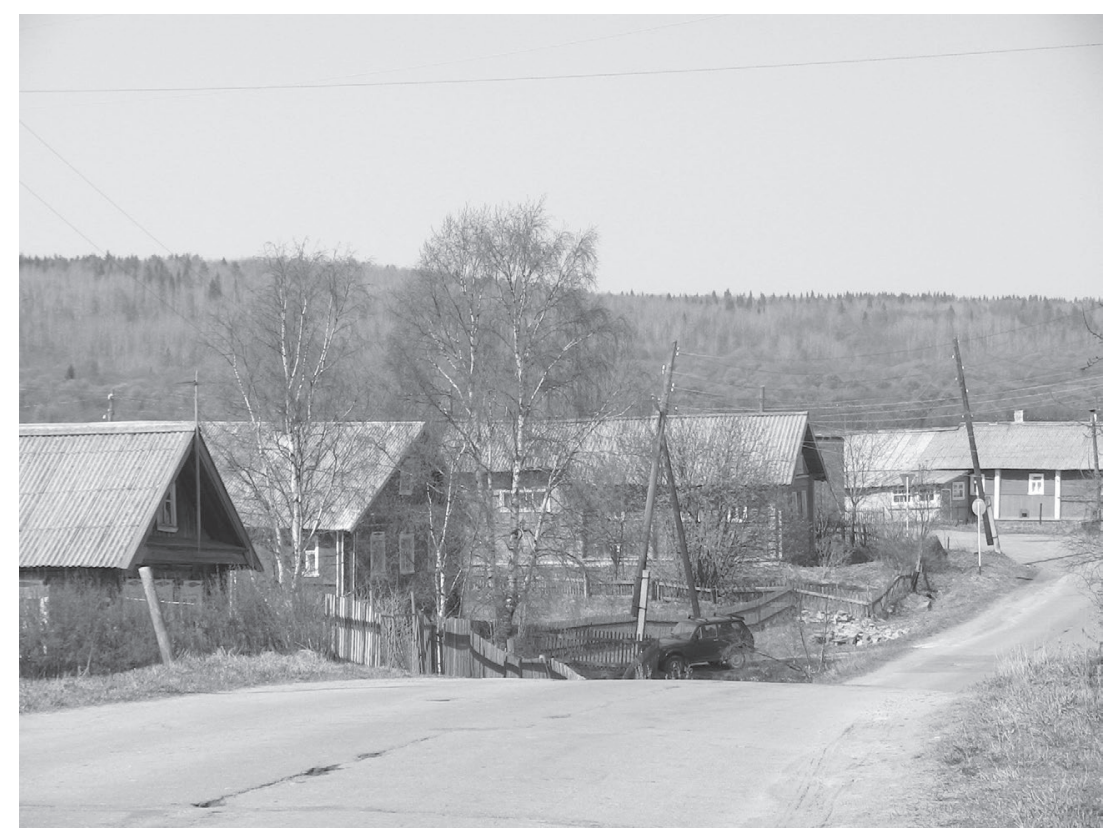

Figure 4.4 Main road in Kalag', Republic of Karelia. I took this picture in spring 2010

archives and add diachronic depth to my analysis. Besides, a new interest arose toward verbal art and the use of puheged for healing purposes that enabled me to shade the concept of power in language with new colors. Indeed, some of the villagers perform puheged in order to choose the land upon where to build their house, to heal someone who has fallen ill, to find lost animals (often the cattle in the forest or swamp), to protect someone from the evil eye, to settle disputes, and so on (see phono-archives at KarNTs RAN). This job was followed by a post-doc position at the University of Aberdeen where I investigated human-animal relations and ways of speaking to and about them. This last project allowed me to dig deeper into village life and language practices I could not focus on before, such as the use of the Vepsian translative case to make predictions after observing oddities in the behavior of the animals or the environment more broadly. Not only I could appreciate in more depth the convoluted relations between Veps, their ways of speaking, and other-than-human entities living in the Vepsän $m a$, but I could also reinforce a relationship of trust that is at the core of my ethical concerns in research practices. If my initial work with Veps was conducted predominantly in the city, the latter studies led me to spend more time in the villages of the Leningrad and Vologda Oblasts. 
Fieldwork, the people with whom I work, the academic ecology to which I relate, drives my methods of research and strongly influences the data I am able to collect. ${ }^{8}$ In other words, I continuously bounce back and forth between my original plans, renewed plans, and life events, which more often than not have opened up new unexpected doors.

\section{Data Collection in Petrozavodsk and the Vepsian Villages}

"Hello! I was just about to give you a call." I received this answer twice just before leaving my field site at the end of my first year of continuous fieldwork. Interestingly, though, neither of my interlocutors had contacted me by phone before, nor had I contacted them. They invited me to take part in some cultural events that involved Veps. By December 2010, it was clear to most of the Vepsian population in Petrozavodsk (and to some of the villages) that if Veps were involved in any event, I should be contacted to go and participate. Admittedly, such behavior continues up to now. This level of trust and engagement required setting a strong foundation for my work from the first day of my arrival. Long-term fieldwork enabled my presence as a researcher to become accepted and trusted.

Thus, I accessed multiple sites both in the city and in the villages (such as schools, universities, the Centre for National Cultures, festivals, dachas, etc.) in order to tackle all the multiple social layers of language use, attitudes and ideologies (Ricento and Hornberger 1996; Ricento 2005). In other words, I employed the "triumvirate of participant observations, interviews and document collection" (Hornberger 2006, 229; Hornberger and Johnson 2011, 275). I employed technical aids such as cameras and camcorders, only if agreed with the interviewed. Otherwise, during formal interviews, I took notes in a notebook-although this was not the preferred way of interacting neither for me nor for those I spoke to. Face-to-face engagement with people of all ages, preferably over a cup of tea, is what proved most useful, engaging, and resourceful. My interviewees provided their informed consent orally. More often than not, however, I also relied on my mobile phone, since valuable data continued to be discussed after the interviews had formally ended. I used the option notes on my phone and took raw notes there, which I later expanded on my laptop. This way, I did not interrupt the flow of conversations, since it looked as though I was sending a text message. Interestingly, while it was accepted that I-as a foreigner-used the phone to text more than to call, I noticed that the locals tend to call more than to write text messages. This observation along with others, spurred my interest and attention on the literacy-orality dichotomy that has shaped my present work.

Besides interviews, employing a modified social network exercise, my main data in the city came from observing and participating in the activities in which Veps were involved (such as concerts, festivals, cooking together, working at the dachas, joining sauna parties, etc.). ${ }^{9}$ The Centre for National Cultures in Lenin Square in Petrozavodsk represented my point of departure. 


\section{Revaluation of Language}

Here, I joined the ensemble Vepsän Hel'm and began reaching out to the Vepsian communities both in the city and in the villages, since most of its members had connections there, too. At the Centre for National Cultures, I also collected a number of leaflets and textbooks that were generously given to me as a gift. Document collection also took place at the National Library and at the Kraevedcheskyy sektor (R. Regional studies branch) of the National Library where Yuliya Zav'yalova introduced me to their intralibrary research database. Long-term participant observation of such activities enabled me to begin to understand the native worldview, engaging in discussions on topics that were important for them and observing language use, in both its written and oral forms (Boas 1940; Malinowski 1922).

I adopted similar techniques in the villages. Besides engaging in various discussions, my investigation in rural areas adjusted to the services available there. I was able to investigate language use with teachers and the heads of school in Kalag' and Šoutjärv', since the Vepsian language is taught there. In Šoutjärv', I could also approach the directors of the Vepsian ethnographic museum and the village library. Many conversations occurred in the teachers' room at school, in the local shops, and in the post office. My investigations in the Leningrad Oblast were possible since I was invited to stay at Galina Lokkina's house in Nemž where she introduced me to her family, neighbors, and attendees of miscellaneous events at the Dom Kul'tury (Figure 4.5) and at Svetlana Ershova's house in Kurb. Since 2013, I have also been visiting Vepsian villages in the Vologda Oblast, such as Pondal and Kuja, where I have taken part in any village activity, such as going to gather berries, fishing, participating in birthday parties and celebrations at the Dom Kul'tury, attending master classes on Vepsian crafts at school, and visiting the local museums (Figure 4.1 and 4.6).

I employ several technological tools, such as a camcorder, a camera, a laptop, and a mobile phone. I use ATLAS.ti software to store and organize the qualitative data. Throughout my fieldwork, I transcribe interviews and discussions that I have filmed with my camcorder. This operation provided three main benefits. First of all, it saves me considerable time transcribing once I have returned from the field site (Heath and Street 2008, 84). Indeed, transcription is often addressed in the literature as a pitfall for many researchers when they return from the field site (Duranti 2006; Dyson and Genishi 2005; Heath and Street 2008); that is, transcribing often becomes an excuse not to get down to business and engage with the literature, while still giving the researcher a sense of accomplishment. Second, while transcribing, I could practice my listening skills and learn new words in Russian and Vepsian. Transcribing helped common words and ideas to emerge from the data. Third, transcription often activated the development of ideas and triggered a reconsideration of some of the hypotheses I had initially fostered. In addition, my laptop enabled me to join Facebook and VKontakte where I could observe written practices peculiar to the younger Vepsian generations. This provided further data on written practices in Vepsian. My camcorder 


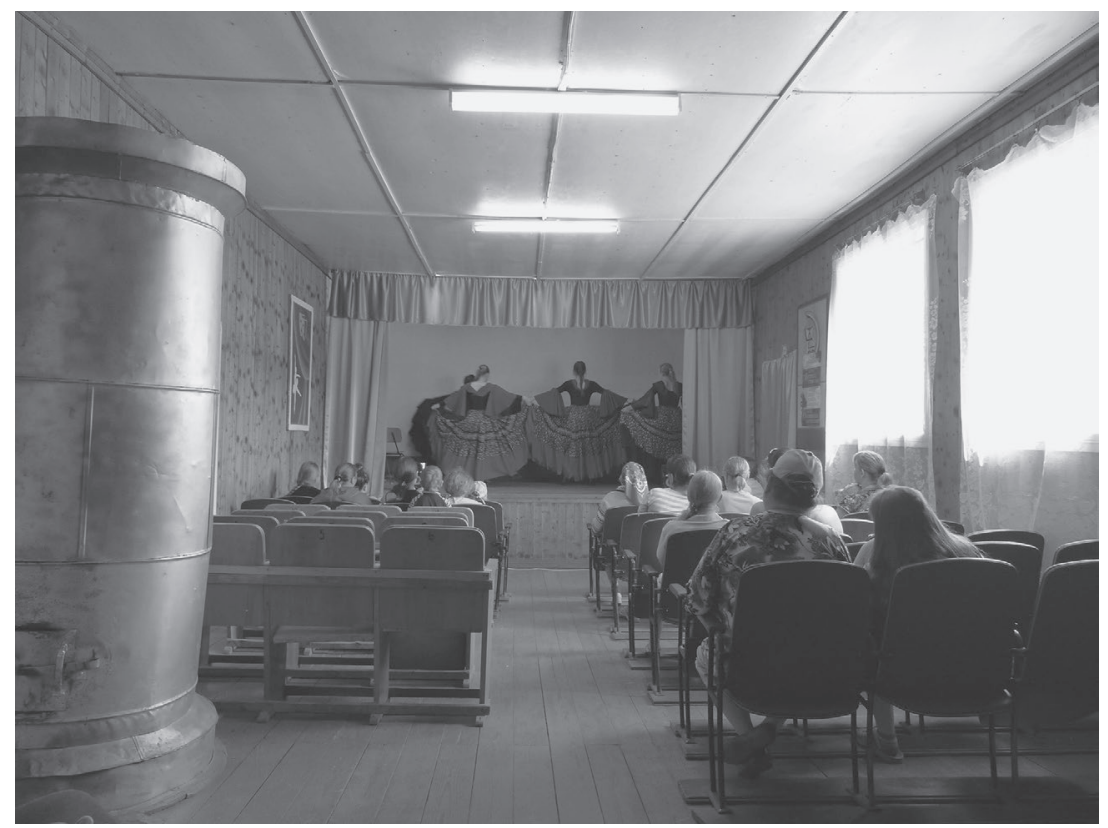

Figure 4.5 Dom Kul'tury (R. House of Culture) in Vil'häl, Leningrad Oblast. I took this picture in summer 2015

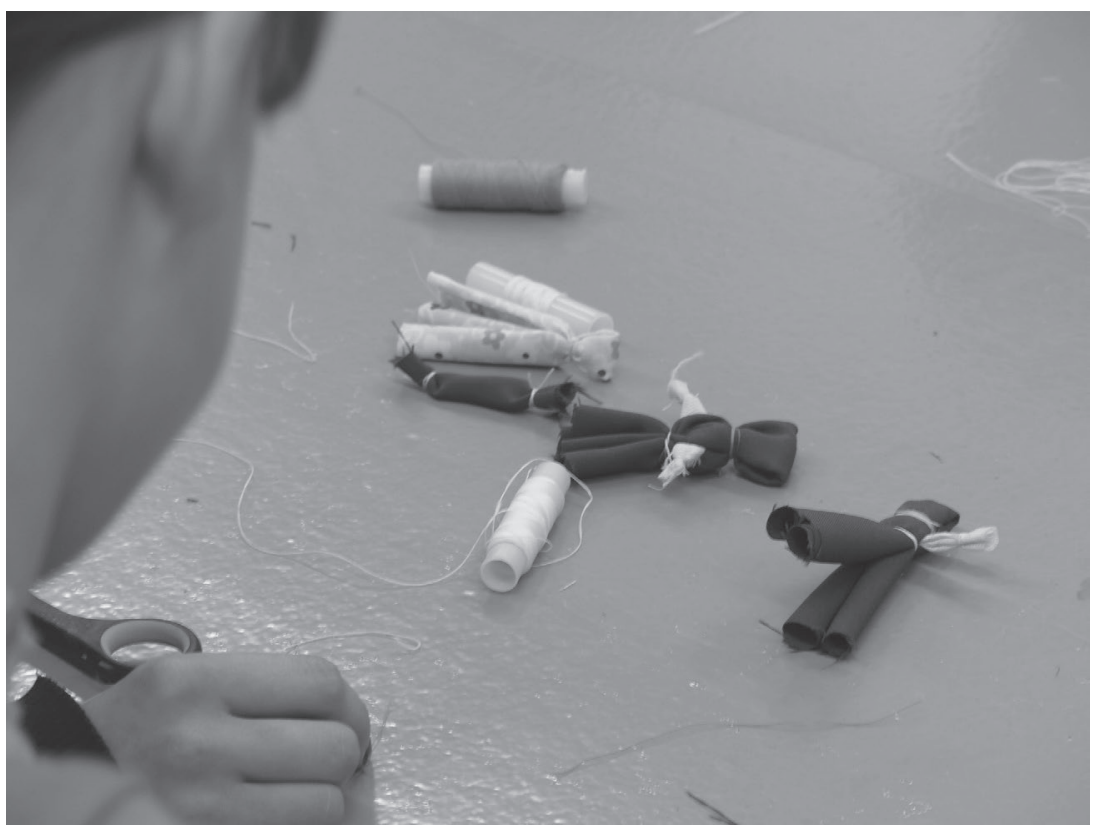

Figure 4.6 Master class at the school in Kuja, Vologda Oblast. I took this picture in autumn 2013 
proved another useful instrument for my data. Before venturing to the field site, I was often told that my interviewees would most likely refuse to be filmed and that the use of audio-recorders would be more appropriate. By contrast, and to my surprise, many let me film them and often forgot about the presence of the camcorder in the room. I used the camcorder in multiple ways. I employed this use mostly during formal interviews. At times, I put it on a tripod; other times, I held it in my hands and filmed activities and places. I sometimes set it on a table and left it there, ignoring it. Galina Lokkina once exclaimed jovially in her own kitchen in Nemž, "Oh dear! What did I just say? And you are still filming!” I was able to film planned interviews and random dialogues and discussions within and out with the domestic environments. The use of a camcorder also allowed me to receive oral informed consent and not to force anyone to sign a written document. Last but not least, both pictures and films became an instrument of exchange and helped me create bonds with the locals. I often made DVD copies of festivals, concerts, and social events and gave them as a gift. In a recent conversation in 2017, I asked Larisa Smolina to help me decipher an interview she had taken in Šokš some years ago and that I had recorded on my webcam. She wrote back after viewing it anew, expressing gratitude for bringing back such good memories. What's more, the research project led by Prof. David Anderson that I recently worked for at the University of Aberdeen allowed me to further cooperate with Ol'ga Zhukova since I could ask her to decipher the Vepsian pubeged found at the phono-archives in Petrozavodsk which Valentina Kuznetsova, its director, kindly granted me to copy. Such a proactive use of new technologies and social network tools have helped me further generate a network of trust and cooperation.

I would like to conclude this chapter by stressing the relevance of archival research that I began appreciating more and more once I started my first post-doc at the University of Tartu (cf. Siragusa and Arukask 2017). The main benefits I gained from such research practices were that I could give diachronic depth to my investigation and I could engage with material that had been gathered but not used by previous researchers, and that I could expand my network by making acquaintance with such knowledgeable persons as the archivists I worked with.

$* * *$

This chapter aimed to validate the methods that anthropologists apply to gather their data. Specifically, I showed that extended fieldwork does not simply equal hanging out somewhere, but requires open-mindedness on behalf of the researcher, which represents the strength of qualitative analysis. This level of open-mindedness in fieldwork enables the researcher to gather the data required to answer their pre-established research questions and more. Thanks to fieldwork, the ethnographer and the people with whom (s)he works can create new life situations together from which everyone benefits and learns. Specifically, in regard to language investigations, 
fieldwork proves indispensable. This way, it can complement structural analyses of language by providing a more rounded investigation of language in relation to dominant ideologies and attitudes, and the broader language ecology. The presence of the researcher can activate new situations where language use and attitude manifest themselves in unexpected ways. The traditional svoy-chuzhoy dualism, for example, extended in ways that were unpredictable, while maintaining the traditional metaphors of inclusion and carefulness attributed to Veps.

The researcher as a symbol of foreign academia and simply foreigner becomes part of the language revival movement (s)he is investigating. The symbolism attached to the researcher can contribute to the promotion of the heritage language and give it value. All of this is also possible thanks to the adoption of new technologies that become part of the revival discourse, too.

To sum up, fieldwork is a give-and-take process which provides advantages for the researcher, for the academic world and non-, and for the population who is promoting their heritage language. A revaluation of the heritage language of the ethnographer can also occur and it matches the revaluation of the endangered language. The advantages of fieldwork are, therefore, not only academic, but in the case of language inquiries, they can be both anthropological and linguistic, and meaningful for everyone involved in them. Besides, in case of the present research, possibilities and dialogue among different academic environments and people have opened. Many Veps and Vepsian scholars and laypersons have expressed the desire to continue working together. And I am sure that there will be further possibilities since, after two years as a Research Fellow at the University of Tartu, I worked for a post-doc position at the University of Aberdeen, and I have now accepted a third post-doc at the University of Helsinki where I am continuing my investigation on Vepsian language use and relations with the environment.

\section{Notes}

1 On the topic, see Hornberger (2006), Johnson (2009, 142), Johnson and Freeman (2009), Levinson et al. (2002), Ramanathan $(2005,99)$, and Ricento and Hornberger (1996).

2 See also Canagarajah (2006), Hornberger and Johnson (2011, 282), Johnson (2009), and Levinson et al. (2002) on the anthropologist as an inadvertent activist.

3 Interestingly, Duranti (1992) noted how among Samoans the allocation of responsibility occurs only after an action has taken place.

4 The same root of this word is also found in other Finnic languages. And they have a similar meaning. For example, in Estonian külas käima means to visit and külaline is the visitor. In this sense the visitor represents a potential expansion of the village. In Finnish the phrase olla kylässä also means to visit. In Vepsian the word visitor (V. adiv) has a different root. The Vepsian word adiv used also to be used for those who were invited to celebrate the New Year in the village. This indicated that they were embraced as part of the family (Vinokurova 1994, 41).

5 KarNTs RAN, Karelian Research Centre, Russian Academy of Sciences, Journal 25 , tape 3197, number 38 . 


\section{Revaluation of Language}

6 Despite having become svoya among the Vepsian population, I was still regarded as chuzhaya among the animals. Indeed, I usually speak Italian to animals and not Vepsian.

7 During discussions with Alex King, I understood that the use of vulgarity and obscenity is gender-dependent in Kamchatka. He heard men saying foul words during their stay there. However, his wife never heard the same words from women. I cannot confirm that this is the case in Vepsian, having conducted research by myself. On a different occasion, Eva Toulouze also confirmed that Russian men tend not to use foul language in the presence of women. She also agreed that in the other Finnic languages the vocabulary of obscenity and vulgarity is much poorer than that of the Russian language.

8 This positive aspect of field work is also highlighted by Brinkmann and Kvale (2005, 162) and Wertheim (2009).

9 The modified social networking exercise enabled me to investigate Vepsian language use in its written and oral form. 


\section{Metaphors of Language Independent Entity Versus Experience of Life}

Svetlana Ershova and I were drinking tea at her dinner table over viewing her garden in Kurb, when she asked me the theme of my work. It was the summer 2011 and I had returned to the field after re-engaging with the scholarly literature and having formulated the main thesis of my dissertation in Aberdeen. I answered that my work had taken a different direction from the one initially established and that I was comparing Vepsian language use in the rural and urban areas. She agreed that there were differences in the understanding and use of Vepsian in those places. "This is how we understand language here [in the villages]. We use Vepsian in this environment, in relation to the world and to its creatures," she said. She continued explaining how the villagers "experience and relate to the surrounding world through language." From her talk, it was clear that in the villages language is generally not associated with political action and/or structural descriptions of linguistic features. This is particularly the case in the Central and Southern Vepsian villages which are less influenced by the political narrative circulating in the Republic of Karelia. Such structural paradigms and political implications of language are mostly present in the city.

Her explanation summarized eloquently what I had heard and observed among the Vepsian communities in rural and urban areas. The villagers, particularly those in their 60s onward, mostly experience the Vepsian language in its oral form as part of the surroundings, in its embodied and social characteristics, and do not detach it from the world in which it is used. The villagers tend to understand language as part of the experience of life, as a mode of experiencing life (cf. Ochs 2012). The organic metaphor which part of academia attaches to language does not comply with the language metaphors held by the Vepsian villagers since they generally do not separate language from life. To put it bluntly, language for them does not evince out of context, it is part of it as well as a way of constructing it. The villagers demonstrated not to adhere to evolutionary approaches of language that conceive it as an organic being in competition with the other languages. They indicated not to comply with the idea that the language that does not win this competition is doomed to die. 
Given these observations from the field and discussions with local dwellers, I want to challenge the biological metaphor of language that dominates the academic and political worlds to try to facilitate mutual understanding among the different agents involved in the revival of Vepsian. And I will do so in two ways. First, I expand on the representation of language as an organic entity in contrast to certain more traditional Vepsian metaphors of language and practices. For example, Vepsian general optimism does not abide by a catastrophic and competitive discourse about language. Second, I will show how certain linguistic categories enter in conflict with experiences of language and its oral mode of expression, which dominate language use in rural areas of the Vepsän ma. Stemming from observation in the field, I claim that lexical movement is generally not accepted as an indication of language shift. Rather I explain such dynamism in relation to the Vepsian interpretation of the svoy-chuzhoy polarity and as part of an ontology in which pragmatism, joint work (Sebr), and common goals allow for movement of practices. Languages do not die, but the socio-economic and political circumstances may disrupt a spontaneous use of the heritage language (cf. Saarikivi and Toivanen 2015, 9). Indeed, what appears to be problematic in regards to Vepsian-Russian bilingualism is social prejudice and discrimination experienced by Veps, reinforced by assimilationist policies, and evolutionary ideologies that have prevented many Veps to speak and experience their heritage language also in rural locales, where the language first emerged and developed. I will show this in more detail in my analysis of code-mixing and code-switching practices.

\subsection{Life Cycle of a Language in Academic and Political Discourse}

The Romantic Movement speculated over the origin of language in search of a possible common proto-language from which all languages would have developed. In the nineteenth century, academic interest turned to the study of those languages (such as Sanskrit) from which modern languages had evolved. Pioneers like Grimm, Bopp, Rask nurtured an interest for comparative work and extended the tree-of-life metaphor to language with all its possible ramifications and developments. Grünthal (2015) showed how the first scholars who studied the Vepsian language indeed applied a similar comparison and referred to Vepsian as the Finnic Sanskrit, believing that it possessed certain archaic traits that the other languages had lost. Thanks also to the influence of Saussure, language was mostly studied and appreciated as an abstract entity, context-less, as per its structural characteristics. Despite his desire to take distance from European scholars, the work of the leader of Stalin's linguistics, Nikolay Marr, on Japhetite languages also contributed to the creation of a progressive and historical approach to language which matched the evolutionary ideologies of the Soviet regime (Smith 1998, 80-89). On one hand, taking these positions enabled the scholars to view similarities and/ 
or differences among modern ways of expression and to determine possible developments in the history of language. On the other, it reinforced a contextfree understanding of language as well as its organic metaphor.

Such a metaphor extended to paradigms of language death. Linguists and sociolinguists faced diminishing worldwide language diversity. The risk of losing linguistic variety generated a reaction from political agencies such as UNESCO, which a century later acted in order to save the estimated endangered languages. UNESCO evaluated that a language is lost every fortnight and that "half of 6,000 plus languages spoken today will disappear by the end of this century" (Crystal 2000; Robins and Uhlenbeck 1991). ${ }^{1}$ The concept of language shift as a result of competition among separate languages began to be used in both academic and political discourse (Haugen 1972; Mackey 1980). As a consequence, new studies committed to find appropriate ways to rescue those languages in the late 1970s to early 1980s (Dorian 1981; Fishman 1991). A large volume of global literature has been dedicated to language revitalization movements (also shown in Chapters 1, 3, 7 , and 8), accepting the old metaphor of language life cycle which persisted in academic rhetoric. Clearly, the organic metaphor is intended to serve the goals of revival movements and to support the activists in the promotion of a language whose use is often not transmitted generationally (as also noted by Errington 2003, 726-727). Such a metaphor has enabled scholars to employ a deplorable and almost cataclysmic language and pressure political institutions into implementing their legislation and protecting language rights. This discourse also reiterated other biological catastrophes that created concern globally (Maffi 2000). And language endangerment soon became synonymous with other biological risks that threatened the Earth (Nettle and Romaine 2000; Romaine 2015). An example of this is the analogy with climate change, as indicated by Cameron (2007).

\section{Doomed Language and Efforts to Rescue It}

In her 1981 book, Language Death: the Life Cycle of a Scottish Gaelic Dialect, Nancy Dorian employed biological terminology to refer to the changes of a language throughout time. She investigated the dynamics of language competition that can ultimately lead to the death of a disadvantaged language. Scholars such as Dorian began grouping languages into those that are safe and lively and those that are endangered, unhealthy, and at risk. This way they followed the model of endangered species discourse, which came into the mainstream in the 1970s. Dorian's reference to language death remained largely uncontested in the 1990s. ${ }^{2}$ Indeed, the shifting language began being variously called, from abandoned language to disappearing language, fading language, receding language and recessive language (Tsunoda 2005, 44). Some even borrowed medical terms and referred to it as moribund (Krauss 1992). The reference to the terminal stages of a language life was in line with Fishman (1991) who introduced a scale called 


\section{Metaphors of Language}

Graded International Disruption Scale for the vitality of a language, moving from a vestigial use to use in formal domains without political independence. Generally, scholars accepted the medical metaphor and the discourse on the health of a language (Kibrick 1991; Sasse 1992). Health refers to the number and age of its speakers and whether or not the language is transmitted generationally. Harmon (1996) took the most extreme position and went as far as to connect the life of a language to the life of any other species. Overall, scholars and academics of the 2000s continued to embrace the evolutionary, biological, and medical metaphors.

Nonetheless, some academic figures understood that this terminology could be questioned and began challenging it (England 2002; Ricento 2000; Skutnabb-Kangas 2000). Skutnabb-Kangas (2000, xxxi) pointed out how such a tragic metaphor is "too strong" and as such it reduces the strength of "real/physical" acts of murder and killing of people. She also identified how people may react emotionally and respond negatively to such a doomed metaphor (Skutnabb-Kangas 2000). What's more, some of these scholars maintained that languages are learned behaviors and not external, out-of-life, independent organisms (Finnegan 2007). In this new frame, the adoption of the word endangered was also a particularly unhappy choice since it reinforced paradigms of a life cycle of a language. My analysis of Vepsian language revival coincides with such considerations. In fact, the present study conforms to paradigms of language-in-context, according to which language is manifested in relation to the environment and surrounding existing forces (Hymes 1972). In fact, I use the phrase language ecology to describe such an interaction (Garner 2004). Language is a situated phenomenon and people manifest language in relation to the surrounding forces and their social symbolism. Furthermore, language can be the context itself, it creates it (cf. Austin 1962; Ochs 2012). Such a metaphor anthropomorphizes language practices and detaches them from life. This angle grew out of discussions over Vepsian revival, the way the Vepsian population generally experiences it and Vepsian ways of speaking in rural areas of Vepsän ma. It is clear, therefore, that employing the biological metaphor can be politically problematic, as it does not necessarily conform to the language metaphors and experiences among the population.

\section{Vepsian Revival, Preservation, and Development of the Language}

The Vepsian activists, especially those who work directly with the standard form of the language, acknowledge that languages may cease to manifest. Many villagers, however, tend not to adopt terms such as death of or to save an endangered language. Languages do not die but manifest in relation to past memories, present occurrences, and future projections and, hence, change and adjust to life situations. Vera Fyolkina with whom I took a stroll around Pondal in 2015 got particularly upset at the use of such a metaphor as she firmly stated that she spoke the language and wondered how 
a language could be dead if she was speaking it. Many Veps demonstrated to understand that the speakers adopt new words and ways of speaking in general and drop others. In particular, those Veps residing in those villages in the Leningrad and Vologda Oblasts do not discuss language as a dying species except for those individuals who are exposed to political and academic discussions of language endangerment. This is often more the case of Northern Veps, due to their proximity to Petrozavodsk and their more active participation in the revival of their heritage language. The village dwellers tend to perceive language as a dynamic phenomenon that manifests itself in its interaction with the surrounding forces and, in fact, language can embody this set of relations itself.

In fact, such subtleties can be found also in the political discourse shared among the activists. Should a conversation on Vepsian language revitalization occur they often adopt the terms, sokhranit' $i$ razvivat' (R. To preserve and develop). While saving a language links to the biological metaphor and suggests that languages can die, to preserve a language has gained a different symbolism among Veps. The terms sokbranit' $i$ razvivat' unequivocally stress the dynamism of the revival process. They link to past traditions and traditional knowledge and launch new ways of expression which project into the future. Such dynamism is found in a language that can develop while maintaining its long-standing and passed-on characteristics and intrinsic worldviews. Interestingly, mostly former university students view Vepsian writing as a bridge between two oral traditions, the one of the babushki (R. Grandmothers) and the other of the children. What's more, the activists favor the term yazyk malochislennogo naroda ( $\mathrm{R}$. Language of a minority group), or rodnoy yazyk (R. Heritage language) putting emphasis on the number of its speakers, on the political status of the language and on its ethnic component, more than on its bealth condition (as implied in the term endangered).

The view of language as a doomed species can be problematic within the political discourse of the Vepsian revival. This pessimistic and organic view would make their efforts unreasonable, as it would denote fighting for a lost cause. Indeed, maintaining a biological metaphor of language and viewing Vepsian as a dying language puts the Vepsian movement in an awkward position. The Vepsian revival movement, instead, was spurred on by the needs and hopes of marginalized communities who saw in perestroika and glasnost the first opportunity to defend and stand up for their language, rights, and needs. Nonetheless, the Vepsian activists continuously need to defend their position to promote the Vepsian language against the policy makers and their at times ambiguous intervention. Indeed, the multiethnic population of Karelia often laments that the regional budget is invested in the promotion of the national languages and not to develop other social services (see Chapter 8 on education). Therefore, the activists need to stand up against the majority of the urban population, which often criticizes them for being favored, also due to their status as minority of the North. The 


\section{4}

terminology chosen to define the generational decline of oral language use is, therefore, socially and politically problematic. Employing a doomed metaphor for the Vepsian language contributes to fuel mistrust toward the activities of the Vepsian activists among the population. Paradoxically, it reinforces the position of the assimilationists since it puts emphasis on the risks involved in promoting diversity rather than on its positive outcomes. Such a tension is highlighted by Zamyatin (2016a) who indicates how the initial zeal and democratic tone of the late 1980s early 1990s policies was followed by centralizing and authoritarian tendencies in the 2000s and 2010s-this rapid shift concurs with some of the views of the multiethnic population of Northwestern Russia, which Vepsian activists need to carefully take into account when promoting their heritage language.

\subsection{Vepsian Language and "Optimism"}

In the nineteenth century, Veps became a subject of interest within academia. In 1853, Lönnrot, the author of the Kalevala, wrote his dissertation on Veps, Om det Nord-tschudiska språket (Swed. On the North-Chudic language). He claimed that Vepsian was already a dying language (Strogal'shchikova 2008a). How can a language be in the throes of dying for more than 150 years (cf. Saarikivi and Toivanen 2015, 15)? During our interview, Mariya Filatova, former student of Vepsian and currently working for the Vepsian TV, asserted,

I know that many scholars think that it is already too late to preserve and develop our heritage language [Rodnoy yazyk]. I know that Lönnrot said that we did not speak the language a long time ago. But I think that it is still possible to preserve Vepsian. I am optimistic and that's what we are. We, Veps, are very optimistic people.

The population of Karelia often applies a complex network of social stereotypes to differentiate the several nationalities living in this territory (see Chapter 2). In this complex network, one of the attributes that is applied to Veps is that they are optimistic people. From their self-descriptions, it seems that this is also how they like to portray themselves on the whole. Indeed, they often extend such an optimistic attitude to life in general and seem to portray the world they live in as a place where catastrophic events do not occur. Ol'ga Zhukova once told me,

My babushka is often shocked by the international news. When she watches the television, she usually comments aloud. I heard her wondering why people live in those places where hurricanes and natural disasters occur. She asked me once, "Why don't they all move here? This is a wonderful land and there is room for everyone. [...] There are no such disasters." 
She did not make any reference to the historical past that her generation suffered. Instead, she referred to the connection people have with the land, and how this land can provide safety to the people who inhabit it. It is not surprising, therefore, that such a view also extends to how language is perceived and understood. None of the Vepsian elderly villagers mentioned the language biological metaphor with its predetermined path, leading to language death. On the contrary, many villagers asserted that there were far more speakers than those the statistical data showed. Zinaida Strogal'shchikova conducted quantitative research in the villages and confirmed this to me. Some even claimed that there were "thousands of speakers around the whole territory where Veps dwell" (cf. Puura et al. 2013). Veps tend to have a vision that expands the Vepsän ma to distant lands where they believe Vepsian is still spoken. Some were very surprised to hear that the Vepsian language was, in fact, endangered when the Endangered Language Project promoted by Google was released in June 2012. ${ }^{3}$ Such language attitudes do not conform to scholarly discussion over language death and shift.

The organic metaphor is intended to serve the goals of revival movements and to support the activists in the promotion of a language whose use is not transmitted generationally. During a presentation on language metaphors and language loss at Kunstkamera in Saint-Petersburg in 2013 where indeed I challenged such an apocalyptic language, the academic audience reacted, "but how can you get financed, otherwise?" By creating a terminology that screams urgency such as death, the first sociolinguists might have also hoped to receive attention from the policy makers and generate a positive reaction. Indeed, this term has attracted massive funding from the Volkswagen Stiftung, European Science Foundation, National Science Foundation, and Hans Rausing. ${ }^{4}$ And the recent project on language endangerment promoted by Google appears to prove that such a metaphor has reached out to a wider audience. However, the work financed by these foundations has not endured without criticism. Muehlmann $(2007,20)$ points out that most of the funding which scholars have received from international foundations has served the purpose of documenting multiple ways of speaking and to archive them, thus, discarding their communicative and engagement account in context. Investing in archiving languages does not guarantee speaking it. Muehlmann (2007) also questions whom such scholarly endeavor benefits the most, whether those who work within academic and often non-governmental institutions or the communities for whom the documentation is intended.

This metaphor often appears to leave behind the people and their multiple experiences of language and reinforces separation between the scholars, policy makers, and speech communities. It does not enable language ecology to be part of the scholarly and political debate and favors its imposition on the people by the elites (mostly academics, in this case). Contrarily, continuing to force the biological metaphor onto the speech communities acts against the reasons why it developed in the first place. Instead of "giving 


\section{Metaphors of Language}

voice" to the people, it stifles it (e.g., their optimistic views). It also allows people to assert that it is natural for a language to die (Skutnabb-Kangas 2000, xxxii). In a nutshell, academic debates on language death may serve to galvanize the powerful into political action. Some of the metaphors we live by serve the purpose also to instigate action (Lakoff and Johnson 1980). However, such metaphors bear a highly politicized weight in context which may interfere with or even deter the purposes of the revival movement itself (Hill 2002) without our awareness (Sapir 1929).

I suggest re-thinking this pessimistic vision of language on behalf of the scholars. And I suggest doing this by focusing again on the experience of a language in relation to its surroundings and as experience itself in order to appreciate each case and its idiosyncrasies, and by focusing on language ecology more broadly.

\subsection{Speaking in Villages: An Experience of Life}

In summer 2011 Galina Lokkina, her granddaughter Alina and I took a bus from Nemž to Kurb. We had decided to visit the Vepsian ethnographic museum in Kurb. The museum, once part of the village school, was shut down in 2009, and Svetlana Ershova, former Maths and Vepsian teacher, had reopened it in a separate building (Figure 5.1).



Figure 5.1 Vepsian ethnographic museum in Kurb, Leningrad Oblast. I took this picture in summer 2011 
In the summer of 2010, Svetlana Ershova renovated the interior of an old administrative building with the support of her family and other volunteers. The museum then received official status as an affiliate branch of the Podporozh'ye Local Lore Museum. They worked indefatigably for two months and their work was done on a voluntary basis, without any regional or federal government financing. A year later, Estonia provided financial support for this initiative. The Council of the Kindred People's Program awarded Svetlana Ershova with the 2011 Ilmapuu Prize and a total of 1,250 Euros. ${ }^{5}$ When she received the prize, Svetlana Ershova admitted not considering it a personal award since they had been working ühtes (V. Together, as one). In her judgment, this prize rewarded not only her own efforts but also the efforts of everyone involved in the initiative, and, thus, meant all the more to her.

Besides the entryway, the museum comprises four rooms. The first room includes a collection of old keys, spinning wheels, cotton, and leather-made clothing and shoes, wooden baskets, and old pictures hung on the walls. In the second room, there are household utensils for the women's khozyaystvo (R. Housekeeping, farming) and the men's fishing and hunting tools. The third room is the museum administrative office and a collection of Soviet school stationery and miscellaneous objects are kept there. The last room is a reconstruction of a traditional Vepsian house interior. It displays a table, surrounded by wooden benches, Jumalčoga for religious icons (Figure 2.3), a bed, and a Russian stove.

Svetlana Ershova was on her way to pick us up at the bus stop when we arrived in Kurb. While she is in her late 50s, Galina Lokkina is slightly older, in her mid-60s, and both of them are fully fluent in Vepsian and Russian. Despite Alina's presence, they spoke mainly Vepsian at the time of our visit. My presence often induced Vepsian speakers to use their heritage language. Svetlana Ershova led us into the first and second rooms of the museum and explained for which purpose some of the objects were designated. Alina kept quiet and listened to the two Vepsian-speaking women, occasionally asking a question or two in Russian to which they replied in Russian. As we entered the administrative office, however, the two women automatically shifted to Russian. The whole conversation continued in Russian. They put the Soviet gramophone on and laughed at the music that came out of it (Figure 5.2). They recollected how they used to study and the kinds of books they used at school. In this room, Svetlana Ershova engaged with Alina more and instructed her on how some old Soviet pens worked. She dipped the pen into the ink container and imitated how the children used to write. As they were showing Alina around they kept repeating to themselves in Russian, "This is interesting to her, too." The Russian language was mostly abandoned as we moved to the next room, the traditional Vepsian house. Some words of Russian origin were included in their speech, such as potom (Later), konechno (Of course), and the adjective nastoyashchiy (Authentic, real) which are now assimilated in Vepsian. 


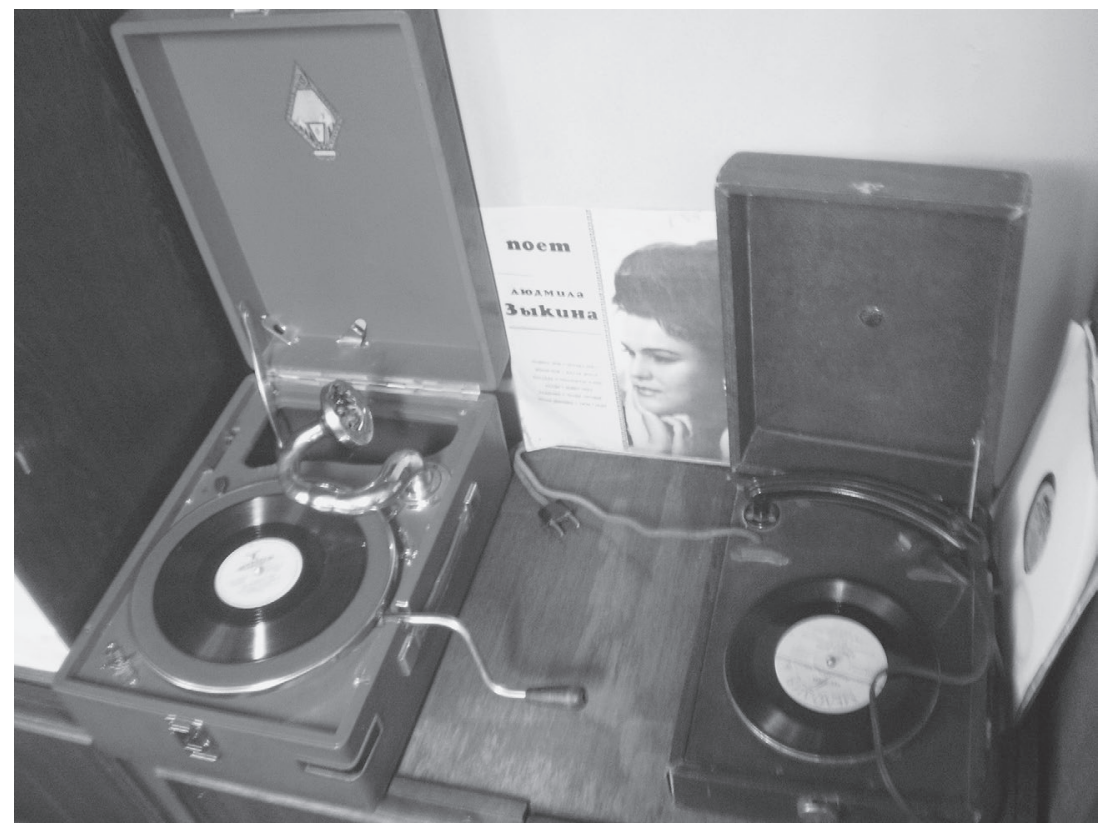

Figure 5.2 Soviet gramophone in the administration office of the Vepsian ethnographic museum in Kurb. I took this picture in autumn 2010

Both Galina Lokkina and Svetlana Ershova shifted mainly to Russian when they first entered the Soviet-looking administrative office where the objects surrounding them had only been used in the Russian language (i.e., at the time of their school education). Their language use resonated with past language experience at a time when the Vepsian language was prohibited and only Russian was allowed in official space. In the other rooms, however, they spoke mostly Vepsian. Galina Lokkina and Svetlana Ershova voiced their heritage language when dealing with the tools which Vepsian women used for the farming and housekeeping, or that the men used during their expeditions in the woods, hunting, and fishing. Their speaking was influenced by present people, past memories, future projections, and language attitudes. Their language practices responded to the environment surrounding them and the kind of experiences they were (re-)living at the time of speech. As such switching between Russian and Vepsian did not indicate language structure awareness and/or awareness of language loss. Such a switch has become an emblem of language experience in context, a response to the forces in place, which to a certain extent have also political resonance (Hymes 1972; Schieffelin and Ochs 1986; Zentella 1997). 


\section{Appropriation: An Ontological Interpretation to Lexical and Morpho-Syntactic Movement}

In this analysis, I show how the main cause for language loss in not necessarily to be found in the phenomenon of languages-in-contact. Interpreting language loss as a consequence of languages-in-contact often follows a sequential approach to life that does not allow the multiplicity of life forces to be part of the discourse on language use. It also stems from an understanding of languages as separate entities and from an accepted structural position that views languages as competing systems with the ability to assimilate one another. Besides, it relies on the fact that when contact between those systems occurs, competition will kick in and the majority language will dominate, assimilating the language of the minority group (Dorian 1981; Myers-Scotton 2002). Evolutionary theories, historical sequentiality, and structural classification provide the basis for such theoretical advancements that tend to neglect experiences of language.

This sequential diagnosis does not apply to the Vepsian language, which despite having been in contact with other languages (particularly Russian) for many centuries, has not been assimilated, due to purely linguistic factors (such as the shift from lexical borrowings only to heavy structural borrowing). The Vepsian language was already classed as endangered more than 150 years ago due to its long-term contact with other linguistic systems. Yet, it did not die out, and neither was it entirely structurally assimilated despite the very strong cultural pressure of the last century, which can be understood as a euphemism for oppression, genocide, and ethnocide. The main causes for the challenging present-day Vepsian language situation are, in fact, a complex grid of contemporary ideological and political reasons some of which have characterized also previous historical epochs. Nonetheless, metaphors of movement within the Vepsian language can be still perceived as a linguistic threat and not as an experience in relation to the world. Linguistic movement from other languages into Vepsian can be viewed as an indicator of language decadence and shift and not be interpreted in line with Vepsian worldviews. During a break at university, Ol'ga Zhukova wondered,

Why is it always a problem for Vepsian to borrow a word from another language? Do we not say computer in Russian, too? It is OK, if Russian speakers borrow an English word and employ it in their vocabulary. But this is immediately perceived as a problem if the same phenomenon occurs in Vepsian.

Veps have generally integrated into their language a number of terms and morphological and phonological traits from the languages spoken by their neighboring groups (Grünthal 2003, 2007; Laakso 2011; Lehtinen 1985, 1990; Puura 2007). This is not surprising given the long-term contact 


\section{Metaphors of Language}

and flow of systems of values and practices (Loginov 1993). My analysis of the symbolism and indexicality attached to the svoy-chuzhoy polarity among Veps leads me to interpret this language phenomenon in relation to a specific ontology that allows for movement of practices, especially if it has pragmatic validation and an expansion of the sebr. In allowing lexical movement, Veps have enriched the semantic fields of every aspect of their daily existence. That is, by using words from different linguistic systems, they have expanded their world and its interpretation. Irma Mullonen at the Academy of Sciences in Petrozavodsk was the first to make reference to wealth when discussing bilingualism. Stalinist linguistics also supported lexical movement from Russian into the other indigenous languages of the Soviet Union and interpreted it as enrichment. This ideology viewed any other neologism in the indigenous languages as nationalist. However, here lexical movement is not only interpreted as a legacy of the Soviet linguistic ideologies but also as a practice which matches long-term Vepsian epistemology in embracing foreign elements into their ways of speaking, I would argue mostly for pragmatic reasons and if they are somehow linked to the original meaning of the word sebr, that of "joint work."

When new elements, either linguistic or more broadly cultural, enter a different cultural system people may embrace them and give them new meanings often matching their worldviews (Baltali 2012). Baltali $(2012,5)$ refers to this cultural integration as a "way of appropriating foreign elements." I will not use the broadly accepted term loanwords, which reinforces paradigms of competition where the dominant language lends its lexicon to the minority language. Rather I use the terms appropriate, taking the terminology developed by Baltali, and shared words. The term loanwords also implies returning what has been borrowed to the linguistic system of origin. In the case of Vepsian, there has sometimes been a back-and-forth movement in the sense that words of Vepsian origin entered the Russian terminology and were then appropriated back again by Veps, as indicated by Myznikov (2004, 306). Hence, my choice to call these words, shared words.

Lexical movement among languages can also be referred to as a semantic field in motion (Pugh 1990) and this word choice also stresses the dynamism of the Vepsian language and its forging capacity. The following table provides some examples of Vepsian terms with a different origin from the heritage language.

The Vepsian verb zavodida (To begin, to start) also has a Russian origin, and so does the expression, midä zavod'ie? (Where to start?) (Pugh 1991). It could be argued that such lexical exchange finds its origin on trade relations and the activities of the missionaries in the area (Pugh 1999, 30). According to Puura et al. $(2013,44)$ Russian terms "in areas such as modern society, religion, military and Soviet terminology" has made their way into Vepsian lexicon. Besides the exchange with Russians, Veps took part of their lexicon also from Sweden and Germany (Pugh 
Table 5.1 Vepsian appropriation of foreign lexicon. The examples are taken from Pimenov $(1965,193)$ and Strogal'shchikova $(2008 a, 21)$

\begin{tabular}{llll}
\hline & Vepsian & Russian & English \\
\hline Slavonic origin & Bajar & boyarin & boyar \\
Car & tsar' & tsar \\
Rad & rabota & work \\
Sused & sosed & neighbor \\
Bagr & bagor & boat-hook \\
Päč & pech' & stove \\
& Blöd & blyudo & dish, course \\
& Kisel & kisel' & kissel \\
Ärmäk & armyak & armiak \\
& balafon & balakhon & shapeless garment \\
& plemännik & plemyannik & nephew \\
& Lužik & lozhka & spoon \\
& Rist & krest & cross \\
& Vepsian & German & English \\
& lambaz & lamm & lamb \\
kuld & gold & gold \\
\hline
\end{tabular}

${ }^{1}$ The Vepsian words rist and kuld have an ancient origin and they are also found in the other Finnic languages.

1999). The most recent terms come from English, especially in regard to business and technology-related spheres (Pugh 1999, 31). In other words, Veps have included in their ways of speaking terms that have enabled them to broaden their domains of use and opportunities for trade, discussion, and general communication.

They have also appropriated syntactic, phonological, and morphological features into their language from those exchanges. The Vepsian words generally maintain consonant clusters at the beginning of those words with a Russian origin such as znamoita (To know) (Pugh 1994). Vepsian has also adopted the Russian suffix -ik-e.g., kalanik (Fisherman), mecoik (Hunter) (Pimenov 1965, 193). Grünthal (2003) looked into Russian influence on Vepsian nominal inflection and identified how the use of the comitative and illative cases among Southern Veps have been influenced by Russian. Vepsian speakers have adopted several Russian conjunctions such as a (And, but), $i$ (And), no (But) (Pugh 1999, 26). The incorporation of the negative prefixal particle $n i$ - also has a Slavonic origin-e.g., ni konz (V. Never) (Pugh 1999, 26). It should also be pointed out how a number of prefixes have entered the Vepsian verbal system (Pugh 1990). 


\section{Metaphors of Language}

The most productive prefix among Vepsian speakers is pro- (Pugh 1990). In her recent $U z$ ' Vepsä-Venälaine Vajehnik (V. The new Vepsian-Russian Dictionary), Nina Zaitseva provided only the verb prostida (To forgive) with the prefix pro-. However, in the newly established website Korpus Vepsskogo Yazyka (R. Corpus of the Vepsian Language), which Nina Zaitseva is developing, the search tool provided several examples, proitta, proidib, proit't'as, proitkat, proid'i, proid'imei, from the Russian verb projti (To go through); probuida, probui, probuizin', probuida, probuiko, from the Russian verb probovat' (To try); provetta, provedib from the Russian verb provodit' (To take, to lead); prostidas, prostišoi, prostida, prostit, prostib, prostigoi, prosti from the Russian verb proshchat'sya (To bid farewell). Lehtinen $(1985,1990)$ and Puura (2007) have also examined Slavonic influence on verbal derivation. And Laakso (2011) points out that embracing Russian structures might in fact have been a survival strategy which allowed Veps to keep speaking their heritage language without having to shift entirely to Russian. Lexical and morphological movement into Vepsian ways of speaking has been abundant, often due to pragmatic, but possibly unconscious, judgments.

Long-term contact has led to movement of terms of Finno-Ugric origin into Slavonic languages (cf. Saarikivi 2006). However, the lexical movement from Vepsian into Slavonic languages appears to be less abundant than the other way round (Puura et al. 2013, 50), and has covered specific domains of use, as indicated by Myznikov (2004). ${ }^{6}$ Indeed, the majority of Russian words with a Finno-Ugric origin tend to indicate aspects of the landscape and fishing (Mullonen 2006; Myznikov 2004, 52; Saarikivi 2006). Myznikov $(2004,58)$ confirms that in general this lexicon is quite marginal if considering the vast vocabulary of the standard Russian language, with the exception of those words related to the activity of fishing. For what concerns Vepsian more specifically, words which appertain to agricultural activities, herbs and plants, place names, and fishing have made their way through into Northwestern Russian language (Loginov 1993, 134; Myznikov 2004). More specifically, Loginov (1993, 134) demonstrates how some of the terms used for fishing have entered Russian lexicon in the territory called Zaonezh'ye where Mullonen (2005) indicated that Veps used to live. Lexical movement into Slavonic languages is visible in some of the contemporary place names-e.g., the name of the village Myatusovo comes from mätas (Hill), Himd'ogi from hijm (Relatives). (Pimenov 1965, 43). Some words used in the Vytegorskiy province, Vologoda Oblast, also have Vepsian origin-e.g., kokach in Russian (Rye pie; V. kokat'), layda in Russian (The middle of the lake. Laid means being in the lake far from the banks in Vepsian), gabuk (Hawk; V. Habuk) (Pimenov 1965, 159).

I suspect that this caution to lexical movement on behalf of Russians living in this Northwestern Russian territory may match a different epistemology of the svoy-chuzhoy dichotomy, more than an emblem for language 
competition. In other words, what is chuzhoy tends to be kept outside of the svoy and such ontology corroborated by a fairly influential hierarchical ideology is reflected also in their language. Indeed, certain languages are perceived as more sophisticated and prestigious than others in which case the movement of words appears more fluid. It could be generally accepted that when an external element is perceived as socially prestigious then it is embraced within the Russian svoy. Instead, if a language is low in the hierarchical ladder, it might not enter the svoy. The recent integration of several English words into Russian can be interpreted as an indicator of acknowledgment of the current prestige and usefulness of the English language. In other words, despite a common svoy-chuzhoy paradigm among Veps and Russians, lexical, and morpho-syntactic movement indicates that it is attached to different language ideologies and ontology. Lexical and morpho-syntactic movement into Vepsian ways of speaking reveals that appropriation of new linguistic features is often based on pragmatism and expansion of the sebr; on the contrary, such movement into Russian ways of speaking indicates an ideology mostly based on prestige and, in the case of place names and fishing, appropriation of local knowledge (cf. Saarikivi 2006). While I initially suspected that such an attitude originated in the Soviet ideologies of progress and civilization, the work of Myznikov (2004) and Mullonen (1999) seems to suggest that it finds its roots in prerevolutionary times.

In a nutshell, throughout the centuries, the Vepsian language speakers have introduced in their ways of speaking lexical, phonological and morphological elements from the languages spoken by the neighboring groups and those groups they conducted trade with and/or missionary expeditions. They experience such a movement as an expansion of their svoy, which is enriched with words, as well as different worldviews, objects, and symbols. For them lexical movement does not equal language loss. Rather it equals language enrichment and embracing more people, worldviews, and knowledge into their sebr.

In my analysis of shared words and morpho-synctactic movement into Vepsian ways of speaking, I have focused on relations, language ecology, and how this is often driven by a steady pragmatic attitude and belief in "joint work" (Sebr). I acknowledge that other bilingual practices such as code-mixing and code-switching hints more directly at social inequality, reveal a more explicit reference to recent periods of repressions and social pressure, and to the assimilation efforts on behalf of the political powers (cf. Léonard 2017). Code-switching is often understood as a bilingual practice in which two (or more) languages are used simultaneously in speech. If code-mixing emphasizes the structure of a language, codeswitching is often referring to the performative aspects of this bilingual practice. A generational differentiation can be noticed when analyzing Vepsian-Russian code-switching as the elderly villagers (those from their 60 s onward), and more generally speakers which are considered fluent, 


\section{Metaphors of Language}

appear not to consciously distinguish the two languages in their speech and to use them more spontaneously in relation to the dominant ecology; whereas, the younger generations both in the city and the villages demonstrate a more conscious use of a purified Vepsian. Providing such a description of code-mixing and code-switching helps identify some of the challenges that Vepsian speakers are currently facing.

\section{Code-Mixing and Code-Switching}

One summer evening in 2011, Galina Lokkina and I visited her brother's family in Nemž. We sat at the table and drank some tea. Galina Lokkina told them how we had gone to the forest and collected two full baskets of mushrooms in the morning. She spoke mainly Vepsian while expressing her respect and gratitude to the forest around their village. This prompted a discussion on the wealth of the Vepsän ma and how proud a person should feel to be living there. The neighbor, a Vepsian lady in her 80s who was also present, reacted to this in Russian and uttered out loud, I am Veps, and I am very proud to be Veps! Galina Lokkina challenged her in Vepsian, So, why do you speak Russian? Speak Vepsian! The old woman repeated what she had just said once again in Russian. Galina Lokkina asked her again in Vepsian, Say it in Vepsian! The woman remained silent and looked puzzled by the request made by Galina Lokkina. When she next replied, though, she spoke Vepsian.

The bilingual speaker of Vepsian and Russian does not always perceive the two languages as separate entities. Among the elderly Vepsian villagers (those from their 60s onward), adopting Russian and/or Vepsian are simply different ways of speaking or, it could be argued, are two codes that are part of a single way of speaking and both individual and social experiences which can better suit specific moments in specific places (cf. Meewis and Blommaert 1998; Novozhilova 2006). The present study recognizes that for the bilingual speaker there is no marked line between the two languages (Auer 2007, 320). Such linguistic boundaries are usually fuzzy (Heller 2007, 7). Indeed, "the assumption of bound linguistic systems as the object of linguistic research is questioned by bilingual practices. This is the challenge which bilingualism continues to represent for linguistics" (Auer 2007, 337). Many linguists and sociolinguists maintain the position that languages are separate entities that can be studied separately and most often language phenomena attached to bilingualism are based on this assumption. ${ }^{7}$ However, others suggest that bilingual analyses need to be contextualized within cultural practices and their shared semiotic value (Auer 2007; Bilaniuk 2005; Makoni and Pennycook 2007). Similarly to Sebba and Wootton (1998), I contextualize such practices; contrarily to them, nonetheless, I do not narrow my analysis to the construction of multiple social identities when employing multilingual practices. In this 
light, the present work does not study language following the structural and symbolic analysis of code-switching as suggested by Myers-Scotton (1993, 2006). Structural code-switching refers to the simultaneous adoption of morphological, phonological, and lexical features of the two (or more) spoken languages. Symbolic code-switching, instead, refers to the social indexicality and symbolism of this phenomenon. Rather, the present work merges these two analyses, as the structural cannot exist without the symbolic and vice versa (Hanks 1996).

Keeping them separate is problematic. First of all, it reinforces the structural bias approach to language instead of its social aspect as mentioned earlier. Second, such a separation often abides by the generative theory in which one language plays a dominant role and this will lead to the death of the minority language (Milroy and Muysken 1995; Myers-Scotton 1993). This way, it also reinforces processes of othering. It also implies viewing bilingualism as a linguistic phenomenon which most likely will end up in the formation of pidgin and creoles (Milroy and Muysken 1995). I, instead, evaluate code-switching as a language experience in context, as the result of relations with the language ecology in which the speaker finds him/herself and as relations themselves. I will, therefore, generate a comparison between different usages of code-mixing and code-switching phenomena, which are relational to the present language ecology, history, and generational differences. Like Li Wei (1998) I am interested in answering the question on why and how people engage in code-mixing and code-switching practices, however, in order to answer to these questions I am not going to create a typology as I am more interested in the interaction with the broader language ecology in the moment of speech events (Blom and Gumperz 1972; Heller 2007), than in making more extensive claims (cf. Muysken 2000; Poplack 2004).

What's more, mixing and switching may contribute to the formation of a new linguistic situation which acquires a new social meaning and may even achieve a certain stability itself (Saarikivi and Toivanen 2015; Sarhimaa 1999). And it is this dynamism and change in the structure and semiotic capacity of ways of speaking and writing among Veps that this volume is overall presenting.

\section{Code-Switching in the Villages-A Generational Concern}

In summer 2011, Larisa Smolina was invited to meet and interview Aleksandra Chirkova (pseudonym), an elderly Vepsian woman, in Šokš, Republic of Karelia. Larisa Smolina, who had studied the standardized form of Vepsian and was now working for the Vepsian radio, was in her late 20s at the time. She invited me to join her, so I went along and sat together with her during her interviews. In the dining room, besides Aleksandra Chirkova, there was also her younger cousin who immediately admitted not being able 


\section{Metaphors of Language}

to speak Vepsian but to understand it. As we sat at the dinner table over a cup of tea, Larisa Smolina began introducing herself:

Larisa Smolina: Minun vanhembad oma Kalageispäi. A muga elän Petrozavodskas. Kus tö olet rodnus? Aleksandra Chirkova: Derevn'as Ržanoe ozero.

Larisa Smolina: A kut vepsäks nece?

Aleksandra Chirkova: Rugiždärv'.

Larisa Smolina: Nece mugažo om Šokšus?

Aleksandra Chirkova: Ka, ka. Šokšus. Cousin: Da, tam derevnya byla ran'she. A seychas'...

Aleksandra Chirkova: No, my $v 1951$ godu pereekhali syuda ... a kak zhili tam? V shkolu khodili ottuda peshkom.

[Larisa continues asking questions in Vepsian and Aleksandra answers in Vepsian to her]

Larisa Smolina [turning to Aleksandra's cousin]: A mozhem radio vykliuchit?
Larisa Smolina: My parents come from Kalag'. But I live in Petrozavodsk. Where are you from?

Aleksandra Chirkova: From the village Ržanoe ozero.

Larisa Smolina: What is it called in Vepsian?

Aleksandra Chirkova: Rugiždärv'. Larisa Smolina: Is it also part of Šokš? Aleksandra Chirkova: Yes, yes, Šokš. Cousin: Yes, there used to be a village there. But now ...

Aleksandra Chirkova [turning to her cousin, yet keeping an eye on Larisa Smolina]: Of course, we moved here in 1951. . . How could one live there? We used to go to school on foot from there.) [... . ]

Larisa Smolina: Can we switch off the radio?

${ }^{1}$ The lines in bold indicate that the speaker used the Russian language.

In this example, code-switching occurs together with a change in the addressee for both Aleksandra Chirkova and Larisa Smolina. If asked, many elders reply that they switch language when their interlocutor cannot understand them. This is also visible in public places such as the shops and post office in the villages. They often justify their language choice as a matter of good manners and politeness. In other words, the person to whom they speak dictates their language choice. The Vepsian speaker consciously drops Vepsian in favor of Russian, once they recognize the inability of their listener to understand and/or speak Vepsian. In this case, their language choice is not dictated by habitus (Blommaert 2005a, 233) but by the awareness that they will not be understood otherwise. Such a practice also aims to reassure the non-Vepsian (mainly Russian) speaker that nothing negative is being said about them. This choice might be colored by political tones, as the risk of being identified as a conspirator might bring memories of discrimination, and persecution, and might not be considered advisable. As Myers-Scotton (1993) indicates, the speakers might be aware of the markedness and indexicality that speaking their heritage language encompasses and, thus, they switch and use the language of the majority to avoid discrimination and abuse.

Otherwise, code-switching occurs more spontaneously among the elderly villagers and may take place when the Vepsian speaker recollects memories of a time where Russian was used to cover certain social domains. Both 
Natal'ya Naumova and Raissa Filippova (pseudonyms), two elderly villagers in Kalag', shifted to Russian as they began talking about work where Russian was mostly used.

\begin{tabular}{|c|c|}
\hline Larisa Smolina: Keneks sinä tegitoi? & Larisa Smolina: What was your job? \\
\hline $\begin{array}{l}\text { Natal'ya Naumova: Minä na } \\
\text { vetrabotnika. }\end{array}$ & $\begin{array}{l}\text { Natal'ya Naumova: I was a } \\
\text { veterinarian. }\end{array}$ \\
\hline $\begin{array}{l}\text { Larisa Smolina: Ka? Sinä olid } \\
\text { vetrabotnikan? }\end{array}$ & $\begin{array}{l}\text { Larisa Smolina: Really? You were a } \\
\text { veterinarian! }\end{array}$ \\
\hline Natal'ya Naumova: Ka. Vetrabotnikan. & Natal'ya Naumova: Yes, a veterinarian. \\
\hline Larisa Smolina: Kus sinä radoid? & Larisa Smolina: Where did you work? \\
\hline $\begin{array}{l}\text { Natal'ya Naumova: Mina radoin tägä } \\
\text { Šokšus. [. . . ] Mindai kaik dokumentad } \\
\text { oma. Khorosho ya uchilas.' Mne dali } \\
\text { mladshyi medfel'dsher. }\end{array}$ & $\begin{array}{l}\text { Natal'ya Naumova: I used to work } \\
\text { here in Šokš. [. .. I I always have } \\
\text { the documents. I studied very well. } \\
\text { And they awarded me as junior med } \\
\text { paramedic. }\end{array}$ \\
\hline
\end{tabular}

Natal'ya Naumova uses the Russian word vetrabotnik (Veterinarian) to talk about her past employment. She hesitated for a moment before naming her position. I suspect this is due to the fact that she might not have known how to call it otherwise. She also switched to Russian when she spoke about her school years. A similar behavior was displayed on a different occasion by Raissa Filippova as she was sitting on a bench in her garden in Kalag':

$\begin{array}{ll}\text { Raissa Filippova: Mama radoi } & \begin{array}{l}\text { Raissa Filippova: Mum worked as a } \\ \text { medsestroy. }\end{array}\end{array}$

Just like Natal'ya Naumova, Raissa Filippova used the Russian term to describe her mother's job appointment. This prompted her continuing speaking Russian. Raissa Filippova also applied the Russian instrumental case to describe her job. Most elderly Vepsian villagers use Russian words when describing their work and school years, such as kolkhozy (R. Collective farms), shkola (School), prepodavat' (To teach), predmet (Subject), urok (Class) and ekzamen (Exam). They also tend to provide numbers in Russian as can be noticed in the interview with Aleksandra Chirkova, who provided the numbers in Russian and Larisa Smolina made her repeat the Vepsian correspondent words:

Larisa Smolina: Konz tö zavodid kävelta školha? Kus nece oli i konz nece oli?

Aleksandra Chirkova: Ka nece oli... [...] V sorok-pervom voin zavodihe. Larisa Smolina: Nell'l'kümne ezmäižel vodel.
Larisa Smolina: When did you begin going to school? When and where?

Aleksandra Chirkova: Yes, that was ... [. . . I I may have begun in 1941.

Larisa Smolina: 1941. 


\section{Metaphors of Language}

Such behavior finds its roots in memories of a time where Vepsian was prohibited and Russian words were adopted to cover most domains of life outside the domestic environment. Referencing back to these times, therefore, triggers the use of Russian. Similarly, memories that depicted conversations with Russian-monolingual individuals also prompt the use of Russian:

Galina Lokkina: Oj, čoma, čoma... Svetlana Ershova: Nece tege Maksim. Maksim tege.

Galina Lokkina: Ka?

Svetlana Ershova: Ka, Maksim potomu, chto zdes' bylo...v obshchem, i pol peredelal, $i$ steny, $i$...
Galina Lokkina: Oh! Beautiful, beautiful ...

Svetlana Ershova: Maksim did this.

Maksim did it.

Galina Lokkina: Yes?

Svetlana Ershova: Yes, Maksim since there was ... in a nutshell, he did the floor and the walls...)

Maksim is a Russian native speaker. The Vepsian native speaker tends also to employ Russian expressions that cannot be covered in Vepsian. This is often viewed as a first indication of language loss (Pugh 1999). However, Veps seem to appreciate such behavior differently since such a practice enables them to cover more domains of use and metaphorically enriches their way of speaking. Galina Lokkina had just made dinner when her neighbor Nina Yur'yevna appeared at her front door: ${ }^{8}$
Galina Lokkina: Nina, lihad vöd söda? Nina Yur'yevna: Voin mihe söda. Galina Lokkina: Molodets! Nina- prosto molodets!

\author{
Galina Lokkina: Nina, can you eat \\ meat? \\ Nina Yur'yevna: Of course, I can. \\ Galina Lokkina: Well done! Nina is \\ simply a good girl!)
}

I was often told that Veps do not usually make compliments (e.g., Molodets, good girl), due to their down-to-earth and pragmatic worldview; hence, the need to use Russian to praise someone.

Sometimes the elderly villagers tell a story speaking mostly Vepsian. Then they repeat the same story a second or third time, mostly using Russian. This happened, for example, when I visited Mariya Chirkova in Toižeg. As I knocked on her door, she was on the phone and let me in, inviting me to take a seat. She continued her conversation on the phone. She was clearly in a state of shock. She was explaining how a bear had attacked her in the morning when a car passed by and picked her up before the bear could reach her. At first, she spoke Vepsian, and then she shifted to Russian and back to Vepsian again for a few times. Repetition in code-switching studies has been observed in other cases where the speaker is bilingual. Repeating the same content in the two languages that the bilingual speaker masters is often meant to put an emphasis in what is being said (Auer 1998, 12). 
The middle-aged Vepsian villagers (those in their 30s-40s) employ the Vepsian language differently. Many admitted being able to understand Vepsian, but not being active speakers themselves. Others, instead, claimed very strongly to speak Vepsian. In their practices, language choice is often driven by ideological (if not political) ambition, having experienced the rise of the Vepsian revival movement. In contrast to their parents' generation, for example, they distinguish one linguistic system from another. Mostly they see languages not as a way of speaking differently (toižin), but as structurally different entities. Hence, they tend to be able to self-analyze their language practices. During an informal discussion, Marina Giniyatullina admitted, "See, I am mixing my own dialect with the standard form now ... I can fluently speak both forms." Marina Giniyatullina is originally from a Vepsian village in the Leningrad Oblast where she grew up speaking Vepsian and Russian. She now lives in Petrozavodsk.

Their language choice is often determined by their awareness of what code-switching indicates socially and politically. This is also the case of Vepsian city dwellers who studied Vepsian at school and university and began to speak their heritage language not during childhood but at a later stage in life. The less fluent the speaker is, the stronger his or her ideological and purist position (Woolard and Schieffelin 1994, 64). In other words, some speakers tend to apply a very purist approach to language, and apart from very few conjunctions, or shared words that have become part of the Vepsian lexicon, no words of Russian origin are heard during their speech. For example, they accurately provide numbers in Vepsian and this is not the case among the elders. If undecided between two synonyms (one in Vepsian and one in Russian), they tend to opt for the pure Vepsian word. Promoting a minority language has often conveyed a search for purity, discarding words and expressions that did not originate in the minority language. ${ }^{9}$ In the case of Veps, insisting on the adoption of pure Vepsian expressions does not concur with the experiences of the Vepsian language of the elderly. As shown earlier, some elderly Vepsian villagers were corrected by middle-aged Veps when they used the Russian language, instead of Vepsian, to count and say numbers. Numbers were used at school and in such institutions children used to be ridiculed (to say the least) for speaking their heritage language; so, they learned to provide numbers in Russian. Nowadays, this switch might have become a habit. When corrected, the elderly often repeated the numbers in Vepsian and smiled. Some shrugged their shoulders as to indicate that one way of saying it corresponded to the other. I also suspect that the adoption of pure Vepsian expressions may bring to the surface memories of backwardness and inferiority, as the elderly are yet again not proper in the way they use their heritage language.

The language attitude of the middle-generation Veps might be prompted, indeed, also by their more frequent interaction with the policy makers and the surrounding multiethnic population whose attitudes are often 


\section{Metaphors of Language}

disparaging. Upon my return from a rehearsal with the ensemble Vepsän Hel'm (V. Vepsian Pearl), Irina Stepanova (pseudonym), a Russian city dweller told me:

I heard your Veps on the radio today. I could understand everything they said. Do you know why? This is because they are so simple. They do not have enough words in Vepsian and always borrow our Russian words.

Irina Stepanova demonstrated to recognize the social power of multilingual practices, as it often happens in multiethnic societies (Woolard 1989). In fact, the use of code-switching can reinforce ethnic stereotypes and social hierarchies (Aikhenvald 2003). Adopting a purist version of Vepsian represents a shield behind which it is possible to operate on the other levels of the revival movement (such as the promotion of Vepsian culture) and justify their work.

In brief, the elderly villagers tend to maintain a position for which languages are not separate entities, but incorporate different morphological and phonological aspects and terms, depending on past memories, present and/or absent individuals. Lexical borrowing and code-switching are experienced as an extension of their own svoy and, hence, are not perceived negatively or as a cause of language endangerment. The elders appear not to view language as a marker of identity, as long as their family, house, animals, and village continue to exist. They indicated to be aware of the distinction between Vepsian and Russian when directly engaging with speakers of Russian only; thus, the switch had an immediate political hue. For the middle generation, instead, language choice often appears to be determined by ideological positions, which respond to the results requested by the policy makers and react to certain challenging attitudes of the surrounding multiethnic population. For this generation language is central to their identity (cf. Zamyatin 2013, 68).

$* * *$

This chapter has demonstrated how the metaphor of a language life cycle can be politically and socially problematic. When it first developed, it served the purpose to attract the attention of the policy makers around the world. In this sense, it has succeeded. However, its contemporary adoption reinforces paradigms of othering and it does not take into account language ecology comprehensively. Not only this biological approach does not comprise language ecology for its complexity, but it might also enter in conflict with existing ontologies of language. Hence, this might create friction with the desired goals of the revival movements. It separates language from action. It implies also that languages are separate entities that compete and eventually one language will assimilate or kill the other. This chapter showed how specific ways of speaking in the heritage language could be in 
opposition to certain academic assumptions about the language life cycle and its sequential steps leading to language death.

This represents a new way of reading the phenomenon of lexical borrowing and code-switching. While both phenomena are often interpreted as an indication of language loss, they can also be experienced as an enrichment of one's heritage language and as an engagement with the overarching language ecology that allows the speakers to experience life in more depth. I prefer, therefore, to link lexical borrowing to ideas of appropriation of foreign words which concurs with the symbolism attached to the svoy-chuzhoy dualism in Vepsian, according to which "joint work" and pragmatism can bring people and practices together, into one's sebr.

Code-switching and code-mixing can be more problematic as they are generationally dependent and linked to a more recent history of oppression and discrimination. The elderly villagers demonstrate not to distinguish language at a conscious level in their speech; unless, they engage directly with a Russian-only speaker. Their language use indicates that political discrimination and policies of assimilation in the form of Russian-only education have influenced their language use. Indeed, when covering such domains, they spontaneously shift into Russian. The middle generation, both in the villages and in the city appear, more aware of the political narrative around language death and loss, and, therefore, make more of a conscious effort in employing a purified version of the language. Such practice can act as a shield against accusations of simplicity and backwardness that still circulate among urban dwellers.

Incorporating the notions of language ecology and language ideologies to the analysis of multilingual practices has allowed me to let historical and socio-political complexities emerge. It has allowed me to appreciate how the use of metaphors among academic circles and political institutions can be reductive, not concur with the wider range of practices and ideologies among speakers, and, thus, consciously or not it risks reinforcing discrimination and processes of "othering."

\section{Notes}

1 UNESCO Endangered Languages. www.unesco.org/languages-atlas/.

2 Brenzinger (1992), Campbell and Muntzel (1989), Crystal (2000), Dixon (1997), Harmon (1996), Kibrick (1991), and Sasse (1992) are some example where the language death metaphor remained uncontested. Nettle and Romaine initially challenged such a metaphor, yet they decided to maintain it, since "languages are intimately connected to humans" $(2000,6)$.

3 The Endangered Languages Project. www.endangeredlanguages.com/.

4 Documentation of Endangered Languages. www.volkswagenstiftung.de/en/ funding/completed-initiatives/documentation-of-endangered-languages-completed. html.

Documenting Endangered Languages. www.nsf.gov/funding/pgm_summ.jsp? pims_id=12816. The Hans Rausing Endangered Languages Project. www.hrelp. org/. 


\section{Metaphors of Language}

5 The Estonian Kindred People's Program awarded the Ilmapuu Prize. http:// finugor.ru/en/node/17864.

6 On lexical movement into Russian, see also Samoilova (2001) and Devitsyn (1991).

7 See Barrett (1998), Milroy and Muysken (1995), Mishoe (1998) and Myers-Scotton (1993, 2002, 2006).

8 I use the patronymic for Nina Yur'yevna since I do not know her surname.

9 On this topic, see also Dorian (1994), Hornberger (2000) and Jaffe (1999). 


\section{A Way to Make Sense of the World Using Dialects in Villages}

As mentioned in a previous chapter, Mariya Filatova and Larisa Smolina are two former students of Vepsian in their late 20s/early 30s who now work as journalists in Petrozavodsk (Figure 1.2). Mariya Filatova runs Vepsian TV programs on the regional channels. She organizes interviews both on site and in studio. Her interviewees speak Vepsian with her. Larisa Smolina has a similar job, but for the Vepsian radio. She is also the coordinator of Paginklub (V. Speaking club) and co-editor together with Vladimir Slavov of four movies in Vepsian, Živatad vepslaižiden elos (Animals in the life of Veps) (2008), Vepslaižen kodin sudäin (Life in a Vepsian home) (2012), Paimnen torvut (The Magic Horn) (2014), and Sel'ktas vedes kala kokib (Fish bite in clean water) (2015). On different occasions, both Mariya Filatova and Larisa Smolina admitted employing mostly the Vepsian standard form in their speech, but also to use "some dialectal expressions" during the interviews. Larisa Smolina explained, "This way it is easier to connect to the elderly people in the villages. They feel that you are closer to them and understand you better."

Vepsian language comprises mostly three different dialects, the Northern, Central, and Southern Vepsian; although, there are differences in the ways villagers speak even within these broader categorization. For many elderly villagers, speaking a dialect often implies making sense of the world and maintaining an engagement with it. For this reason, they often adjust standard Vepsian to phonological, morphological, and lexical features of their dialect of origin. This way, they can understand and react to life events more spontaneously. In fact, they often do not criticize Vepsian standard form, but are not able to immediately relate to it (see Chapter 1). At first, Vepsian standard form sounds like a different way of speaking to their ears.

Building on dialectal differences, I aim to unpack the social understanding of the phrase pagišta toižin (V. To speak differently) further. This phrase indicates that the villagers do not reduce different ways of speaking to a category, such as a specific language or dialect. Speaking differently blurs the categorical boundaries that the standardization of Vepsian required instead. I also make reference to the Vepsian standardized form as opposed to 


\section{A Way to Make Sense of the World}

Vepsian dialectal features. However, a thorough presentation of the Vepsian codified form is only found in Appendix A. Particularly, I will show where the standardized form reduces dialectal varieties to one form and explain how this reduction mismatches dialectal ways of speaking.

\subsection{Speaking Differently: Dialects}

Veps live in a territory that is administratively split in three different regions of the Russian Federation (Map 1). Veps who speak the northern dialect can be found in the southeastern part of the Republic of Karelia. Veps who use central dialects, instead, live in the Babaevo and Vyterga districts of the Vologda Oblast and in the Podporoz'ye, Tikhvin, and Lodeynoe Pole districts of the Leningrad Oblast. The central dialects are further distinguished into eastern and western dialects. The southern-dialect speakers live in the Boksitogorsk province of the Leningrad Oblast. ${ }^{1}$

Many Veps confirmed that all these dialects are mutually intelligible, and, indeed, during my fieldwork, I witnessed misunderstanding among speakers of different dialects only once. Nonetheless, Veps accentuated certain characteristics of their own dialects. On a few occasions, they repeated what I had just said (in standard Vepsian) using their own dialect. In other words, they repeated the word that they could not recognize as familiar and pronounced it in the way it is used in their dialect of origin. This happened to me a couple of times, as I was trying to learn some new words from the dictionary. By repeating the words as pronounced in their own dialect, the elderly did not try to fix or correct my language, but they were making sense of what I was saying by pronouncing and hearing the various idioms in the way that was most familiar to them. I then understood that the native speaker is hearing phonemes and not just sounds (Sapir 1933). That is, the speaker hears meaning in sounds. He or she recognizes sounds within his or her knowledge and system of values and consequently is capable to spontaneously respond to them. Therefore, a Vepsian native speaker subconsciously recognized the phonemes of their own dialect as familiar, not those from a different dialect or the standardized form. On many occasions, Veps commented on dialectal variations thus: "this is how they say in the south/north or in that village." In other words, there was no mention of whether a pronunciation or way of saying was right or wrong, just different (toine in Vepsian). Indeed, speaking in their dialect, hearing and producing phonemes that sound familiar help Veps to make sense of the world, to feel what is happening around them and to be responsive to social and life events. Using the native dialect for Veps subconsciously not only indicates belonging to a group but also primarily encompasses experiencing and sharing worldviews and comprehending events and speech. Indeed, "language" is "heuristic, in the sense that its forms predetermine for us certain modes of observation and 
interpretation" (Mandelbaum 1985, 9). And this can be extended to dialectal variations, too.

\subsection{Dialectal Variations in Phonology}

Tables 6.1 to 6.3 present some of those characteristics that for Veps represent markers of their specific dialect. Some of them have and others have not been selected for the standardized form. On the top part of each table, I indicate the dialect to which each language form belongs. The last column also presents the form that has been adopted in the standard language. I will also make reference to Appendix A since this is where the standard language is presented more thoroughly. I expand on a brief explanation of some examples right after each table in order to provide the context where certain considerations were made. Providing the context

Table 6.1 Dialectal differences in Vepsian phonology. Those examples indicated with an asterisk (*) come from my firsthand field notes

\begin{tabular}{|c|c|c|c|c|}
\hline & $\begin{array}{l}\text { Northern } \\
\text { dialect }\end{array}$ & $\begin{array}{l}\text { Central } \\
\text { dialect }\end{array}$ & $\begin{array}{l}\text { Southern } \\
\text { dialect }\end{array}$ & $\begin{array}{l}\text { Standard } \\
\text { Vepsian }\end{array}$ \\
\hline $\begin{array}{l}\text { J'/d'/g' at the } \\
\text { beginning of } \\
\text { the word }\end{array}$ & $\begin{array}{l}\text { D’äpuraz } \\
\text { ('Icicle')"* }\end{array}$ & $\begin{array}{l}\text { Jäpuraz- } \\
\text { g'äpuraz } \\
\text { ('Icicle') }\end{array}$ & Jäpuraz ('Icicle') & $-j$ \\
\hline $\begin{array}{l}\text { Long/short } \\
\text { stressed } \\
\text { vowels at the } \\
\text { beginning of } \\
\text { the word }\end{array}$ & $\begin{array}{l}\text { Maa ('Land, } \\
\text { world')*1 }\end{array}$ & $\begin{array}{l}\text { Ma ('Land, } \\
\text { world')* }\end{array}$ & $\begin{array}{l}\text { Ma ('Land, } \\
\text { world')* }\end{array}$ & Short vowels \\
\hline $\begin{array}{l}\text { Diphthong } \\
\text { variation } \\
\text { (-ei- or } \\
\text {-ii-) }\end{array}$ & $\begin{array}{l}\text { Meiden } \\
\text { ('Our')" }\end{array}$ & Miiden ('Our')* & Not available & -ei- \\
\hline $\begin{array}{l}\text { Diphthong } \\
\text { variation } \\
\text { (-ū- or } \\
\text {-ui-) }\end{array}$ & $\begin{array}{l}\text { Pičuine } \\
\text { ('Small') }\end{array}$ & Not available & $\begin{array}{l}\text { Use of long } \\
\text { vowels instead } \\
\text { of diphthongs, } \\
\text { pičūne ('Small') }\end{array}$ & -ui- \\
\hline Palatalization & $\begin{array}{l}\text { Ol'en ('I am')*; } \\
\text { not after -i, } \\
\text { 'kävelin' ('I } \\
\text { went') }\end{array}$ & Olen ('I am')* & Not available & Soft form \\
\hline $\begin{array}{l}\text { Geminates } \\
\text { for the third } \\
\text { singular } \\
\text { person in the } \\
\text { indicative }\end{array}$ & $\begin{array}{l}\text { Rippub ('Hel } \\
\text { she hangs')- } \\
\text { no reduction } \\
\text { of geminate } \\
\text { consonants }\end{array}$ & $\begin{array}{l}\text { Ripub } \\
\text { ('He/she hangs') }\end{array}$ & $\begin{array}{l}\text { Ripub } \\
\text { ('He/she hangs') }\end{array}$ & $\begin{array}{l}\text { Geminates } \\
\text { reduction- } \\
\text { e.g., Ripub } \\
\text { ('he/she } \\
\text { hangs') }\end{array}$ \\
\hline
\end{tabular}

${ }^{1}$ On aspects of quantity, see also Tuisk (2010). 


\section{A Way to Make Sense of the World}

aims not only to help the reader contextualize events and episodes, but to reinforce my position according to which people manifest language in specific situations. Language does not happen randomly, but is manifested in relation to the world, to the present forces, ideologies, attitudes, etc. Hence, it needs to be studied for its all-inclusive ecology. The examples demonstrate how Veps experience life socially as well as at a more personal level through the medium of their Vepsian dialect. The phrase "not available" in the tables indicates that I do not have data for certain elements in some of the dialects.

The word d'äpuraz (V. Icicle) came up during a discussion with a group of Vepsian babushki (R. Grandmothers) in a shop in Kalag'. They could not remember the Vepsian word for icicle. I took my Russian-Vepsian dictionary out of my bag and read aloud what was written there. The dictionary indicated the word jäpuraz. The babushki took their time to think, discussed together for a bit, and agreed that it made sense, since $j \ddot{a}$ means ice. So they repeated d'äpuraz after me, adjusting my pronunciation to their dialect. The word jäpuraz has been created for the literary form of Vepsian and the Vepsian elders accepted it in their way of speaking after some consideration.

Another word which requires some consideration is olen (I am), as an indication of a softer pronunciation. Galina Lokkina became particularly irritated by the use of ol'en among the members of the group Vepsän Hel'm in Petrozavodsk. She associated the softer pronunciation with the way Veps living in the Republic of Karelia speak, not Veps from her region, the Leningrad Oblast. Similarly, Ol'ga Zhukova remarked that she does not soften her sounds when teaching Vepsian at university. And she concluded that, "My students speak Vepsian with the same accent as me." When Veps from different regions meet, they sometimes make these considerations, as I could also observe during the meetings at the Paginklub (V. Speaking club).

\subsection{Dialectal Variations in Morphology}

This section shows some dialectal differences in Vepsian morphology and presents standard Vepsian in the last column of Table 6.2.

Discussions over the endings of the words often occurred during the rehearsals of the Vepsian ensemble Vepsän Hel'm (V. Vepsian Pearl). Most of the members of the group came from different Vepsian villages. Some were born in the Leningrad Oblast; others were from the villages in the Vepsian district of the Republic of Karelia. Once again, the differences in the declension did not cause misunderstanding. The comments often referred to different ways of speaking and sparked curiosity, "Oh, so this is how you say it in your village!" If a student of Vepsian was present during the rehearsal, the other members of the group often asked what the standard form was. Once the dialectal differences and standard form were identified, they always tried to agree on one form to sing together. 
Table 6.2 Dialectal differences in Vepsian morphology. Those examples indicated with an asterisk (*) come from my firsthand field notes

\begin{tabular}{|c|c|c|c|c|}
\hline & $\begin{array}{l}\text { Northern } \\
\text { dialect }\end{array}$ & $\begin{array}{l}\text { Central } \\
\text { dialect }\end{array}$ & $\begin{array}{l}\text { Southern } \\
\text { dialect }\end{array}$ & $\begin{array}{l}\text { Standard } \\
\text { Vepsian }\end{array}$ \\
\hline $\begin{array}{l}\text { Third pl. suffix } \\
\text { for imperfect } \\
\text { tense }\end{array}$ & $\begin{array}{l}\text {-b (e.g., } \\
\text { Tulib, } \\
\text { 'they were } \\
\text { coming')* }\end{array}$ & $\begin{array}{l}\text {-ba (e.g., } \\
\text { Tuliba, 'they } \\
\text { were coming') }\end{array}$ & $\begin{array}{l}\text { Not } \\
\text { available }\end{array}$ & $\begin{array}{l}\text {-ba } \\
\text { (see Table A.7) }\end{array}$ \\
\hline $\begin{array}{l}\text { Declension } \\
\text { (adessive: } \\
\text { 'kenel/mil?', } \\
\text { 'where?') }\end{array}$ & $\begin{array}{l}\text { Not } \\
\text { available }\end{array}$ & $\begin{array}{l}\text {-l/-ou (e.g., } \\
\text { Pagastal / } \\
\text { pagastou, 'in } \\
\text { the center of } \\
\text { the village')* }\end{array}$ & 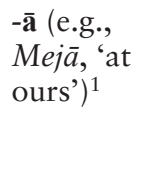 & -1 (see Table A.6) \\
\hline $\begin{array}{l}\text { Declension } \\
\text { (comitative: } \\
\text { 'kenenke/ } \\
\text { minke?', 'who/ } \\
\text { what with?') }\end{array}$ & $\begin{array}{l}\text {-nke (e.g., } \\
\text { Sizarenke, } \\
\text { 'with the } \\
\text { sister) }\end{array}$ & $\begin{array}{l}\text { Eastern dialect } \\
\text {-dme/tme (e.g., } \\
\text { Pertidme, 'with } \\
\text { the house'); } \\
\text { Western dialect } \\
\text {-nke (e.g., } \\
\text { Koiranke, 'with } \\
\text { the dog') }\end{array}$ & $\begin{array}{l}\text {-dme/ } \\
\text { tme (e.g., } \\
\text { Sizartme, } \\
\text { 'with the } \\
\text { sister') }\end{array}$ & -nke (see A.6.) \\
\hline $\begin{array}{l}\text { Declension for } \\
\text { direct object } \\
\text { (genitive: } \\
\text { kenen/min? } \\
\text { 'Whom? } \\
\text { Whose?') or } \\
\text { (partitive: } \\
\text { keda/midä? } \\
\text { 'Whom?') }\end{array}$ & $\begin{array}{l}\text {-n (e.g., } \\
\text { Radon, } \\
\text { 'work')" }\end{array}$ & $\begin{array}{l}\text {-d/t (e.g., } \\
\text { Koncertoid, } \\
\text { 'concerts')* }\end{array}$ & $\begin{array}{l}\text { Not } \\
\text { available }\end{array}$ & $\begin{array}{l}\text {-n for direct } \\
\text { object in positive } \\
\text { sentences; -d/-t } \\
\text { for direct object } \\
\text { in negative } \\
\text { sentences, after } \\
\text { abstract verbs } \\
\text { and to express } \\
\text { indefinite } \\
\text { quantity }\end{array}$ \\
\hline
\end{tabular}

${ }^{1}$ Vepsian codified form uses the ending $-l$ for the adessive case. See Appendix A subsection A.4.

\subsection{Dialectal Variations in Lexicon and on the Discourse Level}

This section shows some dialectal differences in Vepsian lexicon and on the discourse level. Standard Vepsian is also presented in the last column of Table 6.3.

Dialectal differences in Vepsian lexicon and on the discourse level also require some explanation. I personally did not hear the question Midä kulub tiiden agjha? Ol'ga Zhukova confirmed that this is how her babushka greets her friends from the villages around Kurb in the Leningrad Oblast. She also told me that elderly Veps who speak the central dialect tend to ask void-ik? (V. Can you?) in order to know how a person is doing (cf. Korol'kova 2015, 164). The latter question puts the stress on the verb voida (V. Can, be able 


\section{A Way to Make Sense of the World}

Table 6.3 Dialectal differences in Vepsian lexicon and on the discourse level. Those examples indicated with an asterisk $(*)$ come from my firsthand field notes

\begin{tabular}{|c|c|c|c|c|}
\hline & $\begin{array}{l}\text { Northern } \\
\text { dialect }\end{array}$ & $\begin{array}{l}\text { Central } \\
\text { dialect }\end{array}$ & $\begin{array}{l}\text { Southern } \\
\text { dialect }\end{array}$ & $\begin{array}{l}\text { Standard } \\
\text { Vepsian }\end{array}$ \\
\hline $\begin{array}{l}\text { 'How are } \\
\text { you?' }\end{array}$ & $\begin{array}{l}\text { Not } \\
\text { available }\end{array}$ & $\begin{array}{l}\text { Midä kulub tiiden } \\
\text { agjha? (Any } \\
\text { news from your } \\
\text { region?)* }\end{array}$ & Not available & $\begin{array}{l}\text { Kut sinun azjad } \\
\text { oma? (V. 'How } \\
\text { are your things?') }\end{array}$ \\
\hline 'word' & Sana & Vajeh & Not available & Sana, Vajeh \\
\hline 'mushroom' & $\begin{array}{l}\text { Not } \\
\text { available }\end{array}$ & $\begin{array}{l}\text { Western Central } \\
\text { Veps: grib/sen;' } \\
\text { Eastern Central } \\
\text { Veps: babuk* }\end{array}$ & $\begin{array}{l}\text { Babuk, grib and } \\
\text { sen’ (the latter } \\
\text { is used for cure } \\
\text { and healing } \\
\text { purposes) }\end{array}$ & Babuk, grib, sen \\
\hline 'to cry' & Itktä* & Voikta* & Mäläita* & $\begin{array}{l}\text { Itkä, voikta, } \\
\text { mäläita }\end{array}$ \\
\hline $\begin{array}{l}\text { 'thick spruce } \\
\text { forest' } \\
\text { (Mullonen } \\
\text { and Zaiceva } \\
2017,117 \text { ) }\end{array}$ & Pibk & $\begin{array}{l}\text { Western Central } \\
\text { Veps: pibk; } \\
\text { Eastern Central } \\
\text { Veps: pibk, kujo, } \\
\text { räde }\end{array}$ & Vid'a, pibk & Not available \\
\hline $\begin{array}{l}\text { 'swamp, } \\
\text { quagmire' } \\
\text { (Mullonen } \\
\text { and Zaiceva } \\
2017,119 \text { ) }\end{array}$ & $\begin{array}{l}\text { Not } \\
\text { available }\end{array}$ & $\begin{array}{l}\text { Western Central } \\
\text { Veps: nova; } \\
\text { Eastern Central } \\
\text { Veps: nova, nola, } \\
\text { poz'alpoz'e }\end{array}$ & Not available & Nova \\
\hline $\begin{array}{l}\text { Semantics of } \\
\text { the word org } \\
\text { (Mullonen } \\
\text { and Zaiceva } \\
\text { 2017) }\end{array}$ & $\begin{array}{l}\text { 'Thick } \\
\text { forest' }\end{array}$ & $\begin{array}{l}\text { Western Central } \\
\text { Veps: 'Lowland'; } \\
\text { Eastern Central } \\
\text { Veps: 'Lowland, } \\
\text { gully, creek' }\end{array}$ & Not available & $\begin{array}{l}\text { 'Thick forest, } \\
\text { lowland' }\end{array}$ \\
\hline
\end{tabular}

to). ${ }^{2}$ In other words, Veps are interested in whether or not a person is still capable of working, more than in his/her health, which seems more abstract and not having a pragmatic reflection in everyday life. Many Veps claimed not to ask how a person is, but rather what they are doing and where they are going. Aleksey Maksimov told me that people always feel embarrassed and do not know what to answer when someone asks how they are doing. Indeed, the linguists had to calque the Russian kak dela and created the question, kut sinun azjad oma (V. How are your things?) in order to ask how a person is generally doing. Such a question is often used among the activists and city dwellers, but not among the elders in the villages.

The shop assistant in Toižeg made a similar observation when I asked her some questions from a Vepsian-Russian phrasebook, such as midä tö söt murginaks? (V. What do you eat for breakfast?). She commented: 
We never ask what a person has for breakfast. I do not even think that we used to have such a word to indicate breakfast. However, the question is grammatically correct. This is how I would ask what someone had for breakfast, if I ever wanted to know.

The process of standardizing the Vepsian language active use and discourse has followed a specific logic and has responded to social dynamics that are highly politicized. Here I do not engage directly with such a political discourse, since that is discussed in the next chapter. This chapter describes the importance of dialectal variety. In this sense, it partly concurs with the criticism advanced by Mühlhäusler $(1992,2000)$ who emphasizes the importance of linguistic variety in the maintenance of more marginalized languages. Instead, many scholars have focused on the structure of a language in order to promote and revitalize it, neglecting the promotion of dialectal variation (Mühlhäusler 1992, 164). The reduction of language diversity is also referred to as leveling and koineization in the literature (Cheshire et al. 1989; England 2003, 737; Kerswill 2001).

It is clear that promoting both the structure of a language and active discourse provides a more rounded description of a language. Hence, the revival efforts are also more likely to succeed. If the standard language distances itself too much from the spoken dialects, people may simply reject standardization (King 2011). Besides, promoting language diversity enables us not to lose human creativity and intellectual diversity (Enninger and Wandt 1984; Hale 1998; Mithun 1998). An example of this is the Vepsian writer Nikolay Abramov who used to find inspiration for his poetry wandering about, relating to the village of origin, to the land, forest, and lakes that surround it.

The present ethnographic study in urban and rural areas of the Vepsän ma does not entirely agree with the criticism advanced by Mühlhäusler toward the creation of a standard form in the promotion of a minority language. The creation of one Vepsian standard form has resulted from an interaction with political and ideological paradigms in the city. And this is also part of the broader Vepsian language ecology. Besides, promoting standard Vepsian for written purposes has also provided valuable outcomes. It is true, though, that such a political touch to the revival movement has overshadowed other practices and views that the Vepsian city and village dwellers now demand. And for this reason, I presented them here.

This chapter focuses on the importance to maintain dialectal variations when promoting the heritage language of a minority group. Native speakers feel closer to their feelings, the significance of what they hear and want to say when engaging with the dialectal form of their heritage language. Aiming at the development of literacy within revival movements provides several benefits, from advancing the cause and visibility of a minority group to creating 


\section{A Way to Make Sense of the World}

the foundations for more domains of use. Yet, it risks overshadowing uses of the language that emerges from a rich, creative, and often spontaneous engagement with the environment, land, human, and non-human beings. Therefore, promoting the maintenance of dialectal variations does not discard the predominant focus of worldwide movements on literacy; rather, it hints at a multimodal intervention where human creativity is retained as well as numerous verbal interactions with the world, the environment, society, and individuals.

\section{Notes}

1 Dialektnaya osnova vepsskoy orfografii. http://vepsia.ru/yazik/dialekt.php.

2 Cf. the Finnish question kuinka voit? (F. How are you?), which literally means how can you? 


\section{Vepsän kel' and the City}

Forests, fields, lakes, rivers . . .

I find berries, I catch fish.

I know one thing: only the blind

Could abandon this land.

On top of a pinewood the wood grouse performs courtship rituals,

I love his language. ${ }^{1}$

Here they gave me my name

Here they gave me my intellect. ${ }^{2}$

Abramov, N. (1996) Kodima

Nikolay Abramov (1961-2016) was a Vepsian writer and journalist in his early 50s who moved from Ladv, in the Leningrad Oblast, to Petrozavodsk after the Vepsian revival movement had begun. He once explained that Nina Zaitseva had heard about his skills as a Vepsian poet and came to Ladv to recruit him in the early 1990s. His written language is emblematic of those who left the villages and moved to the city as adults, as he can freely swing between his own native dialect and the standard form of Vepsian in his writing. Veps generally accept that those who moved from the villages to the city as adults had mastered the oral form of Vepsian and subsequently could more easily learn how to write in literate, standard Vepsian. Those who moved from the villages at an early age, instead, never or very seldom spoke Vepsian at home. Many claim to understand it when spoken by others, but to speak it with difficulty. People who grew up in urban settings became acquainted with spoken Vepsian mainly during the summer breaks when visiting their babushka (R. Grandmother) in the villages. Some of them express interest for the language and most often wish they had been taught it at an early age, since the lack of time and the complex Vepsian grammatical system make it difficult to learn it as an adult, as shown in Appendix A. For example, Irina Baranova often complained, "My babushka only spoke Vepsian to her friends. She always told me you do not need it! And never spoke it to me. I so regret this." Vepsian educated people at school and/or university usually employ the standard form of Vepsian in both their speaking and writing practices. 


\section{Vepsän kel' and the City}

In Petrozavodsk, many fluent adult speakers of Vepsian are employed in different offices where Vepsian is required. They can make use of their oral knowledge of the language once they have also acquired writing skills in Vepsian. Indeed, Nikolay Abramov admitted that the use of his native village dialect prevailed in his poetry, whereas the standardized written form of Vepsian dominated in the newspaper articles he wrote. While his poetry began to take shape as he was wondering about the land and thinking a couple of lines and only then sitting down to actually perform the act of writing, writing newspaper articles involved specific political and revival goals. Nikolay Abramov confirmed that he chose his vocabulary carefully, depending on the type of writing in which he was engaging. He admitted not to mind using the word tedomašin (V. Computer) in the articles. But he unveiled that he would use the word computer in spoken Vepsian. The word tedomašin has been created for the standard form of Vepsian. Employing this word (as other newly created words) bears highly politicized connotations of which the writer is well aware. Such an observation conforms to the theoretical frame of this work, according to which the language ecology metaphor comprises paradigms of interaction and socialization with the world. In other words, language cannot but be manifested in relation to the present forces, whether they are mostly ideological, political, or other.

This chapter completes the analysis of the Vepsian language in Chapters 4, 5 , and 6 by focusing on Vepsian language use in the city. It examines Vepsian writing practices since this mode of the language prevails and satisfies a number of aims in a city such as Petrozavodsk. At times Vepsian literacy becomes a political tool to gain visibility both nationally and internationally. The activists further appreciate it for its political capacity to bring together the scattered Vepsian villages. Other times using Vepsian writing enables Veps to subvert socially accepted power relationships. It can, for example, symbolize the reaffirmation of the in-group (i.e., Veps) as opposed to the out-group (i.e., the multiethnic society of Karelia) through the adoption of a secret code (Siragusa 2017). It also provides space for people to express themselves in their heritage language, which was not the case before perestroika and glasnost. Therefore, I here elaborate on the broader discussion on language and power and show how literacy bears political overtones in this multiethnic environment.

\subsection{Literacy in Russia}

During my first year of fieldwork in Karelia, I became quite a popular figure among the local intelligentsiya, and this allowed me access to the cultural activities organized there and to take active part in discussions and interviews. One of the local freelance journalists, a woman in her 50s in particular insisted that we met for an interview she would later sell to a local 
newspaper. I accepted and we met in town. One of the first questions that she asked me was which one was my favorite Italian author. That question got me unawares as I was used to be asked on the reasons why I was so interested in Vepsian matters and my experience of Northwestern Russia. I hesitated a bit and mumbled that I was mostly reading in English, and could not think of any favorite Italian author there and then. Not being able to promptly respond to such a question bugged me the whole afternoon as names of Italian authors kept coming to mind; and, in fact, when I think about it, it still bothers me after so many years since this episode occurred. What I felt was embarrassment, as I perceived to be examined and judged as soon as she stepped in and said, "I knew it. They say that in Paris nobody reads, whereas here [in Russia] we read all the time. They call us 'the most reading nation in the world.' "For a moment, I could better empathize with Veps (or any other group that is put down) on how it feels to be labeled as backward and uneducated.

In her eyes, the Soviet prescriptions to elevate the illiterate population to high culture and become "the most reading nation in the world" had indeed succeeded (cf. Anderson 1991; Venediktova 2010). What's more, such remarks matched a conceptualization of the chuzhoy (R. Foreign), which carries in itself ambivalence and polarity when transferred to a discussion about national minorities of Russia and "Westerners" (in such a case, being French or Italian does not make any difference). The "Western" chuzhoy carries apparently contradicting semiotic connotations; on the one hand, it can be perceived as different and dangerous, even as "the enemy." The "West" becomes a rival which has to be beaten at intellectual level as well as any other: indeed I-as a representative of the "West"-often felt part of a race where the winner was who had invented the most important scientific discoveries throughout history. On the other hand, the "West" can be associated with high culture and high art for which it is respected and almost felt as svoy (cf. Ssorin-Chaikov 2008). Because of this ambiguity, in the eyes of many Russians, the two systems, the Russian svoy and the "Western" chuzhoy, can be perceived as either related and close given the common rich cultural background and interest or they can enter in competition and clash, as was the case with the Russian journalist.

Instead, the chuzhoy embodied by the multicultural ethnographic composition of the population of Russia is still often associated with cultural backwardness and inferiority. It is not surprising, therefore, that when given the opportunity to promote their language and culture in the mid- to late'80s, many representatives of the miscellaneous ethnic groups of Russia (either a minority or not) aspired to create a standard form of their heritage language in order to advance high culture and secure their status and rights within such literacy-led State and social ideology (cf. Ricento 2017; Vakhtin 2005; Zamyatin et al. 2012). 


\section{Vepsän kel' and the City}

\subsection{Literacy and Feeling "Not Inferior to Anyone on any Level”}

In November 2009, Nina Zaitseva participated in a training seminar in Petrozavodsk for teachers of the national languages of Karelia. She clarified her position as the creator of standard Vepsian at the beginning of her talk:

Each nationality should aspire to have its own written form. You need to standardize the language as this will enable you to write. Only when you have a standard language can you prove that you can count, name different objects and miscellaneous things and not be inferior to anyone on any level [my emphasis]. ${ }^{3}$

The Vepsian activists who launched the revival movement at the time of glasnost and perestroika found themselves in a socially and politically complex situation. How can Vepsian be promoted and maintained, when it has been repressed and banned for so many years? How can the population be inspired with confidence when they believed there was nothing to teach in Vepsian due to its linguistic poverty? In other words, how is it possible to fight against the belief that Vepsian as a non-literate language was backward and inferior to literate Russian? In a country such as post-Soviet Russia, which many in Karelia regarded as the literate country per excellence, not having a written form constituted a problem. Most of the population of Petrozavodsk value literacy as a very positive skill and a marker of civilization. It comes as no surprise that the Vepsian activists turned to literacy in order to promote their heritage language right after the collapse of the Soviet Union. Creating a written form of Vepsian served the purpose of raising their heritage language up to the level of Russian, so as not to be associated with ignorance and backwardness any longer. In this regard, the Vepsian activists conformed to evolutionary approaches to language where literacy was viewed as the next step in the evolutionary ladder.

Still, Vepsian had only experienced an oral tradition until the late 1920 s to early 1930s. No records have been found of Vepsian writing apart from a dictionary composed in the nineteenth century and a birch bark letter in an old Finno-Ugric language from the sixteenth century (Haavio 1964). The very first concrete attempts to codify and standardize Vepsian occurred at the time of korenizatsiya ( $\mathrm{R}$. Indigenization), when a group of scholars from the Leningrad Oblast, led by Bogdanov, began collecting material on the Vepsian language and created a standard form of the language (Kettunen and Siro 1935; Salminen 2009; Setälä et al. 1951). Nina Zaitseva explained, "These academics embarked on a number of expeditions to the scattered Vepsian villages (mainly in the Leningrad Oblast), collected language material and created an alphabet for the written form of Vepsian." 4 The 1920s-1930s movement mostly developed in the Leningrad Oblast and the villages of Järv' and Šimjärv' became the 
main cultural centers. Šimjärv', specifically, was expected to become the capital of the region. ${ }^{5}$ They stipulated that the literary Vepsian language would be based on the dialect of Pelushi, a Central Vepsian dialect. ${ }^{6}$ They also created new terms specifically to cover some of the lexicon used at school such as känd (V. Case), openduzkirj (V. Textbook), vajehnik (V. Dictionary), and äilugu (V. Plural). ${ }^{7}$ In 1932 and 1936 the very first Vepsian textbook and Vepsian primer were published in a Latin script thanks to their activities (Strogal'shchikova 2008a, 218). A total of 53 primary schools and seven secondary schools were opened (Strogal'shchikova 2008a, 220). Indeed, the Soviet aim to reach out to the various ethnic groups in order to form the Soviet citizen initially involved the creation of an alphabet, the creation of a standard language, followed by the production of teaching material (Hirsch 2000, 2005; Laine 2001; Zamyatin 2013). Under the Soviets the peoples of the North had similar experiences in regard to literacy (Vakhtin 2005). They experienced a "glorious beginning in the 1930s interrupted by the war, then a strong continuation in the 1950s, then a drop in the 1960s-70s, and a resurrection in the 1980s, interrupted by the economic crisis of the early 1990s" (Vakhtin 2005, 131). Vepsian writing also had a very short lifespan since it was banned at the peak of Stalin's terror in 1937. During our interview, Nina Zaitseva reported that in the late 1930s academic figures such as "Hämäläinen were imprisoned not because of their knowledge of Finnish, but because of their work on the Vepsian language" (cf. Strogal'shchikova 2016).

In the late 1980s, the new generation of Vepsian activists looked back at the model established in the 1930s and decided to follow its general approach. Most of them were working and residing in Karelia, not in the Leningrad or Vologda Oblasts. Adopting a written form meant overcoming the difficulty of the administratively split and politically dispersed Vepsian villages, besides making Vepsian socially more prestigious. Language began to symbolize the traditional sebr. As such, it covered a specific economic and political role. As Nina Zaitseva explained,

Standardizing Vepsian meant creating a single form which included all the dialectal differences. Everyone could see some aspects of their own dialect in the standard language and, as a consequence, understand the written texts.

The activists were hoping to restore confidence, to shift the language ideology of the Vepsian population and to prompt language use by employing all the dialects in the standard form and written texts in contrast to 1920 s selection of one dialect as official. Once Vepsian was standardized, they invested in Vepsian education as per the 1920s-1930s model. Nina Zaitseva together with Mariya Mullonen, who also worked at the Academy of Sciences at the time, soon understood that they "could not rely on the family since the language was spoken less and less in the domestic environment." ${ }^{8}$ Nina 


\section{Vepsän kel' and the City}

Zaitseva continued, "So we invested in the teachers. Up to now, our biggest hopes reside in the teachers, the schools and kindergarten."

The activists opted for an institutional intervention. At the time, questions related to how a minority language could otherwise be promoted did not occur. The activists mostly engaged with the political powers since providing concrete results such as statistical data on the number of publications, schools, and pupils also secured political and financial support. The promotion of literacy as per the 1920s-1930s model remained unchallenged (Comrie 1981, 9-10; Grenoble 2003, 48). Literacy remained the focus as opposed to speaking a language within the Vepsian revival movement.

\section{Vepsian Standardization}

The main question that troubled the language movement in the late 1980s was whether or not to follow the steps of the 1930s movement in their language choices. Despite a general consensus on the creation of a written form, the new generations of scholars decided to re-consider previous language choices. They reviewed the alphabet and some grammatical features. The scholar Hämäläinen, who had been arrested for his research on the Vepsian language in the late 1930s, was working again at the Academy of Sciences when Nina Zaitseva completed her studies and began her career as a Vepsian linguist. While he continued his research on the history of the language, Nina Zaitseva and Mariya Mullonen focused on the creation of a written standard for Vepsian. Their starting points materialized in the body of books written in the 1920s-1930s and two texts which Mariya Mullonen and Mariya Zaitseva had compiled in 1969 and 1972, a collection of Vepsian dialects and a Vepsian dictionary, respectively (Zaitseva and Mullonen 1969; Zaitseva and Mullonen 1972). ${ }^{9}$ While holding these books in her hands, Ol'ga Zhukova commented:

When Mariya Mullonen and Mariya Zaitseva produced these texts, they believed that their task was only to document Vepsian. Look, instead, how far we have gone from that.

Indeed, Vepsian writing has developed extensively since then. Inheriting these texts, Nina Zaitseva and Mariya Mullonen focused on the creation of a codified form of the Vepsian language-i.e., the creation of an alphabet, of its lexicon, morphology, and phonology. They opted for the Latin script as in the 1930s. Nina Zaitseva explained that, "Vepsian belongs to the same language family as Karelian, Finnish, and Estonian where the Latin alphabet is adopted and in use." They decided to omit some characters taken up in the 1930s (e.g., $s$ and $c$ ) and to accept other existing graphemes from other alphabets "such as the Czech alphabet, so that it would be easier to read Vepsian elsewhere [that is, not only in Russia]" (Table 7.1). 
Table 7.1 Vepsian alphabet in the 1930s and during glasnost. This table is adapted from Bogdanov et al. (1932, 75-77) and Zaitseva and Mullonen $(2009,14)$

\begin{tabular}{|c|c|}
\hline Vepsian alphabet in the 1920s-1930s & Vepsian alphabet during glasnost \\
\hline $\mathrm{Aa}$ & $\mathrm{Aa}$ \\
\hline Ää & $\mathrm{Bb}$ \\
\hline $\mathrm{Bb}$ & $\mathrm{Cc}$ \\
\hline $\mathrm{Cc}$ & $\check{C} \check{c}$ \\
\hline Çç & $\mathrm{Dd}$ \\
\hline $\mathrm{Dd}$ & $\mathrm{Ee}$ \\
\hline $\mathrm{Ee}$ & $\mathrm{Ff}$ \\
\hline Ff & $\mathrm{Gg}$ \\
\hline $\mathrm{Gg}$ & $\mathrm{Hh}$ \\
\hline $\mathrm{Hh}$ & $\mathrm{Ii}$ \\
\hline Ii & $\mathrm{Jj}$ \\
\hline $\mathrm{Jj}$ & $\mathrm{Kk}$ \\
\hline $\mathrm{Kk}$ & $\mathrm{Ll}$ \\
\hline $\mathrm{Ll}$ & $\mathrm{Mm}$ \\
\hline $\mathrm{Mm}$ & $\mathrm{Nn}$ \\
\hline $\mathrm{Nn}$ & Oo \\
\hline Oo & $\mathrm{Pp}$ \\
\hline Öӧ & $\mathrm{Rr}$ \\
\hline $\mathrm{Pp}$ & Ss \\
\hline $\operatorname{Rr}$ & $\check{S} \check{s}$ \\
\hline Ss & $\mathrm{Zz}$ \\
\hline Şş & $\check{Z} \check{z} \check{z}$ \\
\hline $\mathrm{Tt}$ & $\mathrm{Tt}$ \\
\hline $\mathrm{Uu}$ & $\mathrm{Uu}$ \\
\hline $\mathrm{Vv}$ & $\mathrm{Vv}$ \\
\hline Yy & Üü \\
\hline $\mathrm{Zz}$ & Ää \\
\hline$Z_{z}$ & Ö̈̈ \\
\hline '(hard sign) & ' (soft sign) \\
\hline ' (soft sign) & \\
\hline
\end{tabular}

Other concerns covered Vepsian vocabulary that mostly lacked contemporary words. Both Nina Zaitseva and Irma Mullonen clarified that, "People always lament that there are not enough words in Vepsian." Compensating for the poverty of the Vepsian lexicon became the priority of the language activists. Some aspects of a language are valued more within a multilingual society than others (Woolard and Schieffelin 1994, 


\section{Vepsän kel' and the City}

69). Within multiethnic Karelia, not having a rich and abundant vocabulary is an index of linguistic poverty. On the other hand, a complex and articulated morphological system such as that of the Vepsian language (Appendix A) is not regarded as an index of linguistic wealth. Such a language ideology reinforces a social and political hierarchy. In other words, Russian and its abundant vocabulary gain more social value than the complex Vepsian morphological features. On the example of the longstanding tradition set by Franz Boas, Cruikshank $(2005,3)$ shows how the Athapaskan and Tlingit languages have a complex verbal system which shows a different worldview and more interest in certain aspects of life, but does not indicate simplicity and/or linguistic poverty. In the linguistic hierarchical scale shared by the multiethnic population of Karelia, the Vepsian lexicon is ranked lower than Russian's, whereas the Vepsian verbal system is not ranked higher despite its complexity. Unmistakably in this context, the Vepsian activists responded to the dominant language ideologies of the multiethnic society where their movement took place. They responded by actually bending to the dominant language ideologies where expansion of the vocabulary indicated language wealth. They also responded to a Vepsian population that mostly justified not speaking Vepsian due to the lack of contemporary words. It could be argue that the overarching language ecology in which they began to promote the Vepsian heritage language influenced their promotional choices.

In regard to lexical development, the work of the linguists progressed mainly in three directions-cooperation with teachers, cooperation with researchers and students, and application of Vepsian logic (i.e., morphosyntactic patterns) for the creation of new words. They cooperated with the teachers for the creation of school-related vocabulary. As Nina Zaitseva explained, "part of this vocabulary did not exist until the 1930s." The teachers mostly tested the newly created vocabulary and referred back to the activists to ascertain whether or not these words had been adopted by the pupils. When they had not, the activists kept trying and published new words in the Vepsian bulletin, a booklet with newly created Vepsian words. The language activists cooperate with the researchers and students at university in order to reinstate unused words. During their data collection, the university students gather lexical material that enables them to write their thesis. This material is then analyzed by the linguists at the Academy of Sciences. The students also analyze Vepsian material collected in library archives, such as those in Estonia, which allows them to re-discover unused words. An account of this is the investigation on Vepsian lamentations conducted by Ol'ga Zhukova, which allowed the reintroduction of obsolete words such as $i z o r$ (V. Dear, favorite). The lamentations are a Vepsian genre performed at funerals and weddings (Zaitseva and Zhukova 2012; Zhukova 2015). ${ }^{10}$ Last, the linguists created new words "using the internal logic of the Vepsian language." Ol'ga Zhukova explained that the word hangoine (V. Fork) was not in use among the villagers. However, the word hang (Pitchfork) existed 
in Vepsian, since this tool was used to work the hay. So, the word hangoine was created by adding the suffix -ine to the root of the original Vepsian word hang. ${ }^{11}$ While words such as izor and hangoine are introduced and used at school, I did not witness their use in everyday conversations. Indeed, I heard villagers use the Russian word vilka instead of hangoine. They also do not appear in the transcriptions and texts archived in the website Korpus Vepsskogo Yazyka (R. The Corpus of the Vepsian Language).

The new Vepsian dictionary, Novyy vepssko-russkiy slovar' (R. The new Vepsian-Russian Dictionary), also included several synonyms due to Vepsian dialectal variations. Nina Zaitseva explained:

We do not fear the fact that Vepsian has more than one synonym. The northern Veps say pol'v [V. Knee] and the central Veps say komb. We then decided to regard both as correct and write them as synonyms in the dictionary.

This practice reflects the conscious decision to include all dialects in the standardization process. In regard to Vepsian lexicon, the linguists avoided the risk of linguistic reduction and/or leveling (Cheshire et al. 1989; England 2003, 737; Kerswill 2001). On the contrary, the Vepsian activists aimed to enrich the vocabulary by including all the Vepsian dialects and ways of speaking. The dictionary is generally well received among the educators and writers. The villagers often comment that these are toine (V. Different) ways of speaking and do not value them either as correct or incorrect. The multiethnic population of Petrozavodsk has multiple perspectives on the expansion of Vepsian lexicon. For example, Irina Ivanova (pseudonym) who teaches Russian at university commented, "Then they create new words in Vepsian. I think they have gone too far. This looks like a game to me!"

Nina Zaitseva and Mariya Mullonen employed a different approach when dealing with Vepsian phonology and morphology. The linguists agreed that, "the most intelligible variant [of each separate case] would represent the base for the model language." 12 They did not choose one dialect to be standardized; rather, they selected the forms to be standardized from all the dialects. The codification of Vepsian phonology presented a number of complications since Veps pronounce the same word in multiple ways depending on their dialect of origin (Chapter 6 Table 6.1). The language activists claimed that choosing only one single form for each different pronunciation feature aimed to facilitate the use of the dictionary and help the children in their learning process. Nina Zaitseva showed how some of the 1930s Vepsian textbooks often provided the same word in multiple orthographic versions. She explained:

The child who looks at the written texts is going to wonder what is this? And [(s)he] will turn to Russian where they have rules on how words should be written. How should we write for this child? Do you 
understand? If you give a word to each member of the Vepsian society, they will say it correctly but differently-for example, they will say raavaz and rahvaz and rahvas [V. People].

Therefore, they opted for one common orthographic rule. For example, the word järv (V. Lake) is also pronounced as g'ärv and d'ärv and the word jogi (V. River) is also pronounced as g'ogi and d'ogi. In this case, the language commission opted for the spelling with $j$ at the beginning of the word (Chapter 6 Table 6.1). The codification of Vepsian morphology also presented a rather complex scenario. For this reason, each case was once again "studied and analyzed separately." For example, the commutative case can be formed by adding the suffixes -nke and -dme in the Vepsian dialects. The phrase with the comb can be produced both as sugadme and suganke. The latter was chosen as the standard form since the suffix -dme belonged also to the prolative case. In other words, the activists opted for the adoption of syncretism in regard to phonology and morphology, hoping that this could help the pupils learning Vepsian from scratch at school.

They also employed other strategies to assist the pupils in their learning process. At times, presenting similarities with the Russian model also meant facilitating the acquisition of the Vepsian language for those who had not experienced speaking it at home. An example can be found in the use of the questions where, where to, and where from, whose presentation is modeled on the Russian grammar (Appendix A section A.4.). For example, where Russians apply the preposition $n a(\mathrm{On} / \mathrm{to})$ to indicate movement, Vepsian applies the suffix -le. The Russian phrase idti na rabotu (Go to work) is equivalent to mända radole in Vepsian. Ol'ga Zhukova often repeats in class, "This is the same as in Russian" to help the students learn the Vepsian forms.

As suggested by the examples earlier, the choices made regarding Vepsian morphology and phonology reduced the dialectal variants to one form, in contrast to the codification of Vepsian lexicon. Despite the potential criticism about leveling and koineization found in the literature, this practice does not seem to perturb Vepsian writers and educators. On the contrary, most teachers are very grateful to Nina Zaitseva for her work since they claimed that, "It has facilitated our work in class." Nadezhda Kukkoeva and Yuliya Aprodu explained how convenient it was to be teaching the standardized Vepsian language to those pupils who did not speak the language before coming to school. Nadezhda Kukkoeva is a Vepsian teacher at the Finno-Ugric school in Petrozavodsk. She moved from the Leningrad Oblast to Petrozavodsk where she lives. Yuliya Aprodu is a former Vepsian student at Petrozavodsk State University. She used to work as a journalist in Petrozavodsk. She moved with her young family to her village of origin, Kalag', where she currently lives and teaches Vepsian in the kindergarten. They claimed to be using all the published material and that the language used there was clear and accessible. Mariya Filatova also stressed how 
important it was for her to learn Vepsian at university. This laid the foundation from which she could later appreciate the dialectal differences, useful for her work as a journalist. Natal'ya Silakova also stated,

It is OK to have a written form. Then, we can speak how we speak and employ our dialectal differences. Every language has a standard form and people do not speak the way they write!

However, the feedback that the Vepsian linguists receive on the standardized form varies, depending on where people are from, on their age and on their purpose for using their heritage language. The main adverse criticism toward the literate form often comes from the older villagers (specifically, those in their 60s-80s). Some of them claim not to be able to read the newspapers in Vepsian, for example. Most of them claim that this is due to the alphabet and a minority claims that this is due to the lexical choices. In regard to the alphabet, I should stress that many villagers also have difficulty reading Russian texts, due to the mixed-language education they received as pupils. As for lexical choice, I have already observed in an earlier chapter that sometimes the villagers accepted a different word from that of their dialect only after careful consideration and discussion. Another issue is that a very small number of Veps advocates feel frustrated for not having more voice in the standardization process. They would like to have their teaching material published and available in schools and/or to provide more feedback on the lexical choices made by the Vepsian language committee. Sometimes this frustration ends up in open criticism of the work of the linguists. Admittedly, I witnessed such adverse sentiment on the work of the Vepsian scholars only twice. These two cases are not indicative of a wider sentiment since not everyone in the villages wants to actively participate in the standardization of Vepsian.

Whether receiving positive or negative feedback on standardization process and practice, the initial linguistic targets of the revival movement have mostly been achieved. Thanks to the revival endeavor, some Veps have gained confidence and feel proud not only of being Veps but also of being able to write in Vepsian. Natal'ya Silakova told me,

I will never forget what my grandmother told me once, after I had been bullied for being Veps at school. So, they bully you and you cry. Why? Remember, there will come a day when you will be proud to be a Veps! And this is what happened. I am now extremely proud to be a Veps. Interestingly, those children who used to bully me were Veps themselves. It was like that in those days. [. . .] But in life you need to understand that some people are made to be a mother, others to be career-oriented and I always wondered what my purpose in life was. When I wrote my first stories in Vepsian, I immediately felt what my purpose in life was and I was extremely proud of it. 


\section{Vepsän kel' and the City}

Similarly, Nikolay Abramov admitted feeling intensely proud when he first started to publish his poetry in Vepsian and that he used to wander about with the published book in his pocket and show it to everyone he met in the street. While attending the VII World Congress of Finno-Ugric Peoples in Lahti in 2016, I sat next to Larisa Smolina who pointed out at how there was a clear generational clash in the rhetoric around pride. Indeed, those presenters and activists who were in their 50s and 60s often mentioned pride as the ultimate goal of the revival movement they stood for; whereas, those presenters and activists who were in their 30s and 40s were more focused on what new technologies could be employed in order to advance the movements and engage with new social dynamics. The discussion on pride had become out-of-date for them. As reflected in these examples, which are representative of a general consensus among Vepsian writers and journalists, showing pride in writing in their own heritage language does not equal taking on nationalist ideals (DeFigueiredo and Elkins 2003). On the contrary, the Vepsian writers and activists often stress how their concern for the Vepsian language does not aim to put themselves in opposition to Russian culture. Nina Zaitseva always stresses how she received education on the Russian language and literature, which she considers "the best education I could possibly hope for."

Besides restoring pride among the Vepsian population, the promotion of the Vepsian language has also contributed to the creation of new generations of Vepsian users. And this is a main indicator of reversing language shift (Fishman 1991). Both Nina Zaitseva and Ol'ga Zhukova explained, "At present, the university students write a 50-page long thesis in Vepsian." Some of them now work as teachers of Vepsian in the city or in the Vepsian villages of the Republic of Karelia. Others work as journalists for the Vepsian TV and radio. Others publish articles in the Vepsian newspaper Kodima and the magazine Kipinä. Some actively engage with language and cultural initiatives and participate in the events promoted at the Centre for National Cultures in Petrozavodsk. In the spring of 2011, Larisa Smolina founded a Paginklub with the purpose to meet and practice speaking Vepsian only. Others have founded folklore groups to promote Vepsian traditional music nationally and overseas. The group Noid (V. Sorcerer), for example, participated in Eurovision in Italy in 2011. ${ }^{13}$

\subsection{Language Policy to Support Heritage Language Revival}

The standardization of Vepsian and the revival movement have been made possible thanks to specific legislative measures taken by the policy makers in the Republic of Karelia. This section aims to discuss these acts. It also elaborates on some of the disagreements and misunderstandings between the policy makers, the activists, and the Vepsian population, most of which are caused by ambiguity with regard to the objectives of the political actions promoting Vepsian literacy. The political intervention does not combine the promotion of literacy 
with the promotion of Vepsian village economy where Vepsian developed in its oral mode. In this way, promoting Vepsian literacy often satisfies international standards of indigenous language rights more than it meets the requirements of the Vepsian population (mostly that of the villages, but not only there). The government and its intervention often seem to be much more abstract than the concrete needs, demands, and realities of its local population.

\section{Legislation}

Aleksander Selyanin, former minister of education of Karelia, announced during our interview in 2010 that as long as there was one person wanting to learn Vepsian, they would do all they could to support them. This statement seems to have become a political motto also among the federal powers of the Russian Federation since it was repeated at a hearing at the State Duma in Moscow in the same year, called Yazykovoe mnogoobraziye Rossiyskoy Federatsii: problemy i perspektivy (R. Language diversity of the Russian Federation: problems and perspectives). Such a motto depends on the presence of legislation in line with International Law and the European Charter concerning language rights of indigenous minorities.

The Universal Declaration of Human Rights was adopted in 1948 as a consequence of the atrocities of World War II. It comprises 30 articles. Article 2 aims to guarantee language rights and article 26 the right to obtain education. ${ }^{14}$ Following the Declaration, the United Nations adopted the International Bill of Human Rights in 1966. This consists of two covenants, the International Covenant on Economic, Social and Cultural Rights and the International Covenant on Civil and Political Rights and its two Optional Protocols. ${ }^{15}$ In 2007, the General Assembly of the United Nations also approved the Declaration on the Rights of Indigenous Peoples, whose articles 17 and 45 are dedicated to the right of promoting the culture of the indigenous peoples, to use their resources and to obtain education in their heritage language. ${ }^{16}$ However, the Russian Federation abstained from the vote in 2007.

Challenged by the collapse of the Soviet Union and the new demands from its population, the Russian government approved the Law on the Languages of Peoples of the Russian Federation in 1991, which is now article 68 of the Russian Constitution. ${ }^{17}$ In 1993, Russia adopted a new Constitution, wherein articles 19,26, 68, and 69 guarantee language rights and freedom of expression in the national heritage language. ${ }^{18}$ And in 1996, a federal law on education was also passed, aiming to guarantee education in the national languages (Puura et al. 2013, 113). ${ }^{19}$ Those actions occurred simultaneously with the adoption of new laws at regional level. In late 1980s and early 1990s, the government of Karelia had already decided to invest in the education of Karelian and Vepsian and approved a "program to update and develop the schools in the Karelian ASSR between 1991 and 1995" (Strogal'shchikova 2016, 132). Nina Zaitseva was the author of such a program. In 1991, the Karelian government passed the Non-Russian 


\section{Vepsän kel' and the City}

District Council Act to ensure the use of the Karelian and Vepsian languages in the administration and educational spheres. ${ }^{20}$ Between 1992 and 1993, the Vepsian villages of the Republic of Karelia, Šoutjärv', Kalag', and Šokš obtained national status which led to the establishment of the Vepsian national district in 1994, and the introduction of the Vepsian language education at school (Strogal'shchikova 2016, 142-143). In the same year, a law on education for the indigenous peoples of the Republic of Karelia was also passed. According to this law, the government aimed to guarantee education in the national languages in the Karelian territory. In 1997, the words malochislennyy ( $\mathrm{R}$. Minority, literally small-numbered) and korennoy (R. Indigenous) were added to the title of the law which had previously only referred to the individual ethnic groups-thus, it concerned only Veps in the Republic of Karelia (Strogal'shchikova 2004, 44). In 2000, Vepsian also obtained the status of national language (alongside Karelian), while Russian remained the official state language, according to the Languages in the Republic of Karelia Act. ${ }^{21}$ In the same year, Veps gained the status of minority indigenous peoples of the Russian Federation which granted them also the status of minority indigenous peoples of the North, Siberia and the Far East in 2006 which encompassed also Veps from the Leningrad and Vologda Oblasts in 2009 (Puura et al. 2013; Strogal'shchikova 2016, 14). This enabled the government of Karelia to open a school in Šoutjärv' (Figure 7.1).

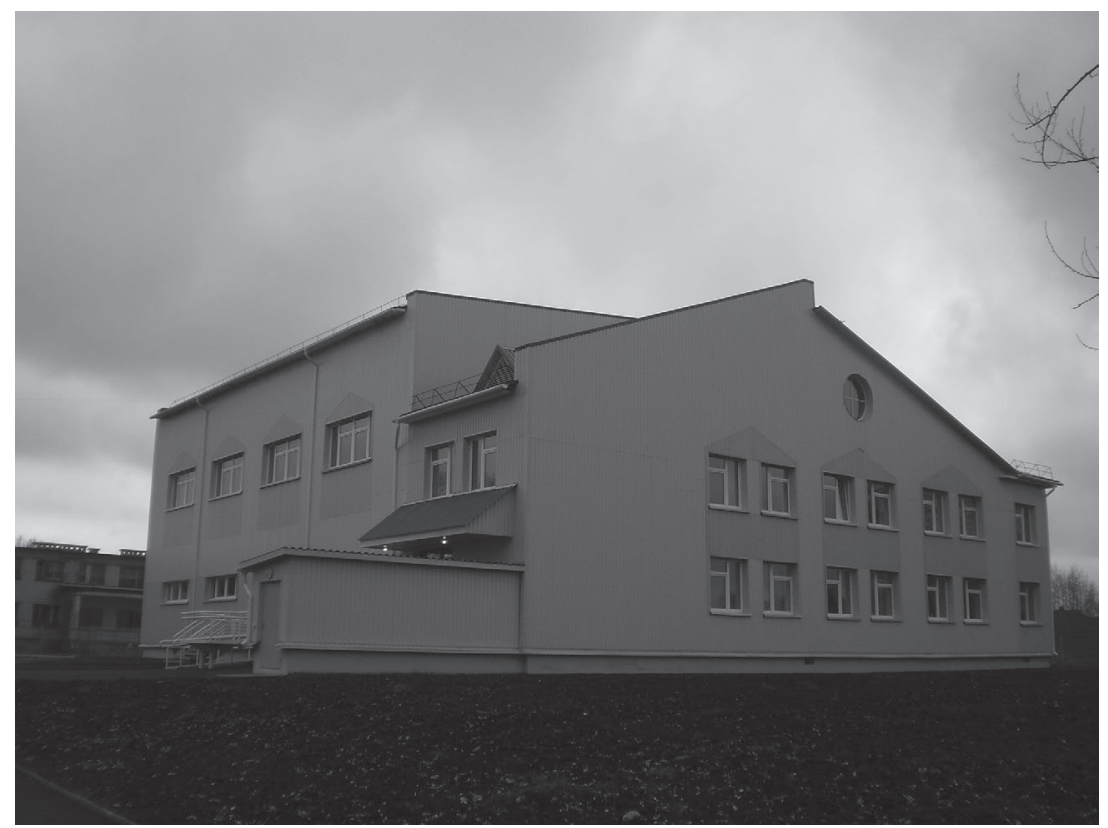

Figure 7.1 School in Šoutjärv', Republic of Karelia. I took this picture in 2010 
The government of Karelia understood minority language revivals in a similar way as it was understood within the framework of international law. Language represented a right that needed to be guaranteed. In this paradigm, literacy and the promotion of the heritage language at school indicated alignment with international standards of human and linguistic rights (Romaine 1995, 283-285; Whiley 1996, 114). In theory, these acts should guarantee the usage of Vepsian both in its oral and written form. In reality, the translation of such acts into practice presents a number of hiccups.

\section{Ambiguous Political Targets: Favoring Literacy but Expecting Speaking}

I interviewed Galina Brun, former Minister of Culture of Karelia in January 2010 in Petrozavodsk. She listed a number of interventions including publications, financial support of folk music ensembles and education to present the activities of the Ministry to support the revival of the Vepsian language and culture. However, she lamented that this work should have gone in two directions. She claimed that once they helped Veps, they would need to become partners with them. When Veps asked for a new school, and the government opened it, she felt that they fulfilled their task. So, she then pleaded Veps to fulfill their tasks and to start speaking the language at home.

The government of Karelia largely supports and finances the Vepsian written form (apart from music and some recently introduced activities) and its promotion at school. However, its ministers expect the population to take on and engage more with speaking, ignoring socio-political structures that hinder Veps from speaking it. Furthermore, they often seem unaware of the fact that these two different modes of language, the written and the oral, require different intervention and promotion (Blommaert 2004, 644; Sebba 2012; Tedlock 1975). Another theoretical confusion can be seen in their approach toward the promotion of Vepsian culture and language. The ministers often appreciate language as an economic resource, specifically for the development of the tourist industry (Heller 2003; Romaine 1995, 283-285; Whiley 1996, 114). They often argue that the promotion of Vepsian culture and language can be instrumental to the tourist industry.22 A subtle ambiguity clouds their argument since language seems to entirely correspond to culture. Thus, they expect that with the promotion of a culture, often materialized in festivals and concerts, spoken language in rural areas should also be guaranteed.

For many Vepsian activists and educators, these theoretical equivocations are primarily caused by the inadequacy and incompetence of some policy makers. Many activists also insist that the policy makers usually implement new legislation without consulting those with more expertise. Thus, their intervention does not result from comprehensive study and analysis. The inconsistent theoretical framework on which the political intervention is based is full of ambiguity and lacks a clear course of action from the implementation of the legislative measures through specific institutionalized 
activities and final targets (cf. Dorian 1994; Hornberger 2000). This lack of clarity and competence often leads to conflict and misunderstandings among the various agents and it does not benefit the revival goals nor does it foster cooperation.

\section{Misunderstandings and Conflicts Among Policy Makers, Activists, and Vepsian Population}

The Vepsian activists see flaws in the solutions and course of action taken by the policy makers. Many complain that the politicians change too often and, therefore, never complete the tasks for which they were initially appointed. Others criticize the complexity and stagnation of Russian bureaucracy, which slows every process down and makes every task a daily challenge. Their concerns also extend to the quality of the political intervention rather than the quantity of the provided resolutions. While the politicians list the activities that their budget finances, the activists demand cooperation for more effective measures for language revival and deplore lack of support for new ideas and training. For example, the Karelian activist Natal'ya Antonova, in cooperation with the Russia-Finland Society, organized a seminar to implement language nests among the Finno-Ugric peoples of the Russian Federation in June 2010. Chapter 8 expands on language nests or language immersion programs where the teachers mostly speak the heritage language at nursery. They also invited a representative from the Ministry of Education, who is in charge of the didactical material for the indigenous groups of the Republic of Karelia. This representative only turned up on the second day of the activities when the program had planned to discuss the previous day's activities. One of the participants in the seminar expressed his disappointment: "She [i.e., the representative] never takes part in any training and applies mainly Soviet methods of translation in the production of language didactical material." He then showed me some Finnish textbooks that this representative from the Ministry of Education had chosen for the schools. They were mainly written in Russian and he shared his frustration:

I would never want my children to study Finnish from these books. You know from the start that they will never learn anything from here. [...] How can you trust them [i.e., the Ministry of Education], when you realize you know more than they do?

A similar discussion took place in Kalag' with some of the teachers who had experience teaching Vepsian and English at school. They were missing the previous deputy of the minister of education, who in their eyes did a better job than the current one and complained,

The new representative from the Ministry of Education cannot even speak the language. She [i.e., the representative] has never even been a teacher and now decides what textbooks we should be using in class. 
Look at this English textbook, for example! All the authors are Russian, not native speakers of English. This book was printed in 1999. The kids do not care about reading texts on American or British politics! But this is all you find in these textbooks.

The activists and educators often condemn a lack of real cooperation with the government, since the final legislative resolutions are often taken quickly and without consulting or involving the activists or language experts in the decision-making process. Exemplary is the implementation of the Yedinyy Gosudarvstennyy Ekzamen (also referred to as EGE), the Single State Exam, which the educators at both the University and at the Academy of Sciences bemoan as counterproductive and harming Vepsian education. Irma Mullonen pointed out that once the students decide what subjects to sit for at the EGE, they immediately drop Vepsian, which cannot be examined as a subject. She explained that the policy makers do not understand the language metaphors advanced by the activists from the Academy of Sciences. And she wondered why it is so difficult to understand that speaking one's own heritage language is an index of wealth. By speaking two languages, one has access to more than one worldview and culture. As a bilingual speaker, she has that experience.

In some of the villages, the conflicting situation between the population and the administration is even more severe. In many villages pharmaceutical services, Dom Kul'tury (R. House of Culture) and/or schools are shut down. Petukhov (2005) stated that the government has always had an ambiguous relation toward Veps. On the one hand, it supported the promotion of the Vepsian culture. On the other, it shut the kolkhozy and left the villages with nothing upon which to live. He specifically complained that in the villages there were no jobs for the youths and that, as a consequence, the youngsters were forced to either leave or fall into the habits of drinking. The village dwellers often complain that they feel neglected, since primary services are missing and it seems that the authorities do not implement and create better opportunities for the villagers. In a moment of frustration when discussing this with other villagers in Kalag', Nadezhda Kozlova (pseudonym) exclaimed, "Next time, I will stand for election myself." It took several years before the reconstruction of the Dom Kul'tury was completed and it reopened in Kalag'. Many of its inhabitants complained about not having a communal space where they could meet, organize gatherings, and engage in a variety of activities. Many felt that their requests had not been listened to and that the head of the village did not consider their demands as central to village life.

Some of the more active villagers take the initiative themselves and create spaces where the Vepsian language and culture can be preserved and maintained. Svetlana Ershova in Kurb, Leningrad Oblast, spent the whole summer of 2010 reconstructing an old administrative building and founded a new ethnographic museum there. She worked on a voluntary basis with no financial support for her efforts from the federal or the regional administration. Similar efforts came from Ryurik Lonin in Šoutjärv' who founded 
the ethnographic museum there. Paginklub (V. Speaking club), led by Larisa Smolina, was also initially run voluntarily at the Centre for National Cultures in Petrozavodsk. At the Paginklub Veps meet and speak Vepsian and also arrange craft activities where they learn how to make Vepsian dolls, kalitki (V. Vepsian pastries) and belts. Larisa Smolina runs the meetings and activities, posts the information and pictures on VKontakte, and promotes the initiative on the radio where she works. She has recently arranged an Internet link so that those away from the Centre can still take part in the meetings. Svetlana Nikolaeva (pseudonym) warned, "People need wage opportunities to support language revival, because the initial enthusiasm for such activities fades away." And yet, I would argue that the enthusiasm which characterized the scholars and activities in the late 1980s has not faded away and Veps continue to promote their language and culture and think of new activities which could sustain their revival goals.

A complex network of factors reinforces the friction between the policy makers, activists, and the Vepsian population. Aligning with international and federal legislative measures guarantees the Vepsian language rights; however, the Karelian administration seems to engage more with external forces than the requests, needs, and voices of its own population (cf. Zamyatin 2016b on international frameworks being manipulated by local authorities). In Petrozavodsk Vepsian writing emerges in relation to such a politicized social context. Therefore, Veps often understand engaging in writing activities in Vepsian as a political tool. The gap between the aspirations of the villagers and the goals of the political institutions is even more critical in the two other regions where Veps traditionally live, the Leningrad and Vologda Oblasts, since such legislative measures are not taken here. Supporting one's heritage language and culture often depends on individual's initiatives, enthusiasm, as well as "collective intentionality" which does not rely on the support from the political and administrative bodies (Searle 1990). An example of this is the fact that parents and grandparents in Pondal tend to bring up their children and grandchildren by speaking Vepsian to them. Nonetheless, as soon as the children finish school, they move away from the village since most services are shut down and there is no job left for them. In the city, they embrace Russian ways of speaking and their heritage language remains at the margin of the linguistic spectrum, as they use it only when they return to the village or when they speak on the phone with other family members and countrymen.

\subsection{Multiple Experiences of Writing}

\section{Writing as a Bridge Between Two Oral Traditions}

Writing is as much a personal activity which is experienced by one's body (Ingold 2000), as a social and political tool to reach out to others (McKay 
1996, 421). Writing in one's mother tongue and experiencing feelings, as a bodily response to it, are enriched by a social understanding of what writing can do (Sebba 2007). Indeed, the written signs carry linguistic but also social and cultural meanings (Sebba 2007) just as much as the spoken language does. Therefore, bodily feelings that find their expression and manifestation in the process of writing can be conceived as social emotions. ${ }^{23}$ That is, they are responsive to the world and are symbolically understood in a similar way by the members of the same community.

What kind of emotions emerge when writing in Vepsian? The Vepsian city dwellers often talk about writing as a socially constructed and shared symbol that links to language and political ideologies, past legacies, and future expectations. As one writes in Vepsian emotions rise reinforced by an awareness of political and social discourses among the elites and the multiethnic society of Petrozavodsk. Consequently, the emotions that emerge from it are also highly politicized. For example, Ol'ga Zhukova has recently published a book of Vepsian fairytales. She admitted aspiring to enrich the stories with a Vepsian touch, so that the children would be able to recognize traits of Vepsian identity in them. Ol'ga Zhukova projected her present work into the future by addressing the purposes of her writing. She appreciated Vepsian writing for its capacity to create a bond between what she had learned during her childhood speaking Vepsian in Kurb, and the coming generations. She fully appreciated her role as a language bearer in the city and her duty as a parent and an educator in the promotion and maintenance of her heritage language. Several young Vepsian women often ponder this responsibility. The young mothers often feel the urge to fulfill the aspirations and ambitions developed during their students' days. In their current practice of writing, the young Vepsian writers and journalists make continuous references to the future as well as to the past. Mariya Filatova stated that there is a big difference in feelings when she adopts Vepsian instead of Russian writing, "This might be because my grandmother and grandfather spoke the language." Vepsian writing, in this sense, connects a past oral tradition to a promised future oral use and links to the political hopes of the Vepsian activists. Writing embodies the present and becomes a bridge between two oral traditions, one belonging to the past and the other to the future. It symbolizes a connection between the language use of the elders whose speaking ability had been socially and politically repressed, and the hopes for future language use.

There is often the confidence that the positive feelings that develop when speaking Vepsian will be maintained through the means of writing and reemerge for the future generations of speakers. When discussing writing, the writers often make reference to its political and social significance more than to the feelings that arise during its creative process. These feelings are often relegated to the oral use of Vepsian. Indeed, speaking Vepsian is regarded as the keeper of more intimate feelings. Feelings suddenly arise and provoke a 
specific language choice in the speaker. An example of this is the following story told by Nina Zaitseva:

We were heading to a Vepsian village on an excursion by bus and I was sitting and talking to the person next to me. As we were approaching the village, we began using more Vepsian. Admittedly, we were mainly speaking Russian. At some point the bus stumbled into a hole and we bounced up in the air. I did not realise this, of course, but the other passengers later told me that as soon as this occurred I started screaming in Vepsian and imploring God for help.

Svetlana Ershova also commented on what it means to her to physically feel a language and how those feelings provide an entirely different experience for the speaker:

Ribuine [V. Candy]! How would you translate this word in Russian? There is no equivalent. You cannot translate it. When I say ribuine, I feel the sweetness of the candy in my mouth. It feels much sweeter when I say it in Vepsian than in Russian.

Similarly, Liubov' Smirnova in Pondal explained that when she speaks her heritage language she feels closer to what she feels and better expresses her deepest emotions. The translation of objects and events into spoken words morphs into personal and social emotions and vice versa. Language becomes the manifestation of the relation between a physical sensation and the surroundings which prompted it (Rosaldo 1980, 53-60). Veps experience specific social and personal emotions when adopting different modes of the language.

\section{Singing in Vepsian as a Personal, Social, and Political Experience}

Singing in Vepsian also matches social, political experiences of language which depend on where, when, and by whom such skill is employed. The villagers usually employ singing as a more spontaneous response to the situation they are living. Galina Lokkina, for example, was recognized as having a good voice and being a good singer, and for this reason, she had often joined choirs both in Nemž and Petrozavodsk. Despite her ability to sing, however, she admitted not having been able to perform any lamentation for years. She said:

When my mother died, however, I could not stop crying and grieving. I had never lamented before, as I never managed to. It had always felt artificial. On this occasion, instead, it just happened. It felt, as though I had always cried and it felt right.

In the city, instead, singing has gained a different social symbolism. Singing often emerges as a political as much as a social need. It often helps the city 
dwellers reconnect with their roots in rural areas and employ the language spoken by their ancestors. Elena Leont'yeva told me, "If I sing in Vepsian, I can feel the language that my mother and grandmother used to speak." She was born in Vidl, Leningrad Oblast, and moved to Petrozavodsk at an early age with her family. Although she cannot speak Vepsian, she understands some. Russian has always been the main means of communication for her. Elena Pavlova, former singer of the group Noid admitted that when she sings a Vepsian lament, she feels like she is "performing a ritual, something secret which is going to be disclosed." Traditions are maintained in the songs and some are resistant to changing them such as Vladimir Solov'yëv who founded Noid in 2007. He added, "However, I appreciate that we need to make changes since our music needs to reach out to the new generations and to adapt to their taste. This way our music becomes interesting to them, too." The Vepsian city dwellers also claim to learn how to sing in Vepsian as "Veps used to do in pre-revolutionary times." During a rehearsal at the Centre for National Cultures, Irina Baranova confirmed that, "Veps used to learn singing as they were practicing together. They did it without employing musical scripts. ${ }^{24}$ People never knew how to read music, but they used to learn it by singing together with the rest of the choir." Yet, the members of Vepsän Hel'm engaged also with written texts during their rehearsal, as some of the choristers did not speak Vepsian and required visual aids to remember the words. Singing, like writing, represents a link between the past traditions and future expectations in the city. It metaphorically fills in a historical gap by recreating an atmosphere that many feel had long gone. As such, singing becomes political action.

The promotion of folk bands such as Vepsän Hel'm and Noid has been a priority investment for the government of Karelia since the late 1980s. The ministers of the government of Karelia often view singing in the national languages as a functional tool to promote tourism in the region. The Republic of Karelia has established a budget for the Vepsian choir of Šoutjärv', whose leader has recently founded a new group in Petrozavodsk. The governmentsponsored group Kantele (from the name of the traditional Finno-Ugric string instrument) has designed a show called Vepsian Fantasies which is often presented to private groups of tourists as a unique account of the indigenous peoples of Karelia. In the case of public performances, these shows also gather members of all the different nationalities of Karelia. A Russian friend from Petrozavodsk who has a particular interest in cultural activities and events stated, "We appreciate attending theatre performances to get over the dark winters and to engage with something joyful during the harshest months of the year." The theaters are often crowded with both young and elderly audiences. The shows often occur at the State National Theatre on Karl Marx Street, right in the center of town. A number of national festivals and events are also arranged there throughout the winter season.

Music has the capacity to unite. Despite the different metaphors of music (more specifically, singing), its adoption is taken positively by all the agents 


\section{Vepsän kel' and the City}

committed to the revival efforts. In this respect, the revival of Vepsian presents also positive generational outcomes as many families happily let their children join the group Linduižed (V. Birds) at the Centre for National Cultures. Often the babushki take their grandchildren to the rehearsals after school. The participation in traditional music events reinforces the relation between the elder and younger generations. After her granddaughter attended a concert in Petrozavodsk, a Russian pensioner whom I met during my first stay there confessed, "I look at what the children can do nowadays and am so happy for them. We did not have such opportunities when we were younger.”

\section{Vepsian Writing to Subvert Power Inequalities Through Secrets and Technology}

One day, after a writing network exercise, the students left the university classroom and whispered to their teacher Ol'ga Zhukova, "We write in Vepsian on VKontakte to share secrets, so nobody can understand what we are discussing." When adopting Vepsian writing as a secret code, the Vepsian students reinforce the traditional symbolism that portrays Veps as quiet and careful people. ${ }^{25}$ They demonstrate an awareness of the power which language has in creating reality and the need to use words carefully. Employing secrets in Vepsian links to both pre-revolutionary language ideologies as well as language habits adopted under the Soviet regime when speaking Vepsian was prohibited. The students demonstrated the ability to link to such ideologies and also to turn secrecy from a social weakness into strength through the use of the Vepsian written form and the adoption of contemporary technologies. They displayed a skill that others do not possess, to be proud of it and not to feel the need to hide it. Power relations of inequality are here reversed (Woolard and Schieffelin 1994, 56), since those who generally dominate public space linguistically are now marginalized. Instead, those who were forced to hide or be ashamed of their knowledge of the Vepsian language can now freely demonstrate the ability to be proficient in it. The students also do not translate what they are discussing into Russian, which usually happens in the villages in the presence of a non-speaker of Vepsian.

The students managed to transform the symbolism of the Vepsian language as backward, away from civilization and spoken in the woods by adopting one of the most recent technological and advanced tools in the history of civilization, the computer. Here, a triple-edged action takes place. First of all, the students employ a symbol of advancement and growth and demonstrate that their heritage language is up to the standard (see also Eisenlohr 2004, 32; Rießler 2013). Vepsian is not inferior to Russian anymore, since it can be employed in public domains. It has an alphabet that enables its use on the computer, to send text message, and generally communicate in the written form. Veps do not need to use the Cyrillic alphabet; instead by employing the Latin characters, Vepsian language acquires 
a new iconicity as it indicates a proximity with other civilizations where Latin characters are used (cf. McIntosh 2010). Second, they created new domains for their heritage language thanks to the adoption of the computer. By doing so, they demonstrated the capacity of Vepsian to relate to contemporary discourses and uses. The emergence of new domains of use proves that a language is apt to change and likely to further develop (England 2005, 113-114; Fishman 1991, 305; Hinton 2001, 6-7). Third, the students demonstrated independence in the promotion of Vepsian and were not dependent on the momentum of the late-1980s movement. The students do not follow any direction imposed from the previous generation of activists and use new technologies and social network tools independently, and not as resources which are provided to them (Duval et al. 2017; Grenoble and Whaley 2006, 103). This last aspect appears of particular relevance as the literature has often criticized the adoption of new technologies in the promotion of a minority language. ${ }^{26}$ The main criticism is that the language activists and the population tend to rely on the new technologies and transfer to them the full responsibility for the preservation of their heritage language (Dauenhauer and Dauenhauer 1998, 70). It is important to own the media and use them for the promotion of the language (Henze and Davis 1999, 3-4). Besides its social and metaphorical implications, using the computer to write in Vepsian also prompts new considerations on the process of writing itself. The Vepsian writer Natal'ya Silakova admitted,

Although I also like to write by hand, I love using the computer. You can play around with it so much more. You can edit more. You can actually understand what you have written when you re-read it. I can hardly decipher my own hand-writing. I can store so much in my laptop to which I can always return, amend and add ideas.

Another technological initiative has been taken up by a young Vepsian activist from Šoutjärv' in the Republic of Karelia, Anna Ankhimova, who has also been leading a project called, Tervhen tulda vepsan male (V. Visiting the Vepsian land). Anna Ankhimova has developed interactive programs for IPads and IPods in order to learn Vepsian words, phrases, and common expressions as well as traditional ways of living in the countryside. This initiative has proven particularly resourceful when promoted at local festivals to engage with children.

Vepsian city dwellers often demonstrate an appreciation of Vepsian writing because of its capacity to link Vepsian traditional worldviews and practices to modern life and open new possibilities for the future. Vepsian writing has contributed to the creation of new domains of use for the language, by laying the grounds for its relational and creative development. Writing has gained positive semiotic connotations that allow for creativity, improvisation, and relationality with the broader language ecology and dynamicity of social life. 


\section{Vepsän kel' and the City}

\section{Linguistic Landscape in Vepsian}

The political implications of Vepsian writing are also visible in the linguistic landscape of rural and urban areas where Veps dwell. I understand linguistic landscape as the language used for road signs, street and place names, shop signs, and government and generally public signs (Landry and Bourhis 1997, 25).

In the city, the linguistic landscape shows little evidence of Vepsian. Public Vepsian writing is secured primarily in places such as the National Library, the Centre for National Cultures, and the State National Theatre on Karl Marx Street (Figure 7.2). It is also visible in educational institutions such as the Finno-Ugric school, the Academy of Sciences and the Baltic-Finnish and Finno-Ugric Faculty of Petrozavodsk State University. Nonetheless, Russian, and Finnish writing prevails over Karelian and Vepsian writing even in those places. The government buildings in the city center are indicated by Russian and Finnish plates (Figure 7.3). Shop signs, street signs, posters, and billboards are generally written in Russian. Some appear in foreign languages and a few in Finnish (Figure 7.4). The absence of Vepsian writing in public domains often reinforces the dominant belief that the Vepsian language is not being used and creates suspicion toward the revival movement. The power of literacy resides in its capacity to turn words into a visual, concrete and touchable object which can be measured (Sebba 2007). Literacy

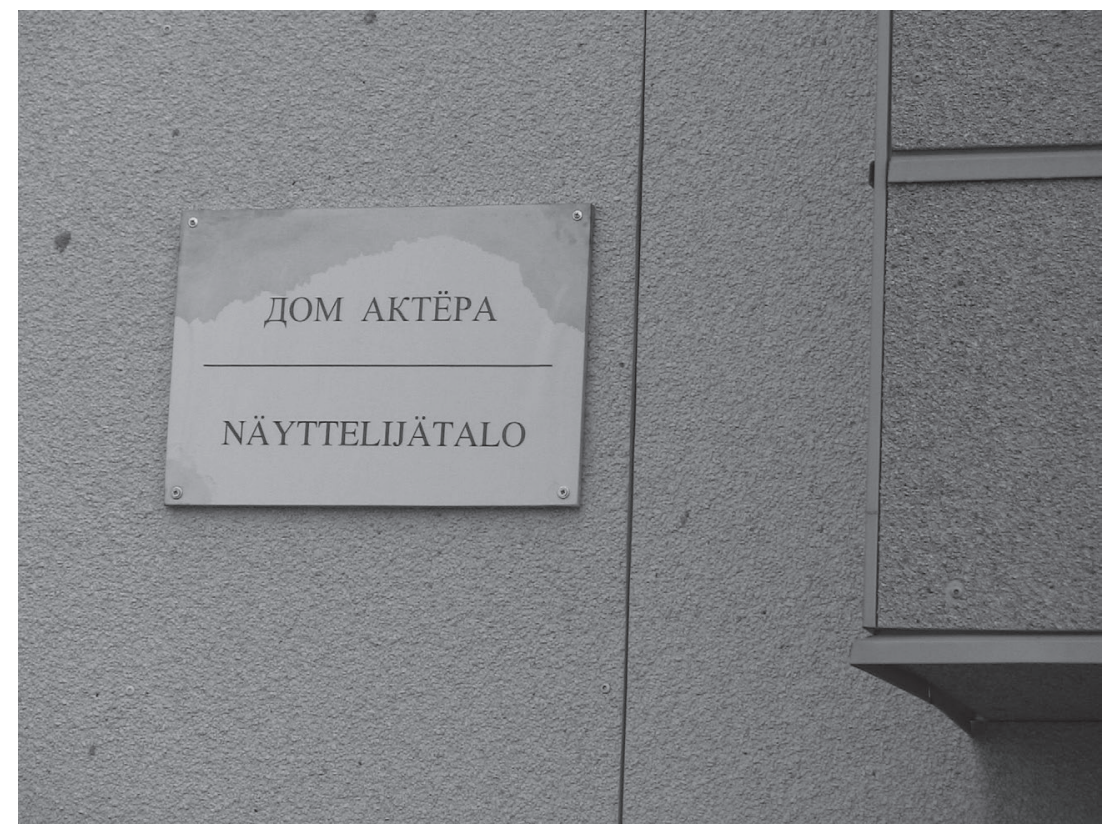

Figure 7.2 A Russian/Finnish sign outside the actors' area at the State National Theatre, Petrozavodsk. I took this picture in 2010 


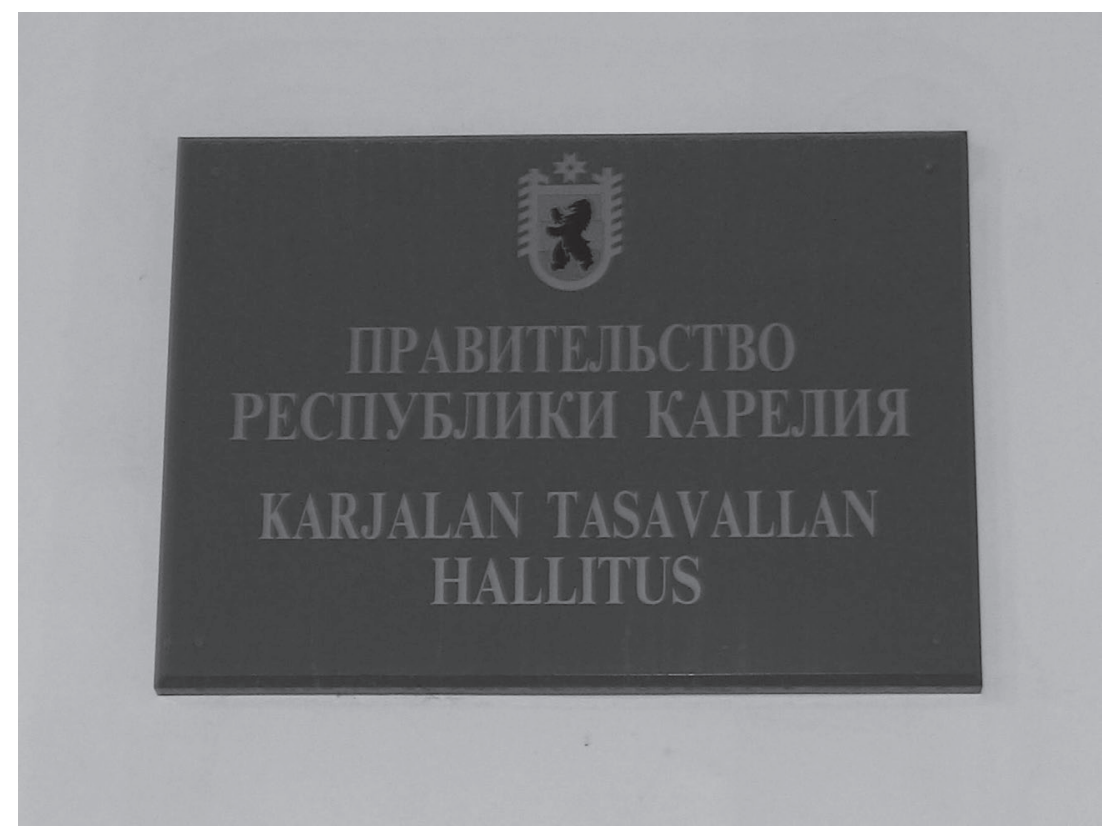

Figure 7.3 A plate in Russian and Finnish, which is situated outside the building of the Government of the Republic of Karelia. I took this picture in 2010



Figure 7.4 Shop in Petrozavodsk. The board sign is written in Finnish, ruokatavaraa, which literally means food stuff. I took this picture in 2010 


\section{Vepsän kel' and the City}

provides the opportunity to the voice of the minority group and representations to come to the surface also visually (Sebba 2007, 5-6).

By identifying the social and political importance of employing Vepsian writing in public space, the Vepsian activists decided to adopt Vepsian signs in the Vepsian district of the Republic of Karelia. They could not extend this resolution to the other two administrative regions of the Russian Federation where Veps live-i.e., the Leningrad and Vologda Oblasts. Irma Mullonen explained that in Russia they have a law which allows the adoption of Russian-only signs in the Russian territory. ${ }^{27}$ In fact, there are only a few roads that connect Russia to other countries where one can adopt Russian names and transcribe them with Latin characters. She found this transcription debatable. When she started working on this project, she stressed that the signs should have been in Vepsian and not been transcribed. They also had to choose only one name for the Vepsian settlements. This was a rather challenging task, since they existed in a number of variants. The activists had to choose the names that they wanted to officially use and that would unify and be recognized in the whole territory.

At the moment, yellow signs in Vepsian are displayed underneath bigger white Russian signs at the beginning and end of the Vepsian villages in the Vepsian district of Karelia (Figure 1.5). It is easy to identify the connection that exists between the form and the content of the signage documents (Cenoz and Gorter 2006, 70). Indeed, the choice of the font, the color and display of the sign already reflect political language attitude and ideologies (Scollon and Scollon 2003). Despite the visually evident language ideology offered by the street signage, this was an important political step that marked the imposition of the activists' position over Russian law. It did mark a success at the political level. However, did it contribute to reversing the language attitude of Veps and the multiethnic population of the Republic of Karelia? Signage is not discussed much among the population. While the Vepsian villagers may notice the yellow signs and most often make a quick remark, "Look! They have put a yellow sign up in the Vepsian language there," many representatives of the other ethnic groups have never traveled to the Vepsian district and have never been exposed to such signage. A Russian teacher from Petrozavodsk once said, "One of my students travelled to the Vepsian district and noticed that the street signage is also written in Vepsian nowadays. This might be interesting for you!" Still, she did not find that it had any social or political impact on the population of Petrozavodsk. The Vepsian street signage project related to language promotion policies and signified a political success, but it did not make much difference among the population of Karelia, either Veps or those belonging to the other groups.

\section{Vepsian Publishing}

The political aspects of Vepsian writing are also evident in Vepsian publishing. Once the Vepsian written form was established, publications of books 
and newspapers increased. The Finnish journal Punalippu dedicated an entire issue to Veps in 1989. It was then followed by the publication of a Vepsian primer in 1991 and a collection of poetry Koumekümnekoum (V. Thirty-three) by Nikolay Abramov in 1994 (Kurs 2001, 75-78).

In 2008, the newspaper Kodima celebrated its twentieth anniversary and the original newspaper was made a broadsheet. This decision showed interest on behalf of the Karelian government in continued promotion and support of Vepsian writing, but mainly it reflected the unceasing commitment and persistence of the Vepsian activists in their negotiations with the authorities. Nina Zaitseva explained,

People refer to me as the mother of Kodima since in the late 1980s I used to knock on everyone's door looking for financial support. I used to cry and to be much thinner than now. So, many were moved by this young, little crying woman and gave me some funds for the newspaper. I am now very grateful to the government of the Republic of Karelia which enables us to print and deliver our paper in the Vepsian villages for free.

Kodima has also recently moved to where the main Periodika publishing house is situated, at the very heart of town. Aleksey Maksimov, who works as the artistic editor of Carelia (former Punalippu) told me, "This was done to put us all under one roof and facilitate discussion and interaction." They also publish the children's magazine Kipinä (F. Spark) in the same building which was upgraded in January 2011 and now has three distinct versions for each language (e.g., Finnish, Karelian, and Vepsian). Galina Baburova and Oksana Churygina, former Vepsian university students, are currently running and managing its fully Vepsian variant. Galina Baburova admitted writing the stories in Vepsian herself-with the help of the dictionary-and managing the distribution of the magazine to schools, libraries, and private readers.

Vepsian publishing is also praised at public events such as the best book of the year competition, which is supported by the government of Karelia. Ol'ga Zhukova told me, "Veps always participate and win something at this competition." In 2009, Marina Giniyatullina and Nadezhda Kukkoeva won the prize for the best book in the Vepsian, Karelian, and Finnish languages (Figure 7.5). Nadezhda Kukkoeva explained that they had compiled a Vepsian primer rich in drawings and colors "to boost the memory of the child with visual aids." Nina Zaitseva confirmed,

This type of book is appropriate for the new generations of learners who come to school not knowing Vepsian. They need simpler books than those we used to print before, since they do not already know Vepsian vocabulary.

The teachers at school particularly appreciate the publication of the primers, of Kipinä and Kodima, since they employ those written texts in their 


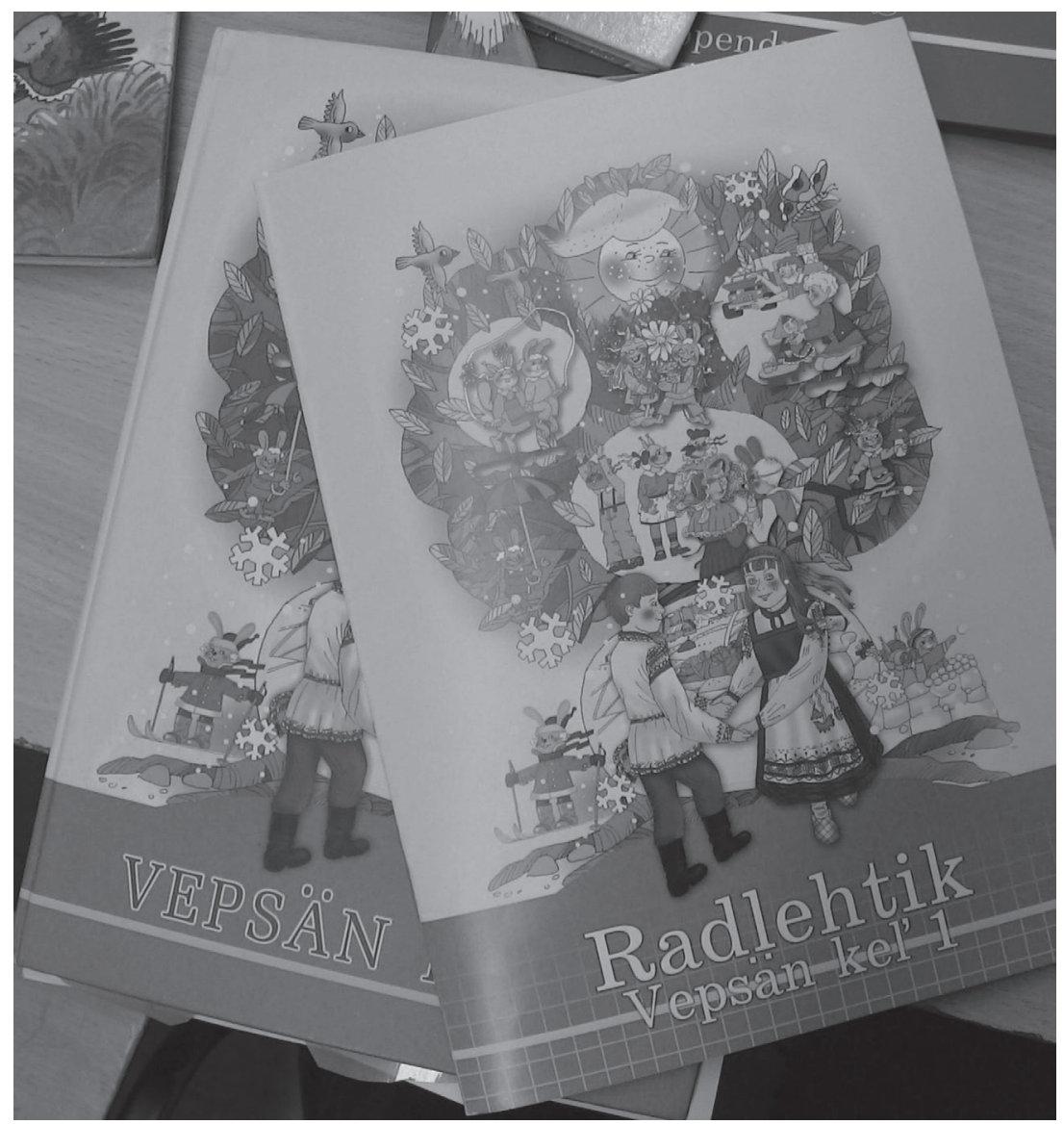

Figure 7.5 Vepsian primer, which won the best book of the year 2009 in the Vepsian, Karelian, and Finnish languages. I took this picture in 2010

activities. The former teacher of Vepsian in Šoutjärv', Elena Kocherina confirmed that it was so much easier now that miscellaneous texts were available. When she began teaching, she had no educational material to support her in her educational endeavor.

In December 2009, another exhibition took place at the exhibition hall on Lenin Prospekt in Petrozavodsk. All the books published in the Republic of Karelia in 2009 were presented there. Members of the government of Karelia attended the event and introduced some of the books. Zinaida Strogal'shchikova was not present despite her being the main editor of the book, Vepsy: na rubezhe XX-XXI vekov (R. Veps: at the turn of the XXXXI cc.). Consequently, Elizaveta Kharitonova presented the book on her 
behalf as a representative of the State Committee of the Republic of Karelia for National Politics, Public Relations and Religious Associations. During the event, Natal'ya Silakova offered to expand on her work as a writer since she had published two books that year. She explained how she had written in both Vepsian and Russian, although she was "more fluent in Russian than in Vepsian." She then admitted "needing the help of linguists such as Nina Grigor'yevna [Zaitseva] to check my Vepsian." She also remarked that her Vepsian book Vauged $\ddot{O}$ (V. White Night) was meant to reach out to a young audience. With this statement, Natal'ya Silakova confirmed that Vepsian writing is often perceived as a political tool to promote the language to the younger generations, in the hope that they will continue to use their heritage language. Vepsian writing is also an indication of social power.

Through Vepsian writing, the Vepsian activists aim also to reach out internationally and receive support for their cause from other networks. In 2008, Zinaida Strogal'shchikova compiled a pocket book on Veps after a Finno-Ugric conference where it was agreed to publish a series of booklets on all the Finno-Ugric ethnic groups of the Russian Federation. This text was written both in Russian and in Vepsian. Ol'ga Zhukova explained,

Six-hundred copies were published in total. However, the whole project never reached the desired outcome since most representatives of the other Finno-Ugric peoples never fulfilled their task. Zinaida Strogal'shchikova was the first one to complete the booklet in both Russian and Vepsian.

More recently, the language activists at the Academy of Sciences also embraced another project called Korpus Vepsskogo Yazyka (R. The Corpus of the Vepsian Language). Nina Zaitseva expressed the desire to have the texts translated into English, so that they could be available also outside the Russian-speaking circles. Publishing in Vepsian began to symbolize a political tool within Karelia at the beginning of the revival movement, which then extended to the Russian Federation. And the Vepsian activists now aim to reach out to an international audience using writing as their main political tool.

$$
* * *
$$

Metaphors of literacy change over time (Coulmas 2002), often depending on the dominant language ideologies and ecology. Writing in the heritage language often bears political implications and repercussions, since it often aims to level power inequalities, to revive national self-esteem, and to provide political visibility among multiethnic societies. Writing is also often viewed as the carrier of old symbols and traditions, which are likely to reemerge with the new generations, and it may often symbolize hope. In this sense, literacy positively contributes to the revival efforts and ultimate goal of generational transmission of one's heritage language.

Nonetheless, the promotion of literacy remains problematic since it bends to the existing and dominant language ideologies that view literacy as 
a step up the evolutionary ladder of a language. The consequent intervention tends to neglect the power of the spoken word. Such negligence might also be driven by miscommunication and conflicts between the activists and the political powers.

The following chapter develops in more depth how the written form is promoted through the medium of education. It also expands on some of the issues presented in this chapter on miscommunication among the various agents involved in the promotion of their heritage language at school.

\section{Notes}

1 With the standardization of Vepsian, the word kel' (V. Tongue) has been added to the vocabulary to refer to the way a person speaks. It had only existed to indicate the physical organ, the tongue, until then. This occurrence has parallels with the etymology of the Russian word yazyk (R. Language and tongue). In this poem, kel' also evokes the sound produced by the wood grouse. Veps consider that the animals inhabiting their land speak Vepsian.

2 I translated this poem from Vepsian.

3 Blommaert (2008) makes an interesting parallel when describing the important of literacy in Congo and how being able to write allows one's voice to emerge and be accounted for.

4 Harris $(1986,46-47)$ expands on what he calls the tyranny of the alphabet in the promotion of a language and how much effort is put into choosing the right alphabet.

5 Korpus vepsskogo yazyka. http://vepsian.ru/about/.

6 Dialektnaya osnova vepsskoy orfografii. http://vepsia.ru/yazik/dialekt.php.

7 Ibid.

8 Mariya Mullonen (1930-2008) was an Ingrian scholar who conducted research on the Vepsian language and taught it at university.

9 Nina Zaitseva explained that Mariya Zaitseva was not a relative of hers, but just "happened to have the same surname."

10 Bridal lamentations among the Finno-Ugric peoples have also been connected to rituals of death (Yurchenkova 2012, 178). Among the Komi, lamentations also bear magical aspects (Misharina 2012).

11 I should, however, point out that the scholar Nikolay Volkov took note of some Vepsian words in his field diaries during his expedition to the Vepsian villages in 1938-1939 (AMAE 13-1-10). One of these words was, in fact, hangoine which stood for "fork." This shows that the late-1980s activists unconsciously recreated a word which had become obsolete in everyday use.

12 Dialektnaya osnova vepsskoy orfografii. http://vepsia.ru/yazik/dialekt.php.

13 Gruppa "Noid" edet na konkurs v Italiyu. http://knk.karelia.ru/2011/10/gruppanoid-edet.html.

14 The Universal Declaration of Human Rights. www.un.org/en/universal-declarationhuman-rights/index.html.

15 The International Bill of Human Rights. www.ohchr.org/Documents/Publications/ FactSheet2Rev.1en.pdf.

16 The Declaration on the Rights of Indigenous Peoples. www.un.org/development/ desa/indigenouspeoples/declaration-on-the-rights-of-indigenous-peoples.html.

17 The Russian Constitution. www.constitution.ru/.

18 Ibid. 
19 Effective Language Politics: the Case of Karelian. www.linguapax.org/wpcontent/uploads/2015/09/CMPL2002_T3_Kryuchkova.pdf.

20 Ibid.

21 Ibid.

22 A discourse about tourism is not new; indeed, Makar'yev (1931) also saw in the Vepsän ma the possibility to develop a tourist resource that would have its economic benefits for the region.

23 On feelings as social emotions see also Briggs (1971), Fisher and Chon (1989, 1), Lutz and White (1986), Rosaldo (1980), and Thoits (1989, 318-320).

24 Treitler $(1986,1992)$ advances similar stances in regard to medieval chants.

25 See also Debenport (2010) on the social importance of concealment practices.

26 See, for example, Auld (2002), Dauenhauer and Dauenhauer (1998), Eisenlohr (2004), Gellner (1983), Henze and Davis (1999). However, it should be noted that except for Eisenlohr, these critiques come from a different communication technology world.

27 Law no. 63221-3, article 11. See also Marten (2010) on the directives given by the law on the language for signage documents. 
$\because$ Taylor \& Francis

Taylor \& Francis Group

http://taylorandfrancis.com 


\section{Education and the Babushka}

In November 2010, Ol'ga Zhukova and I attended a two-day seminar in St. Petersburg on the use of technology among the indigenous minorities of the North, Siberia, and the Far East of the Russian Federation. The Ministry for the Regional Development of the Russian Federation had financed a round table to facilitate a discussion among the various groups. Ol'ga Zhukova, representing Veps, had been invited to participate by Elizaveta Kharitonova from the State Committee of the Republic of Karelia for National Politics, Public Relations and Religious Associations. She enjoyed visiting St. Petersburg, although was not entirely satisfied with the discussions which often derailed from the main topic. Having walked for some time and being already late, we went to have dinner in a shopping center on our last day. At the end of the meal, she sat back on the chair, put her hands on her stomach, and exclaimed in Vepsian pubkandahasai! (V. Hard to breathe when feeling full). She immediately commented,

You see, my students do not know words like this one. They lack this vocabulary and other expressions which cover daily situations. I have learned such terminology through living with my grandparents when I was little. Those expressions come back naturally to me now. My students do not know the richness of such a vocabulary and that's why I can freely speak Vepsian only to Liza [i.e., Elizaveta Kharitonova], Nina Grigor'yevna [Zaitseva], Nad'ya [i.e., Nadezhda Kukkoeva] from the Finno-Ugric school and Marina [Giniyatullina] from Kodima.

Ol'ga Zhukova touched upon some issues linked to Vepsian education and its communicative results and the importance of speaking Vepsian with grandparents who are fluent in Vepsian. She also emphasized how feelings and language are intertwined with and linked to the world where the language originated. Those themes were recurrent in many discussions during my fieldwork in the Vepsian region. Therefore, this chapter elaborates on those topics in the context of Vepsian education and the Vepsian revival movement. Stemming from considerations that emerged during fieldwork, I also investigate the social and educational role played by the babushka 
(R. Grandmother). Specifically, I intend to present Vepsian language ecology in the cities and rural areas through an analysis and comparison of language socialization and language education in schools. ${ }^{1}$

\subsection{Education and Revitalization in History. Current Issues in Language Planning}

Vepsian education was introduced into the mainstream education system for the first time during korenizatsiya (R. Indigenization). Despite its brief life, the first Vepsian educational efforts laid the basis for the revival movement of the late 1980s. Once they had created a Vepsian written form in 1931, a group of academics began organizing Vepsian teaching under the guidance of Hämäläinen and Bogdanov. Their intervention mainly covered the Vepsian region of the Leningrad Oblast. By 1936, 30 books had been published in total. At the time, all subjects were taught in Vepsian, as opposed to contemporary Vepsian education where only the Vepsian language is taught in Vepsian. Between 1935 and 1936, 53 Vepsian primary schools had been opened and counted a total of 2,533 pupils and seven middle schools with a total of 554 pupils (Strogal'shchikova 2008a). After 1937, Vepsian education was prohibited. In 1958-1959, education reforms were implemented in the whole of the Soviet Union and these made instruction in the national languages optional. Such reforms facilitated Russian education only (Grenoble 2003, 194). And this political trend culminated in the Russification policies of the 1970s (Grenoble 2003, 194).

The education system changed again during perestroika and glasnost also thanks to a growth of national awareness and sensitivity among the population. After the standardization of Vepsian, the language activists led by Nina Zaitseva began promoting Vepsian education at school. This time, however, the movement spread in Karelia more than in the Leningrad and Vologda Oblasts. In 1990, the Vepsian language began to be taught at Petrozavodsk State University (Strogal'shchikova 2008a). The musical conservatory introduced Vepsian language education in 1993 (Bogdanova and Strogal'shchikova 2008, 19). In 1994, the Finno-Ugric primary and secondary school Elias Lönnrot was opened in Petrozavodsk. After the establishment of the Vepsian district along the southeastern shore of the Lake Onega in 1994, Vepsian education was also implemented in the Vepsian villages of the Republic of Karelia. In 1995, Vepsian became a compulsory subject in the schools of Šokš, Šoutjärv', and Kalag'. However, the head of the district soon changed in Šokš and the Vepsian language stopped being taught there (Fomin 2004). It has recently being introduced again as former university students could move there to teach their heritage language. Vepsian education within the Russian mainstream education system partly reached out to the other regions where Veps lived and where it is claimed that Veps spoke the language more fluently and more often. Some of these schools where 
Vepsian was taught, however, have gradually been shut down. As Svetlana Ershova explained in Kurb,

Our school was closed in 2009. We still do not know whether or not they are going to re-open it. Some children take a bus from our village to go and study in Vidl every morning. Others stay at the dormitory the whole school year and come to visit their families only during the holidays.

Despite the plea from Zinaida Strogal'shchikova who immediately opposed this decision, the school has not been reopened. In fact, in April 2015 Zinaida Strogal'shchikova told me that the activists in Petrozavodsk are arguing against the administrative bodies in the Babaevo district, Vologda Oblast, which intend to also close the school in Timoshino where Vepsian is taught. The lack of unity and cooperation among the separate administrations where Veps live represents an issue for the promotion and maintenance of the Vepsian language.

A similar lack of unity also exists within the education system itself. While at present the university is managed by the Russian Federation, the primary and secondary schools are the responsibility of the regional administration and the nurseries are under the control of the local (not regional) administration, such as Petrozavodsk, Kalag', and Šoutjärv'. It is important to provide continuity of commitment if the desired educational and language outcomes are to be achieved (Kaplan et al. 2011). Instead, the various institutional bodies have separate conducts and administrations that do not facilitate communication with one another. Thus, the children risk not experiencing continuity of Vepsian education from kindergarten to tertiary education. Often the language material used at school was also used at university, for example. The risk of such disunity is that the decisions taken by each institution may clash. ${ }^{2}$

\subsection{Contemporary Vepsian Education in Cities and Villages}

Contemporary Vepsian education is often challenged by multiple hindrances. For this reason, I now present Vepsian education in Petrozavodsk and the Vepsian villages of Karelia and point out the local challenges.

\section{Vepsian Education in Multiethnic Petrozavodsk}

During my fieldwork in the Republic of Karelia in 2010, Vepsian was taught at the primary and secondary school E. Lönnrot, at Petrozavodsk State University and in voluntarily run courses at the Centre for National Cultures in Petrozavodsk. At the time, the Karelian activist Natal'ya Antonova was also trying to implement language nests which indeed resulted in the opening of a Vepsian language nest in Šoutjärv' in 2011. Obtaining such results had 
challenged the activists in mainly two ways. First, they have been engaging in long-standing negotiations and debates with the political elites. Second, they have also been confronted with a multiethnic population that often views Vepsian education as an obstacle for the accomplishment of their own educational needs and requests. For example, Natal'ya Antonova explained how advocating language nests for the promotion of the heritage language could cause conflict of interest in multiethnic Petrozavodsk:

There are plenty of parents who are queuing to have their children in the kindergarten next year. It is very difficult to obtain a place as there are only a few kindergartens in Petrozavodsk. How can we justify the existence of language nests in the heritage language for 15 children when many Russian parents are waiting to obtain a place in the regular kindergarten? I understand that this creates a conflict of interest and we need to be aware of it.

Many of the Vepsian and Karelian activists acknowledge that the promotion of their heritage language in a multiethnic environment such as Petrozavodsk can spur conflict and dissatisfaction among the rest of the population. The Vepsian activists often find it challenging to advance the needs of their minority group without causing a chain-reaction of discontentment and suspicion. ${ }^{3}$ Thus, they tend to act carefully so as not to upset social balance and to respect the needs and wishes of the members of the other nationalities.

In reality, there is no conflict of interest, but the majority of the population views any support toward the indigenous languages as depravation for the implementation of mainstream public services. Maria Ivanova (pseudonym) remarked how difficult it can be to even claim one's own nationality and needs in such a varied and multicultural environment. She claimed she often felt the need to explain that she is not demanding some sort of benefit by addressing her Vepsian nationality. And she continued:

There is a new fashion now. Our government loves using the word tolerantnost' [R. Tolerance]. They use it all the time. They claim that we need to tolerate. Oh, I hate this word! I would rather use uvazheniye $i$ terpeniye [R. Respect and patience]. We are very good at tolerating. [. . .] But Veps are an indigenous minority here and if we do not promote Vepsian in Karelia, where should we promote it?

While Veps understand the importance to respect differences, the request to tolerate appears to them more of a political shield to hold back on certain decisions regarding the indigenous peoples of Karelia. Indeed, the concept of tolerance is used by the policy makers in the Republic of Karelia as a symbol of democratization, following a general consensus found in the literature (Kubicek 2010, 45). Once again, the policy makers seem to respond 
to international standards more than to the needs and requirements of their own citizens. Most often promoting and maintaining the Vepsian language through the means of education is a daily challenge. It often involves a negotiation with the policy makers and careful consideration for the other nationalities and their attitudes toward Vepsian education since they battle to obtain some of the limited resources available.

\section{Finno-Ugric School E. Lönnrot}

The Finno-Ugric primary and secondary school E. Lönnrot is situated on Herzen Street in the center of Petrozavodsk (Figures 8.1 and 8.2). The classrooms on the ground floor are designated for general primary and secondary school teaching. Here the pupils attend all-subject classes, which are taught in Russian. On the first floor, there are classrooms allocated to Finnish, Karelian, and Vepsian teaching. Room 28, the Vepsian classroom, is located in the left wing of the building. A Russian and Finnish sign on the door indicates that the Vepsian language is taught there (Figure 8.3). Finnish-and-Russian plates and posters are hung on the doors and on the information boards along the corridors of the school. The Russian language tends to dominate both written and spoken language in the corridors, despite the Finno-Ugric component of the school. Indeed, the children and

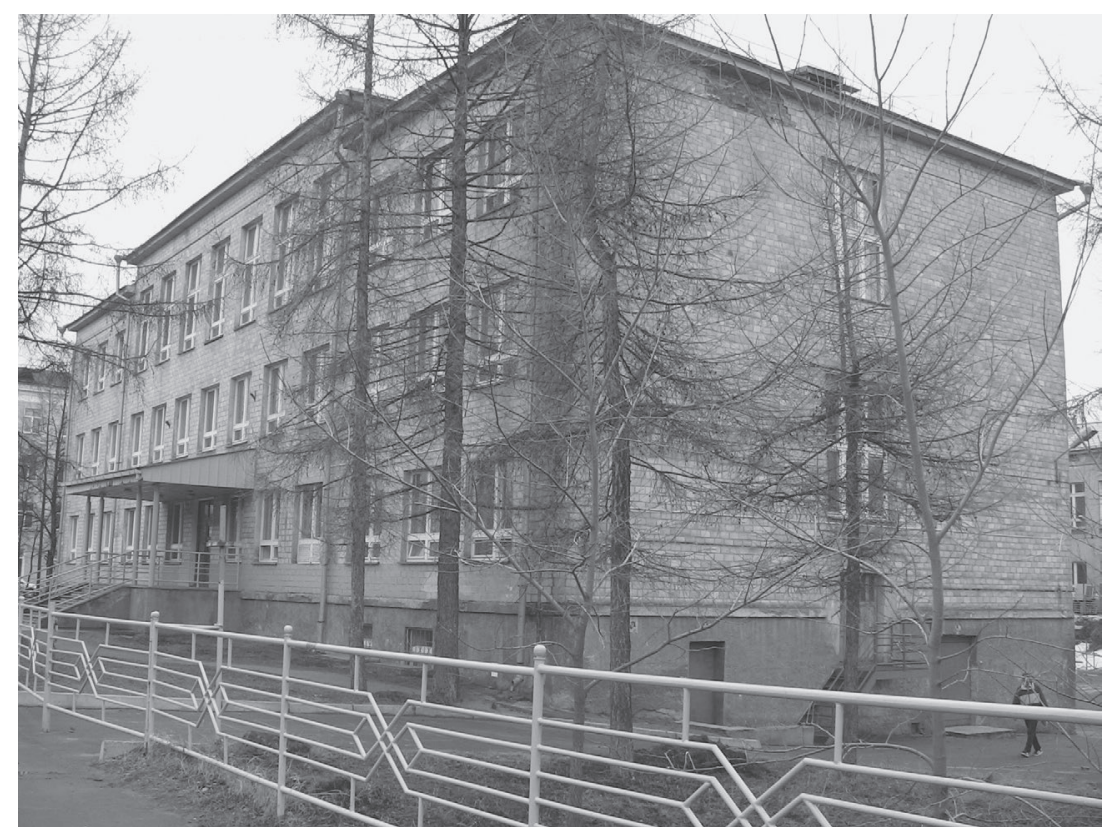

Figure 8.1 The Finno-Ugric school E. Lönnrot in Petrozavodsk. I took this picture in 2010 


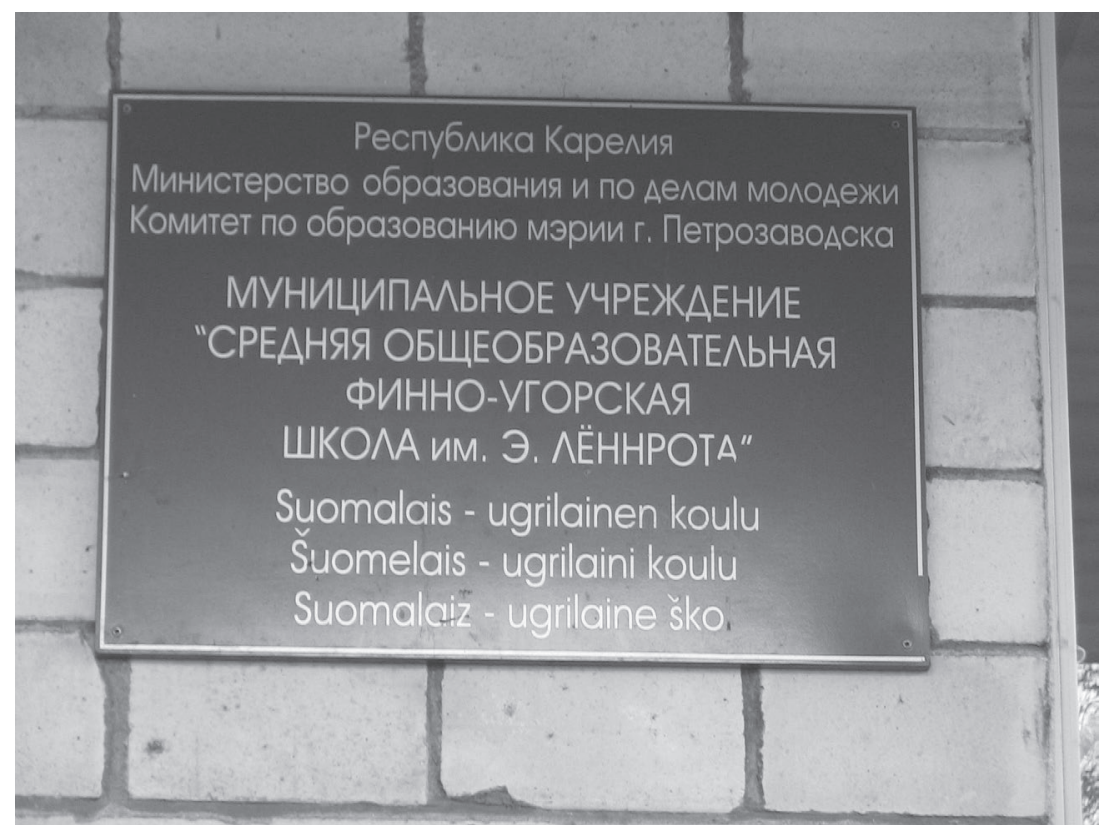

Figure 8.2 The school plate of the Finno-Ugric school E. Lönnrot is written in Russian, Finnish, Karelian, and Vepsian. I took this picture in 2010

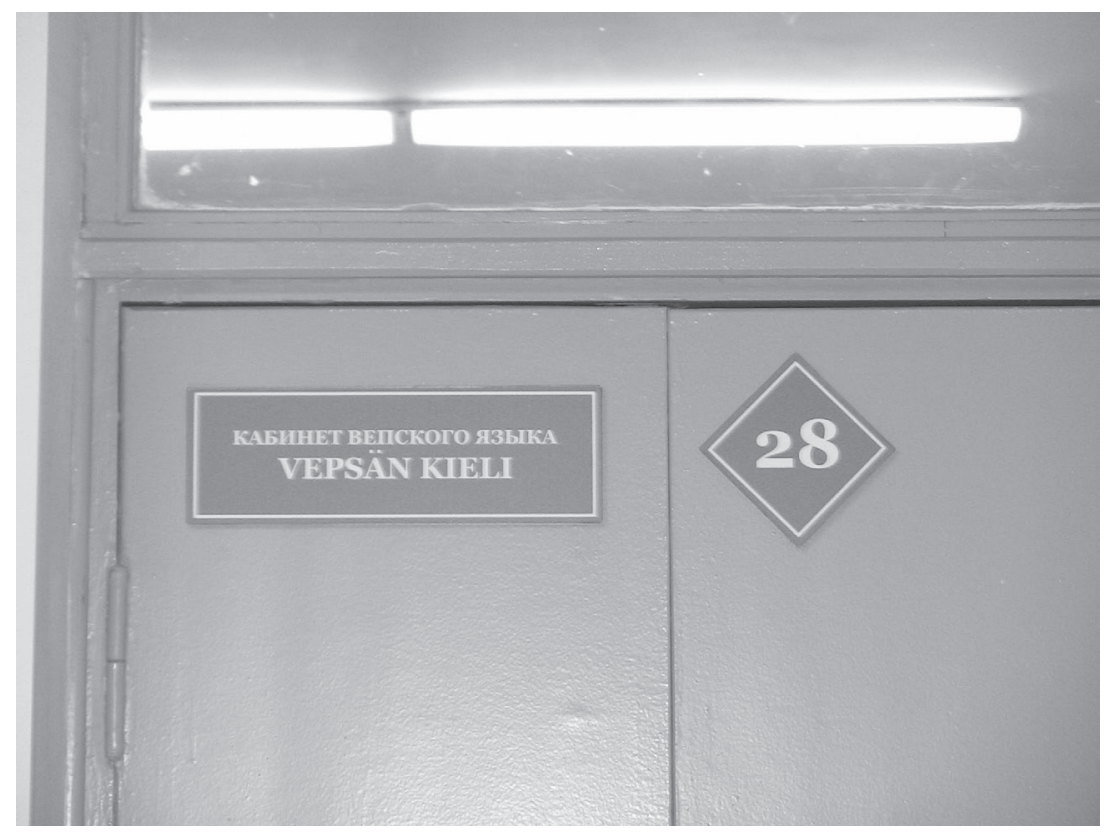

Figure 8.3 Vepsian classroom at the Finno-Ugric school E. Lönnrot. The sign on the door is in Russian and Finnish. I took this picture in 2010 
educators mainly communicate in Russian during the breaks. According to the teachers and activists the reason why the pupils use only little Vepsian outside the classroom can be explained by a number of reasons. They often place responsibility on three main factors. The first is the location of the school itself and its mixed-teaching aspect. The second is the general attitudes toward education in the minority language held by the head of school and policy makers. This leads also to the third aspect, which involves minimal and ineffective training for the teachers by the educational institutions.

The location of the school is problematic. At first glance, its central position satisfies the political purposes of visibility that the activists aimed to achieve at the beginning of the revival movement. Nonetheless, these are counterbalanced by the practicalities which involve being right in the center of the capital of the Republic of Karelia. Galina Lokkina mentioned some of the downsides of this central position for those who live in the outskirts of the city, such as in Kukkovka and Drevlyanka. She said,

My daughter and her husband decided not to enrol my niece at the Finno-Ugric school. Unfortunately, they live far from the centre of town and it would be very inconvenient to take her there every morning. So, they registered her in the closest school in Drevlyanka.

Particularly in the winter, traffic jams regularly occur in the center of Petrozavodsk. One can easily be late for school and/or work trying to access the center from the suburban areas due to the continuous breakdown of public transport, due to the snow and ice on the streets. Being situated in the center of town presents another set of drawbacks for the Vepsian revival goals as Natal'ya Antonova explained:

They decided to move the Finno-Ugric school to the centre of town a while ago. It used to be based outside the centre. Although it was a small school, it had its dignity. They only spoke the national languages there. The school in the city centre, instead, has merged Russian education with education in the national languages. They think they have made it more prestigious by having it in the city centre. On the contrary it goes against the aims that the school used to have. ${ }^{4}$

Not to mention the fact that by being located at the center of town also means being surrounded by the administrative offices and various bureaucracies where the Russian language and the aforementioned language ideologies dominate. Communication in the streets and the offices is primarily conducted in Russian. In other words, the language environment where the school is situated is mainly Russian language-based.

Another set of difficulties is presented by the attitude of the head of school and Ministry of Education toward national education, which is reflected in the organization of the classes (e.g., their timetable) and teacher 
training. In August 2009, a peculiar episode took place right before the school year started. A primary school teacher at the Finno-Ugric school explained how the head of the school had tried to prohibit the teaching of Vepsian, Karelian, and Finnish that year:

Before the school started we experienced a huge dispute over the creation of space for children and families to spend more time together. Our head of school suggested stopping teaching Vepsian, Karelian and Finnish at school. The idea was that the children would not be so tired from studying all these languages. However, this suggestion did not pass.

Many activists commented on the episode. Natal'ya Antonova wondered why the head of a school where Finno-Ugric languages should be privileged, instead, "is not really interested in preserving those languages." Nina Zaitseva also explained how Vepsian education is supported by regional and federal acts, but many people in authority "do not respect them and do not even care if you point that out."

Such an attitude is also reflected in the scheduling of Vepsian teaching hours and the language hierarchy present in the school curriculum. Once enrolled, "the pupils study one hour of Vepsian a week in their first year, 3 hours from the second to the fourth year, two hours from the fifth to the eleventh year" (Kukkoeva 2008, 175). Each school hour lasts 45 minutes. Irma Mullonen and Zinaida Strogal'shchikova lamented that this amount of hours per week is not sufficient to learn a language. ${ }^{5}$ Irma Mullonen also explained that once the pupils decide what subjects to take to the EGE, they quit studying Vepsian and concentrate on the final exams. Furthermore, the Vepsian language is not a compulsory subject, but dopolnitel'nyi (R. Supplementary). Therefore, the parents can choose whether or not to enroll their children in the Vepsian classes. This was confirmed by Margarita Kozlova, whose granddaughter entered the Finno-Ugric school in September 2010. As her son and daughter-in-law were pondering over the subjects that their daughter should be studying, they checked the curriculum and its requirements. They observed that studying Finnish would be compulsory, had the child chosen to study Vepsian. This did not apply the other way round, though. Margarita Kozlova explained:

She's going to study Finnish, not Vepsian. We worried that it would be too much for her. It's compulsory to study Finnish when the pupil attends Vepsian classes. However, it's not compulsory to study Vepsian when the pupils are registered in Finnish classes. We just thought it would be too much for her to study Russian, Vepsian, and Finnish, and later on also English.

Unsurprisingly, there is such a discrepancy between the number of pupils who take on Vepsian and those who take on Finnish. In the school year 
2010-2011, 50 pupils studied Vepsian (215-Karelian, 750-Finnish, 469-English and 16-French) - this number declined to 34 in the school year 2013-2014 (129-Karelian, and 891-Finnish). ${ }^{6}$ Each year, about 25 pupils enter one big class, which is split into subgroups for Karelian and Vepsian. Only a minority registers for Vepsian classes. Nadezhda Kukkoeva, the teacher of Vepsian at the school, explained that the classes used to be smaller before with a total of 12-15 pupils. However, all of them used to study Vepsian.

Finally, the administrative attitude toward the national languages is also reflected in the limited teacher training. Nadezhda Kukkoeva joined the school in 1998 and since then she has been teaching Vepsian from the first to the eleventh class. She said that she received professional training from the Ministry of Education and/or the former Ministry for National Politics, Public Relations and Religious Associations. However, she admitted reading foreign language textbooks to develop new ideas "so that the classes would not be boring but more interesting." It is not uncommon that some teacher training is inadequate for the requirements of the class (Kaplan et al. 2011, 107). For the same reason, she experiments using newspapers and magazines for didactic purposes such as Kodima with the tenth and eleventh classes and Kipinä from the eighth class onward. She has also re-created a micro Vepsän ma in her classroom. The creaking wooden floors and red-and-white curtains, which are in the colors of the traditional Vepsian costume, provide a rural Vepsian house atmosphere, and this can boost Vepsian learning in her opinion. Nadezhda Kukkoeva plans her lesson in different stages. She lets the pupils warm up with a brief discussion on the topics studied in previous classes, such as the weather, the holidays, food, and family. She then introduces the new topic using the blackboard. The last part of the class is usually filled with miscellaneous activities, which at times involve using the computer, playing with toys, and moving around the room. Although many pupils claim they enjoy learning Vepsian, they immediately stop speaking it and turn to Russian once they cross the threshold of the Vepsian classroom.

\section{Vepsian Tertiary Education and Politics}

In 2010-2011, Vepsian tertiary education was administered by the BalticFinnish and Finno-Ugric Faculty at Petrozavodsk State University (also referred to as PetrGU) and the Pedagogical Academy. However, the latter did not run any classes during the time of my fieldwork since no students enrolled that year. In 2013 the Baltic-Finnish and Finno-Ugric Faculty at Petrozavodsk State University was transformed into a department within the Faculty of Philology, due to the limited number of students. Indeed, Vepsian teaching at university has also encountered a number of difficulties, especially in negotiations with the policy makers. Miscommunication with the authorities appears to be the main concern in regard to Vepsian education 
as expectations often differ among the various agents, particularly regarding teacher training and the status of indigenous minority held by Veps. While teacher training is provided for primary and secondary school teachers, as mentioned in the previous section, university teachers receive no training at all. Ol'ga Zhukova told me about her professional growth by a process of trial and error:

I learned through my own experience. At the beginning it was rather difficult since there was no material I could use in class. I have made all the material I am using in class myself. It took a very long time to create it and collect these documents. Right now, it is simpler as I have filed all the documents which I re-use from year to year.

A second hiccup is the status of Veps as a minority of the Russian Federation, which often represents a double-edged sword. While it has provided visibility at regional, federal, and community levels, it has also maximized the expectations that obtaining such a status entails. The policy makers tend to expect Veps to fulfill the same requirements as the more numerous nationalities. In spring 2010, one activists was on her way to university when she told me:

Have you heard that they want to cancel the Vepsian classes at University? [. . .] They have decided to cancel the classes because of the limited number of Vepsian students. This year only 30 students registered for Russian language classes from the whole of Karelia. 30 students! We are a minority group, what do they expect? Do they also expect us to find 30 students?

Similarly, one of the teachers at university expressed frustration coming out of a meeting with the federal education representatives and commented, "It seems that we need to justify our existence [as teachers of Vepsian] every time. We always need to explain why we need to keep teaching Vepsian.” She extended her argument to the fact that the expectations of the government tend to be unrealistic, as they do not take into consideration the present-day language ecology and said,

There has been a demographic drop in the 1990s. Therefore, we were expecting a drop in the number of students. But they [i.e., the Federal Ministry of Education] do not understand this. And they want the same number of students as we used to have. This is not possible.

Cultural pluralism, such as in the multiethnic Republic of Karelia, is complex in nature (Edwards 1981). The various groups present different issues but these do not often appear to be addressed separately or in accordance with the specific requirements of each group. 


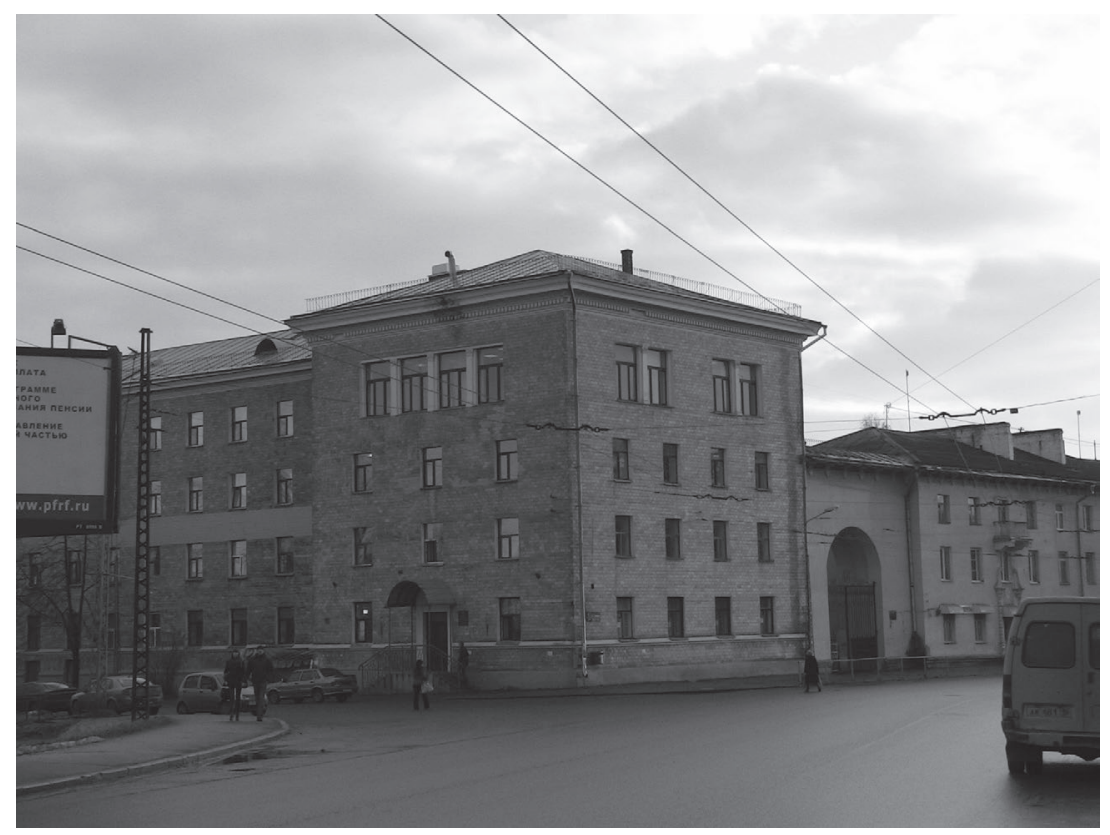

Figure 8.4 Baltic-Finnish and Finno-Ugric Faculty of Petrozavodsk State University. I took this picture in 2010

\section{Baltic-Finnish and Finno-Ugric Department}

Despite such difficulties, the commitment of the educators and activists has also provided many positive results. The Baltic-Finnish and Finno-Ugric Department of Petrozavodsk State University is located on Pravda Street in the center of Petrozavodsk (Figure 8.4). The second floor is dedicated to Karelian, Finnish, and Vepsian teaching. The Vepsian classroom is the smallest. Situated at the end of the corridor, it comprises four desks, a blackboard, and a bookshelf (Figure 8.5). The organization of the faculty has changed since its foundation. The department of the Vepsian and Karelian languages was inaugurated in 1990 and three years later the principal of Petrozavodsk State University opened the Faculty of Pre-Baltic FinnoUgric Philology and Culture (Zhukova 2007; Zhukova 2008, 172). Mariya Mullonen was the first teacher of Vepsian. After Ol'ga Zhukova began to permanently work at the Academy of Sciences, her former students took her position as a teacher of Vepsian at university. At present, Mariya Kosheleva is in charge of the language courses from the first to the fifth year, assisted by Nina Zaitseva who teaches Vepsian dialectology and the history of the Vepsian language. However, it is compulsory that all the students in the faculty study the Finnish language and literature. After this, they can choose 




Figure 8.5 Vepsian classroom at the Baltic-Finnish and Finno-Ugric Faculty of Petrozavodsk State University. I took this picture in 2009

whether to pursue only the Finnish language and literature or to combine those classes with the Karelian language and literature or the Vepsian language and literature. The Finnish-Vepsian curriculum expects the students to attend 448 hours during their first-year course, 384 during their second 
and third year, 320 during their fourth year and 72 during their fifth year (Zhukova 2008, 172). The students learn Vepsian morphology, phonology, and lexicon in their first four years. In the fourth year, the students conduct dialectology research. As Ol'ga Zhukova explained:

They go and collect some language material in the villages we have agreed on. They are asked to comment on what it felt like to be a researcher and to collect some lexical material. Every one of them has a theme. It is very interesting for them. They go and communicate with the locals, and then they come back and write a report on which they are assessed.

This material also represents the foundation for their final thesis. The students link the collected data to a theoretical topic and write their thesis in Vepsian. Right at the end of their fifth year, the students are assessed on the written work. They present a summary of their thesis to a committee that judges its contents and theoretical discussions. In their fifth year, they conduct a teaching practical for seven weeks. They teach approximately 14 lessons which are judged by a committee of linguists and educators. The work of the students also fosters cooperation with the language activists on which Nina Zaitseva commented:

Only 10 years ago the students struggled to write their thesis in Vepsian. It was very difficult to write that thesis and to find the right terminology. They now write 50 pages and seem fine with it. They also bring something new to the lexicon which the scholars regard highly.

Ol'ga Zhukova also elaborated on how the faculty (and later department) has changed in its enrolment guidelines and how the new type of students has also influenced her teaching methods. In the early 1990s, the BalticFinnish and Finno-Ugric Faculty of Petrozavodsk State University used to enroll students with some knowledge of Vepsian. Soon the administration realized that this was counterproductive since fewer and fewer students were enrolling. Since 2004, students who join Vepsian courses do not need to know the language in advance. This increased the number of students from seven to nine per class. Such administrative decisions required that the teachers changed their teaching methods. Ol'ga Zhukova once recollected how in her student days they used to "translate Pushkin on the first day at University." When they introduced students with no knowledge of Vepsian, she had to re-invent her role as a teacher since she no longer had a teaching role model to follow. Ol'ga Zhukova clarified,

So, my job changed. On the one hand, there were more students than before and on the other, the settings had changed. We had changed the curriculum. My own teachers used to teach me on the basis that I 
knew the language. So we used to mainly study the grammar because we already had a lexical basis and knowledge. But as the situation changed at university, my job became more complex. I knew how I studied myself and I had to re-think how to facilitate learning Vepsian from scratch.

The structure of her lessons was very similar to those planned by Nadezhda Kukkoeva at the Finno-Ugric school. The first part of the class was usually a revision of previous topics and it often involved a conversation with the students. Then she introduced the new topic, sometimes adopting the Socratic Method and eliciting some of the answers from the students. The third part of the lesson was usually dedicated to practicing the new topic, either grammatical or lexical. She sometimes tested the students with revision assignments. Those were not always planned as she wanted to test how much had settled in their memory and what topics needed been revised again. This way she kept track of their improvement.

Most students valued the work of Ol'ga Zhukova very highly and often expressed their gratitude for having learned Vepsian from such a thorough and patient teacher. Nonetheless, some also showed interest in how a language is taught in Europe in order to compare the education system in Russia with those overseas. ${ }^{7}$ They often discussed the need to be speaking Vepsian more and the need for educational spaces where they could use Vepsian in its oral mode only. The Russian system of education does not grant an institutional forum for the students to meet and discuss topics such as teaching methods and provide feedback on their classes. Nonetheless, it is widely recognized the importance of authenticating in a systematic way the comments and feedback provided by the students in order to boost teaching (Payne 2006; Van der Walt 2006). This way the students can have access to academic power and contribute to better represent the practices, knowledge and worldviews of their indigenous group (Gilmore and Smith 2005, 67). There are many drawbacks in not involving strongly enough the pupils and the students in the decision-making and curriculum creation processes. ${ }^{8}$ For example, the pupils and the students can lose motivation when they find the subjects uninteresting (Ball 2004, 472). Indeed, Ball (2004) suggests letting them choose the subjects they find interesting and want to learn.

\section{Vepsian Students}

During fieldwork, I noticed that some students showed more interest than others in the revival of Vepsian. Their attitudes manifested themselves both at the time of their studies and once they had graduated and begun their career. At present, some of the students are members of the university choir Toive, whose repertoire comprises songs in the national languages, and others are members of the Vepsian folk group Noid. Some students take part in the student international conferences of the Finno-Ugric languages such 
as IFUSCO. Others become members of the Karelian NGO, Nuori Karjala, and the Vepsian organization, Vepsän Vezad (V. Vepsian sprouts).

On completion of their studies, some students try to pursue a career using Vepsian in Petrozavodsk or the Vepsian villages of the Vepsian district of Karelia since they have developed a passion for it. Others, instead, use their newly acquired skills to pursue a career abroad. For some students their language teacher represents a role model and they aspire to teach Vepsian in the future. Indeed, two former students, with whom I attended some first-year classes in 2010-2011, Anastasiya Evtushenko and Kristina Strel'kovich, are now teaching Vepsian in Šoutjärv' and Šokš, respectively. Other students, once graduated, show national ambitions and try to pursue a career where they can employ Vepsian. Some of them work for the Vepsian radio and TV. Others work for Kodima and Kipinä. Admittedly, the opportunities are limited and some former students give up after years of temporary (sometimes even voluntary) positions. Natal'ya Antonova, who also studied at the State University of Petrozavodsk, introduced another issue, which leads many to abandon their academic interests. And this is constituted by the proximity to Finland. She explained,

There were nineteen of us in my course. Seventeen have now moved to Finland and only two have remained here. I am one of them. My friends do not understand why I am not moving to Finland. They repeatedly ask me: How will you provide a good education for your children? How can you not want to earn more money? Money, money! This is all people think about now. When I live in the village and I eat my home-made tvorog [R. Curd cheese], drink my cow's milk, eat the fruits from the land and the fish my dad has fished, I do not spend more than $1,000$ roubles [ca. $£ 20]$ for weeks.

Finland represents a temptation for many students since it is prospering financially and booming in terms of health and educational services. Some of the students feel that by leaving the Russian Federation, they may realize their dreams, free themselves from the oppression that they feel at home, and see and get to know something new. This situation raises some questions for those who invest in the education industry, since they appreciate that this kind of migration represents a huge loss for the Russian Federation. A university teacher of Russian once wondered, "So, the question we now have is who do we prepare our youth for? For Finland? They leave and do not give anything back to the country that has invested in them." 9

\section{Language Nests}

Natal'ya Antonova can be considered a product of the revival efforts of the national movements begun during perestroika and glasnost in the Republic of Karelia. She is a Karelian woman in her early 40s. While 
preparing dinner in the Karelian style in her kitchen she told me how she did not use to want to speak Karelian to her parents when she was younger. She continued, "My attitude changed after the first couple of years at university. I then understood how important it was to be speaking my heritage language." Once she had completed her studies, she worked at the Ministry of Education of Karelia. However, she found the job unsatisfying as the solutions taken there "were not effective." She explained how the "employees at the Ministry of Education mostly follow a 9-to-5 timetable and avoid taking any decision which can have a real impact. So, I resigned and founded Nuori Karjala."

At a Finno-Ugric congress she met representatives of the Finland-Russia Society. Here they decided to cooperate on a language immersion project and received funds to promote language nests among the Finno-Ugric peoples of the Russian Federation between 2008 and 2013 as this is "a $100 \%$ successful project," they claimed. Language immersion programs where the children are taught mainly in the heritage language can be split into those where the immersion is total $(90 \%$ of the teaching is conducted in the mother tongue and $10 \%$ in the language of the dominant group) or partial $(50 \%$ in the mother tongue and $50 \%$ in the language of the dominant group) (Lindholm-Leary 2001, 31). These models are also referred to as dual immersion models (Cummins 1984, 105; Natsis 1999, 329; Skutnabb-Kangas 2000, 618). The government of the Russian Federation only accepted the implementation of the weaker form of the language nests in its territory. Therefore, the organizers of the language nests among the Finno-Ugric population of the Russian Federation managed to introduce the $50 \%-50 \%$ model. The members of the nongovernmental organization (NGO) Nuori Karjala were not satisfied with the outcome:

In the beginning the government said they would help with the language nests only if we manage to find 15 pupils per group. Then, they introduced other constraints. They did not want the education to be $100 \%$ in the national language and introduced this new law in Moscow. [...] The problem with the $50 \%-50 \%$ model is that you know from the beginning that the results are not going to be good. The parents are ready to send their children to these language nests. But when they see that there's no desire on the part of the elites, they give up.

The language nests opened for the Finnish language in Petrozavodsk and for the Karelian language in Kalevala, in the northwest of the Republic of Karelia. In 2008, they could not open language nests for Vepsian since "Zinaida Strogal'shchikova was not able to recruit the required number of children" as the administration put it. In 2010, they tried to involve Veps in the initiative again, but the administration in Šoutjärv' asserted that there was no classroom available for a language nest. Natal'ya Antonova wondered, "How could they possibly not have room for one 
class when they have just opened a huge new school?" However, in the school year 2011-2012, they succeeded in opening one language nest in Šoutjärv'. Ol'ga Kokorina was selected and given the appointment as a Vepsian teacher. She quit her previous job as a nursery instructor, which a former university student of Vepsian took, and accepted this new position. The implementation of language nests is an example of some of the difficulties that the activists face when dealing with long bureaucratic and political negotiations with local, regional, and federal administrative powers.

\section{Vepsian Education in the Villages of Karelia}

I will next provide an account of the Vepsian language education in the school years 2009-2010 and 2010-2011 in Kalag' and Šoutjärv'. During my fieldwork, the Vepsian language was taught at the nursery, and the primary and secondary school in Šoutjärv' and at the primary and secondary school in Kalag.' The language nest in Šoutjärv' was only introduced after my second visit to Karelia. Therefore, I will not discuss its operation in this work. By providing an account of Vepsian education in the rural areas of the Vepsän ma, this section aims to show some of the difficulties that Vepsian education faces and some of the discrepancies which exist between education and language ecology in the villages.

\section{Vepsian Education in Šoutjärv'}

My observations on Vepsian education in Šoutjärv' led me to agree with part of the literature that highlights the importance of the teacher in the learning process of the pupils. ${ }^{10}$ Specifically, I argue that the teaching professionals are central to the work on indigenous education since the educators can take the lead as community research collaborators given that they know the research site from within (Romero-Little et al. 2007, 610). Indeed, the teachers not only have community-based knowledge, but they can also boost the revival efforts by providing feedback to the activists (Ball 2004, 471; Hornberger 2008, 10).

In Šoutjärv', the educational building complex comprises three units. Two of them are dedicated to primary and secondary education. The new building that the federal budget had financed hosts a large cafeteria, a gym, and two workshop rooms for the boys and the girls (Figure 7.1). The old school building was where the classes were still held. The third building was for the nursery and the village library. During my fieldwork, Ol'ga Kokorina was the Vepsian teacher at the nursery and Irina Koshaleva (pseudonym) at the primary and secondary school in Šoutjärv'. Ol'ga Kokorina used to run her lessons in a very small room, which she had arranged as an orderly dining room in a rural Vepsian house. She had built a fake Russian stove next to which she had arranged tables and 


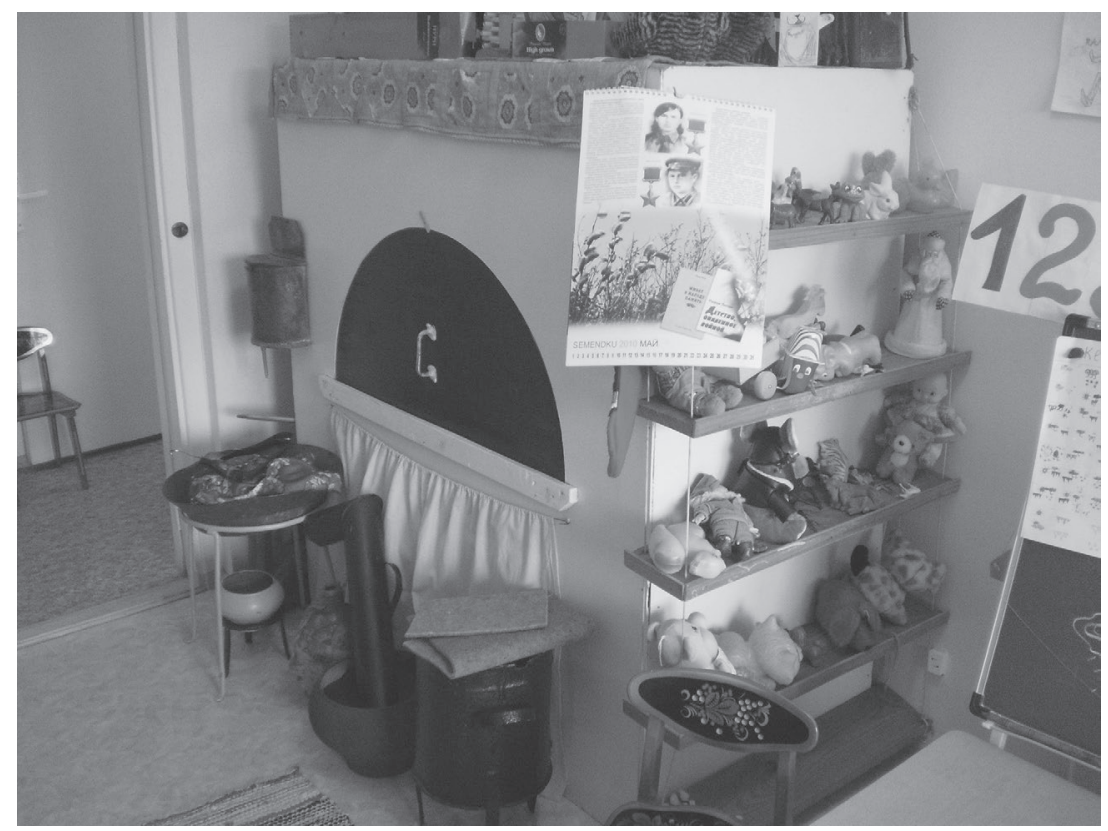

Figure 8.6 Details of the Vepsian classroom at the nursery in Šoutjärv'. I took this picture in 2010

chairs, samovars and other common kitchen tools (Figure 8.6). She had also decorated the classroom with posters, rugs, and drawings and covered it with toys. During her classes, she used repetition techniques that appeared very effective since her pupils understood her instructions and replied in Vepsian. She used to also teach traditional Vepsian songs and games where the pupils employed only spoken Vepsian. Once they learned those songs and games, the children also performed at cultural events where they wore traditional Vepsian costumes.

However, the classrooms at the primary and secondary school were arranged more traditionally with the desks facing the blackboard (Figure 8.7). At the time of my fieldwork, there were ca. 110 pupils enrolled at the school. Most of them were studying Vepsian, which in Šoutjärv' is taught from the first to the eighth class. Irina Koshaleva explained that the children were busy with their exams from the ninth to the eleventh class. Thus, they drop Vepsian and concentrate on their final examinations. During her classes, Irina Koshaleva mainly followed Soviet practices in the teaching of a foreign language. She asked the pupils to translate texts and complete written exercises. The pupils spoke Vepsian primarily when asked to read their written answers. Some of the language activists and village residents were not particularly impressed by the results that her teaching methods 


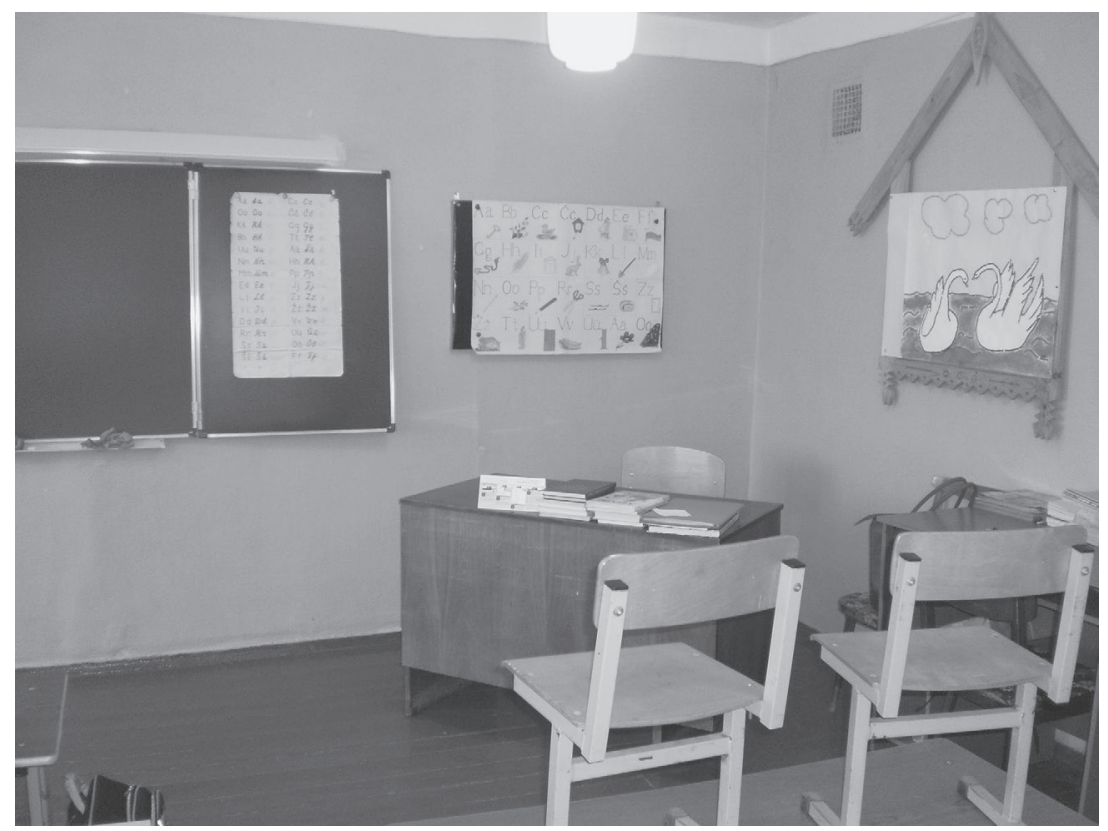

Figure 8.7 Vepsian class in the secondary school in Šoutjärv'. I took this picture in 2010

provide. Marina Sem’yënova (pseudonym), a young woman from Šoutjärv', commented,

She seems not to manage to motivate her pupils. They do not speak Vepsian once they leave the school. The pupils from the school in Kalag', instead, can speak Vepsian once they complete their studies. The teacher there manages to motivate them and to boost their interest.

Irina Koshaleva claimed to be motivated and passionate about her work as a Vepsian teacher. Nonetheless, she rarely participated in the cultural initiatives outside her teaching hours and some of the activists did not appreciate such an attitude. She once claimed that she did not find much support in her enterprise and the creation of teaching material from the language committee in Petrozavodsk. And she disclosed that this had discouraged her. There seemed to be a subtle tension between the Vepsian activists in Petrozavodsk and the former school teacher in Šoutjärv' and this did not foster cooperation nor did it benefit the teaching outcomes. Instead, it is important to foster mutual trust since the relationship among the various agents involved in a revival movement decays when there is lack of trust (Navqi and Coburn 2008). Such a situation seems to have changed once Anastasiya Evtushenko 
took on the role of Vepsian teacher at the school, given her long-term relations and friendship with the activists from Petrozavodsk.

\section{Vepsian Education in Kalag'}

I now need to take the importance of the educators as role models in the promotion of the heritage language a step further. Indeed, observation in Kalag' led me to agree with Echeverria $(2003,357)$, who stresses the importance of a positive and engaging learning environment to meet the pre-set goals. Besides the teachers of the heritage language, the other educators and parents and general community have an influence on the pupils and their perception of the heritage language.

Vepsian is taught from the second to the eighth class in the primary and secondary school in Kalag'. In 2010-2011, there were 67 pupils in total. The number had recently dropped due to the declining birth rate in the 1990s, according to Valentina Klimukova, the school director. During my fieldwork, Vepsian education experienced some developments since the teachers of Vepsian changed and the school building underwent reconstruction. In 2010, some Vepsian classes were taught in a spare room at the local nursery and most of the classes were temporarily taught in a small building on a hill. In the school year 2009-2010, Ol'ga Mironova taught Vepsian while the permanent Vepsian teacher was on maternity leave. During the school year 20102011 Yuliya Aprodu and Mariya Mironova, two former university students, became the new Vepsian teachers. Mariya Mironova is the daughter of Ol'ga Mironova who decided to quit teaching Vepsian in September 2010, so that "her daughter could have the chance to start working at the school." 11 Yuliya Aprodu and Mariya Mironova were employed on a one-year-basis contract. ${ }^{12}$

Overall, Vepsian teaching provides positive results in Kalag'. Valentina Klimukova told me that the Vepsian pupils "perform pretty well at the language competitions which mainly take place in town." Kostya Mironov, for example, won an award for his Vepsian skills in 2010, which also enabled him to join a reward trip to Finland. It should be noted that Kostya Mironov speaks Vepsian at home with his mother and grandmother, as I highlight in the next section. The younger pupils generally enjoy their Vepsian classes. Indeed, a first-year pupil claimed that her favorite subject was Vepsian. She particularly appreciated that her teacher made her classes interesting and fun. Both Yuliya Aprodu and Mariya Mironova experiment in their teaching. Mariya Mironova spends hours preparing her teaching material in the teachers' room. She usually makes paper toys and uses visual aids to boost the memory of the children. Yuliya Aprodu once attended a seminar on communicative teaching methods at a pedagogic institution. Upon her return to Kalag', she said,

It was very interesting to learn new skills. They taught us how to be more interactive in class and showed us some of the positive results from these 
different teaching methods. I think I will try and apply them. I want to do the best that I can. Once you embrace a job, you should always try to do your best. That's why I am investing in new teaching methods.

Indeed, her classes comprise miscellaneous activities where the pupils are required to move, to discuss, and to use the language orally.

Despite the positive results provided by the school and the Vepsian teachers, Vepsian education is challenged by the general language attitudes of some of the educators and parents. Some educators complained about the hiccups caused by the temporary location of the school in two different buildings. Specifically, some pointed out how some subjects such as Vepsian suffered more than others. They regarded this situation as emblematic of a wider language attitude among the educators and school administration. Due to the school restoration, the classes were divided between morning and afternoon shifts. Both Yuliya Aprodu and Mariya Mironova were assigned classes that began with the first shift in the morning and finished with the last shift in the afternoon, comprising long breaks in between. At times, they had to leave the building on the hill to go to the nursery down in the village and back again in order to cover their teaching shifts. Each class lasts 35 minutes and delaying even 5 minutes of class can have an impact on the outcomes of the lesson. Ol'ga Mironova explained how this could cause a loss of motivation in these newly appointed teachers. However, most teachers did not seem too concerned about the difficulties faced by the Vepsian teachers and possible consequences for Vepsian education. During a tea break in the teachers' room, the teacher of Russian whom Valentina Klimukova introduced as "the best teacher in the school" told her colleagues:

My daughter said that she was not feeling well in the morning. So I asked her what classes she would be missing if she did not come to school. She replied, Vepsian, Physical Education and Russian. So, I said, Not to worry, then. I will teach you Russian. As for Vepsian and $P E$, you are not missing anything.

Such dismissive attitudes toward school subjects are spread among some of the teachers and the head teacher. Some subjects are regarded as more important and valuable than others. Vepsian is often perceived as a secondclass subject. The director of the school herself appeared puzzled when I claimed to be interested in studying the Vepsian language and culture as she kept repeating, "Why Vepsian? How bizarre that is—an Italian woman who wants to study the Vepsian language!"

The teachers accept most of the responsibility for how the pupils and the students develop their language attitude (Edwards 1979, 123-124; Lindholm-Leary 2001, 39). Where the educators have a more positive attitude toward the minority language, the pupils are more inclined to learn. Just as the teachers can find ways to motivate their students, they also run 


\section{4}

Education and the Babushka

the risk of discouraging them with pessimistic or negative behaviors and attitudes. The language used inside and outside the classroom needs careful consideration, as it may lead to discouraging the students (LindholmLeary 2001). However, it is clear that this does not entirely depend on the educators.

The parents and extended family have also a huge responsibility on their children's choice. ${ }^{13}$ Ol'ga Mironova explained how difficult it is to keep the pupils motivated in their eighth class, before they drop Vepsian to concentrate on their final exams. She said, "the older pupils often wonder what they need Vepsian for. Of course, they are under the influence of their parents." In Kalag', the roles of parents and educators often overlap. Therefore, those considerations are of particular importance. The pupils reinforce a positive or negative attitude toward the heritage language within the domestic environment. The present generation of parents- that is, those born between 1965 and 1980-often cannot speak Vepsian. Some of them are able to understand it, but cannot actively speak it. Their language attitude and ideologies are often mixed. On the one hand, there is the desire to promote the heritage language. On the other hand, there is no real connection with or feeling for this language and/or belief that it will be useful for their children.

The pupils are not only influenced by their educators and their parents but also the community where they live. ${ }^{14}$ And this comprises the local administration which for a long time did not include Vepsian classes at the local nursery. This decision had an impact on primary teaching since the pupils joined the school with no knowledge or limited knowledge of the language. Ol'ga Mironova explained that using the textbooks with this type of pupil is a challenging task. While Lyudmila used to teach Vepsian at the nursery, and the children used to come to school with some knowledge of the language, in 2010-2011, they did not. And this made it very difficult to teach since they lacked the vocabulary required in the textbooks. The textbook for the second class, for example, was rather difficult for them as there were too many words that they did not know.

She referred to the textbook written by Nadezhda Kukkoeva and Marina Giniyatullina which had won the prize for the best book of the year in 2009. Such situation has improved since Yuliya Aprodu began to teach Vepsian at the nursery.

Vepsian education in Šoutjärv' and Kalag' faces multiple challenges which involve the language attitudes of part of the local population, the way the schools are run and the decisions taken by the local administration. At school the children are introduced to new ways of learning which differ greatly from the ways they are used to in the villages while spending time with their babushki and interacting with the surrounding world. Such a discrepancy finds its origin in Soviet language ideologies, which are the foundation of the 1980s language movement. The written production of the language is often privileged, instead of its oral performance in the school. 
It is the teacher who often dictates the rules and establishes how and what should be learned, instead of letting the children experiment and play with the language in the learning process. A more teacher-centered approach tends to be chosen over a student-centered approach. And this often means that the focus of the class is on teaching grammar rules and translating, as is the Soviet fashion. However, this pedagogical path interferes with language ecology in the villages and the way language used to be transmitted from one generation to the next-i.e., speaking and simultaneously engaging with miscellaneous activities. Contemporary Vepsian education experiences the highest successes when language is also used orally in class, as shown earlier. This is where transmission to the younger generations has proved most effective even in the present day.

\subsection{The Babushka and Her Social and Language Role}

Kostya Mironov was often depicted by his classmates as the best student in Vepsian. Many claim that this was due to the fact that he spoke Vepsian with his babushka at home. His mother Elena Mironova and grandmother Valentina Mironova decided to speak Vepsian instead of Russian to him when he was little. They noticed that at a young age Kostya could not speak either Vepsian or Russian properly. So, they took him to the doctor who advised them to drop one of the two languages to avoid confusion in the child's mind. Such practice was common under the Soviets. Many doctors used to discourage bilingualism, which they implied would cause mental problems in the child. Elena Mironova said, "So, we decided to speak Vepsian to him. It was easier since we have always spoken Vepsian to one another at home." Kostya Mironov, therefore, entered school with an oral knowledge of Vepsian which helped him also learn standard Vepsian. He used to do his Vepsian homework with his babushka, especially when this involved collecting some Vepsian songs and sayings. They regularly participated together in the cultural initiatives promoted in Kalag', Šoutjärv', and Petrozavodsk. In May 2010, for example, they attended the competition Vepsian families in Šoutjärv' (Figure 8.8). As this example suggests the babushka covers an important role in the upbringing of the younger generations in the Vepsian villages. And their role is also vital to the scope of Vepsian language revival since the babushka in the villages can often speak Vepsian.

The babushka tends to help the parents in the upbringing of their children in this northwestern territory of the Russian Federation. The children learn social rules and appropriate ways of behavior from her. Education and upbringing are mostly women's duties. The dedushka (R. Grandfather) generally covers other social duties such as fishing and hunting and other physical work. Women also outnumber men whose lifetime is generally shorter. Although there are differences in the way men and women use the Vepsian language, this volume does not analyze gender differences, as this would deflect the discussion too far. The babushka is the one who looks 


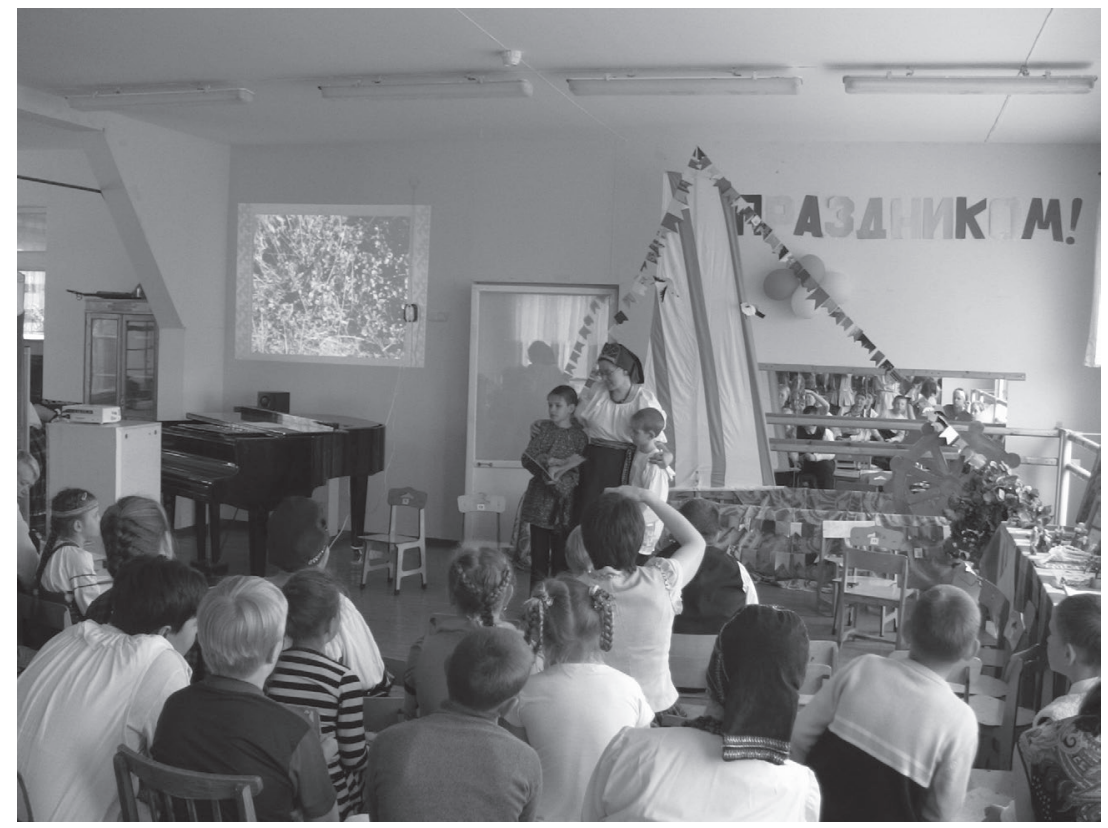

Figure 8.8 Competition Vepsian families in Šoutjärv' in May 2010. I took this picture

after the children while the parents are busy working or even when they take some time off work. In summer 2015 in Pondal, Nadezhda Mednikova was visited not only by her own grandchildren but also their grandchildren's friends and distant relatives. There were days when the veranda was buzzing with laughter and cries from the youngest (in that case, a 1-year-old boy) to the oldest (a 21-year-old girl). Food was always available on the table while children of different age would drop by, grab a snack, and run off again. Nadezhda Mednikova was managing different tasks simultaneously: from washing the clothes in the near stream, to preparing meals, entertaining the youngest ones, and keeping the house warm in the coldest nights.

The babushka is expected to help the mothers bring up the children also in the wintertime, while the fathers are expected to work and provide the financial support that the family needs. However, the jobs in Karelia as well as the Leningrad and Vologda Oblasts are often not well paid or secure. For this reason, many fathers have taken jobs that force them to travel. Some stay away for months if working as sailors or in other jobs that require moving away from home. The babushka is often a highly respected figure among the family members. In the villages, there is often cooperation within the family and everyone assists her when possible. Yuliya Aprodu spent the whole of Saturday evening and Sunday morning helping her babushka cook for a family lunch on a Sunday. When they all sat around the table, they kept 
making fun of her, "our babushka is very strict and we are all very scared. When she says something, you cannot argue with her!" Disrespecting the babushka is generally viewed negatively.

Thanks to this bond many children who live in the city also have the opportunity to engage with village life, particularly in the summer when they tend to spend a couple of months away from home and stay at their babush$k a$ 's home in the village. They learn how to harvest, look after the khozyaystvo (R. Farming and housekeeping), cook local food, and generally engage with the surrounding environment. In the villages, they experience a different physical engagement with the human and non-human creatures. They go and gather berries and mushrooms in the forests. They learn to fish in the rivers which characterize the Vepsian landscape. Galina Lokkina told me as she was looking at her granddaughter Alina playing with her friends in Nemž:

For my Alina this is like living in a fairy tale. She comes here and spends all her time running about with her friends, discovering the world and learning new skills. This summer she has learned how to swim, for example. [Figure 8.9]

It is undeniable that learning from these affectionate family members speeds up and eases the process of acquiring new information (Dekker and

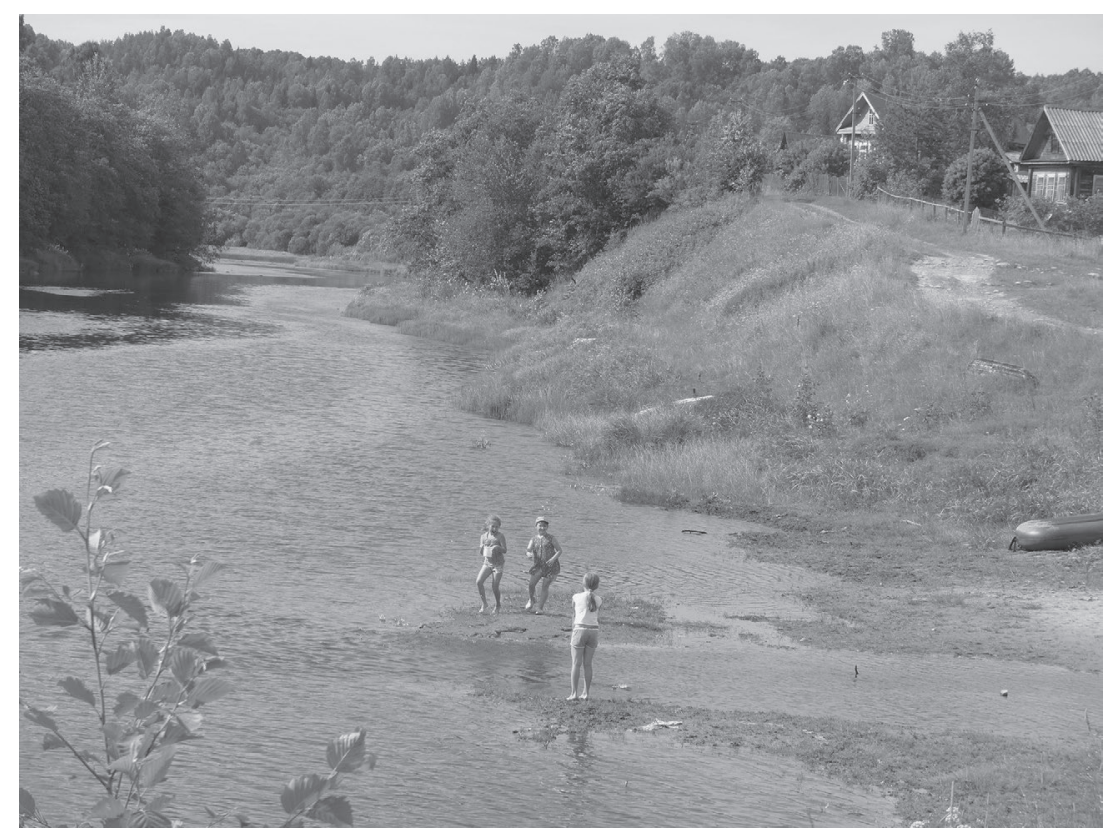

Figure 8.9 Children playing along the river in Vil'häl, Leningrad Oblast. I took this picture in 2015 
Young 2005, 192). Specifically, this appears to be the case in this fairytale environment which develops positive attitudes toward village life in the child (cf. Waller et al. 2017 on the benefits of playing and learning). Once Galina Lokkina heated up her kül'bet' (V. Sauna) in Nemž. She owns a smoke sauna, which means that the steam remains inside the building and does not escape through the usual chimney. All the internal walls are stained in black and it retains a very strong smell of smoked wood. Smoke saunas are renowned among Veps for their beneficial effects on the health of the individual. As we were washing, she started giving me instruction on how to do it properly:

After using the venniki [R. Branches], we do not say spasibo [R. Thank you], we say tervbud käzele, that is health to the hands. Then, we say pezan pän, I wash my hair, peze pän, wash your hair and pezin pän, I washed my hair. ${ }^{15}$

She then admitted that she had not managed to transfer this passion for village life to her daughter, who lives in the city and rarely comes to the village:

It is completely different with Alina [i.e., her granddaughter]. She loves it here. She loves to have a sauna with me. We even study Vepsian together. I read something in Vepsian and then translate it into Russian for her, so she can understand. She insists on repeating the Vepsian words I say.

By pointing out the use of the first singular person in the present and in the past tenses and by using the imperative form, Galina Lokkina had started teaching me some Vepsian grammar. She demonstrated that transmitting Vepsian for her happens in context and without the need to describe the spoken utterances in reference to their grammatical features. Vepsian teaching emerges while engaging in miscellaneous activities and socializing with the world. Language is better transmitted in context among Veps. In other words, not only language utterances are performed in context, but the transmission of language also takes place in context, while being physically engaged in activities (Heath 1983; Philips 1972; Wortham 2008). Language acquisition does not strictly happen in formal schooling (Schieffelin and Ochs 1986, 164). Indeed, Galina Lokkina also showed that she had inherited certain ways of teaching language from the Soviet times. Direct translation from one language to another was often perceived as the appropriate way to learn and teach a language in her school days. Therefore, she feels the need to translate Vepsian into Russian in more formal settings-that is, when they sit and read texts together with her granddaughter. There is a discrepancy between the way the children traditionally learned Vepsian and the way the language is taught at school. ${ }^{16}$ At times, this causes learning difficulties for the pupil who had begun understanding the language in its 
oral production and as a means of interaction with the world and not as a set of rules dictated by an authoritarian figure. Upon my return to Scotland, Galina Lokkina told me in a conversation over Skype:

Alina is struggling at school. In the village she was free to run about. She had such a good time with me, with her friends. And now she has to sit all the time. It is very difficult for her. Imagine what it must be like after spending the summer in such a paradise and then having to sit all the time!

During a discussion over Vepsian education, Natal'ya Silakova eloquently summarized what many feel:

People want to study Vepsian. However, it's not right to teach Vepsian and Karelian like we teach English. Those are not foreign languages here. There are still fluent speakers of Vepsian around the Vepsän ma. We should use the human resources we have! We should be working with the babushki. We should be teaching conversational courses and not only grammar courses. Vepsian grammar is difficult and it puts people off. Of course, we need to teach the grammar later on, but not right away. The best way would be to go to the villages and speak with the babushki.

She stressed three aspects of language education in the Republic of Karelia. And these are the contemporary focus on the grammar, which can discourage early learners; the necessity to use a communicative approach in the beginning of the learning process to raise interest and curiosity in the learners; and the importance of learning the language in the villages. Teaching a language only as a structure made of rules to remember and not for its relational implications can be deterrent to the revival efforts (Filipović et al. 2007, 230). Engaging with the materials, the objects, the environment, and creating situational settings can boost the learning process, promote positive attitudes toward the language, and toward the worldview of that language, its values and its shared symbols (Heath 1983; Castagno and McKinley 2008).

\section{The Elders and Language Revival Programs}

In October 2010, I paid a visit to Mariya Chirkova in Toižeg, a Vepsian village south of Kalag', almost on the border with the Leningrad Oblast. Mariya Chirkova lives by herself in a wooden house right next to the border where the village ends and the forest begins. Her pink-painted wooden house is surrounded by a large garden where she works with bare hands in the summer since the soil is not covered in snow. ${ }^{17}$ The house faces the main road which links Toižeg to Kalag' and in the winter the wind and the dogs are the main 
noises one can hear. Her family lives in Kalag', Šoutjärv', and Petrozavodsk. Therefore, having some company made her very happy and talkative. Toward the end of our interview, she insisted that I came back for another visit, "I live here by myself. Do come and visit me again. There is not much to do here, so this babushka is always very happy to welcome visitors." The summer tends to keep the villagers very busy working the land, managing their gardens, growing flowers, digging potatoes, fixing the cracks on the walls, investing in new windows, fixing the oven and generally preparing for the cold winter months. The other half of the year, instead, tends to be spent quietly within the walls of the house. The villagers pass most of their time quietly at home looking after their khozyaystvo at times knitting, cooking, cleaning, watching $\mathrm{TV}$, and listening to the radio. In the winter, the babush ki rarely get involved in any social and cultural activity and the revival movement does not benefit from their language knowledge and expertise.

Elderly people have been more actively engaged in the promotion and preservation of their heritage language in other revival movements. And this cooperation has proved beneficial for both the grandparents and the revival goals overall (Breinig 2006). Feeling involved in the program, giving a hand, being socially useful for what they know clearly proves a way to invest (and not necessarily financially) in village life (Grenoble and Whaley 2006). Thanks to their knowledge of village life style, the elders can help find ways of teaching and transmitting knowledge to the next generations (Ball 2004; Lipka and McCarty 1994). Besides, they might also enjoy themselves during the revival activities (Ball 2004). Generally, cooperating with the elders in the production of new didactic material can challenge the educators out of their comfort zones (Lipka and McCarty 1994, 280). However, I have observed that this does not represent a risk for the Vepsian teachers. In particular, the younger teachers in the villages have not yet developed a comfort zone and have demonstrated curiosity for and interest in different ways of promoting their heritage language. The challenge seems to pertain to the general public whose opinion toward education is that under the Soviets, the education system was perfect, the Soviet Union used to be a very educated nation, and we were the reading nation per excellence. Questioning those public attitudes might still find resistance.

The language itself can benefit from the process besides the social and educational benefits of engaging the grandparents as it happened in the masterapprentice program developed in California (Hinton 2003, 45). Indeed, new words can be created in the language negotiation between the master and the apprentice (Hinton and Ahlers 1999, 61). The master-apprentice project is probably one of the most successful programs in regard to cooperation with the elders and the promotion of the language. The master-apprentice program expects teams of an elderly speaker and a younger member of society work together for 20 hours a week (Hinton and Ahlers 1999, 60). During this time, the elder and the young person engage in daily activities while speaking their heritage language. The master-apprentice programs follow immersion 
techniques like the language nests. Indeed, each training session is done by giving instructions in the heritage language. Each activity is discussed orally. This program has provided a number of advantages and results such as the "ability to tie the language to traditional activities and values" (Hinton and Ahlers 1999, 59-60). Last, this project has enabled the linguists to document the language and create new language material (Hinton 2003, 45). Involving the elders in the revival program not only provides positive outcomes for the language, but it also boosts village life. The elders use the skills they have previously thought or perceived negatively and/or as useless. Being involved in the revival of their heritage language can entirely turn their language attitude over and make them slip into a more positive mind-set, which induces them into speaking the language to the youths.

Indeed, employing the elderly as language teachers is a well-known phenomenon in language revival. Yet it was important to provide a synopsis of this part of the literature since Vepsian elderly people have only partly been involved in the revival program. Despite the role covered by the babushka in the upbringing of the children, it should be highlighted that speaking the language of the grandparents might be seen as un-cool among the youth in the villages. They might look at the language spoken by other teenagers in the city (or elsewhere) as their role model. Teenagers are often seen as those who bring language innovation and look for their models outside of their domestic environment (Palacios Martínez 2011). In fact, this is more a problem of register than to language - that is, the register of the grandparents and the register of the other teenagers. Natal'ya Antonova made once reference to Amoc, a Saami rapper, who reached the top hits in Finland. She expressed the need not only to refer to the language used by the grandparents but also to expand the domains of use of the minority language and not to be scared to create and experiment new genres in the heritage language.

$* * *$

Stemming from Vepsian education, in this chapter I intended to bring to the surface some of the difficulties that the promotion of a heritage language within the education system may face as well as some discrepancies between language ecology in the villages and the way the language is generally taught at school.

In the city, the education of a heritage language may mainly follow the language ideologies that are dominant there. The promotion of literacy often matches the dominant attitudes toward writing and what it means socially in this multiethnic urban environment. Writing and its promotion are often synonymous with culture and civilization. However, these are not the only hiccups that education of a minority language may face. First of all, the lack of investment in sufficient educational complexes may reinforce tension among a multiethnic population that ends up with groups arguing over the limited resources. Second, delegating the responsibility of the various teaching institutions to various levels of powers (namely, local, regional, 
and federal in the case of the Russian Federation) does not facilitate continuity in the learning process. Plus, the attitudes of all the administrative powers may clash with the education expertise.

In the villages, the education of the heritage language of a minority group may depend on the local administration. Therefore, each village presents a unique portrait of its implementation, encompassing misunderstandings between the educator and the linguist experts in the city. The lack of a nursery may also complicate education since most of the pupils arrive at school with absolutely no knowledge of their heritage language. Those who do, however, might have been learning it at home, while simultaneously engaging with the language and carrying on miscellaneous activities. Most often, this occurs when the grandparents, who play an important role in the upbringing of the child, speak their heritage language to their grandchildren.

Stemming from this analysis the last section of the chapter has presented the language ecology existing in the villages enabling a comparison with other language revival programs where the elders participate more actively. In the villages, the elders know their heritage language as a way to interact with the world and socialize. They have traditionally transmitted the language orally while engaging in the activities. The promotion of the language in a classroom clashes with such an understanding of the language. Such situations have occurred elsewhere. However, some activists have found ways around community-based language practices and have involved the elders in the promotion of the language. An example of this is the master-apprentice program promoted by Hinton.

Despite the extensive literature on the importance of a community-based approach, it is unfortunate that there resistance persists on the part of the administrative authorities to giving a voice to those involved in the revival efforts. From the present work, it has become apparent that the students and the elders might contribute more to the movement, due to their enthusiasm and new ideas and their verbal knowledge of the language, respectively. In the case of the Russian Federation, this might also be an indicator of resistance to change on behalf of the authorities which links back to ideas of suspicion of what is chuzhoy (R. Foreign). Such a worldview seems harmful and to provide counterproductive results at the grassroots levels of society. On the one hand, the authorities invest in the education of the heritage language of minority groups; on the other hand, they resist it. Such contradiction dominates their attitudes and consequent actions not only toward education, but the revival of the heritage language in general (Nevins 2013).

\section{Notes}

1 On the comparison between the language ecology of a place and language education see also Heath (1983), Heath et al. (2008), Mühlhäusler (2000), Philips (1972), Schieffelin and Ochs (1986), and Zentella (2005).

2 Grenoble and Whaley $(2006,22)$ and Crossey (2009) also discuss these risks. 
3 Cf. Shulist (2017) on challenges posed by multilingual education in a multiethnic city.

4 Prestige planning needs to be prompted by the population, rather than from the policy makers (Sallabank 2005). This concept might, indeed, be understood differently and might be relevant for language planning.

5 Indeed, insufficient teaching hours do not enable the pupils to learn the language (Kaplan et al. 2011).

6 Finno-Ugorskaya shkola Eliasa Lionnrota. http://fusch.ru/school/normativedocuments/samoobsledovanie/1750.

7 On different styles of learning, see also Castagno and McKinley (2008).

8 See, for example, Lindholm-Leary (2001), Lincoln (2003), Hornberger (2005), and Redwing Saunders and Hill (2007).

9 At present the Italian education system is facing a similar situation. Many students continue to flee the country and have founded a website which acts as a forum for discussion called cervelli in fuga (I. brains on the run).

10 Hornberger (1998) and Spolsky $(2003,554)$ expand on the role covered by the teachers.

11 According to Milroy and Milroy (1992) and their social network model, the stronger the social ties within a community, the less linguistic innovation occurs. The case of the Mironov family seems to apply to this model.

12 They have since been working as teachers of Vepsian at the nursery and school in Kalag'.

13 See, for example, Gruffudd (2000, 174), Recendiz (2008, 104) and Whitman (2005).

14 This argument is developed by Heath (1983), Lindholm-Leary (2001), Recendiz (2008) and Whitman (2005).

15 The words in bold indicate that Galina Lokkina spoke Vepsian. I agree with Baldwin and Markman (1989) in affirming that there is a relationship between language acquisition and objects.

16 Heath (1983) makes similar claims among three different communities in the Piedmont Carolinas.

17 Zaitseva and Mullonen (1972) also explained how the relationship with the soil can become very physical and intimate among Vepsian villagers. In fact, they claim that the villagers used to spit the seeds from their mouth at the beginning of the summer season. 
$\because$ Taylor \& Francis

Taylor \& Francis Group

http://taylorandfrancis.com 


\section{Conclusion}

\section{Revitalizing a Heritage Language. Toward Multimodality and "Multispatiality"}

In this volume, I have presented the revival of the Vepsian language as a case study of language revival movements, bringing to the surface the complex grid of forces that surround the revitalization of the heritage language of a minority group of the Russian Federation. Indeed, many social and political factors, past and present language ideologies, socially shared systems of values, and practices in a multiethnic environment influence the shaping of the revival movement on a daily basis. Many parallels can be drawn elsewhere. Admittedly, I have only touched upon some social factors such as gender and religion in the present work since they would have deflected the argument too far from my focus on the dynamic between literacy and orality; yet, I recognize that they might be central elsewhere. Similarly, I have touched upon such concepts as identity and voice (Blommaert 2004). Despite not being central to my presentation, they were integrated in other discussions, such as relations in a multiethnic environment, relations with the authorities, and self-description and perception on behalf of Veps. Indeed, this work has construed the socio-political and linguistic understanding of the literacyorality dualism and rural-urban polarity, which emerged from an observation and interpretation of the language ecology more comprehensively. I provide a larger spectrum on the context where language is used. That is, I have observed language practices in context, ideologies, mismatches, and/or agreements with revival activities.

This work is based on two key concepts which runs throughout the book, language ecology and heritage language. The phrase language ecology matches ideas of socialization and use of ways of speaking and writing in relation to the dominant forces present at a specific time in a specific place. These may comprise language ideologies and attitudes. It distances itself from biological metaphors that assume language has a life on its own, detached from the world and those who actually use it in their speech and written acts. Within such a paradigm, language is not only understood to be used in context but also to do things and have the capacity to co-construct reality, and to be a mode of experiencing life.

The choice to employ the phrase heritage language instead of "mother tongue" or "native language" hints at the political status of a minority 
language both at national and international levels. The purpose of this choice is also to contextualize academic language in relation to the current debates on tangible and intangible heritage (Kirshenblatt-Gimblett 1998); hence, it conforms to the general understanding that also academic terms are created and used in context. Besides, this phrase fits in well with the case study that I presented given its focus on the dynamicity and fluidity of the language, and its presentation as something that was used in the past, has continued to develop and change, and still reverberates in the present in a new form and shape. These two concepts-language ecology and heritage language-run throughout the text, while I present the dominance of literacy in revival movements, aiming to highlight its benefits, but also frictions with the revival efforts.

The choice to promote literacy has often predominantly responded to the policies and language ideologies shared in a multiethnic environment. However, it is often the elders who master the heritage language in its oral form and live far away from the administrative and decisional centers. The elderly villagers tend not to contemplate political connotations and linguistic approach to language. These are discussed more often among the urbanites and middle-generation villagers who have grown up aware of the political implications of their heritage language. However, the oral use of the language is often only partially been included in the revival of a minority language. In particular, I am referring to verbal art (such as, puheged and lamentations) and their power to build reality in relation to non-human forces present in this rural environment. I am referring to ways of speaking which demonstrate carefulness and cautiousness as not to upset a balance and disrespect those non-human beings with whom people share their land. This volume has brought to the surface language experiences of those who have only partly reached the revival movement and whose language use is instrumental to the success of such revival efforts. As such, my work concurs with the literature which recognizes power inequalities in language practices and their promotion and creates space for those who are-consciously or not-marginalized (Blommaert 2004; Bourdieu 1992).

The work of the activists may respond to two main political and social language ideologies. First, they might respond to and engage with the directives of the policy makers. Second, they may respond to dominant language ideologies in a multiethnic environment. This way they abide by the language ideologies of the policy makers and a multiethnic population, which, in this case, hold a very hierarchical concept of language. The written form of a language is then viewed and perceived as the next step in the evolutionary ladder, and in this sense the minority language with a strong oral history comes to symbolize backwardness and indicate a "past" that many perceive has long gone. The literacy bias became synonymous with civilization and development under the Soviets and possibly already before the Soviets. Unsurprisingly, the Soviet prescriptions allowed for an institutionalization of those "less-developed" languages in policy that materialized in a plan 
of action to develop the backward peoples of the Russian Empires. In the first stages of the Soviet regime, defeating illiteracy and promoting national literacies aimed to form the Soviet citizen, involving all different nationalities of the USSR. Such language attitudes still exist among the population of Karelia, especially in urban centers where to live kul'turno is regarded positively. Here Russian is generally viewed as a richer and more articulated language than the other indigenous languages. Admittedly, such ideologies have dominated other movements around the world. Therefore, the activists often work in order to reverse this social and linguistic symbolism and give confidence back to a population that had begun to believe that there was nothing to teach in their heritage language due to its linguistic poverty. In other words, creating a written form of the language of the minority group for many activists represent a response to such degrading attitudes toward their own heritage language, which has also allowed for social and political discrimination.

Paradoxically, though, such course of action might have not matched traditional epistemologies and ontologies of the language that had only been used orally in the countryside, as the result of relations with a specific environment, its human and non-human inhabitants, groups with whom the local dwellers came in contact, and as the relations themselves. In fact, the contact with the other groups has brought about an enrichment in the worldview of both groups and this can also be reflected in their language use. Nonetheless, contact, group boundedness, and consequent exchange of practices are viewed differently by the members of the different groups. For some this represents a threat and they fear it; for others, this is an opportunity of enrichment. For some, the "other" can be viewed as inferior and backward or can even come to represent a "rival," especially when it is considered prestigious. The latter ideology can ultimately lead to competition and rivalry. Such ideologies and attitudes are reflected in some structural features of the language, and how language is used in context. Code-switching and lexical borrowing in the ways of speaking of members of the minority group may be an indication of those ideologies. At times, certain language choices unveil long-term cooperative work (Sebr) and local epistemologies and ontologies. Such is the case for lexical borrowing mostly, or what I refer to as shared words in this volume. At other times, ways of speaking and structural features may instead reveal power inequality. What is problematic, indeed, is when people drop the language completely due to specific language ideologies and attitudes that may put them at risk. So, in the case of Veps, they may drop speaking their heritage language in the presence of Russian-only speakers, as to reassure that nothing bad is said about them. It is clear that there are other socio-economic and political reasons that hinder people from speaking their own heritage language.

These considerations are further expanded in Chapter 5, which challenges accepted metaphors of language among the academic environment and policy makers. Among the scholars, language is often seen as an entity that 
came to life at some point in the past, further developed, and is doomed to disappear, due to language competition. Such a metaphor went uncontested for a couple of decades. In the meantime, it has allowed scholars to develop ways to describe the phenomenon of language shift that are based on such a gloomy metaphor. Languages are classified for the health and those that are believed to give sign of a weak health are referred to as endangered (and the whole scale in between "healthy" and "dead"). Language revival programs have attempted to reverse this fall in the health of a language with the aim to save them from their imminent death. I decided to omit such terminology for a number of reasons. First of all, it continues to separate ways of speaking (and writing, for that matter) from life. It detracts languages from their interrelation and constructing capacity, reducing them to a set of rules, external to the ecology in which people experience them. This biological approach also does not include experiences of language among the speakers of the minority language. Second, this metaphor clashes with local epistemologies and spread positive attitudes among the speakers. The belief that one's own heritage language is dying out discriminates fluent speakers of the language, also picturing them as-if already dead. This acts against the very own purposes set by the activists. When such words and phrases as endangered, language death, and save a language began to be used in the literature, they mostly aimed to galvanize political action. This terminology created an urgency from which the policy makers around the world could not turn away. And its use has certainly provoked a reaction and mobilized many global as well as local policy makers. Nonetheless, there is now a need to reconnect with the local language context after more than three decades since the establishment of such a biological metaphor, as it appears not to serve the intended purposes any longer. On the contrary, it often neglects local language ecology. This volume has introduced this argument and hopes to prompt a discussion on the topic. Finding the right terminology to describe a heritage language that is less and less transmitted generationally can be complicated. For this reason, I employ the phrase heritage language and also the words sokbranit' $i$ razvivat' ( $\mathrm{R}$. To preserve and to maintain) instead of spasti (R. To save) in order to stress the dynamicity of language and its metaphorical image as a bridge between the past and the future. I also opted for these terms, since this is how the activists speak about their heritage language.

While Chapters 4, 5, and 6 have presented those who speak their heritage language predominantly in rural areas, Chapters 7 and 8 primarily expanded on language use and promotion in the city. Besides presenting the language choices of the activists, Chapter 7 has provided an account of legislative measures that support the promotion of heritage languages. The policy makers have shown themselves to have ambiguous political objectives and attitudes toward them and to engage more with international language acts than to respond to the immediate needs of the population. Conflicts and misunderstandings often occur between the activists and the 
policy makers. The latter tend to dismiss the suggestions and expertise of the activists in favor of quick and not always thoroughly-thought solutions. Instead, these are often grounded on non-existent research and little appreciation and trust for the population. Indeed, people are demanding institutional space where they can meet and speak their heritage language. Such space was created on a voluntary basis, for example, when the Paginklub was first founded. Also, village life is not equally supported in the different administrative regions where Veps dwell. Northern Veps, thanks to the proximity to the regional capital Petrozavodsk, a dynamic mining industry, and support from the local and regional authorities continue to vibrate with life. This is not the case in the central and southern villages where, paradoxically, the elderly speak their heritage language on a daily basis and relations with the rural environment is strongly based on verbal art (e.g., puheged) and ways of speaking which show respect and carefulness.

Undeniably, the promotion of writing has provided other positive outcomes that the activists hoped for at the beginning of the revival movement. Many writers claim to be proud to be writing in their heritage language. Thanks to the creation of writing, the youth can create new domains of use, also through the use of new technologies. This way, they subvert some of the power inequalities in language by adopting an advanced technological tool such as the computer. Writing has begun, therefore, to indicate hope for the future. However, despite its positive outcomes, focusing only on the superdiversity that literacy, online ways of communication, and urbanization have created risks overshadowing other practices and people living in the villages where the spoken word retain a different kind of power.

Chapter 8 develops this argument further by presenting the promotion of the minority language within the education system. This chapter shows how the educators, the pupils, and the activists often cooperate in the creation of new pedagogic material as well as words. However, most of the complications inherent in the education of the minority language arise when negotiating with the policy makers. First of all, the disunity in the education system can be reflected in the discontinuity of education in the heritage language from the kindergartens to university. Such disunity does not foster cooperation. Another issue is that the promotion of the written mode does not always correspond to the interactional norms and ways of speaking of those who master the language. Education mostly succeeds when the pupils speak their heritage language at home before entering school. In this regard, the social role played by the grandparents can be central to the revival of the minority language. However, the elders are often neglected by the local and regional administration, which is closing down local services and does not often create space where the villagers can meet and engage in social activities. For this reason, in Chapter 8, I provided successful examples of language revival where the elders participate in the promotion of their heritage language, the master-apprentice program. While the aim of this work is not to provide any guidance on how Vepsian should be promoted, sharing 
and communicating these kinds of effective practice back to the activists is intended to foster cooperation among different institutions as well as to satisfy some of their needs to reach out to the audience outside of the Russian Federation.

Here I have presented all the agents involved in the revival of Vepsiannamely, urban and rural dwellers, the youths and the elders, the activists, the policy makers, and the multiethnic population of this northwestern territory of the Russian Federation. I have opened up the issue of language revival movements in a post-Soviet context thanks to extended fieldwork. Specifically, the literacy-orality polarity and urban-rural divide have emerged as core to the present situation of Vepsian revival, but this is also the case elsewhere. The literacy bias concurs with international language standards and language rights. It has enabled the minority group to gain visibility among a multiethnic population and re-establish confidence within a longrepressed group. Literacy has become synonymous with political action, and as such, it has served some of the purposes of the movement. Nonetheless, the literacy bias has overshadowed the language ecology of the rural areas. Through spoken language, new realities are created. Through spoken language, people can experience a different relation with the world form that they experience through literacy. Orality can entail experiences of unity, of enrichment, of contact, and of exchange. In fact, while literacy covers a more political power, orality appears to cover a kind of power that is relational to the rural ecology in which the language first emerged and developed. Its agency resides in its capacity to influence the course of life events, especially in a rural territory, due to its relational power with the creatures dwelling there, comprising human and non-human beings.

In a nutshell, I am not trying to provide specific prescriptions, as per the practice of Soviet ethnographers, or advance a model on how to preserve and maintain heritage languages; yet, I am highlighting that in the case of Veps, and possibly other minorities, not maintaining multimodality in the revival of a minority language can only provide some results and not guarantee speaking the language. As some of the activists have pointed out, the attitudes of the policy makers toward Veps have often been ambiguous and their $50 \%$ investment in the language nests programme, for example, will only provide partial results. My stand on multimodality in the revival of a minority language of Russia aims to open a dialogue with the political administration in understanding the importance of appreciating and respecting language ecology in its complexity. Besides multimodality, the case of Veps unveils the need for a "multispatiality" since language is used differently and for different purposes in urban and rural locales. Such diverse ways of speaking and writing comply with the overarching language ecology with which Veps engage at present. Stemming from the Vepsian revival movement, this volume aims also to reach out to other movements where similar dynamics are manifested. It aims to speak to revival movements of the entire Russian Federation, but also heritage language movements within 
the European Union and elsewhere in order to compare results, successes, and challenges. The literacy and orality dualism and urban-rural divide are key in both post-Soviet and other contexts. It reflects present-day ideologies also in relation to past legacies on the present and to future expectations. This work also speaks to the younger generation of speakers and writers in their heritage language since they are expressing more and more strongly their needs and those of their children in regard to their heritage language. With these ambitions, I end my work hoping to find ways to work ühtes, as a sebr, on those issues, to maintain diversity, creativity, and to further peace, positive messages also within the political discourse on heritage languages and to respect language as well as more broadly human rights.

So I conclude with a question that has recently been risen by other scholars dealing with minority and heritage languages and their promotion: who is responsible for their maintenance and further development? It appears to me that responsibility for maintaining and promoting heritage languages falls on the shoulders of everyone who is involved in the revival movement, but also those who are in contact with minority groups (Henne-Ochoa and Bauman 2015; Puura and Tánczos 2016). As indicated by Toivanen (2015) the majority of the population may hold back and this might be done also at unconscious level which prevents the minority from realizing their goals. The work of present-day scholars in Russia as well as any scholar interested in Finno-Ugric matters finds its foundation on long-term cooperation and common interests. If initially the scope was to unify disperse Finno-Ugric communities, it has more recently turned into a pragmatic endeavor that I suspect has spurred from a present rhetoric of "endangerment" and "loss." I concur with their goals and suggest focusing on the overall language ecology in which language is used, comprising superdiversity mostly in the city and the oral mode of the language as it is used in the villages (including those forms that are perceived as obsolete, such as pubeged and lamentations). So, to possibly romantically end this book, I want to believe that the Vepsian sebr will continue to vibrate, engage dynamically with new forces, and be led by cooperative work, respect, and common goals. 
$\because$ Taylor \& Francis

Taylor \& Francis Group

http://taylorandfrancis.com 


\section{Appendix A}

\section{Introduction. Grammatical Sketch of Vepsian}

This appendix presents the codified form of Vepsian. Yamakoshi (2010) provide the model for the grammatical sketch of Vepsian. Throughout its presentation, it highlights the differences between the dialectal variations mentioned in Chapter 6 and the structural decisions taken by the activists at the time of perestroika and glasnost. The presentation of Vepsian serves not only to show where some dialectal idiosyncrasies are reduced to one form but it may also divulge and contribute to spread the knowledge of Vepsian to a broader, English-speaking audience.

Indeed, a further aim of this section is to present Vepsian grammar in English since this has not been done before. Aleksey Tsykarev is a Karelian activist and member of the NGO Nuori Karjala. He once proudly showed me a poster in English and Karelian that they had produced together with Natal'ya Antonova, the founder of this non-profit organization. He stressed how important it was not to always be using Russian as the only medium to reach out to other people. On several occasions, Nina Zaitseva and Zinaida Strogal'shchikova also expressed the need to surpass the boundaries of the Russian Federation and to reach out to an international audience through the medium of English that they regret not studying at school. Irma Mullonen added that she always recommended that her students should learn English. She believed that this was the language that could bring humanity together. She also explained how they were creating a corpus of the Vepsian language online, which she appreciated needed to be translated into English. Nina Zaitseva who is leading the project confirmed this. The site Korpus Vepsskogo Yazyka (R. The Corpus of the Vepsian Language) includes a synopsis of Veps in history and of their literacy tradition. ${ }^{1}$ Most importantly, it comprises an archive of contemporary and old transcriptions of Vepsian speech (including several lamentations) which researchers can now analyze, thanks to the navigation and search tools. The medium of English is seen as a way to go beyond the limitations of Russian among the activists. In other words, it can enable the international public to become acquainted with the several nationalities of the Russian Federation, their languages and cultures. Vladimir Solov'yëv, founder of the Vepsian group Noid confirmed, "Using only Russian can be problematic. What you write 


\section{Appendix A}

on VKontakte, for example, remains within the boundaries of the Russian Federation and only a few people outside Russia can read it." Taking these observations into consideration, this presentation of Vepsian grammar is in harmony with the Vepsian views and understanding of joint work (V. sebr) and their sense of unity and aims to foster cooperation among academic and other-Institutions.

\section{A.1. Overview}

The Uralic language family comprises two branches, the Finno-Ugric and the Samoyedic languages. Vepsian belongs to the Balto-Finnic subgroup of the Finno-Ugric languages together with Finnish, Karelian, Estonian, Livonian, Olonets Karelian, Ludian, Votic, and Ingrian (Grünthal 2007; Puura et al. 2013).

The Balto-Finnic languages share several common features. They are originally agglutinative languages that join lexical and inflectional morphemes together, although they have partially lost this characteristic over time. As a common morphological trait, they mainly add suffixes and prefixes to the stem of their words in order to link the various parts of a sentence, instead of using, for example, prepositions. However, the Vepsian language not only inflects nouns (18 cases in total) but it also employs prepositions and postpositions (Strogal'shchikova 2008a, 20). In terms of word classes, the Balto-Finnic languages have an elaborate case system and do not have grammatical gender. They have four verbal tenses: present, imperfect, perfect, and pluperfect. The compound tenses are nowadays rarely used in Vepsian, most likely due to Russian influence (Laakso 2001, 191; Zaitseva 2001). The Finnic languages have the indicative, the imperative, and the conditional moods. Part of the lexicon of the Finnic languages is Indo-European and many words have origin in Latvian, Swedish, Latin, and French (Grünthal 2007, 33; Laakso 2001, 201). Vepsian, Karelian, and Ingrian, on the other hand, tended to acquire words from Slavic languages due to Novgorod rule in the territory where they are spoken (Laakso 2001, 202; Pimenov 1965; Pugh 1999). The main stress is on the first syllable. Together with Karelian, Estonian, and Livonian, Vepsian has introduced palatalization to its phonological system, and this might have been due to the Russian influence (Laakso 2001, 186; Pugh 1994, 47). Apart from the consonants $p, b, k, v$, and $f$, all the others can be subjected to palatalization, for example, sur ' (V. Big), pen ' (V. Small) and ap' (V. Father-in-law) (Zaitseva 1995, 7-8).

Vepsian is distinguished from most Finno-Ugric languages in that it does not strictly apply vowel harmony, as is also the case with Estonian (Comrie 1981, 109). It is also distinguished from the other Finno-Ugric languages for generally shortening long vowels and geminate stops (Laakso 2001, 184186). In Vepsian consonant gradation is not always applied, as in Livonian 
(Laakso 2001, 184). Vepsian diphthongs also differ from the other BalticFinnic languages since they end in $-i$ and $-u$ such as maid (V. Milk), poig (V. Son) and haug (V. Log). ${ }^{2}$ In Vepsian there is a synthetic conditional past tense (Laakso 2001, 192).

\section{A.2. Phonology}

\section{A.2.1. Inventory of Phonemes}

Vepsian comprises 29 consonants, 8 vowels and one semivowel (Zaitseva 1995, 7).

\section{Vowels}

The vowels in Vepsian can be divided into two groups: front and back vowels. Those can be further divided into rounded and unrounded (Table A.1).

\section{Diphthongs}

Vepsian diphtongs end in $-i$ and $-u$. The ones ending in $-i$ are: $-\ddot{a} i,-o i,-a i$, $-u i$, $-\ddot{o} i,-i i,-e i$, and $-\ddot{u} i$. Some examples of diphthongs ending in $-i$ are sai (Wedding), eläi (Inhabitant), oiged (Right), söi (Mouth to feed), and ei (No) (Zaitseva 1995, 9). Vepsian diphthongs ending in $-u$ are: $-a u,-o u,-\ddot{a} u$, and -ӧu. These are found in words such as vauged (White) and soudai (Rower) (Zaitseva 1995, 10). As a rule, Vepsian words do not begin with a combination of vowels. ${ }^{3}$ Although, there are some exceptions, such as oiged (V. Right), aid (V. Fence), and aig (V. Time).

\section{Consonants}

Vepsian has 29 consonants, including 12 palatalized, and a semivowel (Table A.2). Some of these consonants can be geminated, for example, tt (t't'), pp, kk, šš, čč, mm, nn, ll (l'l'). ${ }^{4}$

Table A.1 Vepsian vowels (adapted from Zaitseva 1995, 9)

\begin{tabular}{llllll}
\hline & \multicolumn{2}{l}{ Back vowels } & & & Front vowels \\
\cline { 2 - 3 } & Unrounded & Rounded & & Unrounded & Rounded \\
\hline Upper & - & $\mathrm{u}$ & $\mathrm{i}$ & ü \\
Central & - & $\mathrm{o}$ & $\mathrm{e}$ & $\ddot{\mathrm{o}}$ \\
Lower & $\mathrm{a}$ & - & $\mathrm{a}$ & - \\
\hline
\end{tabular}


Table A.2 Vepsian consonants (from Zaitseva 1995, 10)

\begin{tabular}{lllllll}
\hline & $\begin{array}{l}\text { Labial } \\
\text { labiodental }\end{array}$ & Alveolar & Retroflex & Palatal & Velar & Glottal \\
\hline $\begin{array}{l}\text { Stop, Affricate, } \\
\text { Affricative }\end{array}$ & $\mathrm{p}, \mathrm{b}$ & $\mathrm{t}, \mathrm{d}, \mathrm{c}$ & $\mathrm{t}$, , d' & č, ž & $\mathrm{k}, \mathrm{g}, \mathrm{g}$ ' & - \\
$\begin{array}{l}\text { Fricative } \\
\text { Nasal }\end{array}$ & $\mathrm{f}, \mathrm{v}$ & $\mathrm{s}, \mathrm{z}$ & $\mathrm{s}, \check{\mathrm{s}}, \mathrm{z}$ ' & - & - & $\mathrm{h}, \mathrm{h}$ \\
Liquid & $\mathrm{m}, \mathrm{m}$, & $\mathrm{n}$ & - & $\mathrm{n}$, & - & - \\
Semivowel & - & $\mathrm{l}, \mathrm{r}$ & - & $\mathrm{l}, \mathrm{r}$, & - & - \\
\hline
\end{tabular}

\section{A.2.2. Syllable Structure}

The word canon CVC is preferred, for example kaži (Cat) and mänd (Pine). The majority of Vepsian words end in a consonant, for example, koir (Dog) and jaug (Leg). The stem of these words is followed by a vowel which precedes the suffix of the case-e.g., koir $\underline{a}$ - and jang $\underline{a}-.^{5}$

\section{A.2.3. Voicing}

As a rule, "voiced consonants are retained when Russian verbs are borrowed in Vepsian: barabani- (Drum), and the like" (Pugh 1999, 53-54). However, a voiced consonant changes into voiceless before another voiceless consonant in a borrowed word, such as plot-kät (Produce!) (Pugh 1999). This also occurs to the words ending in $-z$ which in the partitive become $-s t$, such as armaz $>$ armas $-t$ (V. Dear).

\section{A.2.4. Vowel Harmony}

The vowel harmony rule implies that a front vowel and a back vowel should not co-occur in the same word (Ebata 2010, 182) (Table A.1). This rule is typical of other Balto-Finnic languages. However, it only occurs in the initial two or three syllables of the words in Vepsian. Lükäita (Throw, abandon) is an example of this. ${ }^{6}$ Many two-syllable words have nevertheless retained vowel harmony, such as hüvä (Well, good) and pähä (On the head). ${ }^{7}$

\section{A.3. Word Classes}

The Vepsian language comprises the following word classes: nouns, pronouns, adjectives, verbs, numerals, adverbs, prepositions, postpositions, conjunctions, particles and interjections (Zaitseva 1995, 17). Nouns, adjectives, pronouns and numerals change in accordance to number and case (Zaitseva 1995, 18). The plural is formed by adding $-d$ to the root of the word. The vowels in the root of the word change before adding the suffixes, $-o>-o+-i,-u>-u+-i,-a>-i,-o+-i,-i>-i,-e>-i,-\ddot{a}>-i$. Table A.3 provides some examples of singular and plural: 
Table A.3 Singular and plural for Vepsian word classes (from Zaitseva 1995, 27-34)

\begin{tabular}{lll}
\hline Singular and root of the word & Plural & $\begin{array}{l}\text { Root of the plural for } \\
\text { the indirect cases }\end{array}$ \\
\hline kodi ('Home, house') & kodid & kodi- \\
kala, kala- ('Fish') & kalad & kaloi- \\
sana, sana- ('Word') & sanad & sanoi- \\
vin, vina- ('Wine, vodka') & vinad & vinoi- \\
čoma ('Beautiful, nice') & čomad & čomi- \\
armaz, armha- ('Dear') & armhad & armhi- \\
\hline
\end{tabular}

\section{A.3.1. Nouns}

Nouns in Vepsian have a singular and plural form. They inflect. There are 18 cases in total and these are nominative, genitive, partitive, translative, abessive, essive-instructive, inessive, elative, illative, adessive, ablative, allative, comitative, prolative, terminative, approximative, additive, and egressive (Table A.6).

\section{A.3.2. Pronouns}

Vepsian pronouns can be divided in into eight groups (Table A.4).

Table A.4 Vepsian pronouns (adapted from Zaitseva 1995, 96)

\begin{tabular}{|c|c|c|}
\hline & Vepsian & English translation \\
\hline $\begin{array}{l}\text { Personal } \\
\text { pronouns }\end{array}$ & 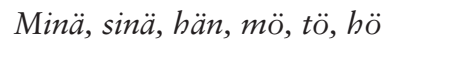 & $\begin{array}{l}\text { I, you, he/she/it, we, you, } \\
\text { they }\end{array}$ \\
\hline $\begin{array}{l}\text { Reflexive } \\
\text { pronoun }\end{array}$ & Iče & Own, oneself \\
\hline $\begin{array}{l}\text { Demonstrative } \\
\text { pronouns }\end{array}$ & Nece, nene, se, ne & This, these, that, those \\
\hline $\begin{array}{l}\text { Interrogative } \\
\text { pronouns }\end{array}$ & $\begin{array}{l}\text { Mi? Ken? Kudamb? Mitte? } \\
\text { Kuverz?’ }\end{array}$ & $\begin{array}{l}\text { What? Who? Which? } \\
\text { Which? How much/many? }\end{array}$ \\
\hline \multicolumn{3}{|c|}{ Relative pronouns correspond to the interrogative pronouns and agree with the nouns } \\
\hline $\begin{array}{l}\text { Negative } \\
\text { pronouns }\end{array}$ & Niken, ni-mi, nikudamb, nimitte & $\begin{array}{l}\text { Nobody, nothing, not one, } \\
\text { none }\end{array}$ \\
\hline $\begin{array}{l}\text { Indefinite } \\
\text { pronouns }\end{array}$ & $\begin{array}{l}\text { Eraz, ken-se, ken-ni, mi-se, mi-ni, } \\
\text { kudamb-se, kudamb-ni, mitte- } \\
\text { se, mitte-ni, kaik, kaikutte, joga, } \\
\text { jogabine, molembad, mougotid, } \\
\text { mugoine, ningoine, toine }\end{array}$ & $\begin{array}{l}\text { Someone, both, such, } \\
\text { another }\end{array}$ \\
\hline $\begin{array}{l}\text { Reciprocal } \\
\text { pronouns }\end{array}$ & $\begin{array}{l}\text { Toine toižen, toine tošt, toine } \\
\text { toiženke, etc. }\end{array}$ & Each other \\
\hline
\end{tabular}


Table A.5 Numbers in Vepsian

\begin{tabular}{lll}
\hline Digit & Cardinal numbers & Ordinal numbers \\
\hline 1 & Üks' & Ezmäine \\
2 & Kaks' & Toine \\
3 & Koume & Koumanz' \\
4 & Nel'l' & Nellänz' \\
5 & Viž & Videnz' \\
6 & Kuz' & Kudenz' \\
7 & Seičeme & Seičemenz' \\
8 & Kahesa & Kahesanz' \\
9 & Ühesa & Ühesanz' \\
10 & Kümne & Kümnenz' \\
11 & Üks'toštkümne & Ühtenz'toštkümnenz' \\
12 & Kaks'toštkümne & Kahtenz'toštkümnenz' \\
20 & Kaks'kümne & Kahtenz'kümnenz' \\
30 & Koume kümne & Koumanz'kümnenz' \\
100 & Sada & Sadanz' \\
200 & Kaks'sadad & Kaks'sadanz' \\
1000 & Tuha & Tuhanz' \\
1000000 & Million & Not applicable' \\
\hline
\end{tabular}

${ }^{1}$ When asked, many Veps admitted never having used the ordinal for one million and not knowing how to form it. Some suggested the form millionz.'

\section{A.3.3. Numerals}

Numerals in Vepsian follow the decimal system. The Vepsian language has both cardinal and ordinal numbers (Table A.5).

\section{A.3.4. Adjectives}

Adjectives agree with the nouns in number and case also in the comparative and superlative degrees. The comparative degree in Vepsian is formed by the suffix $-m b$ (Zaitseva 1995, 87). In the word vanhembile (pl. Elder), for example, vanha- is the root, $-m b$ is the indicator of the comparative, $-i$ is the indicator of the plural and the suffix -le is the suffix of the allative case. ${ }^{8}$ The superlative is formed by using the word kaikid or kaikis before the comparative form. The suffix -im, instead, is used for the word parahim (V. The best).

\section{A.3.5. Verbs}

There are two types of verbs in Vepsian, monobasic and bibasic (Zaitseva 2001, 23). Monobasic verbs have one or two root morphemes, both ending 
in a vowel. Bibasic verbs have two roots, one ending in a vowel and the other in a consonant:

1) The first group comprises two subgroups:

a. Those with the root of the word ending in a vowel, such as lugeda, luge- (To read) and abutada, abuta- (To help);

b. Those with two roots ending in a vowel, such as kaita, kaiče- (To take care of);

2) The second group comprises verbs, such as tulda, tule- (To come) and tehta, tege- (To do) which have one root ending in consonant and one root ending in vowel.

\section{A.4. Morphology}

\section{A.4.1. Nominal Inflection}

As stated earlier, Vepsian nouns and adjectives have a plural form and inflect for case and number (Table A.6).

Table A.6 This table is an adapted version from Zaitseva $(1995,65-66)$. In this table Zaitseva provides examples of 18 cases, while in her latest dictionary (Zaitseva 2010) she omits the last three-i.e., approximative, additive and egressive, providing a total of 15 cases.

\begin{tabular}{llll}
\hline Case & Interrogative pronouns & Singular & Plural \\
\hline Nominative & Ken? Mi? & sana ('Word') & sanad \\
Genitive & Kenen? Min? & Sanan & sanoiden \\
Partitive & Keda? Midä? & Sanad & sanoid \\
Translative & Keneks? Mikš? & Sanaks & sanoikš \\
Abessive & Keneta? Midäta? & sanata & sanoita \\
Essive-Instructive & Kenen? Min? & Sanan & sanoin \\
Inessive & Kenes? Miš? & Sanas & sanoišr \\
Elative & Kenespäi? Mišpäi? & Sanaspäi & sanoišpäi \\
Illative & Kenehe? Mihe? & Sanaha & sanoihe \\
Adessive & Kenel? Mil? & Sanal & sanoil \\
Ablative & Kenelpäi? Milpäi? & Sanalpäi & sanoilpäi \\
Allative & Kenele? Mille? & Sanale & sanoile \\
Comitative & Kenenke? Minke? & Sananke & sanoidenke \\
Prolative & Kedame? Midäme? & Sanadme & sanoidme \\
Terminative & Kenehesai? Mihesai? & Sanahasai & sanoihesai \\
Approximative & Minnoks? & Sanannoks & sanoidennoks \\
Additive & Mihepäi? & Sanahapäi & sanoihepäi \\
Egressive & Minnopäi? & Sanannopäi & sanoidennopäi \\
\hline
\end{tabular}

\footnotetext{
${ }^{1}$ The consonant $-\check{s}$, not $-s$, is used after the vowel $-i$ in Vepsian.
} 


\section{Appendix A}

I decided not to translate the interrogative pronouns here, as some of them cover different capacities and can be translated in several ways. I expand in the description of each case. In regard to the genitive and partitive cases, see Table 6.2 on the differences between dialectal variation and the standard form of the Vepsian language.

Nominative (Ken? Mi?)

The nominative case is used:

1) As the subject of the sentence. For example,
(a) Prihaine lugeb kirjad.
The boy reads the book.

(Zaitseva 1995, 36)

2) To add information about the subject. For example,

(b) Nece ristit, mecnik, völ kerdan kacubti minubu.

This man, a hunter, again looked at me.

This man, a bunter, looked at me again.

(Zaitseva 1995, 36)

3) As a pronominal particle,

(c) Hän om hüvä neičukaine.

She is a good girl.

(Zaitseva 1995, 36)

4) In the case of the nominativus/partitivus absolutus,

(d) Mam ištub laps' üskas.

The mum sat the child in her arms.

The mum sat with the child in her arms.

(Zaitseva 1995, 36)

5) When the verb is in the imperative mood. For example,

(e) Anda minei kirj!

Give me the book!

(Zaitseva 1995, 37)

6) In vocative idioms,

(f) Neičukaižed, tulgat tänna!

Girls, come here!

(Zaitseva 1995, 37)

7) In the case of combined words such as jogirand (The bank of the river) and kodima (Fatherland). 
Genitive (Kenen? Min?)

The genitive is formed by adding the suffix $-n$ to the root of the word. The genitive case is used

1) To express possession,

(g) Neičukaižen lehtik.

Of the girl the notebook.

The notebook of the girl.

(Zaitseva 1995, 37)

2) As a direct object of transitive verbs,

(h) Baboi sanui vunukoile čoman sarnan.

The grandmother told to her grandchildren a nice tale.

The grandmother told a nice tale to her grandchildren.

(Zaitseva 1995, 38)

3) Before some postpositions such as päl (Above), täht (For) and polhe (About)—e.g., Sinun polhe (About you). ${ }^{9}$

\section{Partitive (Keda? Midä?)}

The partitive is formed by adding the suffixes $-t /-d$ (-tal-da in some cases) to the root of the word. For the nouns ending in $-z>-s t$ (bonuz $>$ honust, room), in -ine $>-s ̌ s t$ (prihaine > prihašt, boy). The nouns ending in -l', -n', -r', $-z^{\prime},-z i,-u z^{\prime},-e z,-a z$ also take $-t$, for example kel' $>$ kel't (Tongue, language), pen'> pen't (Big), nor' > nort (Young), keväz' > kevät (Spring), vezi > vet (Water), tervbuz' > tervbut (Health), verez > verest (Fresh) and hambaz > hambast (Tooth). The partitive case is used

1) After numerals-e.g.,

(i) Kaks' kirjad.

Two books.

2) As a direct object: ${ }^{10}$

2a) In negative sentences. For example,

(j) Minä en luge kirjad.

I do not read the book.

2b) Together with abstract verbs-e.g.,

(k) Minä toivotan ozad.

I wish [you] happiness.

2c) To express indefinite quantity. For example,

(1) Minä jön maidod.

I drink milk. 


\section{Appendix A}

\section{Translative (Keneks? Mikšs?)}

The translative is formed by the suffix $-k s(-k s ̌$ after the vowel -i). The translative case is used

1) To express a change. For example, (m) Vezi tegihe jäks.

The water becomes ice.

(Zaitseva 1995, 40)

2) To express goal and change. For example,

(n) Tahtast mamoi pani pirgoikšs.

The dough the mother made for the pies.

The mother made the dough for the pies.

(Zaitseva 1995, 40)

3) To express time,

(o) Tulin adivoibe nedalikś.

I came for a visit for a week.

(Zaitseva 1995, 40)

4) To express in what language one speaks,

(p) Pagižen vepsäks.

I speak Vepsian.

5) To foresee-e.g.,

(q) Habin sibitase- tomaižeks.

If you scratch under your nose, you will get presents.

Abessive (Keneta? Midäta?)

The abessive is formed by the suffix -ta. For example,

(r) Pal'hal päl olen tulnu, paikata.

I came home with bear head, without a headscarf.

The abessive case is used with the preposition ilma (Without)-e.g., Ilma sanoita (Without words) (Zaitseva 1995, 40).

Essive-Instructive (Kenen? Min?)

The essive-instructive is formed by the suffix $-n$. The essive-instructive case is used

1) To express future actions-e.g.,

(s) Uden voden praznikan linneb sur' concert.

For the New Year celebrations there will be a big concert.

(Zaitseva 1995, 47) 
2) To indicate the profession of a person. For example,

(t) Minun mamain radab opendajan.

My mum works as a teacher.

(Zaitseva 1995, 47)

Verbs Expressing a State in or Movement to/From the Innermost of Something. ${ }^{11}$

The verbs expressing a state in or movement to/from the inside of an object are the inessive (Kenes? Miš?), the elative (Kenespäi? Mišpäi?) and the illative (Kenehe? Mihe?). The inessive is formed by adding the suffix $-s(-\check{s}$ after -i) and it expresses a state-e.g.,
(u) Ištu kodiš!
Sit at home!

(Zaitseva 1995, 41)

The elative is formed by adding the suffix -späi (-špäi after -i) and it expresses the movement from the interior of something. For example,

(v) Mamoi tuli laukaspäi.

The mother came from the shop.

(Zaitseva 1995, 42)

The illative is formed by adding the suffixes $-h a,-h o,-h u,-h e,-z e,-\check{z} e$, and it expresses the movement to the innermost of something:

(w) Mänen školaha.

I am going to school.

(x) Hän läksi kinoho.

$\mathrm{He} / \mathrm{She}$ went to the cinema.

(y) Pane babukad puzubu!

Put the mushrooms into the basket!

(z) Ajan Petroskoibe.

I go to Petrozavodsk.

(aa) Dedoi ištuihe veneheze.

Grandfather sat on the boat.

Verbs Expressing a State on or Movement to/From the Top of Something

The verbs expressing a state on or a movement to/from the top of an object are the adessive (Kenel? Mil?), the ablative (Kenelpäi? Milpäi?) and the 


\section{Appendix A}

allative (Kenele? Mille?). The adessive is formed by adding the suffix $-l$ and it expresses the state of being on something:

(ä) Meiden külä seižub järven randal. Our village is situated of the lake on the bank. Our village is situated on the bank of the lake.

(Zaitseva 1995, 45)

The ablative is formed by adding the suffix -lpäi and it expresses movement from the top of something-e.g., Stolalpäi (From the table) (Zaitseva 1995, 46). The allative is formed by adding the suffix -le and it indicates the movement to the top of something:

(cc) Kaži libui päčile.

The cat went on the stove.

\section{Comitative (Kenenke? Minke?)}

The comitative is formed by the suffix -nke. The comitative case indicates company or characteristics of the subject. For example,

(dd) Poig vändab irdal ičeze sebranikanke.

My son plays in the street together with his friend.

(bb) Tuli pert'he mužik mustanke bardanke.

Came home a man black bearded.

A black bearded man came home.

(Zaitseva 1995, 48)

\section{Prolative (Kedame? Midäme?)}

The prolative is formed by the suffix -dme (-tme). The prolative case expresses the place of the location of movement. For example,

(ff) Orav hüppib koivudme.

The squirrel jumps on the birch.

\section{Terminative (Kenehesai? Mihesai?)}

The terminative is formed by the suffixes -hassai (-hosai, -husai, -hesai) and -zesai (-žesai). The terminative case indicates the place where one ends up both in time and space. Some examples are,

(gg) Sinei pidab mända mechasai.

You have to go to the forest (not inside the forest but there where the forest begins). 
(ee) Mušt Loninan polhe eläb minus nechesai.

The memory Lonin of lives in me.

The memory of Lonin [still] lives in me.

\section{Approximative (Minnoks?)}

The approximative is formed by the suffixes -nno, -nnoks and -denno, -dennoks for the plural. The suffixes -nnoks and -denno, -dennoks indicate the direction of motion. The suffix -nno indicates the proximity to something or location,

(ii) Meidennoks tuliba adivod.

Us they came to visit.

They came to visit $u s$.

(ji) Minä mänen läkarinnoks.

I go to the doctor's.

(kk) Stol seižub iknanno.

The table is located next to the window.

(11) Kezal olin babanno.

For the summer I was at my grandmother's.

\section{Additive (Mihepäi?)}

The additive is formed by adding the suffixes -hapäi (-hopäi, -hupäi, -hepäi, -zepäi) and -lepäi. It is used to indicate movement along or toward something-e.g.,

(mm) Paimen kükseb lehmid kodihepäi.

The shepherd drives the cows along the house.

\section{Egressive (Minnopäi?)}

The egressive is formed by adding the suffix -nnopäi for the singular and -dennopäi for the plural. The egressive case refers to the starting point of movement:

(kk) Hän läksi minunnopäi jo amu.

$\mathrm{He} / \mathrm{she}$ left me (my house) a long time ago.

(oo) Külännopäi pidab mända sinna.

From the village one needs to go there.

One needs to go there from the village.

The terminative and the egressive cases hint at inchoative and completive ideas of aspect. 


\section{Appendix A}

\section{A.4.2. Derivation in Nominals}

Many nouns derive from existing nouns such as kirjamišt (Alphabet), kirjam (Letter, character) and kirjišt (Library) from kirj (Book).

\section{A.4.3. Verbal Inflection}

Vepsian verbs inflect, agreeing with the person, number, positive or negative form, and tense. There are four tenses: present, imperfect, perfect, and pluperfect. The Vepsian verbal system is a tense-aspect system. In other words, the present tense conveys actions taking place in the present. The imperfect tense conveys short actions in the past with a link to the present. The perfect tense indicates an action whose results are visible in the present. And the pluperfect tense conveys actions which began in the past and had consequences in the past (Zaitseva 2001). Vepsian verbs can have an active and reflexive voice (Table A.7). The negative is expressed by the verb $e$ which is inflected in the present tense, with the exception of the imperative mood (Laakso 2001, 193) (Table A.7). ${ }^{12}$

As an example of verbal inflection in Vepsian I will provide the verb sanuda (To say/tell) which belongs to the first typology of Vepsian verbs and the reflexive verb pestas (To wash oneself).

Table A.7 Vepsian verbal inflection (adapted from Zaitseva 2010, 503-510)

INDICATIVE

\begin{tabular}{llll}
\hline Present & & & \\
\hline Sanuda ('To say/tell') & Pestas ('To wash oneself') \\
\hline Sing. & Plur. & Sing. & Plur. \\
Sanun & Sanum & Pezemoi & Pezemoiš \\
Sanud & Sanut & Pezetoi & Pezetoiš \\
Sanub & Sanuba & Pezese & Pezesoiš \\
\hline Imperfect & & & \\
\hline Sanuin & Sanuim & Pezimoi & Pezimoiš \\
Sanuid & Sanuit & Pezitoi & Pezitoiš \\
Sanui & Sanuiba ${ }^{1}$ & Pezihe & Pezihe \\
\hline Perfect & & & \\
\hline Olen sanunu & Olem sanunuded & Olen peznus & Olem peznus \\
Oled sanunu & Olet sanunuded & Oled peznus & Olet peznus \\
Om sanunu & Oma sanunuded & Om peznus & Oma peznus \\
\hline
\end{tabular}


INDICATIVE

\begin{tabular}{|c|c|c|c|}
\hline \multicolumn{4}{|l|}{ Pluperfect } \\
\hline Olin sanunu & Olim sanunuded & Olin peznus & Olim peznus \\
\hline Olid sanunu & Olit sanunuded & Olid peznus & Olit peznus \\
\hline Oli sanunu & Oliba sanunuded & Oli peznus & Oliba peznus \\
\hline \multicolumn{4}{|l|}{ IMPERATIVE } \\
\hline \multicolumn{4}{|l|}{ Positive } \\
\hline- & Sanugam & - & Peskamoiš \\
\hline Sanu & Sanugat & Peste & Peskatoiš \\
\hline Sanugaha & Sanugaha & Peskahas & Peskahas \\
\hline \multicolumn{4}{|l|}{ Negative } \\
\hline- & Algam sanugoi & - & Algam peskoiš \\
\hline Ala sanu & Algat sanugoi & Ala peste & Algat peskoiš \\
\hline Algha sanu & Algha sanugoi & Algha peskoiš & Algha peskoiš \\
\hline \multicolumn{4}{|c|}{ CONDITIONAL } \\
\hline \multicolumn{4}{|l|}{ Present } \\
\hline Sanuižin & Sanuižim & Pezižimoi & Pezižimoiš \\
\hline Sanuižid & Sanuižit & Pezižitoi & Pezižitoiš \\
\hline Sanuiži & Sanuižiba & Pezižihe & Pezižihe \\
\hline \multicolumn{4}{|l|}{ Imperfect } \\
\hline Sanunuižin & Sanunuižim & Peznuižimoi & Peznuižimoiš \\
\hline Sanunuižid & Sanunuižit & Peznuižitoi & Peznuižitoiš \\
\hline Sanunuiži & Sanunuižiba & Peznuižihe & Peznuižihe \\
\hline \multicolumn{4}{|l|}{ Perfect } \\
\hline Oližin sanunu & Oližim sanunuded & Oližin peznus & Oližim peznus \\
\hline Oližid sanunu & Oližit sanunuded & Oližid peznus & Oližit peznus \\
\hline Oliži sanunu & Oližiba sanunuded & Oliži peznus & Oližiba peznus \\
\hline
\end{tabular}

${ }^{1}$ See Table 6.2 on the dialectal differences of the third plural person of the imperfect tense. 


\section{Appendix A}

\section{A.5. Syntax}

\section{A.5.1. Word Order}

Vepsian is an inflectional language and as such word order is relatively flexible. The basic order is SVO-e.g.,

\section{(ii) Lapsed ličihe uruhu. $\mathrm{S} \mathrm{V} \mathrm{O}$}

The children crammed themselves in the hole (Silakova 2006, 7).

\section{A.5.2. Voice \\ Reflexive}

The linguists of the late-1980s movement initially decided to use the same form for the first person singular and plural and for the third person singular and plural-e.g., vasttamoi ("I meet" and "we meet") and ei oliži kändnus ("He/she would not turn round" and "they would not turn round") (Zaitseva 2001, 222). Later, however, they began to distinguish the various persons, adopting different suffixes (as shown in Table A.7).

\section{Passive}

Vepsian has preserved the Pre-Baltic construction of the historical passive, in contrast to Karelian (Zaitseva 2001, 161). This means that the subject (plural or singular) of the past action is not mentioned (Zaitseva 2001, 162). For example,

\section{(ij) Lava om pestud.}

The floor is washed.

(Zaitseva 2001, 161)

\section{A.5.3. Tense-Mood}

Vepsian distinguishes the present, past and future tense (Zaitseva 2001, 77). In Vepsian there are four moods: indicative, imperative, conditional, and potential. However, the latter is rarely used (Zaitseva 2001, 159). The use of Vepsian moods does not differ from that of other Finnic languages. The indicative mood is used to express real actions-e.g., tulem (V. We come) (Zaitseva 2001, 120). The imperative mood is used to give orders-e.g., tulgam (V. imperative “we come!") (Zaitseva 2001, 120-121). The conditional indicates desired and conditional actions-e.g., tuližim (V. We would come) (Zaitseva 2001, 120 and 138). 


\section{A.5.4. Yes-No Question}

Yes-no questions in Vepsian are formed by adding the suffix -ik to the main verb-e.g., Oled-ik ? (Are you?).

$* * *$

Presenting the grammatical sketch of Vepsian aimed to highlight the structural characteristics of this language as well as to introduce Vepsian structural features to an English-speaking audience. There is no Vepsian grammar in English and this presentation matches ideas of cooperation and joint work expressed by many Veps.

Appendix A is strictly connected to Chapter 6 on dialectal variations and to Chapter 7 on the social symbolism attached to some of the structural features of Vepsian language, such as its verbal complexity as a symbol of linguistic wealth. In Chapter 7, I demonstrate how the Russian population mainly focuses on the Vepsian lexicon as an indicator of linguistic poverty, instead. Therefore, the grammatical sketch of Vepsian has aimed to stress its morphological, phonological, and syntactic complexity, which is often dismissed by the multiethnic population of Karelia.

\section{Notes}

1 The Corpus of the Vepsian language. http://vepsian.ru/about/.

2 Vepsskiy Yazyk. http://vepsia.ru/yazik/dialekt.php.

3 Ibid.

4 Ibid.

5 Ibid.

6 Ibid.

7 Ibid.

8 Ibid.

9 I do not proovide any reference when the example was given during my Vepsian classes at Petrozavodsk State University and/or during informal conversations.

10 The central Veps use the partitive as a direct object. The northern Veps use the genitive instead. See table 6.2.

11 In order to help the students memorize these cases, their presentation is often modeled on the Russians language at primary, secondary school, and university.

12 The Vepsian students find this complex verbal system very challenging since Russian verbal system is not as articulated. 
$\because$ Taylor \& Francis

Taylor \& Francis Group

http://taylorandfrancis.com 


\section{Archival Sources}

\section{AMAE, Archive of the Museum of Anthropology and Ethnography, Kunstkamera}

Volkov, N. N. Materyal'naya I dukhovnaya kul'tura vepsov (polev. zapisi). 19381939. Fond 13, Opis' 1, no. 10.

Volkov, N. N. Svadebnyy obryad vepsov (fragment). 1928-1930. Fond 13, Opis'1, no. 94.

\section{ERM, Estonian National Museum}

Photo archive. Expedition to Vepsian villages in 1974 by the researcher Lepp Lembit: picture of a woman with her magpie friend. ERM FK 1729: 47.

\section{KarNTs RAN, Karelian Research Centre, Russian Academy of Sciences}

- Journal 3, Tape 625, numbers 4 and 7

- Journal 7, Tape 1302, number 8

- Journal 7, Tape 1304, number II/3

- Journal 7, Tape 1308, numbers 2, 5, and 6

- Journal 7, Tape 1311, number 8

- Journal 14, Tape 2190, number 4

- Journal 14, Tape 2196, number 1

- Journal 18, Tape 2628, number 4

- Journal 18, Tape 2660, number 8

- Journal 19, Tape 2662, number 25

- Journal 19, Tape 2663, numbers 22 and 25

- Journal 25, tape 3197, number 38

- Journal 25, tape 3231, number 44 
$\because$ Taylor \& Francis

Taylor \& Francis Group

http://taylorandfrancis.com 


\section{Bibliography}

Abrahams, Roger D. 1970. “A Performance-Centered Approach to Gossip.” Man $5(2): 290-301$.

Abramov, Nikolay. 1996. "Kodima." In Kodirandaine. Runod i sanutesed vepsän kelel, edited by Nina G. Zaitseva, 3. Petrozavodsk: Karjala.

Ahearn, Laura. 2001. "Language and Agency." Annual Review of Anthropology 30:109-137.

Ahearn, Laura. 2011. Living Language: An Introduction to Linguistic Anthropology. Malden, MA: Wiley-Blackwell.

Aikhenvald, Alexandra P. 2003. "Multilingualism and Ethnic Stereotypes: The Tariana of Northwest Amazonia." Language in Society 32:1-21.

Anderson, David G. 1991. "Turning Hunters Into Herders: A Critical Examination of Soviet Development Policy Among the Evenki of Southeastern Siberia." Arctic 44(1):12-22.

Anderson, David G. 1996. "Bringing Civil Society to an Uncivilized Place: Citizenship Regimes in Russian's Arctic Frontier." In Civil Society: Challenging Western Modes, edited by Chris Hann and Elizabeth Dunn, 99-120. London and New York: Routledge.

Anderson, David G. 2000. Identity and Ecology in Arctic Siberia: The Number One Reindeer Brigade. Oxford: Oxford University Press.

Anderson, David G., and Arzyutov, Dmitry V. 2016. "The Construction of Soviet Ethnography and 'The Peoples of Siberia.'" History and Anthropology 27(2):183209. doi:10.1080/02757206.2016.1140159.

Anderson, Kay, and Smith, Susan. 2001. "Emotional Geographies." Transactions of the Institute of British Geographers 26(1):7-10. doi:10.1111/1475-5661.00002.

Arukask, Madis. 2002. "The Spatial System of Setu Kalevala-Metric Lyrical-Epic Songs." Tautosakos Darbai XVII(XXIV):46-64.

Arzyutov, Dmitry, and Kan, Sergey. 2017. "The Concept of the 'Field' in Early Soviet Ethnography: A Northern Perspective.” Sibirica 16(1):31-74. doi:10.3167/ sib.2017.160103.

Auer, Peter. 1998. "Introduction: Bilingual Conversation Revisited.” In Code-Switching in Conversation: Language, Interaction and Identity, edited by Peter Auer, 1-24. London and New York: Routledge.

Auer, Peter. 2007. "The Monolingual Bias in Bilingualism Research, or: Why Bilingual Talk Is (Still) a Challenge for Linguistics." In Bilingualism: A Social Approach, edited by Monica Heller, 319-339. London: Palgrave Macmillan.

Auld, Glenn. 2002. "The Role of the Computer in Learning Ndjbbana." Language Learning and Technology 6(2):41-58. URL: http://lt.msu.edu/vol6num2/pdf/ auld.pdf. 


\section{Bibliography}

Austin, John L. 1962. How to Do Things With Words. London: Oxford University Press.

Baker, Colin. 2003. "Biliteracy and Transliteracy in Wales: Language Planning and the Welsh National Curriculum." In Continua of Biliteracy: An Ecological Framework for Educational Policy, Research, and Practice in Multilingual Settings, edited by Nancy H. Hornberger, 71-90. Clevedon, Buffalo, Toronto and Sydney: Multilingual Matters Limited.

Baldwin, Dare, and Markman, Ellen. 1989. "Establishing Word-object Relations: A First Step." Child Development 60:381-398.

Ball, Jessica. 2004. "As If Indigenous Knowledge and Communities Mattered: Transformative Education in First Nations Communities in Canada." American Indian Quarterly. Special Issue: The Recovery of Indigenous Knowledge 28(3/4):454479. URL: https://muse.jhu.edu/article/181489.

Bals, Margrethe, Turi, Anne L., Skre, Ingunn, and Kvernmo, Siv. 2011. "The Relationship Between Internalizing and Externalizing Symptoms and Cultural Resilience Factors in Indigenous Sami Youth From Arctic Norway." International Journal of Circumpolar Health 70(1):37-45.

Baltali, Sevil. 2012. "Culture Contact, Cultural Integration and Difference: A Case From Northern Mesopotamia." Stanford Journal of Archaeology:2-17. URL: https://web.stanford.edu/dept/archaeology/journal/01Baltali.pdf.

Balzer, Marjorie M. 1999. The Tenacity of Ethnicity: A Siberian Saga in Global Perspective. Princeton, NJ: Princeton University Press.

Barnum, Howard N. 1976. "The Interrelationship Among Social and Political Variables, Economic Structure, and Rural-Urban Migration." Economic Development and Cultural Change 24(4):759-764.

Barrett, Rusty. 1998. "Markedness and Styleswitching in Performances by African American Drag Queens.” In Codes and Consequences: Choosing Linguistic Varieties, edited by Carol Myers-Scotton, 139-161. New York and Oxford: Oxford University Press.

Bassin, Mark. 2016. The Gumilev Mystique: Biopolitics, Eurasianism, and the Construction of Community in Modern Russia. Ithaca, NY: Cornell University Press.

Basso, Keith. 1996. Wisdom Sits in Places: Landscape and Language Among the Western Apache. Albuquerque: University of New Mexico Press.

Bateson, Gregory. 1972. Steps to an Ecology of Mind: Collected Essays in Anthropology, Psychiatry, Evolution, and Epistemology. Chicago: University of Chicago Press.

Bauer, Henning, Kappeler, Andreas, and Roth, Brigitte, eds. 1991. Die Nationalitäten des Russischen Reiches in der Volkszählung von 1897: Quellen und Studien zur Geschichte des östlichen Europa 32, 2 vols. Stuttgart: Franz Steiner Verlag.

Bauman, Richard. 1977. Verbal Art as Performance. Long Grove, IL: Prospects Heights.

Bauman, Richard, and Sherzer, Joel. 1974. The Ethnography of Speaking. Cambridge: Cambridge University Press.

Bilaniuk, Laada. 2005. Contested Tongues: Language Politics and Cultural Correction in Ukraine. Ithaca and London: Cornell University Press.

Blom, Jan-Petter, and Gumperz, John. 1972. "Social Meaning in Linguistic Structure: Codeswitching in Norway." In Directions in Sociolinguistics, edited by John J. Gumperz and Dell Hymes, 407-434. New York: Holt, Rinehart and Winston.

Blommaert, Jan. 2004. "Writing as a Problem: African Grassroots Writing, Economies of Literacy and Globalization." Language in Society 33:643-671. doi:10.1017/ S0047404504045014. 
Blommaert, Jan. 2005a. "Bourdieu the Ethnographer: The Ethnographic Grounding of Habitus and Voice." The Translator 11(2):219-236. doi:10.1080/13556509. 2005.10799199.

Blommaert, Jan. 2005b. Discourse: A Critical Introduction. Cambridge: Cambridge University Press.

Blommaert, Jan. 2008. Grassroots Literacy: Writing, Identity and Voice in Central Africa. London and New York: Routledge.

Blommaert, Jan. 2009. "Ethnography and Democracy: Hymes's Political Theory of Language." Text and Talk 29(3):257-276. doi:10.1515/TEXT.2009.014.

Blommaert, Jan. 2010. The Sociolinguistics of Globalization. Cambridge: Cambridge University Press.

Blommaert, Jan. 2013. Ethnography, Superdiversity and Linguistic Landscapes: Chronicles of Complexity. Bristol: Multilingual Matters.

Blommaert, Jan. 2014. "Sociolinguistics." In The Routledge Handbook of English Language Studies, edited by Constant Leung and Brian V. Street, 131-144. London: Routledge.

Blommaert, Jan, and Dong, Jie. 2010. Ethnographic Fieldwork: A Beginner's Guide. Bristol and New York: Multilingual Matters.

Blommaert, Jan, and Rampton, Ben. 2011. "Language and Superdiversity." Language and Superdiversities 13(2):1-22.

Boas, Franz. 1940. Race, Language and Culture. New York: The Free Press; London: Collier-Macmillan Limited.

Boas, Franz. 1966. Introduction to Handbook of American Indian Languages. Lincoln and London: University of Nebraska Press.

Boeke, Julius H. 1953. Economics and Economic Policy of Dual Societies. New York and Haarlem: Tjeenk Willink and Zoon.

Bogdanov, G., Hämäläinen, Matti, and Mihkijev, Aleksey. 1932. Ezmäne Vepsiden azbuk i lugendknig. Leningrad: Valtion Kustannusliike kirja.

Bogdanov, Nikolay I. 1951. K istorii Vepsov (po materyalam toponimiki). Izvestiya Karelo-Finskogo filyala Akademii Nauk SSSR, pp. 23-31.

Bogdanova, Elena V., and Strogal'shchikova, Zinaida I. 2008. "Vepsy Respubliki Kareliya: Pravovoy Status." In Vepsy: na rubezhe XX-XXI vekov. Po materyalam mezhregyonal'noy nauchno-prakticheskoy konferentsii 'Vepsy—korennoy malochislennyy narod Rossiyskoy Federatsii: perspektivy sokhraneniya i razvitiya', edited by Zinaida I. Strogal'shchikova, 7-23. Petrozavodsk: KarNTs RAN.

Bourdieu, Pierre. 1992. Language and Symbolic Power. Padstow and Cornwall: Polity Press.

Breinig, Jeane. 2006. “Alaskan Haida Stories of Language Growth and Regeneration." American Indian Quarterly. Special Issue: Indigenous Languages and Indigenous Literatures 30(1/2):110-118. URL: https://muse.jhu.edu/article/194704.

Brenzinger, Matthias, ed. 1992. Language Death: Factual and Theoretical Explorations With Special Reference to East Africa. Berlin and New York: Mouton de Gruyter.

Breton, Roland. 1991. "The Handicaps of Language Planning in Africa." In Focus on Language Planning: Essays in Honor of Joshua A. Fishman. Vol. 3, edited by David F. Marshall, 153-174. Amsterdam and Philadelphia: John Benjamins Publishing Company.

Briggs, Jean L. 1971. Never in Anger: Portrait of an Eskimo Family. Cambridge, MA: Harvard University Press; London: Oxford University Press.

Brinkmann, Svend, and Kvale, Steinar. 2005. "Confronting the Ethics of Qualitative Research.” Journal of Constructivist Psychology 18(2):157-181. doi:10.1080/ 10720530590914789. 


\section{Bibliography}

Bromley, Yulian, and Shkaratan, Ovsei. 1972. "The General and the Particular in Historical, Ethnographical and Sociological Research." Current Anthropology 13(5):569-574. doi:10.1086/201290.

Bubrikh, Dmitry V. 2005. "Proiskhozhdeniye Karel'skogo Naroda: Povest' O Soyuznike i Druge Russkogo Naroda Na Severe." In Pribaltiysko-Finskoe Yazykoznaniye. Izbrannye Raboty, edited by Dmitry V. Bubrikh, 347-379. Saint Petersburg: Filologicheskii fakul'tet SPbGU.

Burawoy, Michael. 2003. "Revisits: An Outline of a Theory of Reflexive Ethnography.” American Sociological Review 68(5):645-679.

Cameron, Deborah. 2007. "Language Endangerment and Verbal Hygiene: History, Morality, and Politics." In Discourses of Endangerment: Ideology and Interest in the Defence of Language, edited by Alexandre Duchêne and Monica Heller, 268-285. London: Continuum.

Campbell, Lyle, and Muntzel, Martha C. 1989. "The Structural Consequences of Language Death." In Language Obsolescence, edited by Nancy Dorian, 181196. Cambridge: Cambridge University Press.

Canagarajah, Suresh. 2006. "Ethnographic Methods in Language Policy." In An Introduction to Language Policy: Theory and Method, edited by Thomas Ricento, 153-169. Oxford: Blackwell Publishing.

Candela, Antonia. 2005. "Local Power Construction in a School of Socially Marginalized Students." In Language, Literacy, and Power in Schooling, edited by Teresa L. McCarty, 189-209. Mahwah, NJ: Lawrence Erlbaum.

Castagno, Angelina E., and McKinley, Bryan. 2008. "Culturally Responsive Schooling for Indigenous Youth: A Review of the Literature." Review of Educational Research 78(4):941-993.

Cenoz, Jasone, and Gorter, Durk. 2006. "Linguistic Landscape and Minority Languages." The International Journal of Multilingualism 3:67-80.

Cervelli in Fuga. 2017. Accessed June 28, 2017. URL: www.cervelliinfuga.com/.

Cheshire, Jenny, Edwards, Vik, and Whittle, Pamela. 1989. "Urban British Dialect Grammar: The Question of Dialect Leveling.” English World Wide 10:185-225.

Comrie, Bernard. 1981. The Languages of the Soviet Union. New York: Cambridge University Press.

Conquest, Robert. 1986. The Harvest of Sorrow: Soviet Collectivization and the Terror-Famine. London and Melbourne: Hutchinson.

Coulmas, Florian. 2002. Writing Systems: An Introduction to Their Linguistic Analysis. Cambridge: Cambridge University Press.

Crossey, Mark. 2009. "The Role of Micropolitics in Multinational, High-Stakes Language Assessment Systems." In The Politics of Language Education: Individuals and Institutions, edited by J. Charles Alderson, 147-165. Bristol, Buffalo and Toronto: Multilingual Matters.

Cruikshank, Julie. 2005. Do Glaciers Listen? Local Knowledge, Colonial Encounters, and Social Imagination. Vancouver: University of British Columbia Press.

Crystal, David. 2000. Language Death. Cambridge and New York: Cambridge University Press.

Cummins, Jim. 1984. Bilingualism and Special Education: Issues in Assessment and Pedagogy. Avon: Multilingual Matters.

Dauenhauer, Nora M., and Dauenhauer, Richard. 1998. “Technical, Emotional, and Ideological Issues in Reversing Language Shift: Examples From Southeast Alaska." In Endangered Languages: Current Issues and Future Prospects, edited by Lenore A. Grenoble and Lindsay J. Whaley, 57-98. Cambridge: Cambridge University Press.

Davidov, Veronica. 2013. "Ecological Tourism and Minerals in Karelia: The Veps' Experience With Extraction, Commodification, and Circulation of Natural 
Resources." In The Ecotourism-Extraction Nexus: Political Economies and Rural Realities of (Un)Comfortable Bedfellows, edited by Bram Büscher and Veronica Davidov, 129-148. London: Routledge.

Debenport, Erin. 2010. “The Potential Complexity of 'Universal Ownership': Cultural Property, Textual Circulation, and Linguistic Fieldwork.” Language \& Communication 30:204-210.

The Declaration on the Rights of Indigenous Peoples. 2017. Accessed June 28, 2017. URL: www.un.org/development/desa/indigenouspeoples/declaration-on-the-rightsof-indigenous-peoples.html.

DeFigueiredo, Rui J. P., and Elkins, Zachary. 2003. "Are Patriots Bigots? An Inquiry into the Vices of In-Group Pride." American Journal of Political Science 47(1):171-188.

Dekker, Diane, and Young, Catherine. 2005. "Bridging the Gap: The Development of Appropriate Educational Strategies for Minority Language Communities in the Philippines." Current Issues in Language Planning 6(2):182-199. doi:10.1080/14664200508668280.

Deng, Zhenglai. 2009. China's Economy: Rural Reform and Agricultural Development. Singapore and Hackkensack, NJ: World Scientific.

Devitsyn, Viktor A. 1991. "Proyavleniya Finno-Ugorskaya substrata v leksike i fonetike russkikh govorov nizhegorodskoy oblast." Linguistica Uralica 27(4): 272-276.

Dialektnaya osnova vepsskoy orfografii. 2011. Accessed October 2011. URL: http:// vepsia.ru/yazik/dialekt.php.

Dixon, Robert M. W. 1997. The Rise and Fall of Languages. Cambridge: Cambridge University Press.

Documentation of Endangered Languages. 2017. Accessed June 28, 2017. URL: www.volkswagenstiftung.de/en/funding/completed-initiatives/documentation-ofendangered-languages-completed.html.

Documenting Endangered Languages. 2017. Accessed June 28, 2017. URL: www. nsf.gov/funding/pgm_summ.jsp?pims_id=12816.

Dorian, Nancy C. 1981. Language Death: The Life Cycle of a Scottish Gaelic Dialect. Philadelphia: University of Pennsylvania Press.

Dorian, Nancy C. 1994. "Purism vs. Compromise in Language Revitalization and Language Revival." Language in Society 23(4):479-494.

Dragadze, Tamara. 1978. "Anthropological Fieldwork in the USSR." Journal of Anthropological Society of Oxford 9:61-70.

Duranti, Alessandro. 1992. "Intentions, Self, and Responsibility: An Essay in Samoan Ethnopragmatics." In Responsibility and Evidence in Oral Discourse, edited by Jane H. Hill and Judith T. Irvine, 24-47. Cambridge: Cambridge University Press.

Duranti, Alessandro. 2003. "Language as Culture in US Anthropology: Three Paradigms." Current Anthropology 44(3):323-347.

Duranti, Alessandro. 2006. "Transcripts, Like Shadows on a Wall.” Mind, Culture, and Activity 13(4):301-310. doi:10.1207/s15327884mca1304_3.

Duval, Erik, Sharples, Mike, and Sutherland, Rosamund, eds. 2017. Technology Enhanced Learning: Research Themes. Cham and Switzerland: Springer.

Dyson, Anne H., and Genishi, Celia. 2005. On the Case: Approaches to Language and Literacy Research. New York: Teachers College Press.

Ebata, Fuyuki. 2010. "Sakha (Yakut)." In Grammatical Sketches From the Field, edited by Yasuhiro Yamakoshi, 179-212. Tokyo: Research Institute for Languages and Cultures of Asia and Africa (ILCAA).

Ebongue, Augustin E., and Hurst, Ellen, eds. 2017. Sociolinguistics in African Contexts: Perspectives and Challenges. Cham: Springer. 


\section{Bibliography}

Echeverria, Begona. 2003. "Schooling, Language, and Ethnic Identity in the Basque Autonomous Community.” Anthropology \& Education Quarterly 34(4):351-372.

Edwards, John R. 1979. Language and Disadvantage. London: Edward Arnold.

Edwards, John R. 1981. "The Context of Bilingual Education." Journal of Multilingual and Multicultural Development 2(1):25-44. doi:10.1080/01434632.198 1.9994036.

Effective Language Politics: The Case of Karelian. 2017. Accessed June 28, 2017. URL: www.linguapax.org/wp-content/uploads/2015/09/CMPL2002_T3_ Kryuchkova.pdf.

Eisenlohr, Patrick. 2004. "Language Revitalization and New Technologies: Cultures of Electronic Mediation and the Refiguring of Communities." Annual Review of Anthropology 33:21-45. doi:10.1146/annurev.anthro.33.070203.143900.

The Endangered Languages Project. 2017. Accessed June 28, 2017. URL: www. endangeredlanguages.com/.

England, Nora C. 2002. "Commentary: Further Rhetorical Concerns." Journal of Linguistic Anthropology 12(2):141-143. doi:10.1525/jlin.2002.12.2.141.

England, Nora C. 2003. "Mayan Language Revival and Revitalization Politics: Linguists and Linguistic Ideologies." American Anthropologist, New Series, Special Issue: Language Politics and Practices 105(4):733-743. doi:10.1525/ aa.2003.105.4.733.

England, Nora C. 2005. “Mayan Efforts Toward Language Preservation.” In Endangered Languages, edited by Lenore A. Grenoble and Lindsay J. Whaley, 99-116. Cambridge: Cambridge University Press.

Enninger, Werner, and Wandt, Karl-Heinz. 1984. "Language Ecology Revisited: From Language Ecology to Sign Ecology." In Studies in Language Ecology, edited by Werner Enninger and Lilith H. Haynes, 29-50. Weisbaden, Germany: Franz Steiner Verlag GMBH.

Errington, Joseph. 2003. "Getting Language Rights: The Rhetorics of Language Endangerment and Loss." American Anthropologist 105(4):723-732. URL: http://isites.harvard.edu/fs/docs/icb.topic269253.files/Syncretism/Errington \% 20 Article.pdf.

The Estonian Kindred People's Program Awarded the Ilmapuu Prize. 2017. Accessed June 28, 2017. URL: http://finugor.ru/en/node/17864.

Fabian, Johannes. 1979. "Rule and Process: Thoughts on Ethnography as Communication." Philosophy of the Social Sciences 9(1):1-26. doi:10.1177/ 004839317900900101.

Ferguson, Jenanne. 2013. "Khanna Bardyng? = Where Are You Going?: Rural-urban Connections and the Fluidity of Communicative Practices Among Sakha-Russian Speakers." PhD diss., University of Aberdeen.

Filipović, Jelena, Vučo, Julijana, and Djurić, Ljiljana. 2007. "Critical Review of Language Education Policies in Compulsory Primary and Secondary Education in Serbia." Current Issues in Language Planning 8(2):222-242. URL: www.tandfonline.com/doi/pdf/10.2167/cilp103.0.

Finnegan, Ruth. 2007. The Oral and Beyond: Doing Things With Words in Africa. Chicago: University of Chicago Press; Oxford: James Currey; Pietermaritzburg: University of KwaZulu-Natal Press.

Finno-Ugorskaya shkola Eliasa Lionnrota. 2017. Accessed June 28, 2017. URL: http://fusch.ru/school.

Fisher, Gene A., and Chon, Kyum K. 1989. "Durkheim and the Social Construction of Emotions." Social Psychology Quarterly. Special Issue: Sentiments, Affect and Emotion 52(1):1-9.

Fishman, Joshua A. 1991. Reversing Language Shift: Theoretical and Empirical Foundations of Assistance to Threatened Languages. Clevedon: Multilingual Matters. 
Fishman, Joshua A., ed. 2001. Can Threatened Languages Be Saved? Reversing Language Shift, Revisited: A 21st Century Perspective. Clevedon: Multilingual Matters.

Fishman, Joshua A. 2006. "What Is Reversing Language Shift (RLS) and How Can It Succeed?" In Language Loyalty, Language Planning and Language Revitalization, edited by Nancy H. Hornberger and Martin Pütz, 79-112. Clevedon, Buffalo and Toronto: Multilingual Matters Limited.

Foley, Douglas E. 2002. "Critical Ethnography: The Reflexive Turn." Qualitative Studies in Education 15(4):469-490. doi:10.1080/09518390210145534.

Fomin, Nikolay. 2004. "Vepsskoy natsional'noy volosti-10 let.” Kodima 2, 2004.

Garner, Mark. 2004. Language: An Ecological View. Oxford: Peter Lang.

Geertz, Clifford. 1973. The Interpretation of Cultures. New York: Basic Books.

Gelb, Michael. 1993. “'Karelian Fever': The Finnish Immigrant Community During Stalin's Purges.” Europe-Asia Studies 45(6):1091-1116.

Gellner, Ernest. 1983. Nations and Nationalism. Ithaca, NY: Cornell University Press.

Gilgun, Jane, Daly, Kerry, and Handel, Gerald, eds. 1992. Qualitative Methods in Family Research. California, CA: SAGE.

Gilmore, Perry, and Smith, David M. 2005. "Seizing Academic Power: Indigenous Subaltern Voices, Metaliteracy, and Counternarratives in Higher Education." In Language, Literacy, and Power in Schooling, edited by Teresa L. McCarty, 67-88. Mahwah, NJ and London: Lawrence Erlbaum Associates Publishers.

The Government of Karelia. 2017. Accessed June 28, 2017. URL: www.gov.karelia.ru.

Grandstaff, Peter J. 1980. Interregional Migration in the USSR: Economic Aspects, 1959-1970. Durham, NC: Duke University Press.

Grenoble, Lenore A. 2003. Language Policy in the Soviet Union. Dordrecht: Kluwer Academic Publishers.

Grenoble, Lenore A., and Whaley, Lindsay J., eds. 1998. Endangered Languages: Language Loss and Community Response. Cambridge: Cambridge University Press.

Grenoble, Lenore A., and Whaley, Lindsay J. 2006. Saving Languages: An Introduction to Language Revitalization. Cambridge: Cambridge University Press.

Gruffudd, Heni. 2000. "Planning for the Use of Welsh by Young People." In Language Revitalization: Policy and Planning in Wales, edited by Colin H. Williams, 173-207. Cardiff: University of Wales Press.

Grünthal, Riho. 2003. Finnic Adpositions and Cases in Change. Helsinki: Société Finno-Ougrienne.

Grünthal, Riho. 2007. "Finnic Languages and Baltic Sea Language Area." Incontri Linguistici 30:29-48. doi:10.1400/77473.

Grünthal, Riho. 2011. "Population Decline and the Erosion of the Veps Language Community." In The Ethnic and Linguistic Context of Identity: Uralica Helsingiensia 5, edited by Riho Grünthal and Magdolna Kovács, 267-293. Helsinki: Suomalais-ugrilainen seura, Tiedekirja [jakaja].

Grünthal, Riho. 2015. Vepsän kielioppi. Helsinki: Suomalais-Ugrilainen Seura.

Gruppa "Noid" edet na konkurs v Italiyu. 2017. Accessed June 28, 2017. URL: http://knk.karelia.ru/2011/10/gruppa-noid-edet.html.

Guang, Lei. 2005. “The State Connection in China's Rural-Urban Migration.” International Migration Review 39(2):354-380. doi:10.1111/j.1747-7379.2005. tb00270.x.

Haavio, Martti. 1964. "The Oldest Source of Finnish Mythology. Birchbark Letter no. 292." Journal of the Folklore Institute 1(1/2):45-66.

Hale, Ken. 1998. "On Endangered Languages and the Importance of Linguistic Diversity." In Endangered Languages, edited by Lenore A. Grenoble and Lindsay J. Whaley, 192-216. Cambridge: Cambridge University Press. 


\section{Bibliography}

Hallett, Darcy, Chandler, Michael J., and Lalonde, Christopher E. 2007. “Aboriginal Language Knowledge and Youth Suicide.” Cognitive Development 22(3):392399. URL: http://web.uvic.ca/ lalonde/manuscripts/2007CogDevt.pdf.

Handler, Richard. 1988. Nationalism and the Politics of Culture in Quebec. Madison and London: The University of Wisconsin Press.

Hanks, William F. 1996. Language and Communicative Practices. Boulder and Oxford: Westview Press.

Hannerz, Ulf. 2004. Foreign News: Exploring the World of Foreign Correspondents. Chicago and London: University of Chicago Press.

The Hans Rausing Endangered Languages Project. 2017. Accessed June 28, 2017. URL: www.hrelp.org/.

Harmon, David. 1996. "Losing Species, Losing Languages, Connections Between Biological and Linguistic." Southwest Journal of Linguistics 15:89-108.

Harris, Roy. 1986. The Origin of Writing. LaSalle, IL: Open Court.

Harvilahti, Lauri. 2012. "Finland." In A Companion to Folklore, edited by Regina F. Bendix and Galit Hasan-Rokem, 391-408. Malden: Wiley-Blackwell.

Haugen, Einar. 1972. “The Ecology of Language." In The Ecology of Language: Essays by Einar Haugen, edited by Anwar S. Dil, 57-66. Stanford: Stanford University Press.

Heath, Shirley B. 1983. Ways With Words: Language, Life, and Work in Communities and Classrooms. Cambridge: Cambridge University Press.

Heath, Shirley B., and Street, Brian. 2008. On Ethnography: Approaches to Language and Literacy Research. New York, NY: Teachers College Press and National Conference on Research in Language and Literacy (NCRLL).

Heathershaw, John. 2010. "Central Asian Statehood in Post-Colonial Perspective." In Stable Outside, Fragile Inside? Post-Soviet Statehood in Central Asia, edited by Emilian Kavalski, 87-107. Farnham: Ashgate.

Heller, Monica. 2003. "Globalization, the New Economy and the Commodification of Language and Identity." Journal of Sociolinguistics 7(4):473-492. doi:10.1111/j.1467-9841.2003.00238.x.

Heller, Monica, ed. 2007. Bilingualism: A Social Approach. Basingstoke: Palgrave Macmillan.

Henne-Ochoa, Richard, and Bauman, Richard. 2015. "Who Is Responsible for Saving the Language? Performing Generation in the Face of Language Shift." Journal of Linguistic Anthropology 25(2):128-150. doi:10.1111/jola.12083/ pdf.

Henze, Rosemary, and Davis, Kathryn A. 1999. "Authenticity and Identity: Lessons From Indigenous Language and Education." Anthropology \& Education Quarterly 30:3-21. doi:10.1525/aeq.1999.30.1.3.

Hill, Jane J. 2002. "'Expert Rethorics' in Advocacy for Endangered Languages: Who is Listening and What do They Hear?" Journal of Linguistic Anthropology 12(2):119-133.

Hinton, Leanne. 2001. "Language Revitalization: An Overview." In The Green Book of Language Revitalization in Practice, edited by Leanne Hinton and Ken Hale, 3-18. New York: Academic Press.

Hinton, Leanne. 2003. "Language Revitalization." Annual Review of Applied Linguistics 23:44-57.

Hinton, Leanne, and Ahlers, Jocelyn. 1999. "The Issue of 'Authenticity' in California Language Restoration." Anthropology \& Education Quarterly, Authenticity and Identity: Lessons From Indigenous Language Education 30(1):56-67. doi:10.1525/aeq.1999.30.1.56.

Hinton, Leanne, and Hale, Ken, eds. 2001. The Green Book of Language Revitalization in Practice. New York: Academic Press. 
Hirsch, Francine. 1997. "The Soviet Union as a Work-in-Progress: Ethnographers and the Category Nationality in the 1926, 1937, and 1939 Censuses." Slavic Review 56(2):251-278.

Hirsch, Francine. 2000. "Toward an Empire of Nations: Border-Making and the Formation of Soviet National Identities." Russian Review 59(2):201-222.

Hirsch, Francine. 2005. Empire of Nations: Ethnographic Knowledge and the Making of the Soviet Union. Ithaca, NY: Cornell University Press.

Hornberger, Nancy H., ed. 1997. Indigenous Literacies in the Americas: Language Planning From the Bottom Up. Berlin: Mouton de Gruyter.

Hornberger, Nancy H. 1998. "Language Policy, Language Education, Language Rights: Indigenous, Immigrant, and International Perspectives." Language in Society 27(4):439-458.

Hornberger, Nancy H. 2000. "Bilingual Education Policy and Practice in the Andes: Ideological Paradox and Intercultural Possibility." Anthropology and Education Quarterly 31(2):173-201.

Hornberger, Nancy H. 2005. "Opening and Filling Up Implementational and Ideological Spaces in Heritage Language Education." Modern Language Journal 89:605-612.

Hornberger, Nancy H. 2006. "Negotiating Methodological Rich Points in Applied Linguistics Research: An Ethnographer's View." In Inference and Generalizability in Applied Linguistics, edited by Micheline Chalhoub-Deville, Carol Chapelle, and Patricia Duff, 221-240. Philadelphia, PA: John Benjamins.

Hornberger, Nancy H., ed. 2008. Can School Save Indigenous Languages? Policy Practice on Four Continents. New York: Palgrave Macmillan.

Hornberger, Nancy H., and Johnson, David C. 2007. "Slicing the Onion Ethnographically: Layers and Spaces in Multilingual Language Education Policy and Practice." TESOL Quarterly. Special Issue on Language Policy 41(3):509-532.

Hornberger, Nancy H., and Johnson, David C. 2011. "The Ethnography of Language Policy." In Ethnography and Language Policy, edited by Teresa L. McCarty, 273-289. New York and London: Routledge.

Hornberger, Nancy H., and Swinehart, Karl F. 2012. "Not Just Situaciones de la Vida: Professionalization and Indigenous Language Revitalization in the Andes." International Multilingual Research Journal 6(1):35-49. doi:10.1080/19313152 .2012.639281.

Horton, John, and Kraftl, Peter. 2006. "Not Just Growing up, But Going on: Materials, Spacings, Bodies, Situations." Children's Geographies 4(3):259-276. doi:10.1080/14733280601005518.

Humphrey, Caroline. 2007. "Alternative Freedoms." Proceedings of the American Philosophical Society 151(1):1-10. URL: www.innerasiaresearch.org/CHsite/ pdfs/CH2007\%20Alternative\%20Freedoms.pdf.

Hunter, Ernest, and Harvey, Desley. 2002. "Indigenous Suicide in Australia, New Zealand, Canada and the United States." Emergency Medicine 14(1):14-23. doi:10.1046/j.1442-2026.2002.00281.x.

Hymes, Dell. 1962. "The Ethnography of Speaking." In Anthropology and Human Behavior, edited by Thomas Gladwin and William Sturtevant, 13-53. Washington, DC: Anthropological Society of Washington.

Hymes, Dell. 1972. "Models of the Interaction of Language and Social Life." In Directions in Sociolinguistics: The Ethnography of Communication, edited by John Gumperz and Dell Hymes, 35-71. London: Basil Blackwell.

Hymes, Dell. 1974. "Ways of Speaking." In Folklore: Performance and Communication, edited by Dan Ben-Amos and Kenneth Goldstein, 433-451. The Hague: Mouton. 


\section{Bibliography}

Hymes, Dell. 1996. Ethnography, Linguistics, Narrative Inequality: Toward an Understanding of Voice. London: Taylor and Francis.

Inghilleri, Moira. 2003. "Habitus, Field and Discourse: Interpreting as a Socially Situated Activity." Target 15(2):243-268. doi:10.1075/target.15.2.03ing.

Ingold, Tim. 2000. The Perception of the Environment: Essays in Livelihood, Dwelling, and Skill. London and New York: Routledge.

Ingold, Tim. 2004. "Culture on the Ground: The World Perceived Through the Feet." Journal of Material Culture 9(3):315-340. URL: http://employees.oneonta.edu/ walkerr/Issues/Ingold\%202004.pdf.

Ingold, Tim. 2008. "Anthropology Is Not Ethnography." Proceedings of the British Academy 154:69-92. URL: http://core.roehampton.ac.uk/repository2/content2/ subs/d.steedman/d.steedman1684/Ingold \%20(2008)\%20Anthropology\%20 is $\% 20$ not $\% 20$ ethnography.pdf.

The International Bill of Human Rights. 2017. Accessed June 28, 2017. URL: www. ohchr.org/Documents/Publications/FactSheet2Rev.1en.pdf.

Jääts, Indrek. 2017. "Illegally Denied: Manipulations Related to the Registration of the Veps Identity in the Late Soviet Union." Nationality Papers: The Journal of Nationalism and Ethnicity 45(5):1-17. doi:10.1080/00905992.2017. 1315393.

Jaffe, Alexandra. 1999. "Locating Power: Corsican Translator and Their Critics." In Language Ideological Debates, edited by Jan Blommaert, 39-66. Berlin and New York: Mouton de Gruyter.

Johnson, David C. 2009. "Ethnography of Language Policy." Language Policy 8(2):139-159. doi:10.1007/s10993-009-9136-9.

Johnson, David C., and Freeman, Rebecca. 2009. “Appropriating Language Policy on the Local Level: Working the Spaces for Multilingual Education." In Negotiating Language Policies in Classrooms: Teachers as Change Agents, edited by Ofelia Garcia and Kate Menken, 13-31. New York: Routledge.

Kaiser, Robert J. 1994. The Geography of Nationalism in Russia and the USSR. Princeton, NJ: Princeton University Press.

Kaplan, Robert B., and Baldauf, Richard B. 1997. Language Planning From Practice to Theory. Clevedon: Multilingual Matters.

Kaplan, Robert B., Baldauf, Richard B., and Kamwangamalu, Nkonko. 2011. "Why Educational Language Plans Sometimes Fail." Current Issues in Language Planning 12(2):105-112. doi:10.1080/14664208.2011.591716.

Kerswill, Paul. 2001. "Mobility, Meritocracy and Dialect Levelling: The Fading (and Phasing) Out of Received Pronunciation." In British Studies in the New Millennium: Challenge of the Grassroots, edited by Pilvi Rajamäe, 45-58. Tartu: University of Tartu.

Kettunen, Lauri, and Siro, Paavo. 1935. Näytteitä Vepsän Murteista. Helsinki: Suomalais-Ugrilainen Seura.

Kibrick, Aleksander E. 1991. "The Problems of Endangered Languages in USSR." In Endangered Languages, edited by Robert H. Robins and Eugenius M. Uhlenbeck, 257-270. Oxford and New York: Berg.

King, Alex D. 2011. Living With Koryak Traditions: Playing With Culture in Siberia. Lincoln and London: University of Nebraska Press.

Kirby, David G. 1979. Finland in the Twentieth Century. London: Hurst.

Kirshenblatt-Gimblett, Barbara. 1998. Destination Culture: Tourism, Museums, and Heritage. Berkeley, Los Angeles and London: University of California Press.

Klement'yev, Evgeniy I. 1988. "Osnovnye tendendtsii razvitiya inzhenernotekhnicheskikh kadrov lesnoy promyshlennosti Karelii (1945 g.- konets 50-kh godov)." In Voprosy istorii Evropeyskogo Severa, edited by Lev V. Suni, 13-20. Petrozavodsk: Petrozavodsk Gosudarstvennogo universiteta. 
Klement'yev, Evgeniy I., Kozhanov, Aleksandr A., and Strogal'shchikova, Zinaida I., eds. 2007. Vepsy: modeli etnicheskoy mobilizatsii. Sbornik materyalov i dokumentov. Petrozavodsk: izdaniye osushchestvleno pri finansovoy podderzhke sekretaryata Barentseva.

Kochkurkina, Svetlana I. 1989. Drevniye Vepsy po arkheologicheskimi materiyalam. Problemy istorii i kul'tury vepsskoy narodnosti. Petrozavodsk: KarNTs RAN.

Kolesov, Aleksandr S., Kotkin, Evgeniy E., Goldenberg, Mikhail L., Gromov, Vladimir V., Gromtsev, Andrei N., Landgraf, Vladimir Yu., Skripkin, Mikhail S., and Chekhonin, Vladimir B., eds. 2007. Karelia: Guidebook. Petrozavodsk: Scandinavia.

Korol'kova, Lyudmila. 2007. “Sotsyal'no-ekonomicheskiye aspekty zhizni vepsskoy derevni 1920-1930 godov (po materyalam mestnykh gazet)." In Vepsy $i$ etnokul'turnyye peremeny XX veka, edited by Seppo Lallukka, 57-75. Helsinki: Studia Slavica Finlandensia.

Korol'kova, Lyudmila. 2015. Vepsy: fotografii i rukopisi iz sobraniya Rossiyskogo etnograficheskogo muzeya. Saint-Petersburg: Inkeri.

Korpus vepsskogo yazyka. 2017. Accessed June 28, 2017. URL: http://vepsian.ru/ about/.

Kostiainen, Auvo. 1996. "Genocide in Soviet Karelia: Stalin's Terror and the Finns of Soviet Karelia." Scandinavian Journal of History 21(4):332-341. URL: www. genealogia.fi/emi/art/article255e.htm.

Kovalev, Erik A. 2006. "Koroli podplava v more chervonnykh valetov. Moscow: ZAO Tsentrpoligraf." In Zimnyaya voyna baltiyskikh podvodnykh lodok (1939-1940 22.). Voennaya Literatura. URL: http://militera.lib.ru/h/kovalev_ea2/07.html.

Krauss, Michael. 1992. “The World's Languages in Crisis.” Language 68:4-10. URL: https://sustainableunh.unh.edu/sites/sustainableunh.unh.edu/files/images/ Krauss(1992).pdf.

Krupnik, Igor. 2005. “'When Our Words Are Put to Paper.' Heritage Documentation and Reversing Knowledge Shift in the Bering Strait Region." Études/Inuit/Studies 29(1-2):67-90. URL: https://core.ac.uk/download/pdf/59257131.pdf.

Kubicek, Paul. 2010. "Applying the Democratization Literature to Post-Soviet Central Asian Statehood.” In Stable Outside, Fragile Inside? Post-Soviet Statehood in Central Asia, edited by Emilian Kavalski, 37-52. Farnham: Ashgate.

Kukkoeva, Nadezhda A. 2008. "O prepodavanii Vepsskogo yazyka v MOU 'Srednyaya obshcheobrazovatel'naya finno-ugorskaya shkola im. Eliasa Lennrota' g. Petrozavodska." In Vepsy: na rubezhe XX-XXI vekov. Po materyalam mezhregional'noy nauchno-prakticheskoy konferentsii 'Vepsy-korennoy malochislennyy narod Rossiiskoy Federatsii: perspektivy sokbraneniya i razvitiya', edited by Zinaida I. Strogal'shchikova, 174-177. Petrozavodsk: KarNTs RAN.

Kurets, T. C. 2000. Russkiye zagovory Karelii. Petrozavodsk: PetrGU.

Kurs, Ott. 2001. “The Vepsians: An Administratively Divided Nationality.” Nationalities Papers 29(1):69-83. doi:10.1080/00905990120036385.

Kurtz, Matthew. 2006. "Ruptures and Recuperations of a Language of Racism in Alaska's Rural/Urban Divide." Annals of the Association of American Geographers 96(3):601-621. doi:10.1111/j.1467-8306.2006.00708.x.

Laakso, Johanna. 2001. “The Finnic Languages.” In Circum-Baltic Languages, edited by Östen Dahl and Maria Koptjevskaja-Tamm, 179-212. Volume 1: Past and Present. Philadelphia: Johns Benjamins.

Laakso, Johanna. 2011. "Contribution of the Small Finnic Languages to Research on Areal and General Linguistics.” URL: http://homepage.univie.ac.at/Johanna. Laakso/paris.html.

Ladson-Billings, Gloria. 2005. "Reading, Writing, and Race: Literacy Practices of Teachers in Diverse Classrooms." In Language, Literacy, and Power in Schooling, edited by Teresa L. McCarty, 133-150. Mahwah, NJ: Lawrence Erlbaum. 


\section{Bibliography}

Laine, Antti. 2001. "Where East Meets West: The Last Stand of Finns and Karelians in Contemporary Karelia?” Nationalities Papers 29(1):53-67. doi:10.1080/00905990120036420.

Lakoff, George, and Johnson, Mark. 1980. Metaphors We Live By. Chicago: The University of Chicago Press.

Landry, Rodrigue, and Bourhis, Richard Y. 1997. Malta: A Linguistic Landscape. Malta: University of Malta.

Lassiter, Luke E. 2005. "Collaborative Ethnography and Public Anthropology." Current Anthropology 46(1):83-106. URL: www.journals.uchicago.edu/doi/ pdfplus/10.1086/425658.

Law no. 63221-3. 2017. Accessed June 28, 2017. URL: www.antropotok.archipelag.ru/text/a082.htm.

Leasure, J. William, and Lewis, Robert A. 1967. "Internal Migration in the USSR: 1897-1926." Demography 4(2):479-496.

Lehtinen, Tapani. 1985. "Venäjän verbisemantiikkaa itämerensuomessa: karjalan ja vepsän inkoatiiviverbit." Sananjalka 27:63-84.

Lehtinen, Tapani. 1990. "Venäjän aspektien heijastumia vepsän verbijärjestelmässä." In Itämeren suomalaiset kielikontaktit. Läänemeresoome keelekontaktid, edited by Sari Vaula, 59-68. Helsinki: KKTKJ.

Léonard, Jean L. 2017. "Écologie (socio)linguistique: evolution, élaboration et variation.” Langage \& Société 160-161:267-282.

Levinson, Bradley A. U., Cade, Sandra L., Padawer, Ana, and Elvir, Ana P., eds. 2002. Ethnography and Education Policy Across the Americas. Westport, CT: Praeger.

Liddicoat, Anthony J. 2004. "Language Planning for Literacy: Issues and Implications." Current Issues in Language Planning 5(1):1-17. doi:10.1080/14664200 408669076.

Lincoln, Felicia. 2003. "Language Education Planning and Policy in Middle America: Students' Voices." In Continua of Biliteracy: An Ecological Framework for Educational Policy, Research, and Practice in Multilingual Settings, edited by Nancy H. Hornberger, 147-165. Clevedon, Buffalo, Toronto and Sydney: Multilingual Matters Limited.

Lindholm-Leary, Kathryn J. 2001. Dual Language Education. Bristol: Multilingual Matters Limited.

Lipka, Jerry, and McCarty, Teresa L. 1994. "Changing the Culture of Schooling: Navajo and Yup'ik Cases." Anthropology \& Education Quarterly. Alternative Visions of Schooling: Success Stories in Minority Settings 25(3):266-284. doi:10.1525/aeq.1994.25.3.04x0144n.

Loginov, Konstantin K. 1993. Materyal'naya kul'tura i proizvodstvenno-bytavaya magiya russkikh zaonezhiya (konets XIX-nakhalo XX v.). Saint-Petersburg: Nauka.

Long, Joseph J. 2010. "Negotiating Belonging: Ritual, Performance and Buriat National Culture in Pribaikal'e, Southern Siberia.” PhD diss., University of Aberdeen.

Lucas, Robert E. B. 2007. "Migration and Rural Development." Agricultural Development Economics Division (ESA) FAO 4(1):99-122. URL: www.fao.org/3/a-ai193e.pdf.

Lutz, Catherine, and White, Geoffrey M. 1986. "The Anthropology of Emotions." Annual Review of Anthropology 15:405-436. doi:10.1146/annurev. an.15.100186.002201.

Mackey, Weinreich. F. 1980. “The Ecology of Language Shift.” In The Ecolinguistic Reader, edited by Alwin Fill and Peter Mühlhäusler, 67-74. London: Continuum.

Maffi, Luisa. 2000. "Language Preservation vs. Language Maintenance and Revitalization: Assessing Concepts, Approaches, and Implications for the Language Sciences.” International Journal of the Sociology of Language 142:175-190. 
Makar'yev, Stepan. 1931. Po Sovetskoy Karelii: kratkiy spravochnik dlya ekskursanta i turista po Karelii. Leningrad and Petrozavodsk: Kir'ya.

Makar'yev, Stepan. 1932. Vepsy. Etnograficheskii ocherk. Leningrad: Gosudarstvennoe Izdatel'stvo.

Makoni, Sinfree, and Pennycook, Alastair, eds. 2007. Disinventing and Reconstructing Languages. Clevedon: Multilingual Matters.

Malinowski, Bronisław. 1922. Argonauts of the Western Pacific. London and Henley: Routledge and Kegan Paul.

Mallory, James P., and Adams, Douglas Q. 2006. The Oxford Introduction to ProtoIndo-European and the Proto-Indo-European World. Oxford: Oxford University Press.

Mandelbaum, David G., ed. 1985. Selected Writings of Edward Sapir in Language, Culture and Personality. Berkeley: University of California Press.

Marten, Heiko F. 2010. "Linguistic Landscape Under Strict Language State Policy: Reversing the Soviet Legacy in a Regional Centre in Latvia." In Linguistic Landscape in the City, edited by Elana Shohamy, Eliezer Ben-Rafael, and Monica Barni, 115-132. Bristol, Buffalo and Toronto: Multilingual Matters.

McCarty, Teresa L., ed. 2005. Language, Literacy, and Power in Schooling. Mahwah, NJ: Lawrence Erlbaum Associates.

McIntosh, Janet. 2010. "Mobile Phones and Mipoho's Prophecy: The Powers and Dangers of Flying Language." American Ethnologist 37(2):337-353. doi:10. 1111/j.1548-1425.2010.01259.x.

McKay, Sandra L. 1996. "Literacy and Literacies." In Sociolinguistics and Language Teaching, edited by Sandra L. McKay and Nancy H. Hornberger, 421-445. Cambridge: Cambridge University Press.

McNeill, Patrick, and Chapman, Steve. 2005. Research Methods. Third edition. London and New York: Routledge.

Mead, William R. 1952. "Finnish Karelia: An International Borderland." The Geographical Journal 118(1):40-54.

Meewis, Michael, and Blommaert, Jan. 1998. "A Monolectal View of Codeswitching: Layered Code-switching Among Zairians in Belgium." In Codeswitching in Conversation: Language, Interaction, and Identity, edited by Peter Auer, 76-98. London and New York: Routledge.

Milroy, Lesley, and Milroy, James. 1992. "Social Network and Social Class: Toward an Integrated Sociolinguistic Model.” Language in Society 21(1):1-26. doi:10.1017/S0047404500015013.

Milroy, Lesley, and Muysken, Pieter. 1995. One Speaker, Two Languages: CrossDisciplinary Perspectives on Code-Switching. Cambridge: Cambridge University Press.

Misharina, Galina. 2012. "Funeral and Magical Rituals Among the Komi." Folklore:155-172. URL: www.folklore.ee/folklore/vol47/misharina.pdf.

Mishoe, Margaret. 1998. "Style-switching in Southern English." In Codes and Consequences: Choosing Linguistic Varieties, edited by Carol Myers-Scotton, 162177. New York and Oxford: Oxford University Press.

Mithun, Marianne. 1998. "The Significance of Diversity in Language Endangerment and Preservation." In Endangered Languages: Current Issues and Future Prospects, edited by Lenore A. Grenoble and Lindsay J. Whaley, 163-191. Cambridge: Cambridge University Press.

Moriarty, Mairead, and Pietikäinen, Sari. 2011. “Micro-Level Language-Planning and Grass-Root Initiatives: A Case Study of Irish Language Comedy and Inari Sámi Rap." Current Issues in Language Planning 12(3): 363-379.

Muehlmann, Shaylih. 2007. "Defending Diversity: Staking Out a Common Global Interest." In Discourses of Endangerment: Ideology and Interest in the Defence of Language, edited by Alexandre Duchêne and Monica Heller, 14-34. London: Continuum. 


\section{Bibliography}

Mufwene, Salikoko S. 2004. "Language Birth and Death." Annual Review of Anthropology 33:201-222. doi:10.1146/annurev.anthro.33.070203.143852.

Mühlhäusler, Peter. 1992. "Preserving Languages or Language Ecologies? A Topdown Approach to Language Survival.” Oceanic Linguistics 31(2):163-180.

Mühlhäusler, Peter. 1996. Linguistic Ecology: Language Change and Linguistic Imperialism in the Pacific Region. London and New York: Routledge.

Mühlhäusler, Peter. 2000. "Language Planning and Language Ecology." Current Issues in Language Planning 1(3):306-367. doi:10.1080/14664200008668011.

Mullonen, Irma I. 1999. "Suffiksal'nyye modeli v toponimii Prisvir'ya." In Severnorusskiye govory. Vypusk 7, 72-89. Saint-Petersburg: Saint-Petersburg University Press.

Mullonen, Irma I. 2005. "Vepsian Oikonymy." Onomastica Uralica 3. Settlement Names in the Uralian Languages:51-64.

Mullonen, Irma I. 2006. "Foneticheskaya integratsiya pribaltiysko-finskoy toponimii v russkuyu toposistemu Zaonezh'ya.” Slavica Helsingiensia 27:282-292.

Mullonen, Irma I. 2012. "Prirodnye i kul'turnye faktory formirovaniya vepsskoy etnicheskoy territorii." Trudy Karel'skogo nauchnogo tsentra RAN 4:13-24.

Mullonen, Irma, and Zaiceva, Nina. 2017. “Areal Distribution of Veps Topographical Vocabulary." Linguistica Uralica LIII 2:106-123.

Mullonen, Mariya I. 2007. "Vepsskiye yazykovye materialy v archive Karyel'skogo nauchnogo tsentra." In Vepsy $i$ etnokul'turnyye peremeny XX veka, edited by Seppo Lallukka, 31-39. Helsinki: Studia Slavica Finlandensia.

Muysken, Pieter. 2000. Bilingual Speech: A Typology of Code-Mixing. Cambridge: Cambridge University Press.

Myers-Scotton, Carol. 1993. Duelling Languages: Grammatical Structure in Codeswitching. Oxford: Clarendon.

Myers-Scotton, Carol. 2002. Contact Linguistics: Bilingual Encounters and Grammatical Outcomes. Oxford: Oxford University Press.

Myers-Scotton, Carol. 2006. Multiple Voices: An Introduction to Bilingualism. Oxford: Blackwell Publishing.

Myznikov, Sergey A. 2004. Leksika finno-ugorskogo proiskhozhdeniya v russkikh govorakh severo-zapada: etimologicheskiy i lingvogeograficheskiy analiz. SaintPetersburg: Nauka.

Natsis, James J. 1999. "Legislation and Language: The Politics of Speaking French in Louisiana." The French Review 73(2):325-331.

Navqi, Rahat, and Coburn, Helen. 2008. "Assessment Policy in Teacher Education: Responding to the Personnel Implications of Language Policy Changes." Current Issues in Language Planning 9(3):235-248. doi:10.1080/1466420080 2139521.

Nettle, Daniel, and Romaine, Suzanne. 2000. Vanishing Voices: The Extinction of the World's Languages. Oxford and New York: Oxford University Press.

Nevins, Eleanor M. 2013. Lessons From Fort Apache: Beyond Language Endangerment and Maintenance. Chichester: Wiley-Blackwell.

Novozhilova, E. 2006. "Pereklyucheniye kodov v rechi sovremennykh nositeley vepsskogo yazyka." In Sovremennaya nauka o vepsakh: dostizheniya i perspektivy, edited by Irina Yu. Vinokurova, I. E. Grishina, Nina G. Zaitseva, Irma I. Mullonen, and Vyacheslav P. Orfinskiy, 135-163. Petrozavodsk: KarNTs RAN.

Ochs, Elinor. 2012. "Experiencing Language." Anthropological Theory 12(2):142160. doi:10.1177/1463499612454088.

Olson, David. 1994. The World on Paper: The Conception and Cognitive Implications of Writing and Reading. Cambridge: Cambridge University Press.

Ong, Walter J. 1982. Orality and Literacy: The Technologizing of the Word. London and New York: Methuen. 
Palacios Martínez, Ignacio M. 2011. “The Language of British Teenagers: A Preliminary Study of Its Main Grammatical Features." Journal of the Spanish Association of Anglo-American Studies 33(1):105-126. URL: www.spertus.es/ publications/ignacio/2011 palaciosmartinezatlantis.pdf.

Patton, Michael. 2003. Qualitative Evaluation and Research Methods. Newbury Park: SAGE.

Paxson, Margaret. 2005. Solovyovo: The Story of Memory in a Russian Village. Washington, DC: Woodrow Wilson Center Press; Bloomington and Indianapolis: Indiana University Press.

Payne, Mark. 2006. "Foreign Language Planning in England: The Pupil Perspective." Current Issues in Language Planning 7(2-3):189-213. doi:10.2167/clip094.0.

Perepis. 2010. Accessed June 28, 2017. URL: www.gks.ru/free_doc/new_site/ perepis2010/croc/perepis_itogi1612.htm.

Petukhov, Anatoliy. 1992. "Trudnaya sud'ba potomkov Vesi.” Publitsistika, 1992.

Petukhov, Anatoliy. 2005. "Vepsy: vchera, segodnya . . . a zavtra?" Vologodskaya Oblast, 2005.

Philips, Susan U. 1972. "Participant Structures and Communicative Competence: Warm Springs Children in Community and Classroom." In Functions of Language in the Classroom, edited by Courtney Cazden, Vera John, and Dell Hymes, 370-394. New York: Teachers College Press.

Philips, Susan U. 2000. "Power.” Journal of Linguistic Anthropology 9(1-2):194-196.

Phillipson, Robert. 2003. English-Only Europe? Challenging Language Policy. London and New York: Routledge.

Pimenov, Vladimir V. 1964. "Vepsy." In Narody Evropeiskoi Chasti SSSR, edited by Sergei P. Tolstov, 364-376. Narody Mira: Etnograficheskie Ocherki. Moscow: Nauka.

Pimenov, Vladimir V. 1965. Vepsy. Ocherk etnicheskoy istorii i genezisa kul'tury. Moskva and Leningrad: Izdatel'stvo Nauka.

Pivoev, Vasiliy M. 2003. Kul'tura Karelii: podrobnoe uchebnoe posobe dlya obshcheobrazovatel'nykh uchrezhdenii Respubliki Karelii. Petrozavodsk: Verso.

Poplack, Shana. 2004. "Code-switching." In Soziolinguistik: An International Handbook of the Science of Language and Society, edited by Ulrich Ammon, Norbert Dittmar, Klaus J. Mattheier, and Peter Trudgill, 589-596. Berlin: Walter de Gruyter.

Pugh, Stefan. 1990. "A Baltic-Finnic Semantic Field in Motion." Sonderdruck aus den Finnisch-ugrischen Forgschunge L:1:1-19.

Pugh, Stefan. 1991. "The End of 'Beginning' in Karelo-Veps?” Ural-Altaische Jahrbücher 10:8-15.

Pugh, Stefan. 1994. "The Fennicization of Russian Verbs in Karelian and Veps: A Question of Degree.” Ural-Altaische Jahrbücher 13:45-55.

Pugh, Stefan. 1999. Systems in Contact, Systems in Motion: The Assimilation of Russian Verbs in the Baltic Finnic Languages of Russia. Uppsala: Studia Uralica Upsaliensia.

Puura, Ulriikka. 2007. "Vepsän kielen momentaaniset ja frekventatiiviset verbijohdokset. Johdosten rakenteen, merkityksen ja käytön tarkastelu." Master's thesis, University of Helsinki.

Puura, Ulriikka, Karjalainen, Heini, Zaitseva, Nina, and Grünthal, Riho. 2013. The Veps Language in Russia: ELDIA Case-specific Report. Mainz, Wien, Helsinki, Tartu, Mariehamn, Oulu and Maribor: Studies in European Language Diversity 25.2 .

Puura, Ulriikka, and Tánczos, Outi. 2016. "Division of Responsibility in Karelian and Veps Language Revitalization Discourse." In Linguistic Genocide or 


\section{Bibliography}

Superdiversity? New and Old Language Diversities, edited by Reetta Toivanen and Janne Saarikivi, 299-325. Bristol and Buffalo: Multilingual Matters.

Pyyry, Noora. 2013. “'Sensing With' Photography and 'Thinking With' Photographs in Research Into Teenage Girls' Hanging Out.” Children's Geographies 13(2):115. doi:10.1080/14733285.2013.828453.

Ramanathan, Vaidehi. 2005. "Rethinking Language Planning and Policy From the Ground Up: Refashioning Institutional Realities and Human Lives." Current Issues in Language Planning 6(2):89-101. doi:10.1080/14664200508668275.

Recendiz, Nicanor R. 2008. "Learning With Differences: Strengthening Hňähňö and Bilingual Teaching in an Elementary School in Mexico City." In Can School Save Indigenous Languages? Policy Practice on Four Continents, edited by Nancy H. Hornberger, 99-124. New York: Palgrave Macmillan.

Redwing Saunders, Sabrina E., and Hill, Susan M. 2007. "Native Education and In-Classroom Coalition-Building: Factors and Models in Delivering an Equitous Authentic Education." Canadian Journal of Education / Revue canadienne de l'éducation. Coalition Work in Indigenous Educational Contexts / Le travail de coalition et l'éducation des autochtones 30(4):1015-1045. doi:10.2307/20466677.

Reeves, Madeleine. 2007. "Travels in the Margins of the State: Everyday Geography in the Ferghana Valley Borderlands." In Everyday Life in Central Asia: Past and Present, edited by Jeff Sahadeo and Russell Zanca, 281-300. Bloomington, IN: Indiana University Press.

Ricento, Thomas. 2000. "Historical and Theoretical Perspectives in Language Policy and Planning." Journal of Sociolinguistics 4(2):196-213. doi:10.1111/ 1467-9481.00111.

Ricento, Thomas, ed. 2005. An Introduction to Language Policy: Theory and Method. Malden, MA: Blackwell Publishing.

Ricento, Thomas. 2017. "Conceptualizing Language: Linguistic Theory and Language Policy." In Dynamics of Linguistic Diversity, edited by Hagen Peukert and Ingrid Gogolin, 13-30. Hamburg: John Benjamins Publishing Company.

Ricento, Thomas, and Hornberger, Nancy H. 1996. "Unpeeling the Onion: Language Planning and Policy and the ELT Professional." TESOL Quarterly 30(3):401-427. doi:10.2307/3587691.

Rießler, Michael. 2013. “Towards a Digital Infrastructure for Kildin Saami.” In Sustaining Indigenous Knowledge: Learning Tools and Community Initieatives on Preserving Endangered Languages and Local Cultural Heritage, edited by Erich Kasten and Tjeerd de Graaf, 195-218. Fürstenberg: SEC Publications, Varlag der Kulturstiftung Sibirien.

Robins, Robert H., and Uhlenbeck Eugenius M., eds. 1991. Endangered Languages. Oxford: Berg.

Rodionova, Aleksandra. 2017. "Morfologicheskiye marker dialektnoy rechi govorov yuzhnoy Karelii.” URL: http://resources.krc.karelia.ru/illh/doc/knigi_stati/ rodionova.pdf.

Rogers, Douglas. 2009. The Old Faith and the Russian land: A Historical Ethnography of Ethics in the Urals. Ithaca: Cornell University Press.

Romaine, Suzanne. 1995. Bilingualism. Second edition. Oxford: Blackwell.

Romaine, Suzanne. 2015. "The Global Extinction of Languages and Its Consequences for Cultural Diversity." In Cultural and Linguistic Minorities in the Russian Federation and the European Union: Comparative Studies on Equality and Diversity, edited by Heiko F. Marten, Michael Rießler, Janne Saarikivi, and Reetta Toivanen, 31-46. New York: Springer.

Romero-Little, Mary E., McCarty, Teresa L., Warhol, Larisa, and Zepeda, Ofelia. 2007. "Language Policies in Practice: Preliminary Findings From a Large-Scale 
National Study of Native American Language Shift.” TESOL Quarterly 41(3):607618. doi:10.1002/j.1545-7249.2007.tb00093.x.

Rosaldo, Michelle Z. 1980. Knowledge and Passion: Ilongot Notions of Self and Social Life. Cambridge: Cambridge University Press.

The Russian Constitution. 2017. Accessed June 28, 2017. URL: www.constitution. $\mathrm{ru} /$.

Saarikivi, Janne. 2006. "Substrata Uralica: Studies on Finno-Ugrian Substrate in Northern Russian Dialects." PhD diss., University of Helsinki.

Saarikivi, Janne, and Toivanen, Reetta. 2015. "Change and Maintenance of Plurilinsgualism of the Russian Federation and the European Union." In Cultural and Linguistic Minorities in the Russian Federation and the European Union: Comparative Studies on Equality and Diversity, edited by Heiko F. Marten, Michael Rießler, Janne Saarikivi, and Reetta Toivanen, 3-30. New York: Springer.

Saarinen, Sirkka. 2001. "The Myth of a Finno-ugrian Community in Practice." Nationalities Papers: The Journal of Nationalism and Ethnicity 29(1):41-52. doi:10.1080/00905990120036376.

Sallabank, Julia. 2005. "Prestige From the Bottom Up: A Review of Language Planning in Guernsey." Current Issues in Language Planning 6(1):44-63. doi:10.1080/14664200508668272.

Salminen, Timo. 2009. "In Between Research, the Ideology of Ethnic Affinity and Foreign Policy: The Finno-Ugrian Society and Russia From the 1880s to the 1940s. The Quasquicentennial of the Finno-Ugrian Society.” Suomalais-Ugrilaisen Seuran Toimituksia = Mémoires de la Société Finno-Ougrienne 258:225-262. URL: www.sgr.fi/sust/sust258/sust258_salminen.pdf.

Samoilova, Natalia. 2001. "Variation in the Adaptation of Finnic Loanwords in Russian." Linguistica Uralica 27(3):161-173. URL: www.kirj.ee/public/va_lu/ 137-3-1.pdf.

Sanjek, Roger, ed. 1990. Fieldnotes: The Makings of Anthropology. Ithaca, NY: Cornell University Press.

Sapir, Edward. 1921. Language: An Introduction to the Study of Speech. New York: Harcourt, Brace.

Sapir, Edward. 1929. "The Status of Linguistics as a Science.” In Culture, Language and Personality, edited by David G. Mandelbaum, 207-214. Berkeley, CA: University of California Press.

Sapir, Edward. 1933. "La Réalité psychologique des phonèmes." Journal de Psychologie Normale et Pathologique 30:247-265.

Sapsford, Roger, and Jupp, Victor. 1996. Data Collection and Analysis. London, Thousand Oaks and New Delhi: SAGE.

Sarhimaa, Anneli. 1999. Syntactic Transfer, Contact-induced Change, and the Evolution of Bilingual Mixed-codes: Focus on Karelian-Russian Language Alternation. Studia Fennica Linguistica 9. Helsinki: Finnish Literature Society.

Sasse, Hans-Jurgen. 1992. "Theory of Language Death." In Language Death: Factual and Theoretical Explorations With Special Reference to East Africa, edited by Matthias Brenzinger, 7-30. Berlin and New York: Mouton de Gruyter.

Sayer, Andrew. 1984. Method in Social Science: A Realist Approach. London, Melbourne, Sydney, Auckland and Johannesburg: Hutchinson.

Schieffelin, Bambi B., and Ochs, Elinor. 1986. "Language Socialization." Annual Review of Anthropology 15:163-191. doi:10.1093/OBO/9780199766567-0111.

Schieffelin, Bambi B., Woolard, Kathryn A., and Kroskrity, Paul V. 1998. Language Ideologies: Practice and Theory. Oxford: Oxford University Press.

Scollon, Ron, and Scollon, Suzie W. 2003. Discourses in Place: Language in the Material World. London, UK: Routledge. 


\section{Bibliography}

Searle, John R. 1990. “Collective Intentionality and Action.” In Intention in Communication, edited by Philip R. Cohen, Jerry Morgan, and Martha Pollack, 401415. Cambridge, MA: MIT Press.

Sebba, Mark. 2007. Spelling and Society: The Culture and Politics of Orthography Around the World. Cambridge: Cambridge University Press.

Sebba, Mark. 2012. "Multilingualism in Written Discourse: An Approach to the Analysis of Multilingual Texts." International Journal of Bilingualism 17(1):97118. doi:10.1177/1367006912438301.

Sebba, Mark, and Wootton, Tony. 1998. "We, They, and Identity: Sequential Versus Identity-related Explanation in Code-switching." In Code-switching in Conversation: Language, Interaction, and Identity, edited by Peter Auer, 262-289. London and New York: Routledge.

Seigworth, Gregory. 2000. "Banality for Cultural Studies." Cultural Studies 14(2):227-268. doi:10.1080/095023800334878.

Setälä, Emil N., Kala, Juho H., Tunkelo, Emil A., and Peltola, Reino. 1951. Näytteitä äänis- ja keskivepsäan murteista. Helsinki: Suomalais-Ugrilainen Seura.

Shearer, David R. 2006. "Stalinism, 1928-1940." In The Cambridge History of Russia: Volume III the Twentieth Century, edited by Ronald G. Suny, 192-216. Cambridge: Cambridge University Press.

Shulist, Sarah. 2017. "A Tale of Two Languages: Indigenous Language Education and Ideologies in an Urban Context." Revista Linguística 13(1):168-187. doi:10.17074/linguistica.v13i1.10426.

Silakova, Natalia. 2006. Todesižed sebranikad. Petroskoi: Periodika.

Siragusa, Laura. 2017. "Secrecy and Sustainability: How Concealment and Revelation Shape Vepsian Language Revival.” Anthropologica 59(1):74-88. doi:10.3138/anth.591.T07.

Siragusa, Laura, and Arukask, Madis. 2017. "Reflecting the 'Field': Two Vepsian Villages and Three Researchers." Sibirica 6(1):75-105.

Skutnabb-Kangas, Tove. 2000. Linguistic Genocide in Education-or World-Wide Diversity and Human Rights? Mahwah, NJ: Lawrence Erlbaum.

Slezkine, Yuri. 1994. Arctic Mirrors: Russia and the Small Peoples of the North. Ithaca and London: Cornell University Press.

Smith, Jeremy. 1999. The Bolsheviks and the National Question, 1917-23. London: MacMillan Press Limited.

Smith, Laurajane, and Akagawa, Natsuko, eds. 2009. Intangible Heritage. London and New York: Routledge.

Smith, Michael. 1998. Language and Power in the Creation of the USSR 19171953. Berlin and New York: Mouton de Gruyter.

Sommer, Łukasz. 2014. "Historical Linguistics Applied: Finno-Ugric Narratives in Finland and Estonia." The Hungarian Historical Review 3(2):391-417. URL: http://epa.oszk.hu/02400/02460/00008/pdf/EPA02460_hungarian_historical_ review_2014_2_391-417.pdf.

Spencer, Jonathan. 1997. "Post-Colonialism and the Political Imagination." Journal of the Royal Anthropological Institute (N.S.) 3:1-19. doi:10.2307/3034362.

Spolsky, Bernard. 2003. "Reassessing Māori Regeneration.” Language in Society 32(4):553-578.

Spolsky, Bernard. 2004. Language Policy. Cambridge: Cambridge University Press.

Ssorin-Chaikov, Nikolai. 2008. "The Black Box: Notes on the Anthropology of the Enemy.” Inner Asia 10:7-63.

Stocking, George W., ed. 1984. Observers Observed: Essays on Ethnographic Fieldwork. Madison: The University of Wisconsin Press.

St. Petersburg Times. 2011. Accessed August 2011. URL: www.sptimes.ru/index. php?action_id=2\&story_id=18713. 
Street, Brian. 1984. Literacy in Theory and Practice. Cambridge: Cambridge University Press.

Street, Brian, ed. 2001. Literacy and Development: Ethnographic Perspectives. London: Routledge.

Strogal'shchikova, Zinaida I. 2004. "Problemy stanovleniya natsional'nogo obrazovaniya karelov i vepsov na sovremennon etape." In Sovremennoe sostoyaniye i perspektivy razvitiya karel'skogo, vepsskogo i finskogo yazykov v Respublike Kareliya, edited by T. S. Kleerova and S. P. Pasyukova, 41-47. Petrozavodsk: KarNTs RAN.

Strogal'shchikova, Zinaida I. 2006. "Vepsy: etnodemograficheskie protsessy (proshloe i nastoyashchee)." In Sovremennaya nauka o Vepsakh: dostizheniya i perspektivy, edited by Irina Yu. Vinokurova, I. E. Grishina, Nina G. Zaitseva, Irma I. Mullonen, and Vyacheslav, P. Orfinskiy, 378-413. Petrozavodsk: KarNTs RAN.

Strogal'shchikova, Zinaida I. 2007. "O sozdanii avtonomnykh obedineniy vepsskoy narodnosti." In Vepsy: modeli etnicheskoy mobilizatsii. Sbornik materialov $i$ dokumentov, edited by Evgeniy I. Klement'yev, Aleksandr A. Kozhanov, and Zinaida I. Strogal'shchikova, 193-195. Petrozavodsk: izdaniye osushchestvleno pri finansovoy podderzhke sekretaryata Barentseva.

Strogal'shchikova, Zinaida I. 2008a. Vepsy: Istoriko-etnograficheskiy ocherk. Petrozavodsk: Periodika.

Strogal'shchikova, Zinaida I., ed. 2008b. Vepsy: na rubezhe XX-XXI vekov. Po materyalam mezhregional'noy nauchno-prakticheskoy konferentsii 'Vepsykorennoy malochislennyy narod Rossiyskoy Federatsii: perspektivy sokbraneniya i razvitiya.' Petrozavodsk: KarNTs RAN.

Strogal'shchikova, Zinaida I. 2016. Vepsy v etnokul'turnom prostranstve evropeyskogo severa. Petrozavodsk: Periodika.

Tedlock, Dennis. 1975. "Learning to Listen: Oral History as Poetry." Boundary: The Oral Impulse in Contemporary American Poetry 2, 3(3):707-728. doi:10.2307/302186.

Thoits, Peggy A. 1989. “The Sociology of Emotions.” Annual Review of Sociology 15:317-342.

Thompson, John M. 1990. Russia and the Soviet Union. An Historical Introduction from the Kievan State to the Present. Boulder, San Francisco, Oxford: Westview Press.

Toivanen, Reetta. 2015. "Obstacles and Successes." In Cultural and Linguistic Minorities in the Russian Federation and the European Union: Comparative Studies on Equality and Diversity, edited by Heiko Marten, Michael Rießler, Janne Saarikivi, and Reetta Toivanen, 83-106. Cham: Springer.

Toivanen, Reetta, and Saarikivi, Janne, eds. 2016. Linguistic Genocide or Surperdiversity? New and Old Language Diversities. Bristol, Buffalo and Toronto: Multilingual Matters.

Treitler, Leo. 1986. "Orality and Literacy in the Music of the European Middle Ages." In The Oral and the Literate in Music, edited by Tokumaru Yosihiko and Osamu Yamaguti, 38-56. Tokyo: Academia Music.

Treitler, Leo. 1992. “The 'Unwritten' and 'Written Transmission' of Medieval Chant and the Start-Up of Musical Notation.” The Journal of Musicology 10(2):131191. URL: www.posgrado.unam.mx/musica/lecturas/historiaInterpretacion/ JSTOR/Treitler-Unwritten.pdf.

Tsunoda, Tasaku. 2005. Language Endangerment and Language Revitalization. Tasaku and Berlin: Mouton de Gruyter.

Tsvetkova, Nadezhda N. 1993. "Antropologiya vepsov (obzor i novyye dannyye)." In Istoricheskaya etnografiya. Problemy arkheologii i etnografii. Vypusk 4, 26-48. Saint-Petersburg: Saint-Petersburg University Publisher.

Tuisk, Tuuli. 2010. "Some Aspects of Quantity in Central Veps." Linguistica Uralica 96(4):241-249. doi:10.3176/lu.2010.4.01. 


\section{Bibliography}

UNESCO Endangered Languages. 2017. Accessed June 28, 2017. URL: www.unesco. org/languages-atlas/.

UNESCO Red Book on Endangered Languages: Europe. 2017. Accessed June 28, 2017. URL: www.helsinki.fi/ tasalmin/europe_index.html.

The Universal Declaration of Human Rights. 2017. Accessed June 28, 2017. URL: www.un.org/en/universal-declaration-human-rights/index.html.

Vakhtin, Nikolai. 2001. Yazyki narodov severa v XX veke. Ocherki yazykovogo sdviga. St. Petersburg: Evropeyskiy Universitet v Sankt-Peterburge.

Vakhtin, Nikolai. 2005. "Two Approaches to Reversing Language Shift and the Soviet Publication Program for Indigenous Minorities.” Etudes Inuit 29(1-2):131-147.

Van der Walt, Christa. 2006. "University Students' Attitudes Towards and Experiences of Bilingual Classrooms." Current Issues in Language Planning 7(23):359-376. doi:10.2167/clip104.0.

Varfolomeeva, Anna. 2016. "The Soul of Stone: Mineral Symbolism in Vepsian Villages in Karelia." Laboratorium 2:11-31. URL: www.soclabo.org/index.php/ laboratorium/article/view/618.

Vaschenko, Alexander, and Smith, Claude C., eds. 2010. The Way of Kinship: An Anthology of Native Siberian Literature. Minneapolis: University of Minnesota Press.

Venediktova, Tatiana. 2010. "Reading Differently as a Cultural Challenge in Russia: On Literature, National Unity, and the Promises of Pluralism." In Dilemmas of Diversity After the Cold War: Analyses of Cultural Difference, edited by Michele R. Rivkin-Fish and Elena Trubina, 174-192. Washington, DC: Woodrow Wilson International Center for Scholars.

Ventsel, Aimar. 2011. "Siberian Movements: How Money and Goods Travel in and Out of Northwestern Sakha." Folklore. Electronic Journal of Folklore 49:113130. doi:10.7592/FEJF2011.49.ventsel.

Vertovec, Steven. 2007. "Super-diversity and Its Implications." Ethnic and Racial Studies 30(6):1024-1054. doi:10.1080/01419870701599465.

Vikhoreva, Irina. 2010. "La regione della Carelia e l’isola Kiži: Tesi di Laurea.” MA diss., Universita’ La Sapienza di Roma.

Vinokurova, Irina Yu. 1988. "Ritual pervogo vygona skota na pastbishcha u vepsov." In Obryady i verovaniya narodov Karelii: Sbornik statey, edited by Aleksey P. Konkka and Eino S. Küru, 4-26. Petrozavodsk: KarNTs RAN. URL: http://resources.krc.karelia.ru/library/doc/articles/ritual.pdf.

Vinokurova, Irina Yu. 1994. Kalendarnyye obychai, obryady i prazdniki Vepsov (Konets XIX-nachalo XX vv). St. Petersburg: Nauka.

Vinokurova, Irina Yu. 1996. Traditsionnyye prazdniki Vepsov pronezh'ya (konets $X I X$-nachalo $X X v v$.). Petrozavodsk: Izdatel'stvo PetrGU.

Vinokurova, Irina Yu. 2006. Zhivotnye $v$ traditsionnom milovozzrenii Vepsov. Petrozavodsk: Izdatel'stvo PetrGU.

Vinokurova, Irina Yu. 2014. "Vepsskie mifologicheskiye personazhi, svyazannye s zemledeliyem: etnokul'turnye istoki i genesis." Trudy KarNTS RAN 3: Seriya Gumanitarnyye issledovaniya:33-42.

Vinokurova, Irina Yu. 2015. Morfologiya Vepsov. Entsiklopediya. Petrozavodsk: PetrGU.

Wagner, Roy. 1975. The Invention of Culture. Englewood Cliffs: Prentice Hall.

Waller, Tim, Ärlemalm-Hagsér, Eva, Hansen Sandseter, Ellen B., Lee-Hammond, Libby, Lekies, Kisti, and Wyver, Shirley. 2017. The SAGE Handbook of Outdoor Play and Learning. London: SAGE.

Ward, Chris. 1993. Stalin's Russia. London and New York: Edward Arnold.

Wei, Li. 1998. "The 'Why' and 'How' Questions in the Analysis of Conversational Code-switching." In Code-switching in Conversation: Language, Interaction, and Identity, edited by Peter Auer, 156-179. London and New York: Routledge. 
Wertheim, Suzanne A. 2009. "Who's Using Who? The Fieldworker as Documenter and Tool of Language Revalorization." Language \& Communication 29:271-285.

Whiley, Terence G. 1996. "Language Planning and Policy." In Sociolinguistics and Language Teaching, edited by Sandra L. McKay and Nancy H. Hornberger, 103148. Cambridge: Cambridge University Press.

Whitman, Robert. 2005. "Julia's 'Story' of Schooling: A Borderlands Account." In Language, Literacy, and Power in Schooling, edited by Teresa L. McCarty, 89-110. Mahwah, NJ and London: Lawrence Erlbaum Associates Publishers.

Wilce, James M. 2009. Language and Emotion. Cambridge: Cambridge University Press.

Woolard, Kathryn A. 1989. Double Talk. Bilingualism and the Politics of Ethnicity in Catalonia. California: Stanford University Press.

Woolard, Kathryn A., and Schieffelin, Bambi B. 1994. "Language Ideology.” Annual Review of Anthropology 23:55-82. doi:10.1146/annurev.an.23.100194.000415.

Wortham, Stanton. 2008. "Linguistic Anthropology of Education.” URL: http:// repository.upenn.edu/cgi/viewcontent.cgi? article=1160\&context=gse_pubs.

Wortham, Stanton, and Rymes, Betsy, eds. 2003. Linguistic Anthropology of Education. Westport, CT: Praeger.

Yamakoshi, Yasuhiro. 2010. Grammatical Sketches From the Field. Tokyo: Research Institute for Languages and Cultures of Asia and Africa (ILCAA).

Yegorov, Sergey B. 2006. "Vepsko-Russkoe mezhetnicheskoe vzaimodeystviye." In Sovremennaya nauka o Vepsakh: dostizheniya i perspektivy, edited by Irina Yu. Vinokurova, I. E. Grishina, Nina G. Zaitseva, Irma I. Mullonen, and Vyacheslav P. Orfinskiy, 237-250. Petrozavodsk: KarNTs RAN.

Yurchenkova, Nina. 2012. "About Female Deities in the Mythology of Finno-Ugric Peoples.” Folklore. URL: www.folklore.ee/folklore/vol47/yurchenkova.pdf.

Zaitseva, Mariya, and Mullonen, Mariya. 1969. Obraztsy vepsskoy rechi. Leningrad: izdatel'stvo Nauka.

Zaitseva, Mariya, and Mullonen, Mariya. 1972. Slovar'vepsskogo yazyka. Leningrad: Nauka.

Zaitseva, Nina G. 1989. "Vepskiy yazyk i problemy ego razvitiya.” In Problemy istorii i kul'tury vepsskoy narodnosti, edited by Vladimir V. Pimenov, Zinaida I. Strogal'shchikova, and Yu. Yu. Surzasko, 95-102. Petrozavodsk: Karel'skiy filial AN SSR.

Zaitseva, Nina G. 1995. Vepsän kelen grammatik. Petroskoi: Petroskoin valtionyliopiston kustantamo.

Zaitseva, Nina G. 2001. Vepsskiy glagol: sravnitel'no-sopostavitel'noye issledovaniye. Petrozavodsk: Periodika.

Zaitseva, Nina G. 2009. Novyy russko-vepsskiy slovar.’ Petrozavodsk: Periodika.

Zaitseva, Nina G. 2010. Novyy vepssko-russkiy slovar.’ Petrozavodsk: Periodika.

Zaitseva, Nina G., and Mullonen, Mariya I. 2009. Uz'venä-vepsläine vajehnik. Petrozavodsk: Periodika.

Zaitseva, Nina G., and Zhukova, Ol'ga Yu. 2012. Käte-ške käbedaks kägoihudeksObernis'-ka miloy kukushechkoy. Petrozavodsk: Karel'skiy nauchnyy tsentr RAN.

Zamyatin, Konstantin. 2013. An Official Status for Minority Languages? A Study of State Languages in Russia's Finno-Ugric Republics. Helsinki: Uralica Helsingiensia.

Zamyatin, Konstantin. 2016a. "Russian Political Regime Change and Strategies of Diversity Management: From a Multinational Federation Towards a NationState." Journal on Ethnopolitics and Minority Issues in Europe 16(1):19-49. URL: www.ecmi.de/fileadmin/downloads/publications/JEMIE/2016/Zamyatin.pdf.

Zamyatin, Konstantin. 2016b. "Russia's Minority Education and the European Language Charter." In Linguistic Genocide or Surperdiversity? New and Old 


\section{Bibliography}

Language Diversities, edited by Reetta Toivanen and Janne Saarikivi, 249-283. Bristol, Buffalo and Toronto: Multilingual Matters.

Zamyatin, Konstantin, Pasanen, Annika, and Saarikivi, Janne. 2012. Kak i zachem sokbranit' yazyki narodov Rossii? Helsinki.

Zentella, Ana C. 1997. Growing Up Bilingual: Puerto Rican Children in New York. Oxford and Malden: Blackwell.

Zentella, Ana C. 2005. Building on Strength: Language and Literacy in Latino Families and Communities. New York: Teacher's College Press.

Zhukova, Ol'ga Yu. 2007. “O prepodavanii vepsskogo yazyka v Petrozavodskom gosudarstvennom universitete." In Vepsy i etnokul'turnyye peremeny XX veka, edited by Seppo Lallukka, 163-167. Helsinki: Studia Slavica Finlandensia.

Zhukova, Ol'ga Yu. 2008. "O podgotovke spetsyalistov po Vepsskomu yazyku v GOU VPO RF 'Petrozavodskiy Gosudarstvennyy Universitet." In Vepsy: na rubezhe $X X-X X I$ vekov. Po materialam mezhregional'noy nauchno-prakticheskoy konferentsii 'Vepsy—korennoy malochislennyi narod Rossiiskoy Federatsii: perspektivy sokbraneniya i razvitiya,' edited by Zinaida I. Strogal'shchikova, 170-174. Petrozavodsk: KarNTs RAN.

Zhukova, Ol'ga Yu. 2015. Vepsskiye Obryadovyye Prichitaniya: ot poetiki zhanra $k$ poetike slova. Petrozavodsk: karel'skiy nauchnyy tsentr RAN. 


\section{Index}

agency 4, 10, 20-2, 200

babushka xiii, 31, 104, 127, 131, 163, 185-7, 190-1

careful(-ly, -lness) 10, 22-3, 50, 53, 85-90, 97, 104, 132, 141, 152, 166-7, 184, 196, 199; see also agency chuzhoy xiii, 4, 35, 50, 79, 83-5, 88, 90, 97-8, 100, 110, 112-13, 121, 133, 192; see also svoy

code-mixing 100, 113-15, 121; see also code-switching

code-switching 78, 100, 113-16, 118-21, 197; see also code-mixing

demographics 10, 27, 112, 172

fieldwork ix, xxii, xxv, 9, 46, 73-9, $81-4,90,93-4,96-7,124,132,163$, $165,171,176,179-80,182,200$

heritage language $1,3-6,9,11,14,18$, $23,45-6,53,56,61-2,69,72,74$, $80,82,85,88,90-1,97,100,103-4$, 107-8, 110, 112, 116, 119-21, 129, 132-4, 138, 141-3, 145-50, 152-3, 159-60, 164, 166, 178, 182, 184, 190-2, 195-201

khozyaystvo xiii, 26, 28, 30-1, 39, 45, 51, 56, 107, 187, 190

language attitude $5,19,21,37,46,55$, 74, 77-80, 82-3, 85, 93, 97, 105, $108,113,119,126,156,167,169$ 71, 183-4, 189, 191-2, 195, 197-8 language ecology 3-6, 8, 16-17, 19, $50,56,63-5,70,74,76-7,97,102$, 105-6, 113, 115, 120-1, 129, 132,
$138,153,164,172,179,185,191-2$, 195-6, 198, 200-1

language ideology 4-5, 8-10, 14, 17-21, 23, 28, 44, 53, 56, 74, 77-83, 90, 93, 97, 100, 109-10, 113, 119-21, 126, 129, 132-3, 135, 138, 149, 152, 156, 159, 169, 184, 191, 195-7, 201

language metaphor xxiii, 3-4, 16, $18,55,74-5,78,82,99-106,109$, $120-1,132,147,159,195,197-8$

language planning $10,15-17,19,78$, 164,193

literacy 1, 3-4, 8, 10-11, 14-20, 23, $37,64,69-70,93,129-30,132-6$, 142-3, 145, 154, 159-60, 191, 195-6, 199-201, 203; see also orality

orality $1,4,8,11,14-15,17,19,93$, 195, 200-1; see also literacy

paginklub xi, 1, 13-14, 67, 76, 123, 126, 142, 148, 199

power 4, 9-10, 14, 16, 19-23, 27, 31, $36,54,56,72,77,80,92,120,132$, 136, 143, 152, 154, 159-60, 176, 179, 191-2, 196-7, 199-200

puheg(ed) xii, 22, 32, 72, 86-7, 92, 96, 196, 199, 201

responsibility $85,97,149,153,165$, 169, 183-4, 191, 201

sebr xii-xiii, xxiii, xxv, 9, 20, 28, 31-2, $35,38-9,44,56,64,68,70,79$, $82-3,85,100,110,113,121,135$, 197, 201, 204

svoy xiii, 4, 9, 28, 32, 50, 79, 82-6, 90, 97-8, 100, 110, 112-13, 120-1, 133; see also chuzhoy 